\title{
Leadership, Organizational Culture, Knowledge Productivity and Value Creation in Four Successful Korean Companies
}

Toward guidelines for people-oriented business leaders 


\section{Leadership, Organizational Culture, Knowledge Productivity and Value Creation in Four Successful Korean Companies}

Toward guidelines for people-oriented business leaders 


\section{Promotion Committee:}

Chairman:Prof. Dr. T.A.J. Toonen University of Twente

Promotor: Prof. Dr. J.W.M. Kessels University of Twente

Members: Prof. Dr. P.J.C. Sleegers University of Twente

Prof. Dr. A.J. Groen University of Twente

Prof. Dr. D-S. Cho Seoul National University

Prof. Dr. H. van den Bosch Open University

Prof. Dr. C.P.M. Wilderom University of Twente

ISBN : 978-90-365-3934-0

Copyright @ 2015, by Suk Jean Kang

Cover art: Suk Jean Kang

All rights reserved. No part of this publication may be reproduced, stored in a retrieval system, or transmitted in any form or by any means, electronic, mechanical, photocopying, recording, or otherwise, without the prior written permission of the author.

E-mail: kang-ceoconsult@hanmail.net 


\title{
Leadership, Organizational Culture, Knowledge Productivity and Value Creation in Four Successful Korean Companies
}

Toward guidelines for people-oriented business leaders

\section{DISSERTATION}

\author{
to obtain \\ the degree of doctor at the University of Twente, \\ on the authority of the rector magnificus, \\ prof. dr. H. Brinksma, \\ on account of the decision of the graduation committee, \\ to be publicly defended \\ on Wednesday 9th of September 2015 at 16.45
}

by

Suk Jean Kang

born on 25th of May 1939

in Sangju, Korea 
The promotor prof. dr. J.W.M. Kessels has approved this dissertation 


\section{Preface and acknowledgements}

Value creation is widely recognized as one of the top priorities for businesses and institutions and therefore is the most important objective and responsibility of leaders.

In today's knowledge-based society, understanding what leadership characteristics can create a knowledge-productive organizational culture and contribute to meeting corporate objectives of value creation is important for business leaders and also for academics. This study was intended to increase that understanding. The origins of the conceptual framework of this study emerged during my experience as chairman of GE Korea for 20 years, where I gained an in-depth understanding of the importance of value creation. While working closely with Jack Welch, then chairman of GE, I became interested in developing a knowledge-productive organizational culture. This study explored the relationships between leadership characteristics, organizational culture, knowledge productivity, and value creation through an empirical analysis of four leading Korean companies that achieved high value creation and sustainable growth over a long period, especially the research period (2000-2010).

In this study, I used both qualitative analysis, collecting data from selected interviews with CEOs, executives, and managers of the four leading Korean companies, and also quantitative analysis, using survey data collected from a larger sample of members of those companies in order to enhance the reliability of the empirical research findings.

In order to share the research findings with business leaders in various fields, and also to reduce the gap between academic approaches and today's fast-progressing business environment and management practice, I developed guidelines for business leaders, based on the research findings and in cooperation with 30 respected business leaders in Korea.

Despite the abundant research literature exploring the relationships between leadership characteristics and organizational culture, studies on the role of knowledge productivity related to value creation are sparse. Therefore, it took considerable time to develop the conceptual framework further and to design a feasible research method. Despite these difficulties, I continued to strive toward a clear goal with the following mission: to develop a new approach, to clarify the relationships between the four main factors, and to reduce the gap between academic studies and practical business management in today's fast-changing knowledge economy. My hope is that readers of 
this study will benefit from my efforts.

After I retired from GE where I spent 30 years, I had the opportunity to help CEOs in leading their businesses by offering advice and support, while also lecturing at the Graduate School of Business of Ehwa Womans University in Seoul as an invited professor. At that time, Prof. Dong-Sung Cho, dean of the Graduate School of Business at the Seoul National University, organized a dinner meeting with me and Prof. Joseph Kessels, dean of TSM, the Business School at the University of Twente in the Netherlands, who was visiting Seoul by the invitation of Prof. Cho. At the dinner meeting, we discussed various subjects of business management, including the GE case. To answer their questions as to how at that time GE had become the company in the world with the highest value creation, net profit and market value, I described the people-oriented, non-bureaucratic, and knowledge-productive open organizational culture of GE, and the specific leadership style of Jack Welch, then chairman, who created that innovative organizational culture, respecting organization members and their knowledge and ideas. While explaining the GE case, I found myself drawing on the paper placemat at the dinner table a framework of the relationships between leadership style, organizational culture, and productive utilization of creative knowledge of the organization members, the characteristics of GE management related to value creation. This drawing eventually became the sketch for the conceptual framework of this study. My dinner companions strongly recommended that I engage in further academic study to elucidate this concept of the relationships among the various constructs.

This is how I decided to start this research project at the University of Twente and how Dr. Joseph Kessels, professor of Human Resource Development, guided my academic research. It has been a wonderful adventure of more than seven years.

I sincerely appreciate the efforts of both Prof. Joseph Kessels and Prof. Don Sung Cho who motivated me to start this PhD program and continuously encouraged and guided my research. I would also like to thank Prof. Chul-Ho Shin, vice president of Sungshin University, who guided and advised me about research methods during the research period.

I would like to express my sincere appreciation to my most admired former colleague and friend Mr. Jack Welch, former chairman of GE, whose successful management and leadership style became the model for the conceptual framework of this research (pp. 28-32). I also would like to express my thanks to my former colleagues Mr. Paolo 
Fresco, former vice chairman of GE and chairman of Fiat, and Mr. William Conaty, former senior vice president and CHRO (chief human resources officer) of GE for their time and effort in helping me write about the GE case. They both spent most of their working lives at GE and have an in-depth understanding of GE's management, leadership, organizational culture, and value creation.

I am very grateful to the management of LG Electronics and the LG Group, Samsung Electronics and the Samsung Group, Shinhan Bank and the Shinhan Finance Group, and the WoongJin Group who accepted and supported my empirical research on their companies. Thanks also to all the executives and managers who participated in my interviews and completed the surveys.

During the past seven years of my research at the University of Twente, I spent so much time with my colleagues and friends in the departments of Behavioral Management and Social sciences (BMS) at UT and TSM Business School. I express my thanks to all of them: Ivo Matser, Asad Malekzadeh, Vin Morar, Tjeerd Hobma, Carola Bouwens, Rachel Liedenbaum and many others.

I also sincerely express my appreciation to those respected business leaders who contributed to the processes of developing "Guidelines for business leaders" by reflecting on my research findings and sharing their own experiences and knowledge of how to lead businesses.

I am greatly indebted to Dr. Eun-Soo Lee and Dr. Young-Sam Cho for their support for my research on the case studies and the analyses of the various research data.

Finally, thanks to my beloved wife, Seung-Yeon Lee, and my family members who understood and supported my academic study in the Netherlands, where I spent a lot of time completing the study.

My $\mathrm{PhD}$ dissertation seems to be just the beginning of my in-depth understanding into the fields of knowledge productivity and value creation. I am grateful to all who supported me in this research endeavor.

Suk-Jean Kang

Enschede, The Netherlands

September 2015 



\section{Table of Contents}

\section{Chapter 1. Introduction to leadership, organizational culture, knowledge productivity, and value creation}

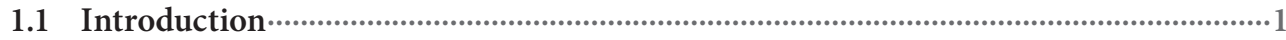

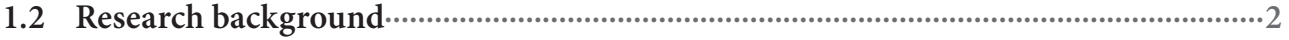

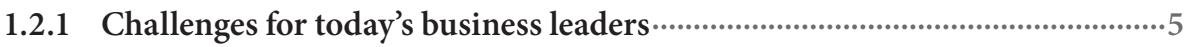

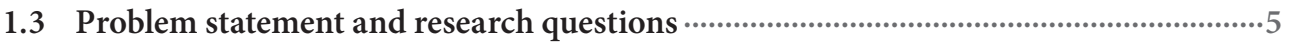

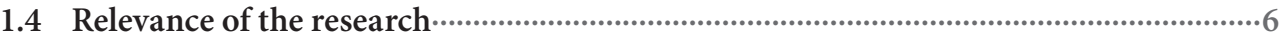

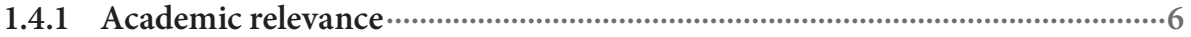

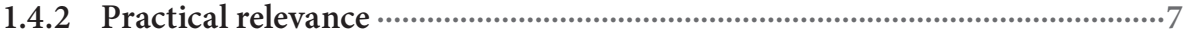

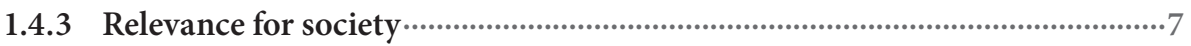

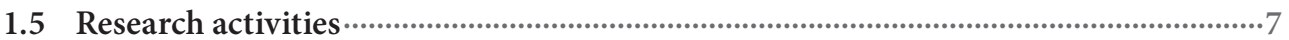

Chapter 2. Literature review and exploration of the main concepts related to leadership, organizational culture, knowledge productivity, and value creation

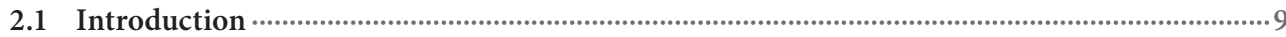

2.2 Leadership

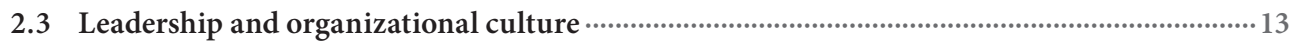

2.4 Knowledge and knowledge productivity …….................................................................... 15

2.5 Leadership and knowledge productivity $\ldots$

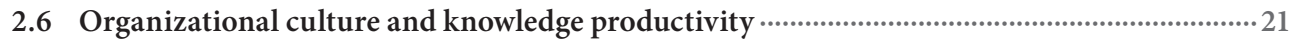

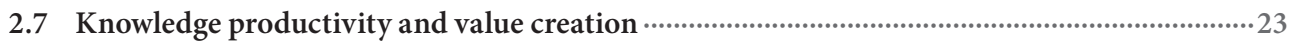

2.8 Leadership and value creation ........................................................................................... 24

2.8.1 Leadership, corporate reputation, and image …...........................................................2 25

2.8.2 Leadership and corporate social responsibility

2.8.3 Leadership and employee satisfaction ……........................................................... 26

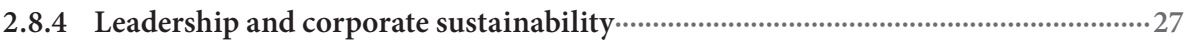

2.8.5 Leadership and financial performance ….................................................................28

2.9 Toward a conceptual framework of the relationships among leadership, organizational culture, knowledge productivity, and value creation ……..................................28

2.9.1 GE case 
2.9.2 Conceptual framework ……...................................................................

2.9.3 Relationship between leadership and value creation …………………..............34

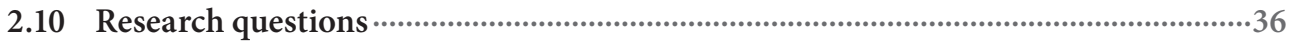

Chapter 3. Research design and methodology: case studies of four major Korean companies

3.1 Introduction

3.2 Development of research instruments: quantitative and qualitative analyses ……....39

3.2.1 Quantitative analysis: development of survey questionnaire …......................40

3.2.2 Exploratory factor analysis and reliability test …….......................................51

3.2.3 Confirmatory factor analysis …….............................................................5

3.2.4 Qualitative analysis: development of interview guidelines..............................60

3.2.5 Variables related to value creation ...................................................................62

3.3 Case studies on leadership, organizational culture, knowledge productivity, and value creation in four Korean companies ............................................................63

3.3.1 Selection criteria

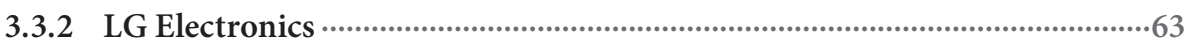

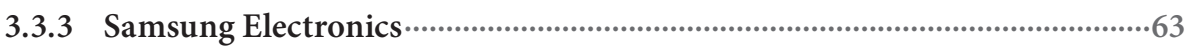

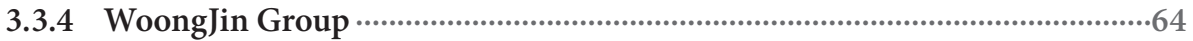

3.3.5 Shinhan Bank ……...............................................................................

3.4 Designing guidelines for business leaders ……...........................................................64

Chapter 4. Findings from the case studies: LG Electronics

4.1 General overview

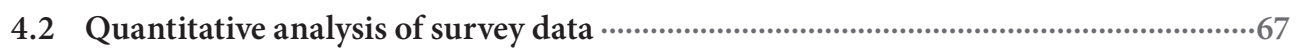

4.2.1 Demographic characteristics .............................................................6.67

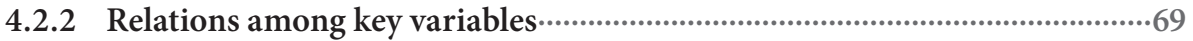

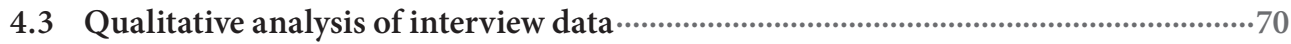

4.3.1 Leadership style ...................................................................................70

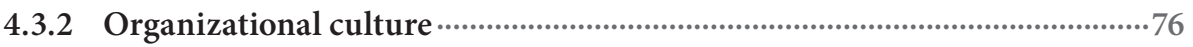

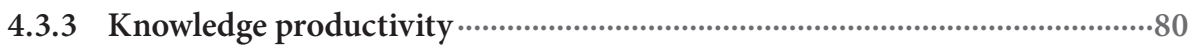

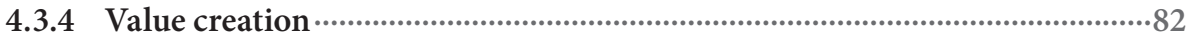

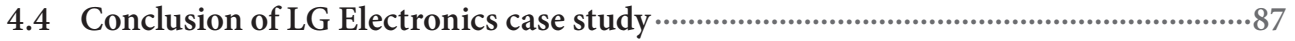


Chapter 5. Findings from the case studies: Samsung Electronics

5.1 General overview

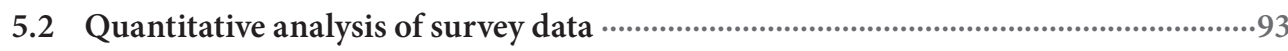

5.2.1 Demographic characteristics .............................................................93

5.2.2 Relations among key variables ................................................................95

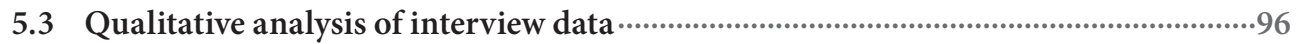

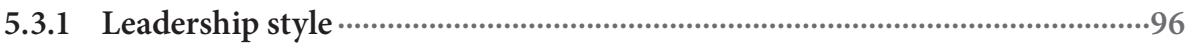

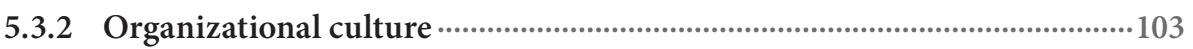

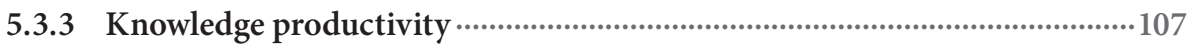

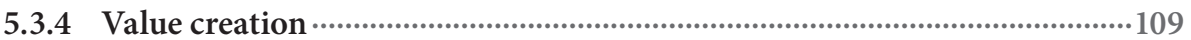

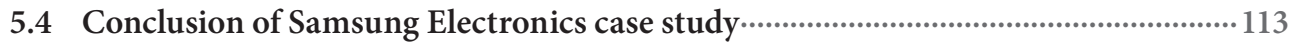

\section{Chapter 6. Findings from the case studies: WoongJin Group}

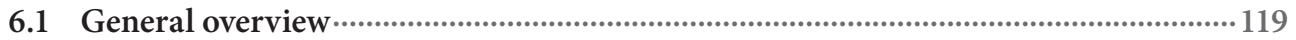

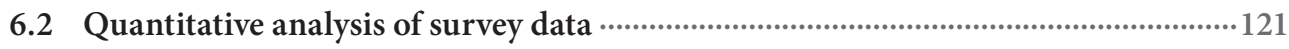

6.2.1 Demographic characteristics ...............................................................121

6.2.2 Relations among key variables................................................................... 123

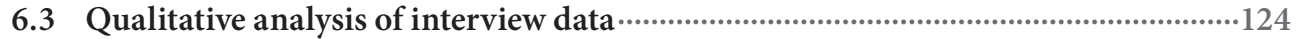

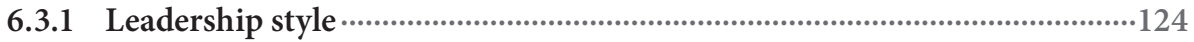

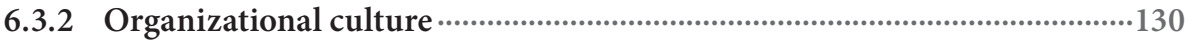

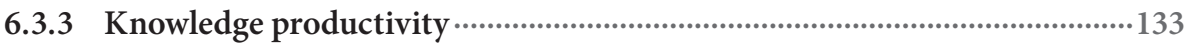

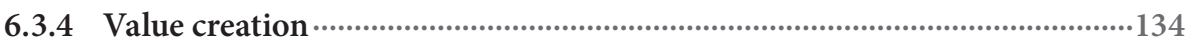

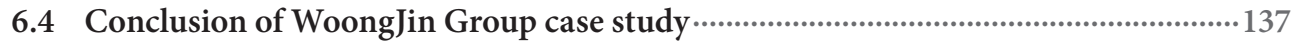

\section{Chapter 7. Findings from the case studies: Shinhan Bank}

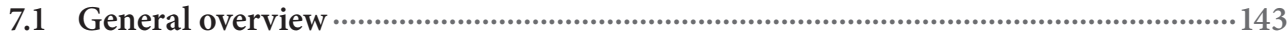

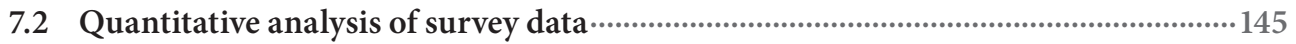

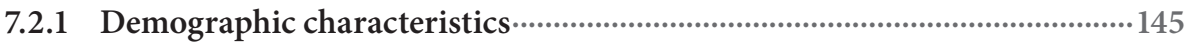

7.2.2 Relations among key variables …............................................................ 147

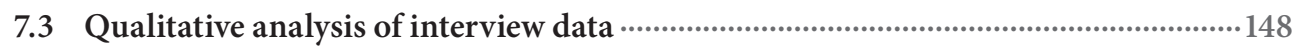

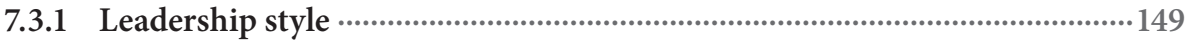

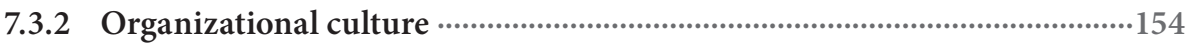


7.3.3 Knowledge productivity

7.3.4 Value creation

7.4 Conclusion of Shinhan Bank case study

\section{Chapter 8. Cross-case analysis of similarities and differences among the four companies}

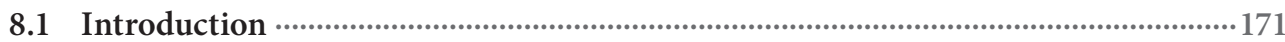

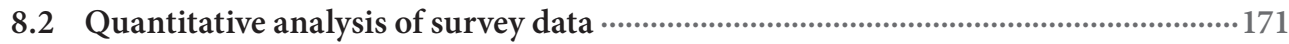

8.2.1 Demographic characteristics ….............................................................. 171

8.2.2 Relations among key variables …............................................................... 174

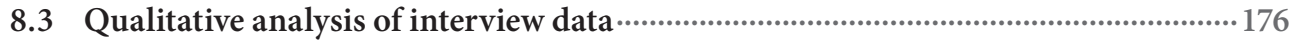

8.3.1 Leadership and organizational culture ................................................. 176

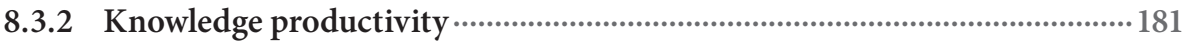

8.3.3 Value creation ..................................................................................... 183

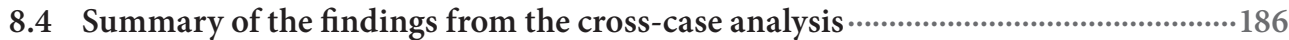

\section{Chapter 9. Conclusion and discussion}

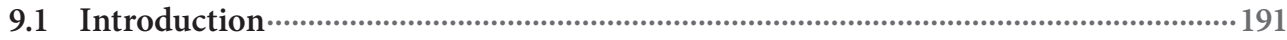

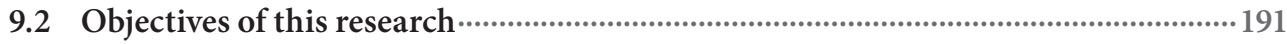

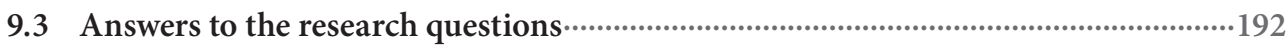

9.3.1 How do the characteristics of leadership relate to organizational culture, knowledge productivity, and value creation of the company?.......................192

Conclusion 1. Leadership and organizational culture ...............................192

Conclusion 2. Leadership and knowledge productivity..............................194

Conclusion 3. Leadership and value creation ..........................................195

9.3.2 How do organizational culture, knowledge productivity,

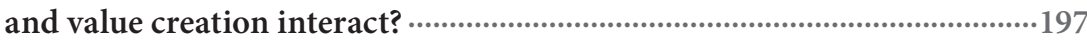

Conclusion 4. Organizational culture and knowledge productivity ….......197

Conclusion 5. Knowledge productivity and value creation ......................198

9.3.3 What leadership style is favorable for creating a knowledge-productive organizational culture and achieving sustainable high value creation?...201

Conclusion 6. Favorable Leadership style for sustainable value creation..... .201

9.3.4 Evolution of leadership style in Korea 
9.3.5 Traditional concept of employee versus co-worker and fellow worker $\cdots . . .207$

9.3.6 Guidelines for business leaders ...........................................................2 210

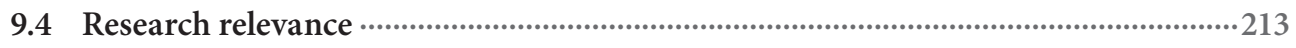

9.4.1 Academic relevance ........................................................................2 213

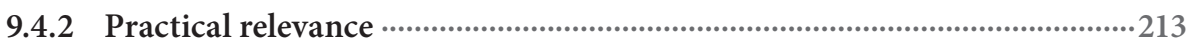

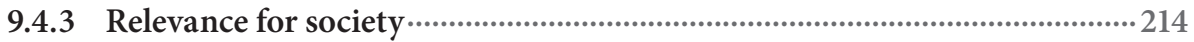

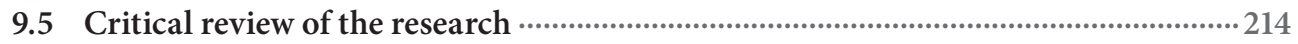

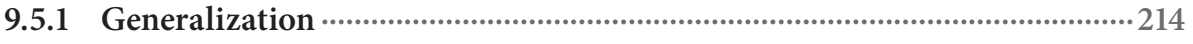

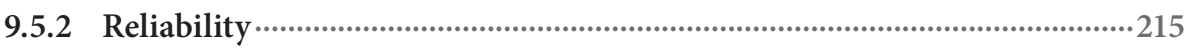

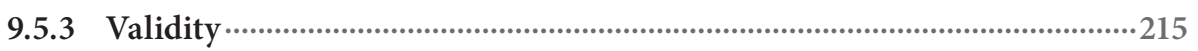

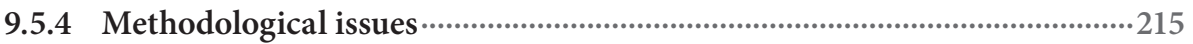

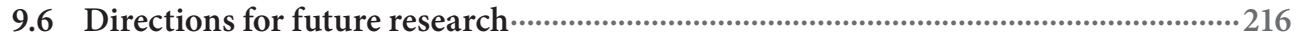

9.6.1 Leadership and organizational culture ..............................................216

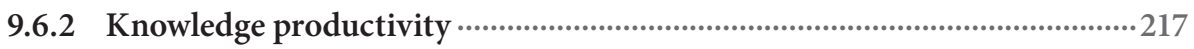

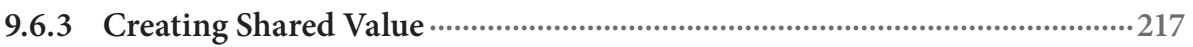

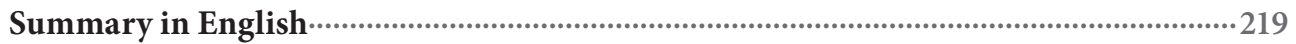

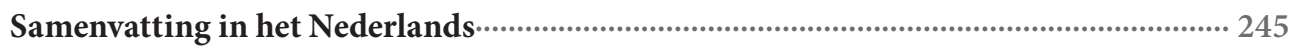

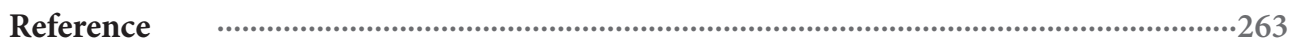

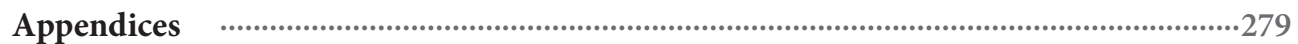

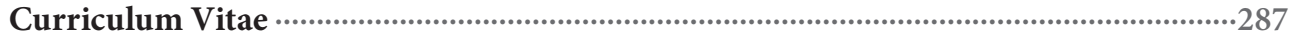





\section{Chapter 1. Introduction to leadership, knowledge productivity, and value creation}

\subsection{Introduction}

Value creation is widely considered today as one of the most important objectives for leadership of businesses and institutions and for economic development. In the context of this research, value creation in business management encompasses the concepts of: (a) revenue and net profit growth; (b) increasing corporate market value; (c) increasing satisfaction of employees and customers; (d) improving corporate reputation and image; (e) fulfilling corporate social responsibility; and (f) sustainability. This research explores how leadership characteristics and value creation in business organization are related, and describes the interaction of four factors: leadership, organizational culture, knowledge productivity and value creation.

Through value creation, a company can meet stakeholders' expectations, such as those of investors who placed their trust in the capabilities of the company management. Value creation allows employees to have vision and dreams for the future and encourages them to do their best for the company with a strong sense of organizational commitment and team spirit (Weiss, Dawis, England, \& Lofquist, 1967). Value creation enables sustainable growth of the company. Value creation allows the company to contribute to society by meeting its corporate social responsibility (Husted \& Allen, 2007). Therefore, value creation should be considered as the main responsibility and role of top management and leadership in the business world (Rho, Lim, \& Hwang, 2004).

Business environments have experienced substantial changes over a short period of time. During the digital technology revolution, information and communication technologies changed especially rapidly, impacting the fundamentals of today's global business environment. Naisbitt (1982) forecasted these changes and described them as "megatrends" decades ago.

Information and communication technology accelerated progress in the knowledge economy. As a result, the application of knowledge became more important than capital, raw materials, and physical labor as the main means of production (Bukowitz \& Williams, 2000; Drucker, 1993; Stam, 2007). For effective knowledge development and building a knowledge-productive organization, all knowledge and ideas of the people in an organization should be utilized productively to improve 
creativity, aid problem solving, and achieve radical innovation (Kessels \& Keursten, 2002). A culture of open communication contributes to learning and enables the exchange of knowledge and experience. A knowledge productive organization is one in which continuous improvement and radical innovation of products, services, and work processes can be observed (Kessels, 2004; Kessels, Verdonschot, \& De Jong, 2011). Such an organizational culture motivates people to be innovative and creative, encourages them to feel a real sense of accomplishment, and brings out their best capabilities, fostering organizational commitment and team spirit for achieving the vision and goals of the company. These factors are also important for value creation and sustainable future growth.

Leadership is also fundamental to building a knowledge productive, value creating organization. Organizational culture depends heavily upon the leadership styles of top management, especially those of the founder, chairman, and chief executive officer (Schein, 1985; Schein, 1992; Schein, 2004). The leadership style and characteristics of leaders who help organizations to build a knowledge productive and people empowering organizational culture that fosters high value creation must therefore be identified.

These assumptions provide the starting point for this research, which explores the relations among four key concepts: leadership, organizational culture, knowledge productivity, and value creation. This study sheds new light on the most desirable leadership style for building a knowledge productive organizational culture and achieving high value creation and sustainable growth in the global knowledge economy.

This research project starts with an exploration of existing studies in this domain, providing a basis for elaboration of the main variables in this study. The empirical part of the study involves data collection instruments specifically designed to apply to four leading Korean companies in which successful value creation and sustainable growth have been achieved in recent decades.

\subsection{Research background}

In the 21st-century knowledge economy, rapid advances have been made in science and technology, especially in the areas of semiconductors and information and communication technologies. These advances have impacted the business environment more than in any other era, perhaps more than steam power in the era of the Industrial Revolution. Survival and sustainable growth of businesses in this rapidly changing environment have become even more challenging. Business leaders 
today must face intense global competition in the knowledge economy. To cope with this competition, these leaders must learn how to build a strong knowledgeproductive and competitive organization to achieve high value creation and meet objectives that enable sustainable company growth.

Competitive companies are built on a base of strong organizational culture. A strong organizational culture in the context of the business world can be described as follows. First, in such a strong organizational culture, people are able to become more creative and innovative. The organization can utilize their knowledge and ideas in a productive way (Trice \& Davis, 1993). Freedom within the organization and a boundary-less open culture is important to foster creativity and innovation (Jung, Wu, \& Chow, 2008).

Second, psychological ownership and team spirit on the part of employees is characteristic of workers in a people-oriented strong organizational culture. Pierce, O'Driscoll, and Coghlan (2004) argued that individuals experience psychological ownership when they are treated with recognition and respect. Employees with psychological ownership may develop positive attitudes and stronger organizational commitment whether they are shareholders or not. According to Avey, Wernsing, and Palanski (2012), individuals with psychological ownership feel more enthusiastic about working toward the organization's targets, feel more accountable to the target, and experience a greater sense of belongingness to the organization. The more leaders respect and empower their employees as human beings and value the opinions and ideas of the people within the organization, the more people in the organization can develop psychological ownership. When they have a sense of psychological ownership, people enjoy their work and put passion and energy into it, giving their best effort in order to achieve the company's long-term vision and goals and short-term objectives.

The phrase "psychological ownership of employees" in the Korean language, “주인의식" (Juin-Eisik), is commonly used in the business community in Korea to describe the mind and spirit of organization members who love the company and their work, and do their best for the company with a sense of loyalty as strong as that of the owner of the company. In this research, the phrase "psychological ownership" is unrelated to the concept of share ownership.

"Juin-Eisik" (psychological ownership) is a common phrase that describes the working attitude of empowered people in a highly people-oriented organizational culture (Jung et al., 2008; Shin \& Zhou, 2003). When a leader respects the employees of the company as human beings and demonstrates trust in and respect for their opinions and ideas (Bass, 1985), people in the organization do not think of 
themselves as mere employees who were hired by the company just to perform tasks. When they have a sense of psychological ownership, employees think of themselves as valuable team members working together for the good of the company. Juin-Eisik (psychological ownership) is closely linked with sense of responsibility, sense of mission, loving and enjoying work, and trusting leaders and the company. Employees who have a sense of psychological ownership think of the company and their work the same way and with the same mind as the company owners, although they are not shareholders. They strive to do their best for the company.

Third, leaders in a strong organizational culture effectively communicate a challenging vision and entrepreneurship (Shin \& Zhou, 2003; Tsui, Zhang, Wang, Xin, \& Wu, 2006) within the organization. They share their vision and values with all members of the organization in a boundary-less and open way (Slater, 1999).

The purpose of this research is to understand and define those leadership styles that are optimal for creating a strong knowledge-productive organizational culture, one that leads the company to achieve high value creation and sustainable growth. A preliminary conceptual framework showing the proposed relationships among the four main factors is presented in the Figure 1.

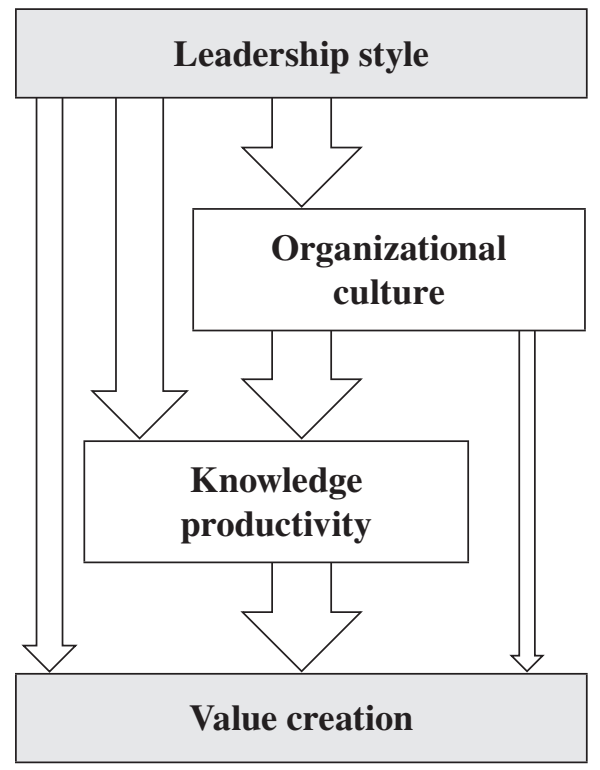

Figure 1 The relationships among leadership, organizational culture, knowledge productivity, and value creation 


\subsubsection{Challenges for today's business leaders}

Today's leading business managers recognize the importance of knowledge productivity for value creation. Successful leaders are those who make continuous efforts to keep up with the fast-changing business environment of today's knowledge society. They prioritize the building of a knowledge-productive organizational culture to achieve high value creation and sustainable company growth. Such efforts require changes and ongoing development of leadership style and organizational culture. In recent decades, these have become more people-oriented and less bureaucratic. The focus has shifted from profitability at all costs to knowledge productivity and value creation.

In today's business world, with its dependence on advanced technologies, innovation and creative knowledge application, business leaders must manage companies to keep up with changes and adapt to the fast-changing business environment in order to survive. Leaders must protect their companies from potential risks arising from rapid changes, while at the same time identifying and creating new growth opportunities from those risks and changes. Leaders and team members should face challenges with a spirit of entrepreneurship and a highly innovative attitude and approach. Therefore, characteristics of leadership and organizational culture have become more diverse and complex than in previous decades.

This research aims to identify leadership characteristics that facilitate the development of a knowledge-productive organizational culture that creates new growth opportunities and achieves sustainable growth despite potential risks and crises in today's fast-changing business environment. Because of the fast-changing factors, academic studies on leadership, organizational culture, knowledge productivity, and value creation may face considerable challenges. Addressing the intricate relationships among these four key factors in today's business environment and reducing the gap between real-time business management in the field and findings from academic research are the main objectives of this study. In addition, promotion of active collaboration between researchers and business leaders is important to enhance the practical implementation of academic research findings, which is a common problem in the business world.

\subsection{Problem statement and research questions}

When society is moving towards a knowledge economy where the improvement and innovation of products, services, and work processes is critical for sustainability of enterprises and institutions, developing an in-depth understanding of the 
relationships among leadership, organizational culture, knowledge productivity and value creation become crucial. Therefore, this study will explore these relationships to understand better the changing role of leadership and how it may affect the process of value creation.

In addition to the need for in-depth understanding of the relationships between leadership and value creation in a knowledge society, it is also crucial that academic research in this field offer direct support to leaders in the fast changing day-to-day business world. Many business leaders experienced practical gaps between the academic studies and the challenges in the business fields they face in a fast changing technology-driven economy. This study aims at reducing this gap by involving business leaders and top managers in an important research project: developing practical guidelines for leadership on the basis of the findings of an empirical analysis. The following research questions reflect important challenges for today's business leaders and will guide direction of this study.

1) How do the characteristics of leadership relate to organizational culture, knowledge productivity, and value creation of the company?

2) How do organizational culture, knowledge productivity, and value creation interact?

3) What leadership style is favorable for building a knowledge productive organizational culture and achieving sustainable high value creation?

4) Is it possible to design a set of guidelines for leadership on the basis of the answers to questions 1, 2, and 3 in order to achieve high value creation in knowledge productive organizations?

\subsection{Relevance of the research}

The concluding part of this introductory chapter summarizes the relevance of the study.

\subsubsection{Academic relevance}

The results of this study may shed new light on the complex relationships among leadership characteristics, organizational culture, knowledge productivity, and value creation. The answers to the research questions may fill in the shortcomings of current theories and help to narrow the gap between scientific research and the challenges that leaders face in today's business world. 


\subsubsection{Practical relevance}

The conceptual framework underpinning this research has been developed from the author's 20-year experience of managing a world leading global corporation and from the cases of other successful companies. The theory and concepts of this research are intended to be practical and can be applied and implemented in real business management. The research objective is to identify effective leadership styles for building a knowledge-productive organizational culture so as to achieve high value creation which is undeniably the main objective of business leaders today. The research activities associated with this study were conducted in close collaboration with business leaders, which will contribute to the adaptation of the findings in their day-to-day business practice. The findings and conclusion of this study will give clear direction to business leaders for building an organizational culture that facilitates knowledge productivity, with a strong people-orientation, to achieve high value creation and build sustainable growth capability.

\subsubsection{Relevance for society}

The findings and conclusions of this study explore people-oriented leadership styles and organizational cultures that create favorable conditions for learning, knowledge development, experimentation, and innovation. These leadership styles and organizational cultures not only create sustainable economic growth and job opportunities, they also promote a strong psychological ownership within organization members, which makes their work more meaningful, which is beneficial for many participants in the community to which a company belongs. High value creation enables companies to fulfill their corporate social responsibilities and act as good corporate citizens.

\subsection{Research activities}

In order to build a sound basis for the conceptual framework, answer the research questions, and reduce the gap between the academic world and the challenges business leaders are facing in a fast-advancing, technology-driven economy, this study includes the following research activities:

1) A literature review and exploration of the main concepts related to the four main factors (leadership, organizational culture, knowledge productivity, and value creation) in Chapter 2.

2) Developing a research methodology for a multiple case study of four major 
Korean companies exploring the main factors of the conceptual framework in Chapter 3.

3) An analysis of the findings from the case studies combining qualitative and quantitative methods in Chapters 4 to 7.

4) Conducting a cross-case analysis finding patterns, similarities and differences in the four cases in Chapter 8 .

5) Conclusions to the study in which the research questions are answered and the limitations of this study and original ambitions are reflected in Chapter 9.

6) Designing guidelines for leadership and validating them in discussion with business leaders and top management in Chapter 9.

While working towards the objectives indicated in this study, it is important to promote active collaboration between researchers and business leaders to enhance the practical implementation of the research findings. Therefore, thirty selected CEOs took part in critical discussions on the main concepts in this study, the research findings and the implications for guidelines for business leaders. Most of the CEOs are members of leading Korean industry and management organizations, such as, the Korea Management Association, the Federation of Korean Industries, and the Korea Employers Federation. 


\section{Chapter 2. Literature review and exploration of the main concepts related to leadership, organizational culture, knowledge productivity, and value creation}

\subsection{Introduction}

The reality of leadership in the business world has changed rapidly, becoming much more complex as a result of the fast-advancing knowledge economy with its high technology and increased global competition. Knowledge productivity for value creation, sustainable capability, and a more people-oriented humanitarian society has become increasingly important. Many leadership theories have attempted to deal with this complexity. However, for academic studies it is difficult to keep pace with the speed of change in the business world. Despite this drawback, it is worthwhile to review the most influential theories in relevant subject areas from which key elements may be derived for an updated leadership framework focusing on value creation by means of knowledge productivity. This chapter offers a literature review on topics related to the main concepts of this research: leadership, organizational culture, knowledge productivity and value creation.

\subsection{Leadership}

Leadership has been studied extensively over a long period of time, and perspectives on this topic are diverse. The study of leadership has passed through several distinct stages. In the 1930s and 1940s, many studies were based on trait theories, while in the 1950 s and 1960 s, behavioral theories were emphasized. The situational and contingency theories of the 1960s and 1970s gave way to the transformational and strategic leadership theories of the 1980s and 1990s, which focused on top management and the role of the CEO (Alimo-Metcalfe, Alban-Metcalfe, Bradley, Mariathasan, \& Samele, 2008). These theories seek to explain different aspects of leadership such as contingency adaptability for managing uncertainty and changes, and the strategic role of leaders (House \& Aditya, 1997).

Among the diverse leadership theories introduced and studied over the decades, those most frequently applied include the situational, transactional, transformational, servant, and strategic leadership theories and the contingency model. These are discussed in detail below.

Hersey and Blanchard (1982) introduced a situational leadership theory, which postulated four leadership styles combining two factors: relationship behavior and task behavior. These two factors relate to the different maturity and development 
levels of followers. Possible leadership styles combining these two factors include; telling (S1: high task focus, low relationship focus), selling (S2: high task focus, high relationship focus), participating (S3: low task focus, high relationship focus), and delegating (S4: low task focus, low relationship focus). Each leadership style is appropriate for certain types of situations. The choice is determined by the followers' maturity level, which is defined as the degree to which followers are ready and willing to tackle the task the group is facing (House \& Aditya, 1997). Leaders must consider employee maturity criteria when selecting employees for particular tasks. Situational leadership theory suggests that an effective leader needs to be flexible (McMurray \& Bentley, 1987) and willing to give different levels of job-related autonomy to followers contingent on their level of maturity.

Although situational leadership theory has strengths that support decision-making and other aspects of daily life in the business world, research demonstrating the robustness of the theory is lacking. In addition, follower maturity is poorly defined, and the rationale is inadequate as to why and how particular tasks and relationship behaviors correspond to the various follower maturity levels (Marques \& Simon, 2006). Transactional leadership theory explains leadership style in terms of two main factors: contingent reward and management-by-exception (Bass, 1985). However, describing today's diverse complexity of leadership styles and the characteristics of organizational culture using a combination of just two leadership factors, as was attempted in most previous research, has become increasingly difficult.

In his book, Leadership (1978), Burns introduced the concept of transforming leadership, which he described as a process in which leaders and followers help each other to advance morale and increase motivation. Bass (1985) extended the work of Burns (1978) and introduced the term "transformational" in place of "transforming", explaining how transformational leadership could be measured, as well as how it impacts follower motivation and performance. The followers of a transformational leader feel trust, admiration, loyalty, and respect for the leader. In contrast to Burns (1978), Bass (1985) suggested that leaders can simultaneously utilize both transformational and transactional leadership styles. The four elements of transformational leadership are: (1) idealized influence or charisma, (2) inspirational motivation, (3) intellectual stimulation, and (4) individualized consideration (Bass, 1985; Northouse, 2010).

These four dimensions of transformational leadership better reflect the peopleoriented and intellectually stimulating environment in which a knowledgeproductive organizational culture can be created (Chang \& Lee, 2007; Sarros, Cooper, \& Santora, 2008). However, transformational leadership theory does not 
address the relationships among intellectual stimulation, knowledge productivity, organizational culture, and value creation in a specific business context.

Fiedler (1967) introduced the contingency model. This theory assumes that leaders are consistent in their behavior, and that they are either task-oriented or relationship-oriented. In accordance with this notion, Curtin (1995) lists four basic leadership styles based on leaders' characteristics: autocratic, laissez-faire, democratic, and servant leadership. These leadership styles are classified by the degree of job-related autonomy and the level of participation in the decision-making process that a leader grants to followers. An autocratic leader simply issues detailed orders and expects them to be carried out automatically. Laissez-faire is the opposite: leaders let subordinates do virtually as they please. A democratic leader allows people to participate in decision-making (Curtin, 1995). A servant leader regards him or herself as the steward of resources provided by the organization. Leaders of this type serve others while achieving results in line with the organization's values and integrity.

Vroom and Jago (1988) identified five decision-making processes: Autocratic I (leader makes decisions alone based on his or her own experiences and information), Autocratic II (leader makes decisions alone with consideration of information from followers), Consultative I (leader makes decisions with consideration of individual opinions of followers), Consultative II (leader makes decisions with consideration of group opinions of followers), and Group (leader delegates decision-making to followers). The leader's choice of decision-making process depends on the level of followers' participation (Harrison \& Pelletier, 1997). This decision-making model helps leaders to make decisions according to the properties of the problems they face. The model also reflects varying degrees of participation by subordinates (Kao \& Kao, 2007). Other researchers argue that leaders need charisma. Charisma is a feeling of personal attraction to others; the stronger the attraction, the stronger the power of charisma (Bass, 1990; Fiol, Harris, \& House, 1999; Tosi \& Greckhamer, 2004). Leaders have charisma when people and followers respect and trust them (Tosi et al., 2004), want to follow them, and believe in their capabilities. Charisma is not based on power or control. Charismatic leaders propose and take actions to bring about good things for the company and its people in future (Tsui et al., 2006).

Servant leadership theory describes highly humanitarian and people-oriented leadership in which followers are respected as human beings. Servant leaders are known for their team-building work and community spirit. Their values reflect the values of a democratic open society in which respecting human rights is important. The following ten characteristics of servant leadership are described in Greenleaf's 
paper (Spears, 2002): listening, empathy, healing, awareness, persuasion, conceptualization, foresight, stewardship, commitment, and building community. However, these characteristics are mostly focused on humanitarian and relationship-oriented subject matter, not on the priority objectives and goals of today's business management, such as knowledge productivity, value creation, and sustainable capability for the future growth of the company.

Finally, Nahavandi and Malekzadeh (1993) grouped strategic leadership styles in combinations of two main factors, as shown in Figure 2.1. Challenge-seeking (high and low) and desire for control (high and low) are divided into four different categories: challenge-seeking, highly controlling innovator (Type I); challengeseeking, participative innovator (Type II); challenge-averse, highly controlling status quo (Type III), and challenge-averse, delegating (Type IV). These categories correspond to outward and inward changes in the company. They also reflect the degree of follower participation in decision-making processes.

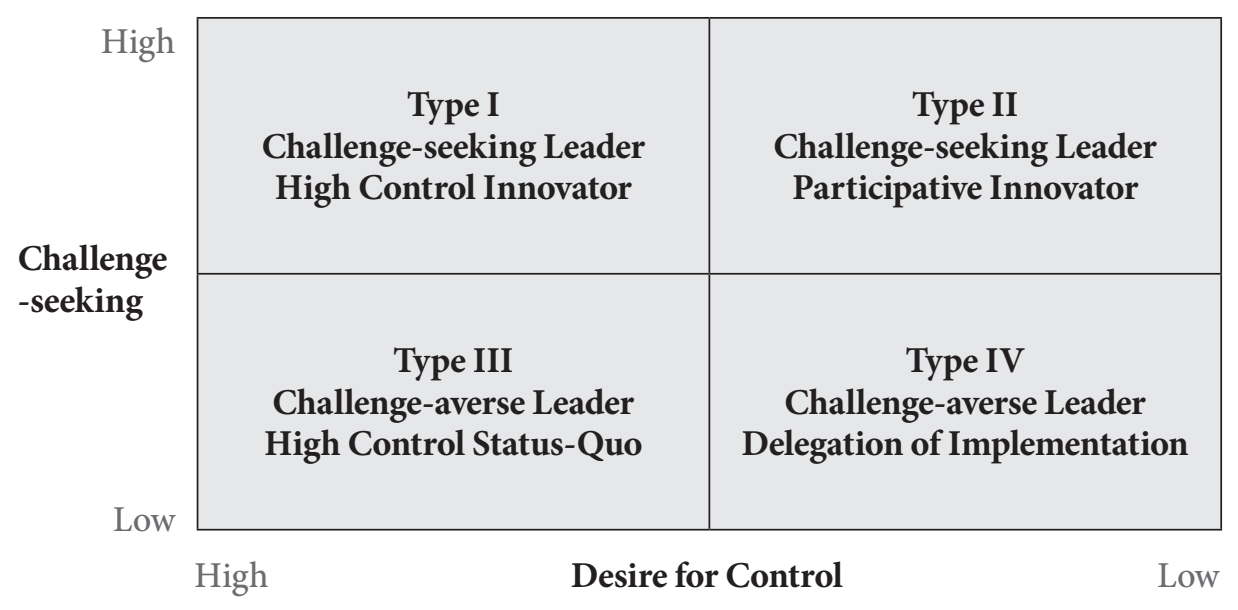

Figure 2.1 Strategic leadership style (Nahavandi \& Malekzadeh, 1993)

Other researchers have tried to study and identify leadership characteristics which are important to describe leadership styles, such as the participation of followers in decision-making processes, job-related delegation, and autonomy granted to followers (Denison, 2000). Leaders have also been described as innovative, visionary, and challenge-seeking (Trice \& Davis, 1993).

Academic research on leadership has progressed continuously, following changes in 
industry, society, and management leadership styles. Leadership styles in business management have changed and progressed substantially in recent decades, becoming more diversified and complicated.

\subsection{Leadership and organizational culture}

Organizational culture as a subject of formal study has captured the interest of a variety of researchers (e.g. Barney, 1986; Deal \& Kennedy, 1982; Pettigrew, 1979; Schein, 1985; Schein, 1992). Pettigrew (1979) described organizational culture as the total of all symbols, languages, ideologies, beliefs, rituals, and myths within an organization. These concepts are interdependent to varying degrees. There is some convergence in the way that they relate to functional problems of integration, control, and commitment. O'Reilly (1989) also stated that organizational culture is typically defined as a complex set of values, beliefs, assumptions, and symbols that define the way in which a firm conducts its business.

Ergeneli, Gohar, and Temirbekova (2007) described culture as interpretations or meanings of significant events that result from the common experiences of members of a society.

Organizational culture is defined and measured using a variety of parameters, including strength (Kotter \& Heskett, 1992), traits (Denison \& Mishra, 1995), congruence (Quinn \& McGrath, 1985), types (Cameron \& Freeman, 1991), and shared values (O'Reilly, Chatman, \& Caldwell, 1991). These have been related to performance at the firm level and commitment at the individual level (AlimoMetcalfe et al., 2008; Tsui et al., 2006).

Recent studies about CEO leadership styles have tended to focus on the relationships among CEO leadership style, organizational culture, and performance (Berson, Oreg, \& Dvir, 2008) and the involvement of the CEO in innovation (Chang \& Lee, 2007). The most frequently applied theories are those of transformational leadership and strategic leadership. Bass and Avolio (1993) applied transformational and transactional leadership theories to explain organizational cultures, describing each culture as a reflection of the leadership style. Transformational leadership underlines concepts such as organizational citizenship behaviors and openness to new and creative ideas (Hutchings \& Michailora, 2004; Jung et al., 2008; Shin \& Zhou, 2003), while transactional leadership stresses rules and formal procedures that may mark the boundaries of employees' creativity.

Strategic leadership is defined as a leader's ability to provide vision, maintain flexibility, think strategically, and work with others to initiate changes that lead to a 
viable future for the organization (Ireland \& Hitt, 1999). The strategic leadership perspective can also be distinguished from other leadership perspectives in that it applies only to the top management team in an organization (Cha, 2005).

Research by Taormina (2007) showed that flexible leadership behaviors are more positively related to an innovative culture than controlling leadership behaviors. By contrast, controlling leadership behaviors are more related to a bureaucratic culture than flexible leadership behaviors. CEO leadership plays an important role in developing vision and shaping an organization's culture based on the CEO's decisions, actions, and behaviors (Brown, Gallagher, \& Brown, 2008). In this context, Schein (2004) suggested that culture and leadership are two sides of the same coin. Leaders first create culture when they form groups and organizations. Culture is created by shared experience, but the leader initiates this process by imposing his or her beliefs. It can be argued that the only thing of real importance that leaders do is to create and manage culture (Schein, 2004).

Organizational cultures involve empowerment (Jung et al., 2008; Oldham \& Cummings, 1986), human resource development (Oldham \& Cummings, 1986), and improvement and innovation (Kessels, 2004; Wilderom, Van Den Berg, \& Wiersma, 2012). Thus, these characteristics of organizational cultures may determine the criteria for the leadership styles in an organization.

However, if elements of a culture become dysfunctional, leaders have a key responsibility to perceive the problems within the existing culture and promote cultural evolution and change that will ensure the survival of the group in an everchanging environment (Schein, 2004).

Davis (1984) postulated that founders and CEOs are the primary sources, transmitters, and maintainers of organizational culture. Trice and Beyer (1993) stated that cultural leaders may have distinctive personal traits and exhibit unique behaviors. Deal and Kennedy (1982) also highlighted the role of the visionary executive in building organizational culture. Some leaders are more directly involved than others, contributing to new knowledge and idea development and providing inspiration from their long experience in operating businesses (Shin, 1996).

Most studies included in this review examined the relationship between leadership and organizational culture. Schein (2004) claimed that organizational culture depends heavily upon leadership style. These two factors are very closely related and similar. However, as a result of the fast pace of society and the evolution of leadership style and organizational culture in recent decades, these concepts are more diversified and complicated today than they were in the past. Leadership style can be described as a combination of various characteristics. Therefore, defining the 
relationship between leadership, which is a combination of various characteristics, and organizational culture, which is also a combination of various elements, has become a more complicated task than existing academic theories can handle. This study attempts to reflect the diverse and complicated characteristics of leadership and organizational culture in today's business context, and also to define the relationship between leadership and organizational culture in modern terms.

\subsection{Knowledge and knowledge productivity}

Drucker (1969) claimed that knowledge would become the core resource in society, and knowledge workers would become the leading group of workers. Drucker (1993) also stressed the importance of the development of a new economic theory that puts knowledge at the center of the wealth creation process. Drucker (1999) elaborated on this new economic theory and described a set of management guidelines for improving knowledge worker productivity. He claimed that knowledge worker productivity is the biggest challenge facing management in the 21st century. The ability to learn internally in firms stimulates knowledge workers' ability and strength (Drucker, 1999).

Making knowledge productive did not receive much attention until researchers began to explore a theory of knowledge productivity (Harrison \& Kessels, 2004; Huang \& Jim Wu, 2010; Stam, 2007). The term "knowledge productivity" refers to the capability of a team or organization to gather relevant information, transform this information into new capabilities, and apply these capabilities for the gradual improvement and radical innovation of work processes, products, and services (Kessels, 1996). Since Kessels (1996), inspired by Drucker (1993), first introduced the term "knowledge productivity", academic research related to this new concept has continued and expanded (e.g., De Jong, 2011; Stam, 2007; Van Lakerveld, 2005). The concept of "knowledge productivity" is closely related to the widely used term, "knowledge management". However, a critical difference is that knowledge productivity should be regarded as an organizational learning process. Further, knowledge cannot be managed in the same ways as other resources in the organization. Knowledge creation and applying knowledge to business operations is accomplished by empowered people, not by controlling and managing knowledge. This might be one of the reasons why leadership styles and organizational cultures have changed substantially in recent decades, becoming more people-oriented and nonbureaucratic with increased delegation and freedom within the organization. In such organizational cultures, applying knowledge in the context of business operations 
has become more important than ever before. When an organizational culture is open, non-bureaucratic, and people-oriented, leaders show respect for people and their knowledge and ideas. In such organizations, knowledge creation and applying knowledge in practical ways is the main activity (Huang \& Jim Wu, 2010).

Therefore, this research uses the term "knowledge productivity" to describe futureoriented knowledge creation, knowledge sharing, knowledge improvement, and knowledge application for achieving corporate goals and high value creation by companies, industries, and economies of countries. However, the literature on knowledge management as well as that of knowledge productivity deals with many common aspects. For this reason, this review touches on both domains.

Knowledge is crucial for the continual improvement and radical innovation of existing products, services, and work processes (Kessels, 1996). In an economy where the only certainty is uncertainty, the one certain source of sustainable competitive advantage is knowledge. Therefore, knowledge creation promotes continuous innovation and provides competitive advantage (Nonaka \& Takeuchi, 1995). When markets shift, technologies proliferate, competitors multiply, and products become obsolete almost overnight, successful companies are those that consistently create new knowledge, disseminate it widely throughout the organization, and quickly embody it in new technologies and products (Nonaka, 1991). Nonaka and Takeuchi (1995) described the process from knowledge creation to continuous innovation and to competitive advantage, as shown in Figure 2.2.

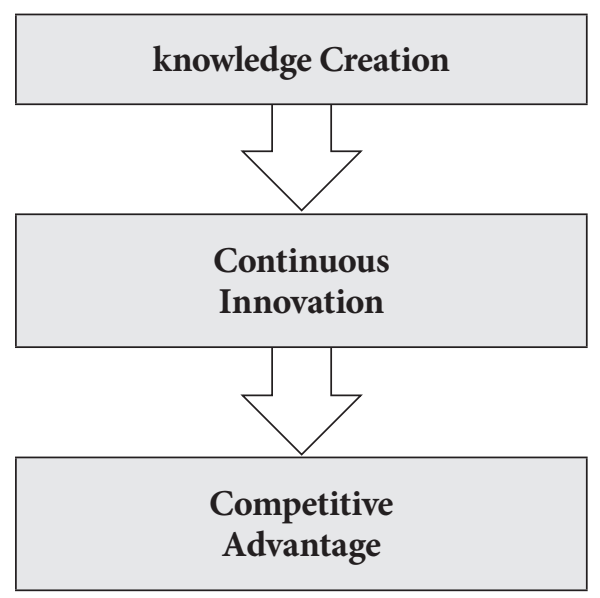

Figure 2.2 From knowledge creation to competitive advantage (Nonaka \& Takeuchi, 1995) 
In the a rea of knowledge, Nonaka (1991) described two types of knowledge: (1) explicit knowledge, which is both formal and systematic; and (2) tacit knowledge, which is highly personal and accumulated from experiences and (so is) hard to formalize. The distinction between tacit and explicit knowledge suggests four basic patterns of creating knowledge in an organization: (1) from tacit to tacit, (2) from tacit to explicit, (3) from explicit to explicit, (4) from explicit to tacit.

Nonaka's (1991) knowledge creation theory is largely based on the case of the successful Japanese automobile industry, mainly Toyota, which achieved substantial sustainable improvements and progress. Today's knowledge creation patterns and sources are increasingly innovative and creative as a result of rapidly advancing science and high technology. The knowledge creation theory developed based on the model of a successful automobile company is now applicable to other rapidly advancing and diverse high-technology and information industries. The original knowledge creation theory also needed to evolve and develop through the progress of integrating it with new knowledge concepts in high technology industries (Woodman, Sawyer, \& Griffin, 1993).

In recent decades, economies and societies have changed from primarily manufacturing-based, industrialized economies into increasingly information technology-based, knowledge economies in which the productivity of knowledge is recognized as the core element for value creation by businesses, industries, and entire economies. Therefore, creating high knowledge productivity has become the major challenge for companies to achieve high value creation goals.

In the 21 st-century, societies are constantly and rapidly transforming into knowledge economies in which the development and application of knowledge becomes more important than traditional assets such as capital, material, and physical labor (Kessels \& Keursten, 2002). The two main factors of knowledge productivity are human resources and workers' learning capability. Furthermore, Woo and Park (2001) insisted that for sustainable growth of firms, it is critical to realize that individuals' knowledge assets are vital for success, and that companies should invest greater efforts in exploiting effective and productive utilization of such knowledge assets.

Keursten, Verdonschot, Kessels, and Kwakman (2006) argued that exploiting productive utilization of knowledge in an organization leads to greater productivity when knowledge creation and application is expressed in day-to-day management practice. Kessels et al. (2011) asserted that in fact knowledge productivity combines two main processes: the factual improvements and innovations of products, services, and work processes (KP1), and increased sustainable capability to improve and 
innovate in the future (KP2). KP2 follows from KP1, and these two processes interact with each other. KP2 is similar to the process of continuous radical innovation and improvement leading to what is called in Korea "sustainable development of future growth engine business" (Bae et al., 2010; Kim \& Chung, 2007).

On the basis of their research, Kessels et al. (2011) came to the conclusion that the process of knowledge productivity should be considered as inherently a learning process that includes information collecting, problem analysis, competency development, and the creative application of these competencies in new, previously unknown situations.

An organizational learning culture is essential for improving and maintaining a knowledge productive organization. Therefore, supporting competency development is at the heart of knowledge productivity. For systematic development of the required organizational learning culture, Kessels (1996) recommended a "corporate curriculum" that supports the seven learning functions described below.

1) Subject matter expertise: Acquiring subject matter expertise and professional knowledge directly related to the organization's business and core competences. Subject matter expertise is at the heart of innovation.

2) Problem solving: Learning to identify and deal with new problems using the acquired subject matter expertise and domain-specific knowledge. It is important that domain-specific knowledge can be applied to solving new problems.

3) Reflective skills and meta-cognitions: Reflective skills and meta-cognitions are helpful for finding ways to locate, acquire, and apply new knowledge. They form the basis for understanding how the knowledge creation process operates. To achieve innovative results, people need the skills, freedom, and authority to engage in open communication. However, this autonomy is balanced by the responsibility for achieving innovative results.

4) Communication skills: Successful innovation processes are often supported by specific communication skills. Acquiring communication and social skills helps people access the knowledge networks of others so that they can successfully participate in communities of practice and make learning at the workplace more productive. 
5) Self-regulation of motivation and affinity: Acquiring skills to self-regulate motivation, affinity, emotions, and affections concerning both working and learning. People can be innovative in those domains in which they intrinsically already feel motivated. Therefore, the work environment should facilitate discovery of the main affinities and motivation of their staff members.

6) Peace and stability: Times and places of peace and stability are needed for deepening understanding, creating synergy, and integrating new knowledge in existing processes and procedures. However, too much peace and stability may lead to complacency and prevent the stimulating tensions created by new challenges.

7) Creative turmoil: Causing creative turmoil stimulates radical innovation. The cause is often an existential threat: a matter of winning or losing, surviving or falling. Challenge seeking, risk taking, and entrepreneurship make use of creative turmoil as a driver of future growth. However, not all unrest leads to creative turmoil. The learning functions of peace and stability and creative turmoil can clearly conflict, even though they are supposed to complement one another.

Knowledge productivity has become the key driver of value creation and it is closely related with leadership and organizational culture. Therefore, the next sections focus on the relation of knowledge productivity with leadership, organizational culture and value creation.

\subsection{Leadership and knowledge productivity}

This study aims to identify leadership styles that drive an organization to create knowledge continuously, share that knowledge throughout the organization, and apply it effectively to practical daily operations. Leadership style can help an organization to become knowledge-productive and to achieve high value creation and sustainable capability.

Schumpeter (1987) argued that innovations are the result of leaders displaying entrepreneurship. However, he considered leadership as something for elites, and therefore entrepreneurship was viewed as a matter of individual traits. Leadership in a knowledge-creating firm must be open and flexible rather than a fixed control mechanism. Avolio, Sivasubramaniam, Murry, Jung, and Garger (2003) developed measures of five facets pertaining to shared leadership: inspiring leadership, intellectual stimulation, individual consideration, contingent reward, and 
management by exception. These five facets provide useful and timely assistance in boosting innovative potential. Various forms of shared leadership gain prominence in the contemporary workplace (Hooker \& Csikszentmihalyi, 2002). Today, knowledge is created through dynamic interaction. Leadership in the knowledgecreating firm requires active commitment from all members of the organization, not just from a few elites. In knowledge-creating firms, the planning and implementation of strategy is integrated instead of being separated (Teece, 2003).

In this context, Politis (2002) insisted that the role of leadership is increasingly changing from information and knowledge gatekeeping to knowledge creation and knowledge sharing involving all employees. Leadership plays various roles: developing and promoting the sharing of knowledge assets and creating, energizing, and connecting (Nonaka, Toyama, \& Konno, 2000). The knowledge creation process should be integrated under clear leadership so that a firm can create knowledge continuously and dynamically. The knowledge creation process should become a discipline for members of the organization in terms of how they think and act in identifying, defining, and solving problems (Nonaka et al., 2000).

In every organization, leaders should become the role models for others, directly affecting the knowledge management process and implementing the agreed approach (Singh, 2008). According to the study of Lee (1999), CEOs' leadership styles are essential for effective knowledge sharing in firms. Lam (2002) found that transformational leadership can affect the process and achievement of an organization's learning. Indeed, transformational leadership encourages and emphasizes a spirit of teamwork and involvement (Nguyen \& Mohamed, 2010). In order to transfer and transform personal knowledge into organizational knowledge, knowledge sharing should be led by the organization's top managers and leaders. If knowledge management does not spread from the top to all levels in the organization, knowledge management programs are unlikely to be effective (DeTienne, Dyer, Hoopes, \& Harris, 2004). According to the recent empirical study of Song, Kolb, Lee, and Kim (2012), transformational leadership has a directly positive impact on organizational knowledge creation and an indirectly positive influence on organizational knowledge creation through employees' work engagement as a mediator.

Kludge, Stein, and Licht (2001) pointed out that leaders across all levels of an organization have a unique and vital role to play in managing knowledge. It is particularly important for the CEO to be involved in the knowledge-sharing process. In the same vein, Von Krogh (1998) believed that the commitment of high-level 
executives determines the amount of resources allocated and the amount of time allowed for members to engage in the creation and sharing of knowledge. Furthermore, DeTienne et al. (2004) asserted that to enhance knowledge sharing, leadership should be focused on culture, trust, cooperation, and incentive.

Greengard (1998) insisted that senior managers must understand the value of knowledge management in order to support and play a constructive role in decisionmaking. Beckman (1999) pointed out that the responsibility of top managers of the company in the knowledge management process is to motivate the employees, provide equal opportunities and developmental tools, and scientifically measure and reward the performances, behaviors, and attitudes required for effective knowledge management. Debowski (2006) also claimed that the role of the knowledge leader is to provide strategic vision, motivate others, communicate effectively, act as a coach, and implement knowledge development plans.

Takeuchi (2001) described three ways in which CEOs and other top managers should provide direction for knowledge management. First of all, top managers must articulate a "grand theory" of what the company as a whole ought to be. Second, top managers must incorporate their vision for knowledge management into the firm's objectives and policy statement. Third, top managers must make strategic decisions to support knowledge management efforts.

Asoh, Belardo, and Neilson (2002) identified leadership, culture, and technology as success factors affecting knowledge management. Anantatmula (2007) proved that leadership is the key factor for successful implementation of knowledge management. A CEO's leadership can stimulate creativity in individual employees, diffuse knowledge for effective application, and increase the effects of knowledge management motivating employees (Koski, 2001). Also, Makri and Scandura (2010) suggested that creative leadership reflects the CEO's commitment to the development of social and human capital and knowledge development. Thus, leaders have a unique and vital role to play in enabling continuous knowledge creation and innovation, effective sharing of knowledge assets within the organization, and applying knowledge for value creation processes and the creation of wealth (Kilroy, 1999). Thus, the leadership style of the CEO has a strong impact on creating an organizational culture favorable for knowledge productivity within the company.

\subsection{Organizational culture and knowledge productivity}

An important question is what organization culture empowers and motivates people in the organization to become creative and innovative, one in which people create 
knowledge continuously and share that knowledge throughout the organization, and then effectively apply it for value creation to build a knowledge productive company.

A knowledge-friendly culture with a positive attitude toward acquiring knowledge is one that highly values learning in the form of experience, expertise, and rapid innovation both on and off the job. Firms with such a culture attract and hire people who reinforce their positive orientation (Davenport, De Long, \& Beers, 1998). In the same vein, Alavi, Kayworth, and Leidner (2006) stressed that certain types of organizational values lead to different types of knowledge management behavior and that these behaviors lead to varying outcomes. Thus, cultural values such as sharing, openness, and trust lead to positive knowledge productivity, which in turn leads to innovation. Knowledge productivity is possible only in the context of what might be called an "intelligent organization". The culture of such an organization values and highlights intelligence, and sharing of information and ideas (Koski, 2001).

Gold, Malhotra, and Segars (2001) demonstrated the relationship among particular organizational values, knowledge-productive capabilities, and subsequent organizational effectiveness. They concluded that organizations with more open and supportive value orientations are predisposed toward constructive knowledge behaviors such as firm employees sharing insights with others. They argued that these values form part of the firm's knowledge infrastructure capability, which may influence the organizational abilities to innovate, respond rapidly to change, and be responsive to new market demands. Another study by Delong and Fahey (2000) identified specific value orientations that facilitate or hinder knowledge sharing. They argued that value orientations such as trust and collaboration lead to greater willingness among the members of the organization to share insights and expertise with each other.

Entrepreneurial cultures are more receptive to innovation (Burgelman, 1983; Kanter, 1989). Thus, organizations with entrepreneurial cultures acquire knowledge more effectively through exploration, engage in generative learning, and develop new behaviors to support learning (Slater \& Narver, 1995). Organizations with entrepreneurial cultures are willing to exchange ideas and information; thus, employees within such firms are open to adapting ideas created outside their organizations (Menon \& Varadarajan, 1992). Tseng (2010) asserted that an adhocracy culture enables knowledge conversion and improves corporate performance better than clan and hierarchical cultures. Therefore, if the organization can nurture an adhocracy culture, an environment in which knowledge 
workers can learn, feel comfortable, and have the opportunity to be creative and innovative, this may lead to improved corporate performance and increased organizational value. Research in the area of entrepreneurial culture supports the proposition that organizations placing great emphasis on entrepreneurship are more likely to generate insightful and innovative new information (Brockman \& Morgan, 2003).

Other research focuses on concepts related to knowledge creation and its relationship to creating value. For example, Lee and Choi (2003) examined various enablers of knowledge creation, such as the positive relationships among organizational culture, collaboration, trust, and learning, and knowledge creation processes. They concluded that shaping such cultural factors is key to the ability to manage knowledge effectively.

Although studies of knowledge management and organizational culture have helped to validate the importance of cultural values for firms, highlighted knowledge management initiatives, and provided insights into some important values, a detailed analysis is required that outlines specific types of values and how these values relate to knowledge productivity and subsequent outcomes. Moreover, previous research focuses almost exclusively on the processes of knowledge sharing and knowledge creation. Other processes, such as knowledge seeking and use, the tools to support knowledge management, and the outcomes associated with these processes also need to be carefully examined. In addition, the literature to date has not considered the choice of technologies in support of knowledge productivity and how such choices may be influenced by organizational values (Alavi et al., 2006).

Alawi, Marzooqi, and Mohammed (2007) insisted that trust, communication, information systems, rewards, and organizational structure are positively related to knowledge sharing in organizations. The findings in the literature reviewed for this study suggested positive relationships among organizational culture, knowledge creation, learning, and innovation. However, the relationship between organizational culture and knowledge productivity needs to be more clearly defined. This is one of the goals of this study.

\subsection{Knowledge productivity and value creation}

This study investigates how knowledge can become productive, contributing to high value creation and development of future growth, thereby improving sustainable capability for innovation. The growing importance of knowledge has changed the role of human operations in economic transactions. The focus is shifting from the 
appreciation of physical labor and the ability to coordinate and regulate to the ability to contribute to knowledge generation and application (Castells, 1998; Drucker, 1993). Knowledge productivity is therefore increasingly important for value creation (Kessels, 1996; Kessels, 2004), and has become the main objective of today's business management and the most important responsibility of business leaders. Stam (2007) argued that knowledge productivity is the process of transforming knowledge into value. In addition, Robinson, Anumba, Carrillo, and Al-Ghassani (2006) found that knowledge management is inextricably linked to corporate sustainability.

The previous studies mainly focused on the relationships among knowledge development, culture, leadership, and innovation. However, they seldom mentioned the relation between knowledge productivity and value creation. As knowledge productivity has become the main factor for value creation in business management, this area needs more in-depth research.

\subsection{Leadership and value creation}

This section reviews the literature on the concepts and theories related to both leadership and value creation. In this research, the value creation concept encompasses six factors: (1) revenue and net profit growth; (2) firm market value; (3) high employee satisfaction; (4) company reputation and image; (5) corporate social responsibility (CSR); and (6) corporate sustainability.

Recent research highlights transformational leadership as a highly effective style predictive of organizational performance (Dvir, Eden, Avoli, \& Shamir, 2002; Jung et al., 2003). Clearly, top management leadership is closely related to corporate performance. Wilderom et al. (2012) stressed that performance is significantly related to charismatic leadership. Also, Peterson, Walumbwa, Byron, and Myrowitz (2009) claimed that transformational leadership mediates the relationship between a leader's positive psychological traits and firm performance. Recently, Carmeli, Schaubroeck, and Tishler (2011) stressed the role of empowering leadership behavior, which leads to enhanced team potency. Such leadership behavior shapes the context for information exchange, joint decision-making, and collaboration. It nurtures confidence among team members and has positive implications for firm performance.

In the following sections, the relationships between leadership and the other value creation factors (corporate reputation, corporate image, CSR, employee satisfaction, and corporate sustainability) are reviewed. 


\subsubsection{Leadership, corporate reputation, and image}

Many authors argue that corporate reputation is closely associated with the CEO's image and reputation. These factors can alter the outcome of organizational efforts to establish effective customer relationships (Jin \& Yeo, 2011). Intangible assets, such as reputation, credibility of the corporation and its CEO, and customer relationships affect customer satisfaction and loyalty. In addition, CEO and company reputation, corporate relationships, and communication are inextricably linked to leadership because they contribute to a CEO's ability to direct and control desired outcomes (Jin \& Yeo, 2011). Image and reputation of a company as well as of the CEO seem to really matter. Roberts and Dowling (2002) confirmed a positive relationship between reputation and financial performance.

However, published studies of the relationship between leadership and corporate image and reputation are scarce. Leadership has mainly been studied in relation to organizational culture and behavior, and image and reputation have mostly been studied under the auspices of marketing management. In this study, therefore, the relationships among leadership, corporate image, and reputation are investigated further.

\subsubsection{Leadership and corporate social responsibility}

The concept of corporate social responsibility (CSR) has been evolving for decades in response to societal and political changes. McGuire (1963) posited the idea of social responsibility, stating that corporations have both economic and legal obligations, but also certain responsibilities to society as a whole. Frederick (1986) summed up the fundamental idea of CSR: that business corporations have an obligation to work for social betterment. Pride and Ferrell (2006) defined CSR as a company's obligation to exert a positive impact while minimizing its negative impact on society. Carroll (1979) divided CSR into four domains: economic, legal, ethical, and discretionary philanthropic responsibilities. Though there are many definitions, most authors use Carroll's four-dimension model of CSR.

CSR is more important now than ever before because of heightened customer consciousness, public opinion, and governments, who force corporations to take greater responsibility for the environment for the good of society, and to demonstrate ethical behavior. Most corporations (i.e., large, small, and medium enterprises) realize the importance of CSR. Kwon and Kim (2010) studied the effect of CSR on corporate image evaluation, comparing differences in the effect of CSR on major participants, including CEOs and company employees. This study indicated that employees' active participation in CSR activities impacted corporate image 
more positively than CEOs' participation. In addition, non-profit-oriented charitable CSR activities impacted corporate image more positively.

Waldman, Siegel, and Javidan (2006) studied the relationship between transformational leadership and CSR in American and Canadian firms. CEO intellectual stimulation was found to be significantly associated with the propensity of a firm to engage in "strategic" CSR, or those CSR activities that are most likely to be related to the firm's corporate strategies. In the same vein, Waldman, Sully de Luque, Washburn, and House (2006) suggested that the vision and integrity of a leader improved the social responsibility values of followers, especially those of shareholders and other stakeholders. By promoting CSR activities, companies can not only foster favorable stakeholder attitudes and provide better support, but also in the long run, they can build corporate image, strengthen stakeholder-company relationships, and enhance stakeholders' advocacy behaviors (Du, Bhattacharya, \& Sen, 2010).

In most cases, when a company has successfully achieved its revenue objectives and goals for net profit growth and market value increases, then it can fulfill its social responsibilities more effectively, especially its discretionary and philanthropic social responsibilities. Corporate management principles, leadership philosophy, and organizational culture are closely related to fulfillment of these responsibilities.

\subsubsection{Leadership and employee satisfaction}

Today, culture and society are more people-oriented than in previous decades. Employees' expectations of their companies and leaders have changed. Hart and Quinn (1991) assessed employee satisfaction using a scale of perceived organizational performance. Employee satisfaction has become an important factor for measuring value creation of a company. In that study, when leaders respected their employees as human beings, listening and considering their opinions and ideas, employee satisfaction levels improved.

Various other aspects related to leadership and employee satisfaction have been examined. Chang and Lee (2007) stated that both leadership and organizational culture can positively and significantly affect the operation of a learning organization. In turn, effective operation of learning organizations has a significantly positive effect on employee job satisfaction.

Berson et al. (2008) found that CEOs of organizations that value benevolence tend to emphasize support and cooperation among employees. Such supportive cultures are associated with greater employee satisfaction. Berson and Linton (2005) asserted that transformational leadership has a strong impact on employee job satisfaction 
and overall satisfaction with the organization. They found that a transformational leadership style was strongly and positively related to organizational quality and a climate in which employees pay greater attention to the quality of their work, and in which overall satisfaction and job satisfaction are high. Several studies have confirmed a mostly positive relationship between the behaviors of charismatic (Bryman, 1992) and transformational (Podsakoff, Mackenzie, Moorman, \& Fetter, 1990; Podsakoff, Mackenzie, \& Bommer, 1996) leaders and employee satisfaction, organizational commitment, trust, organizational citizenship behaviors, and job satisfaction (Mischel, 1973, Wang, Tsui, \& Xin, 2011), which supports our expectation of a strong relationship between leadership and value creation. When leaders effectively communicate their vision, they win the confidence of their followers, which in turn improves communication satisfaction between the leader and the follower (Pavitt, 1999). Castaneda and Nahavandi (1991) suggested that the most satisfied subordinates were those who perceived their supervisors' behaviors as both relationship-oriented and task-oriented.

The most common factors leading to worker stress and dissatisfaction are those related to the nature of the job itself, and the context within which inter-personal relationships between employees and supervisors take place (Barnett \& Brennan, 1997). According to Korte and Wynne (1996), deterioration of relationships in an organization may result from reduced interpersonal communication between leaders and workers. This limited communication has a negative influence on job satisfaction and may lead to employees leaving their jobs. Thus, leadership style and employee satisfaction are closely related, and leadership has a profound impact on employee satisfaction. Therefore, an important part of the leadership role in improving employee satisfaction is empowering people and creating a peopleoriented, open organizational culture of mutual trust, with boundary-less open communication between leaders and employees.

\subsubsection{Leadership and corporate sustainability}

Sustainability of a company strongly depends on successful value creation in terms of revenue and profit growth, market value increase, corporate reputation, and image upgrade. This study explores the role of knowledge productivity as a factor for value creation and corporate sustainability. Kessels et al. (2011) argued that knowledge productivity combines improvements and innovations of products, services, and work processes with an increased sustainable capability for radical innovation in the future. Gloet (2006)'s study described ways of linking knowledge management and human resource development, by which organizations can develop 
leadership and management capabilities that support sustainability in business, environmental, and social justice contexts.

\subsubsection{Leadership and financial performance}

Leadership style impacts financial performance and value creation of a firm directly and indirectly between the organizational culture and knowledge productivity of the firm. Zhu, Chew, and Spangler (2005) claimed that leadership is one of the key driving forces for improving firm performance. Top management leadership is considered one of the most important factors influencing corporate financial performance (Jin \& Yeo, 2011). Hambrick and Mason (1984) argued that CEO characteristics, such as personal values, are linked with organizational structure and financial performance. Waldman, Ramirez, House, and Puranam (2001) asserted that charismatic CEO leadership is related to financial performance. In addition, charismatic CEO leadership is highly related to financial performance in organizations with uncertain and volatile environments.

In this section on the relationships between leadership and value creation, we presented the findings of many studies that elaborate on the impact of charismatic and transformational leadership on various aspects of value creation, specifically the financial aspects, corporate image and reputation, employee satisfaction, CSR, and sustainability. In the empirical part of this study, we examine this complex relationship further.

\subsection{Toward a conceptual framework of the relationships among leadership, organizational culture, knowledge productivity, and value creation}

In the previous sections, literature on the main variables and the relationships among them was examined. Before bringing them together in a conceptual framework for this study, it is important to discuss a number of characteristics of one of the very successful companies that inspired many business leaders: General Electric (GE). Another reason for including the GE case here is that the author served for more than 20 years (1980-2001) as CEO of GE in Korea. During this period, many strategic long-term partnerships were established between GE, a U.S.based firm, and leading Korean companies. These win-win partnerships offered important learning experiences and provided in-depth understanding of how leadership, organizational culture, knowledge productivity, and value creation may be facilitated in leading Korean companies. These partnerships strongly contributed 
to GE's globalization strategy and the development of the Korean high-tech industry. These experiences heavily influenced the author during the development of the conceptual framework and the research questions of this study. Following the GE case a discussion of the four main leadership characteristics is presented. This section concludes with the detailed research questions that form the basis of the empirical part of this study.

\subsubsection{GE case}

GE is regarded as an example of successful leadership, organizational culture, knowledge productivity, and value creation. Jack Welch, the former CEO of this company (1981-2001) demonstrated high-challenging, innovative entrepreneurship and people-oriented empowering leadership, and created highly knowledgeproductive, innovative, non-bureaucratic open organizational culture in which people brought out their best capabilities for meeting the company goals and vision. As a result, GE became one of the most admired companies with the highest value creation in the world during the period 1996-2001.

GE is known as a success model of leadership, a people-oriented and knowledgeproductive organizational culture with high value creation. The GE case is an inspirational example for the conceptual framework of this study. In addition to the sources from previous research and published reports, the information on the GE case is also based on the author's 20 years of experience working with Jack Welch as the CEO of GE Korea, and on interviews with two former senior executives of GE: Paolo Fresco, who worked with Welch as a vice chairman of GE, and Bill Conaty, who worked with Welch as senior vice president in charge of human resources development, reporting directly to Welch. The meetings with these former executives of GE provided more inside background on the model of leadership and organizational culture at GE.

In 1981, Jack Welch became Chairman of GE. In a short period of time, he radically changed the traditional organizational culture of the 120-year-old company for the first time since Thomas Edison founded the firm. Welch intended to create a nonbureaucratic, boundary-less, open, and people-oriented organizational culture where people were empowered and encouraged to become innovative, creative, and challenged to meet the corporate vision and goals. He strongly emphasized that the company should utilize people's knowledge, brains, and ideas as valuable human capital (Becker, 1964) instead of just considering them as employed workers, the traditional bureaucratic way of viewing human resources. These radical and rapid changes in culture revived the company and turned GE into a leading knowledge- 
productive and competitive global enterprise.

Welch implemented a people-oriented management approach focusing on creating a knowledge-productive organization (Slater, 1999). As a result, the company achieved the highest value creation ever recorded up to that time, reporting the largest net profit and market value in the world during the mid- to late 1990s. According to Fortune Magazine (Khan, 1999), GE was ranked No. 1 on the list of The World's Most Admired Companies of 1998 and 1999. According to 15 years of Fortune reported by HayGroup (April, 2012), GE was the World's Most Admired Company in the industry from 1997 to 2010. Welch was selected as The World's Most Admired CEO by Fortune Magazine from 1997 to 1999 . Key elements of success in the GE case included:

1) High challenge-seeking entrepreneurship, similar to the concept of Nahavandi and Malekzadeh (1993).

2) People-oriented leadership and culture, empowering people and organizations, non-bureaucratic open culture, respecting people as human beings, and respecting knowledge and ideas of the people.

3) Building an innovative and creative knowledge-productive organizational culture, similar to the concept of Kessels (1996) with boundary-less open communication and effective sharing of knowledge and ideas within the company, similar to the concept of knowledge worker by Drucker (1999).

Welch never stopped talking about making GE "the world's most competitive enterprise" (Krames, 2005). His message was simple and clear. He often spoke wise maxims to GE people such as, "Hate bureaucracy and boundaries. Destroy them" (Slater, 1999, p. 259), "Use peoples' brains and ideas. Not their hands and legs" (Slater, 1999, p. 49), and "Change radically; step by step change never will lead to success" (Slater, 1999, p. 10). The following list of six of Welch's rules was published by Fortune in 1989 and later in the study of Tichy and Sherman (1993).

1) Control your destiny or someone else will.

2) Face the reality as it is, not as it was or as you wish it were.

3) Be candid with everyone.

4) Don't manage, lead.

5) Change before you have to.

6) If you don't have competitive advantage, don't compete (Tichy \& Sherman, 1993). 
In addition, Krames (2005) described Welch's winning leadership formula as based on the "four E's", which are

1) Energy and passion to lead an organization with highly challenging entrepreneurship,

2) Energizing and empowering people in the organization,

3) Edge (the ability to make sharp and rapid decisions on time with confidence from leaders and competitive spirit, and to know the value of speed)

4) Execution capability when the decision is made.

Although GE is generally described as one of the most successful firms in the world and Jack Welch is portrayed as a role model for modern corporate leadership, critics have found some difficulties with GE's way of doing things, especially related to the restructuring of the organization and business portfolios. When Welch was appointed Chairman in 1981, GE was the only surviving remaining company among the top 12 best U.S. companies that had been selected by the Dow Jones and Wall Street Journal in 1900.

Therefore, the clear mission given to Welch when elected as chairman was to restructure GE businesses and rebuild the company, and not to follow the 11 companies that had already disappeared. GE was significantly diversified in almost 170 different business areas at that time. Welch started aggressive restructuring of the entire GE business portfolio based on the core confidence and global competitiveness of each business, keeping those core businesses which were No. 1 or No. 2 in the world, the top performers. GE sold almost 110 businesses, which were not among the core confidence businesses, and merged almost 70 future-oriented new businesses within a short period of time. During this restructuring process, 100,000 of 400,000 employees had to leave the company. Severe criticism was directed at Welch; it seemed that "neutron Jack" was destroying GE, the symbol of American pride.

Another often criticized aspect of GE is its "revitalization strategy" for managing human resources, where the lowest $10 \%$ of underperforming staff were recommended to find new jobs inside and outside of the company. These characteristics of Welch's new business culture could be interpreted by outsiders as harsh and excessively performance-driven. On the other hand, GE leaders created a highly professional working climate in which achievement, entrepreneurship, and innovation were recognized, valued, and celebrated. However, GE people, including the business division leaders and employees, understood the people management 
system to be linked with performance evaluation as a GE revitalization model, which means that the lowest-performing $10 \%$ of employees were given opportunities to find new positions better suited to their talents within GE and elsewhere in order to revitalize their future career development rather than keeping them in the same low-performing positions.

In the example of GE, a people-oriented and high-challenging visionary leader created a highly knowledge-productive organizational culture where empowered people were allowed sufficient freedom to become innovative and creative, doing their best to achieve the vision and goals of the company with a strong sense of psychological ownership. Under this leadership and within this company culture, knowledge and ideas of the people in the organization were utilized in a productive way to achieve high value creation. The GE case indicates that people-oriented, highchallenging, and visionary leadership can create a knowledge-productive organizational culture that fosters high value creation, which is the main objective and goal of major corporations today, and therefore the key responsibility and challenge for business leaders.

Many Korean leading companies admired the GE model and benchmarked its practices, frequently adopting its approach to business innovation and changes, thus creating open organizational cultures in which employees' knowledge and ideas were effectively utilized, and people were empowered to develop a strong sense of psychological ownership.

\subsubsection{Conceptual framework}

For this study, on the basis of the previous discussion, a new conceptual framework was developed, shown in Figure 2.3, which illustrates the relationships among leadership, organizational culture, knowledge productivity, and value creation. From the findings of the literature and the understanding of the GE case, we expect that in leading Korean companies, a knowledge-productive organizational culture is a people-oriented, boundary-less, non-bureaucratic, and open culture in which the freedom to be creative is valued. Such a knowledge-productive organizational culture flourishes under people-oriented leadership when it is accompanied by nonbureaucratic empowerment and high-challenging, visionary entrepreneurship. 


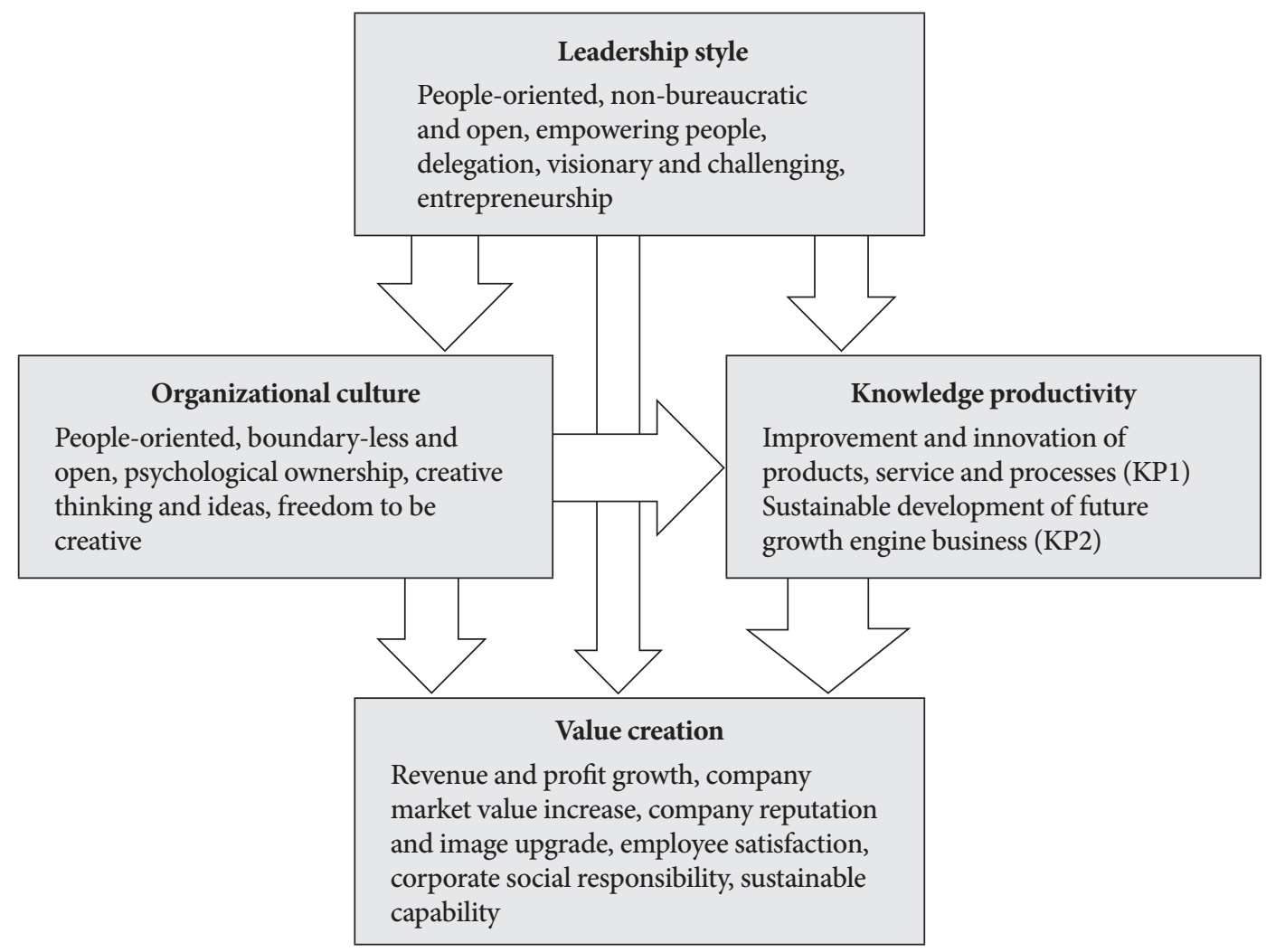

Figure 2.3 Conceptual framework of the relationship among leadership, organizational culture, knowledge productivity, and value creation

The main questions asked by business leaders today can be summarized as follows:

1) How can high value creation and sustainable growth capability be achieved?

2) How can a strong knowledge-productive organizational culture be created?

3) What are the key elements for building a knowledge-productive organization?

4) What leadership style is effective and desirable for building a highly knowledgeproductive organization?

The literature reviews in the previous sections revealed that researchers in this area expect positive correlations among leadership, organizational culture (Schein, 2004), and knowledge productivity (Kessels, 2004). However, these expectations need more tangible and concrete definitions and indicators. With regard to the specific relationships among the four main variables included in this study (leadership, 
organizational culture, knowledge productivity, and value creation), empirical findings and research on these specific relations are scarce. Therefore, in order to examine the relationships among the four main variables, empirical research is herein conducted focusing on four Korean leading companies: Samsung Electronics, LG Electronics, Shinhan Bank, and WoongJin Group in connection with the findings from the related literature review.

\subsubsection{Relationships between leadership and value creation}

The approach to value creation in relation with organizational culture and knowledge productivity may differ depending upon leadership style. We explore four leadership styles that were observed throughout the development process in Korean industries and business corporations during the following Five-Year Economic Development Plan periods: the first plan (1962-66), the second plan (1967-71), the third plan (1972-76), and the fourth plan (1977-81) (Park, 2009). During these four periods and the subsequent democratization process in Korea, human rights grew to be well recognized and respected in society. People-oriented and knowledge-based management became important in Korean organizations. Figure 2.4 shows four leadership styles as observed during the Korean economic development process and their relationships with organizational culture, knowledge productivity, and value creation in Korean industries. 


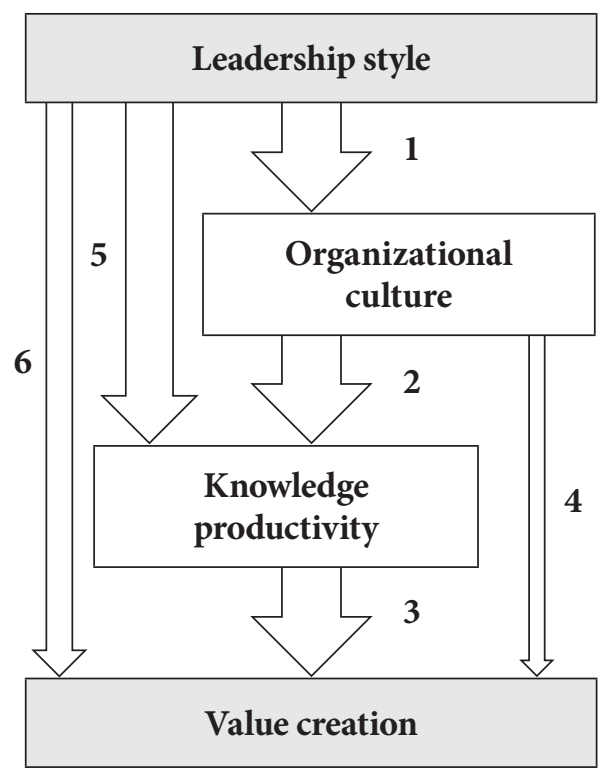

Leadership Mechanism
A Type: Mainly 1-2-3 \& 1-4 with selective 5 approach High-challenging Non-bureaucratic Empowerment

B Type : Mainly 1-2-3 \& 1-4 with active 5 approach High-challenging Non-bureaucratic Entrepreneurship

C Type : Less 1-2-3 \& 1-4 Active 5 and 6 approach Challenging Top-down control

D Type: Minimum 1-2-3 \& 1-4 Mainly 6 and some 5 approach Status-quo seeking Bureaucratic Top-down control

Figure 2.4 Four types of leadership leading to value creation

From a leadership perspective there are six approaches to influence value creation.

Note: Approach $1 \quad$ Leadership related to organizational culture

Approach 2 Organizational culture related to knowledge productivity Approach 3 Knowledge productivity related to value creation

Approach 4 Organizational culture related to value creation

Approach 5 Leadership directly contributes to knowledge productivity depending upon subject matter

Approach $6 \quad$ Leadership directly related to value creation

\section{Type A Leadership}

The main characteristics of Type A leadership are people-oriented, non-bureaucratic and open, prioritizing delegation; visionary and highly challenge-seeking; entrepreneurial, with a focus on an organizational culture that is boundary-less, 
open, and non-bureaucratic. In such a culture, people do their best with a strong psychological ownership, utilizing their knowledge and ideas for value creation of the company. The influence of leadership on value creation can be described as a 1-2-3 approach promoting culture (1) and knowledge productivity (2), with the result of value creation (3), as shown in Figure 2.4.

\section{Type B leadership}

The main characteristics of Type B leadership are closely related to those of Type A, except that Type B leaders prefer to be more directly involved in improvement of knowledge productivity, fostering an organizational culture that is open and avoids bureaucracy. Often, this approach is a result of the leaders' own long management experience. Successful founding leaders often exhibit Type B leadership characteristics. The influence of leadership on value creation can be described as a 1-2-3 approach promoting culture (1) and knowledge productivity (2), with the result of value creation (3). Type B leadership often directly contributes to knowledge productivity, especially for important strategic projects and decisions (5), as shown in Figure 2.4.

\section{Type C leadership}

Type C leadership can be described as bureaucratic, top-down control, charismatic, and challenging, with limited delegation, and reinforcement of stability. The influence of this type of leadership on value creation is a more direct contribution to knowledge productivity (5) and value creation (6). The 1-2-3 approach shown in Figure 2.4 is less prominent.

\section{Type D leadership}

The main characteristics of Type D leadership are similar to those of Type C, except that Type $\mathrm{D}$ leaders prefer to control knowledge management and value creation more directly, focusing on an organizational culture that is bureaucratic and topdown, with centralized control and limited delegation. The influence of leadership on value creation is mostly realized through direct control and contributions to value creation (6). The 1-2-3 approach is minimal, as shown in Figure 2.4.

\subsection{Research questions}

This discussion of the problem statement of how leadership can enable sustainable value creation in a corporation leads to the following research questions: 
1) How do the characteristics of leadership relate to organizational culture, knowledge productivity, and value creation of the company?

According to existing academic research and from practical management experience, leadership impacts the formulation of organizational culture more than other factors (Schein, 1985; Schein, 1992; Schein, 2004). In turn, organizational culture impacts people's ability and willingness to be creative and innovative. The literature review in this chapter revealed that organizational culture influences knowledge development and knowledge productivity, which in turn impact value creation (Kessels, 1996; Kessels, 2004), the most important objective of business management. Depending upon the leadership style, the impact and level of direct participation and influence of a leader on organizational culture, knowledge productivity, and value creation may vary. The main objective of this study is to identify the relationships among these four main factors.

2) How do organizational culture, knowledge productivity, and value creation interact?

Successful companies today have achieved high value creation through utilizing the knowledge and ideas of people in their organizations in highly productive ways. Many of those companies have boundary-less, non-bureaucratic, and open organizational cultures with freedom for people to become more creative, innovative, and imaginative. Building such a creative organizational culture seems to be important for today's business leaders.

3) What leadership style is favorable for building a knowledge productive organizational culture and achieving sustainable high value creation?

Leadership contributes significantly to the creation of a knowledge-productive organizational culture, which is important for the sustainable value creation of a company in today's knowledge economy. The answers to questions 1 and 2 offer building blocks for defining desirable leadership styles for value creation, which is the main objective of this study.

4) Is it possible to design a set of guidelines for leadership on the basis of the answers to the questions 1, 2, and 3 in order to achieve high value creation in knowledge productive organizations? 



\section{Chapter 3. Research design and methodology: case studies of four major Korean companies ${ }^{1}$}

\subsection{Introduction}

The main objective of this study is to explore the relationships between specific leadership characteristics and value creation. Important factors in such relationships include the organizational culture and knowledge productivity. To meet this objective and address and answer the research questions, the empirical research focuses on four leading Korean companies. The research design included a literature search on the main topics, from which a conceptual framework was developed (Chapters 1 and 2), followed by a survey and additional interviews. Data on the variables related to financial and economic aspects of value creation were provided by the Korean Industry Research Institution. This research design can be described as a multiple case study of four companies. The cross-case analysis (in Chapter 8) was conducted on the basis of a quantitative analysis of the survey findings and a qualitative analysis of data from the interviews. This chapter describes the construction of the research instruments, selection of the four cases, factor analysis of the survey findings, and reliability testing.

\subsection{Development of research instruments: qualitative and quantitative analysis}

Leadership characteristics are mostly invisible, which makes them difficult to measure and define in a practical way. Survey questionnaires for quantitative analysis may be insufficient to represent the variety of leadership styles, organizational cultures, and knowledge productivity evident in today's businesses environment.

The traditional concept of value creation can be measured using quantitative data from a survey supplemented by real financial data on firm performance. However, the concept of value creation in this research includes additional intangible key factors, such as corporate reputation and image, employee satisfaction, corporate

\footnotetext{
${ }^{1}$ The development and testing of the research instruments have been published as:

Kang, S. J., Kessels, J., Lee, E. S., \& Cho, Y. S. (2014a). Measuring the CEO leadership style and the organizational culture. Journal of CEO and Management Studies, 17(1), 77-102.

Kang, S. J., Kessels, J., Lee, E. S., \& Cho, Y. S. (2014b). The development and its validation of knowledge productivity and value creation. Journal of CEO and Management Studies, 17(3), 23-44.
} 
social responsibility, and sustainability. Therefore, both quantitative and qualitative analyses were used in this study to supplement the tangible data. The outcomes of quantitative and qualitative analysis were compared to ensure reliability. Through the interviews, direct opinions from top managers of the firms, such as the chairman and CEO, were included in the analysis. Information about leadership style, organizational culture, knowledge productivity, and value creation from the quantitative analysis were combined with the data obtained from interviews with top management and subordinates in the same company. This combined methodology is helpful in understanding the long-term vision, entrepreneurship, management principles, and philosophy of each of the companies included in this study.

\subsubsection{Quantitative analysis: development of survey questionnaire}

Staff in the human resources departments of each company aided in distributing survey questionnaires and collecting survey data. In total, 480 survey questionnaires were distributed to executives, managers, and other employees of the four companies, and 387 respondents returned their completed questionnaires anonymously. For the quantitative analysis, all 387 survey responses from the four companies were usable (Samsung Electronics: 70, LG Electronics: 100, Shinhan Bank: 100, WoongJin Group: 117). All respondents were full-time executives, senior managers, managers, and employees.

The survey items were developed on the basis of the literature review in Chapter 2, combining elements from previous research with new items developed to fit the conceptual framework of this study. A full overview of survey characteristics, question items, keywords, and sources is presented in Table 3.1. The survey consists of a total of 106 items: 28 items on leadership, 21 items on organizational culture, 29 items on knowledge productivity, and 28 items on value creation. The survey questionnaire was designed and then sent out to the four participating companies in 2010.

The first step in developing the survey questionnaire was to review existing research in the areas of leadership, organizational culture, knowledge productivity, and value creation to find key words and relevant survey questionnaire items to explore the characteristics and relationships of the four main concepts in focus in this study. In the second step, specific items were selected that reflect the research concepts and incorporate characteristics of the main variables. In the third step, the items were transformed into a questionnaire scored on a five-point scale from (1) I fully disagree to (5) I fully agree. A pilot version of the questionnaire was distributed in 
one of the four companies. On the basis of the pilot survey, some items were removed and others were refined. The survey questionnaire was developed in both English and Korean; however, the Korean version was distributed to the four participating Korean companies. 


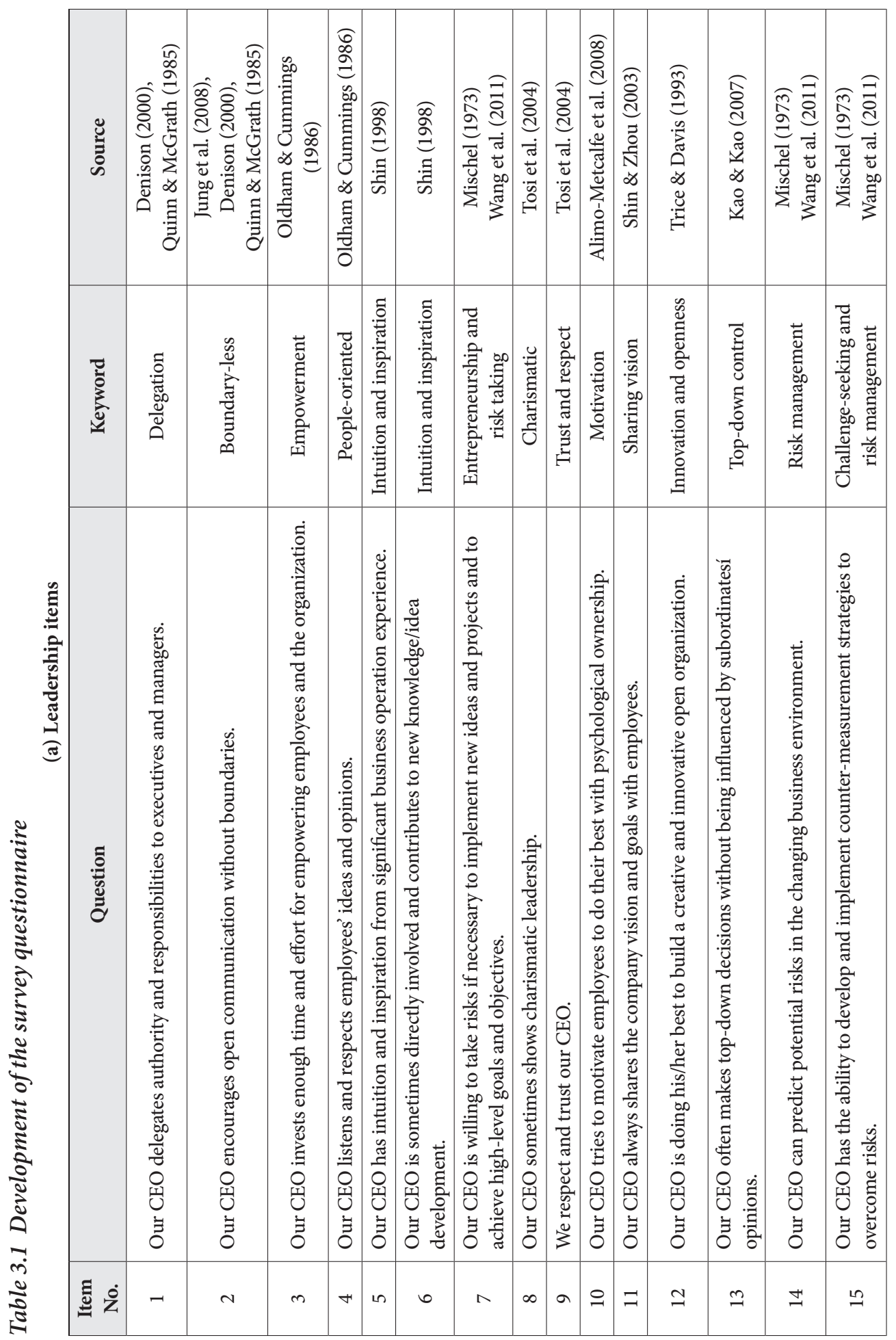




\begin{tabular}{|c|c|c|c|c|c|c|c|c|c|c|c|c|}
\hline 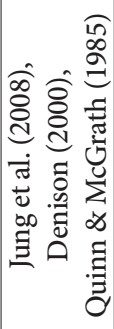 & 3 & 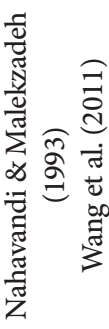 & 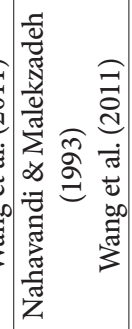 & 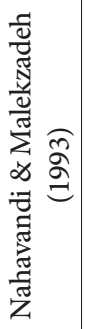 & 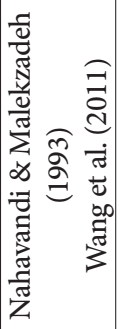 & 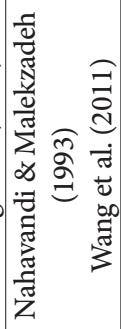 & 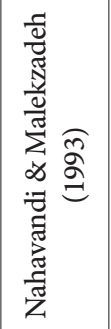 & 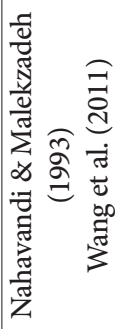 & 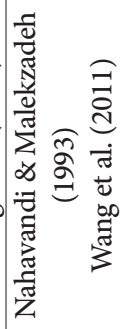 & 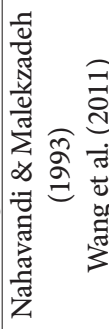 & 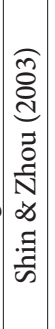 & 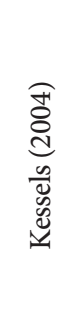 \\
\hline 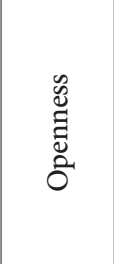 & 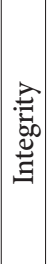 & 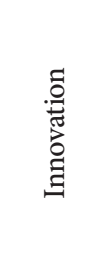 & 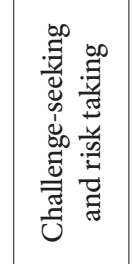 & 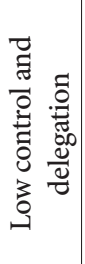 & 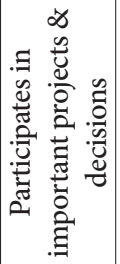 & 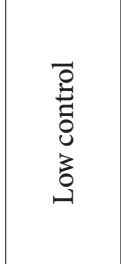 & 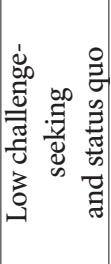 & 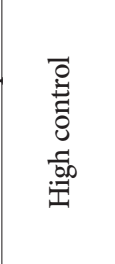 & 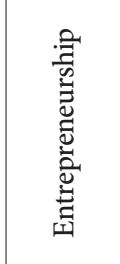 & 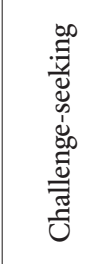 & 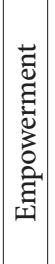 & 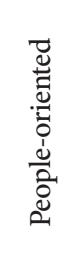 \\
\hline 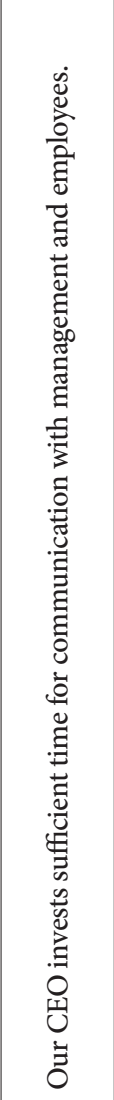 & 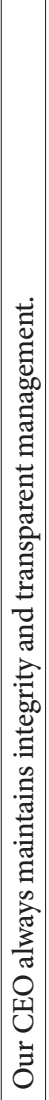 & 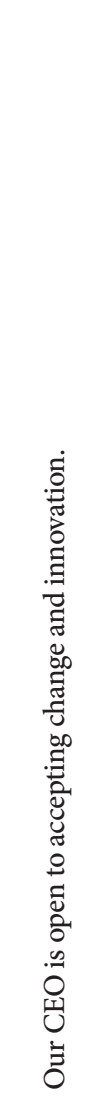 & 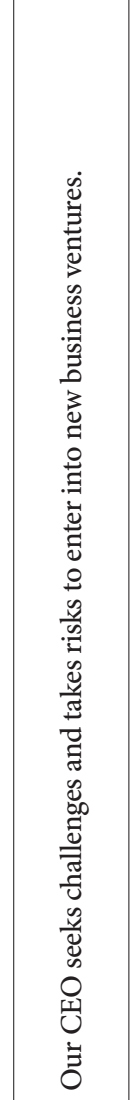 & 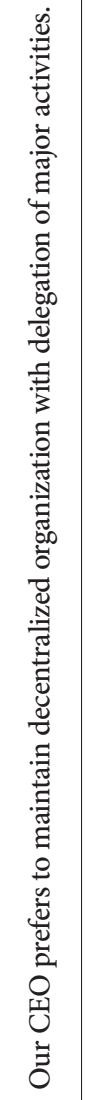 & 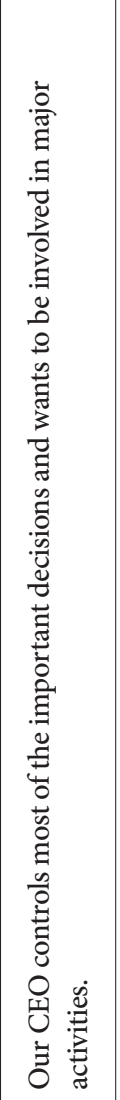 & 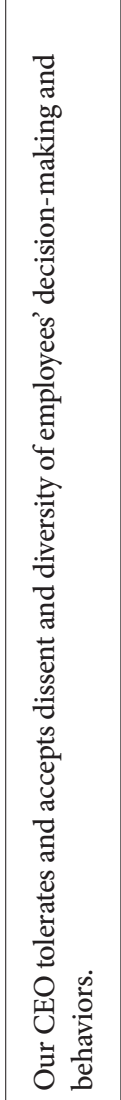 & 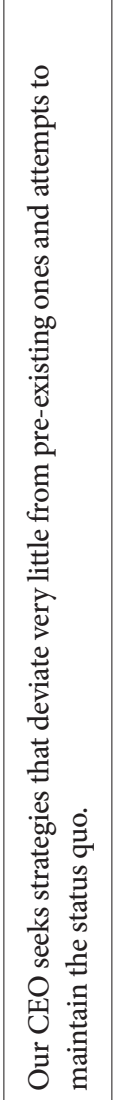 & 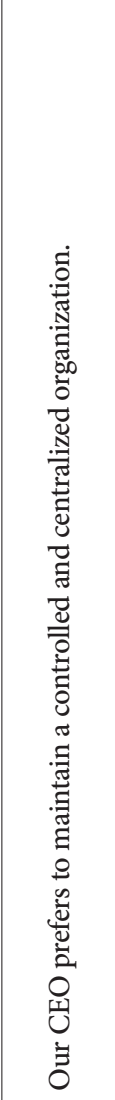 & 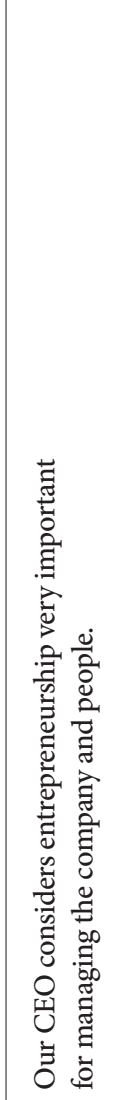 & 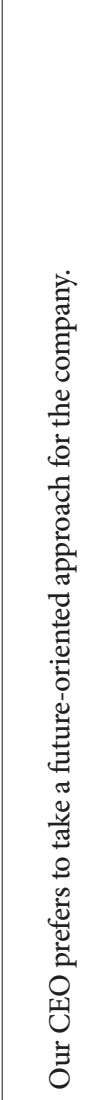 & 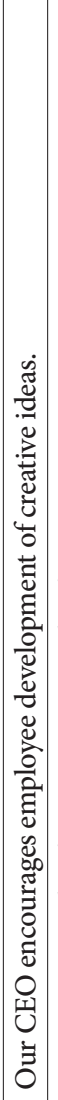 & 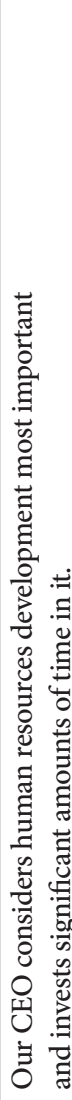 \\
\hline 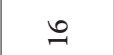 & $\beth$ & $\stackrel{\infty}{=}$ & 2 & శి & $\vec{\sim}$ & ป & $\tilde{\sim}$ & $\stackrel{\sim}{\Delta}$ & $\stackrel{\mathscr{2}}{\sim}$ & $\underset{\sim}{*}$ & $\hat{\sim}$ & $\stackrel{\sim}{\sim}$ \\
\hline
\end{tabular}




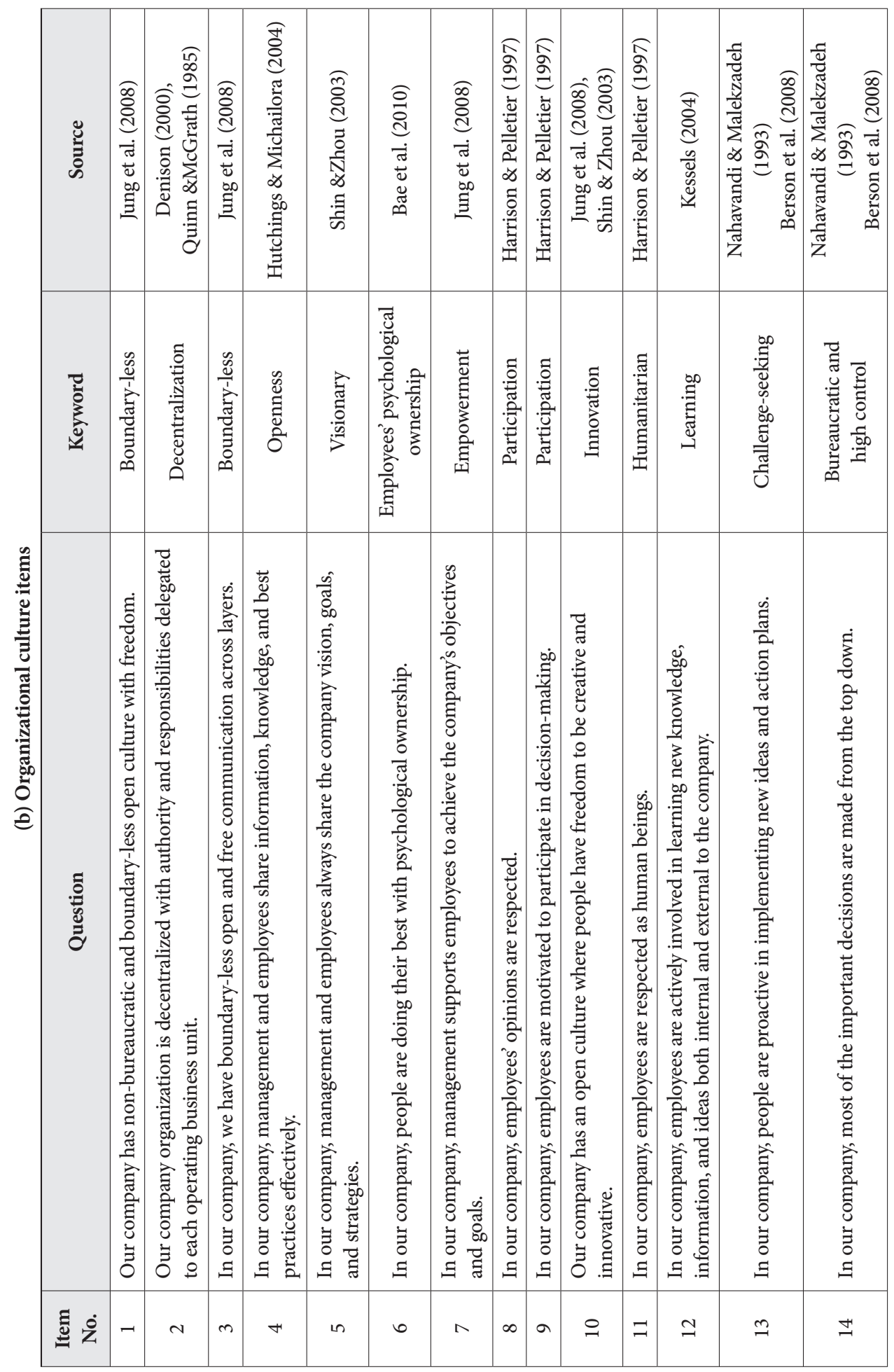




\begin{tabular}{|c|c|c|c|c|c|c|}
\hline 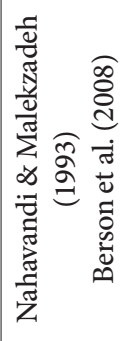 & 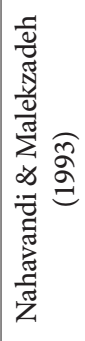 & 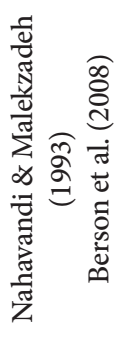 & 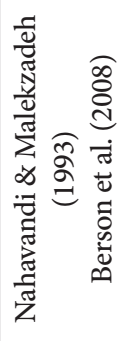 & 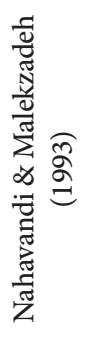 & 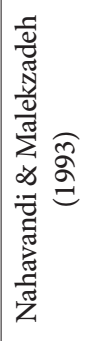 & 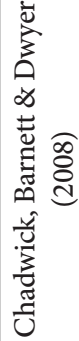 \\
\hline 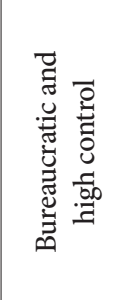 & 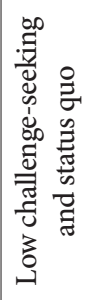 & 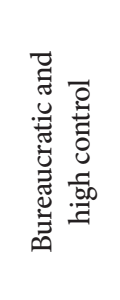 & 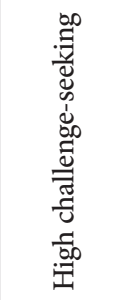 & 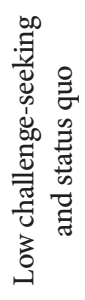 & 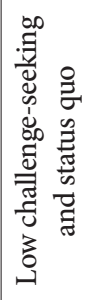 & 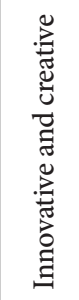 \\
\hline 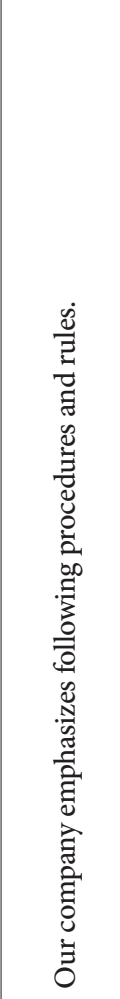 & 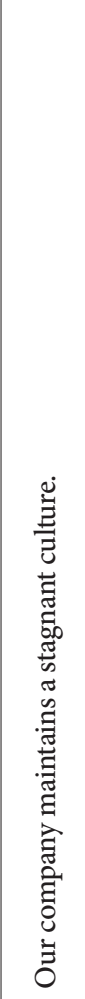 & 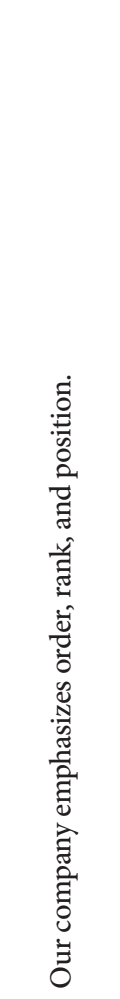 & 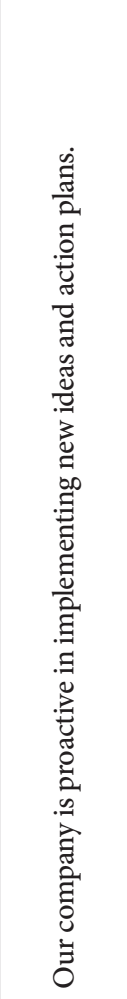 & 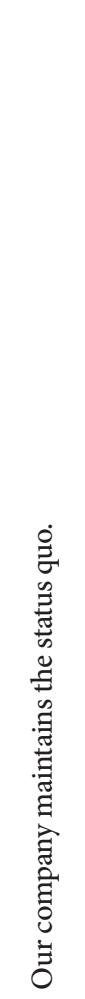 & 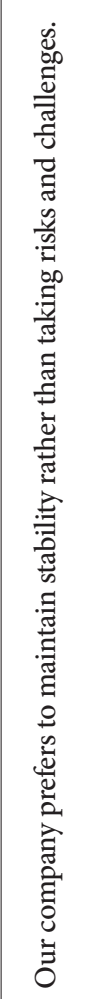 & 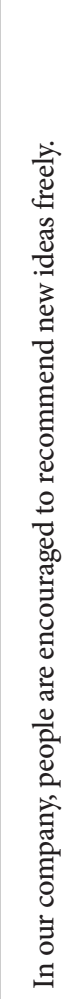 \\
\hline$\stackrel{12}{\sim}$ & $\stackrel{0}{-1}$ & 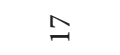 & $\stackrel{\infty}{=}$ & $\stackrel{2}{ }$ & సి & $\vec{\sim}$ \\
\hline
\end{tabular}




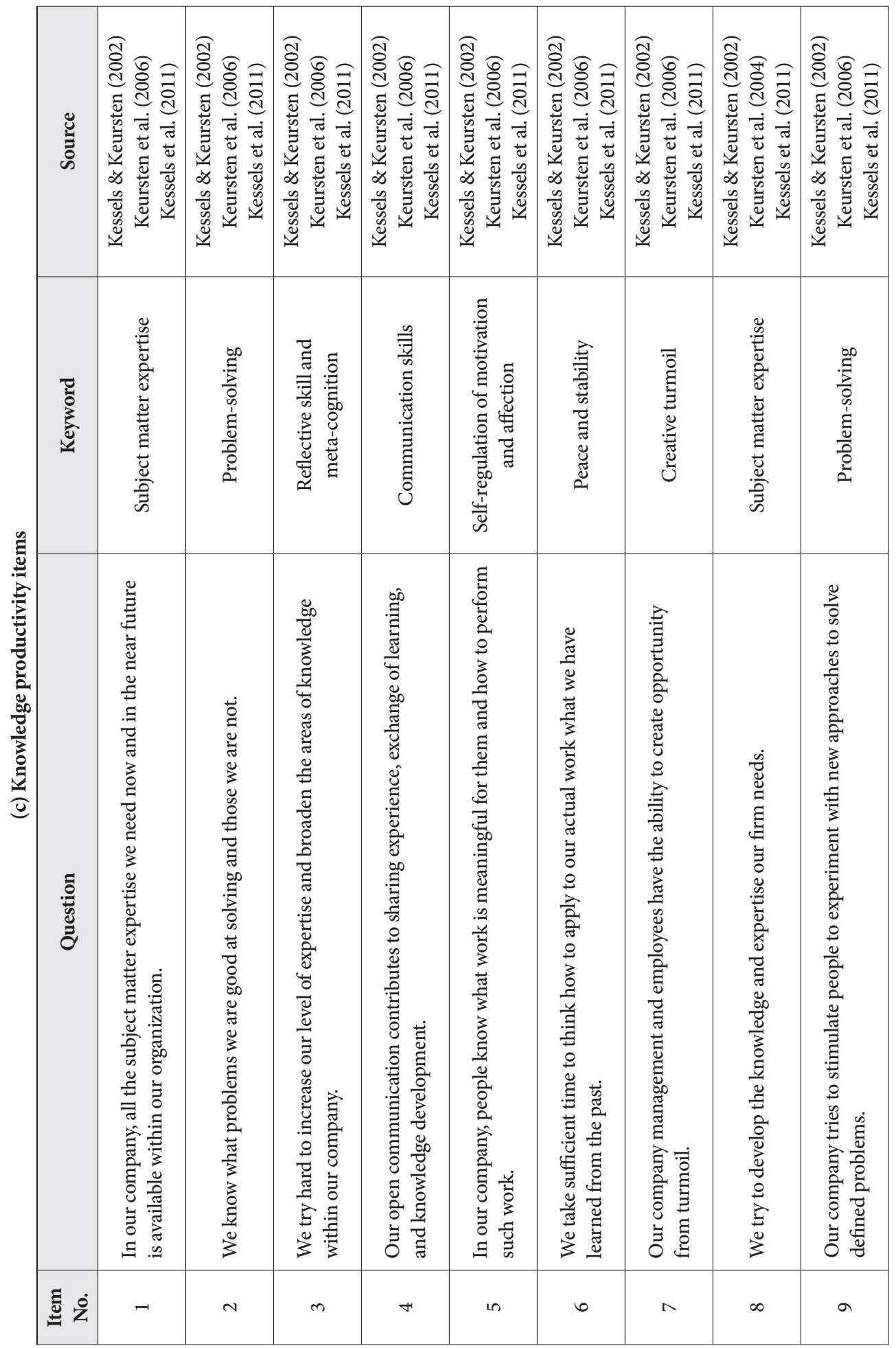




\begin{tabular}{|c|c|c|c|c|c|c|c|c|c|c|c|}
\hline 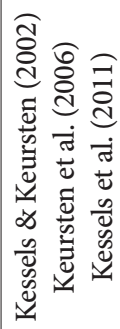 & 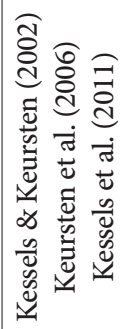 & 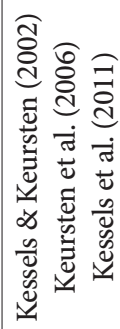 & 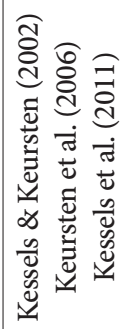 & 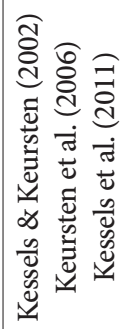 & 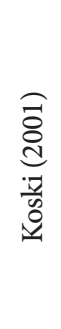 & 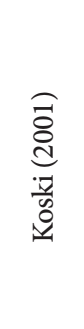 & $\begin{array}{l}\text { बू } \\
\stackrel{\partial}{\sigma} \\
\frac{\hat{0}}{2}\end{array}$ & 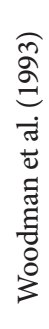 & 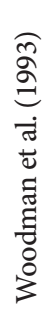 & 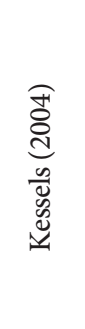 & 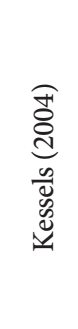 \\
\hline 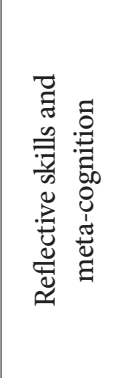 & 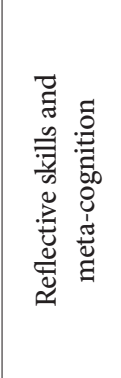 & 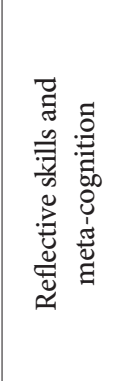 & 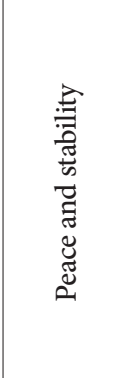 & 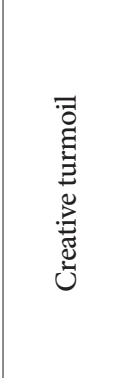 & 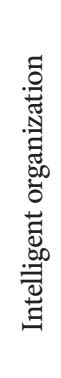 & 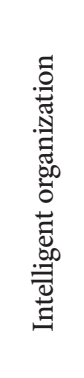 & 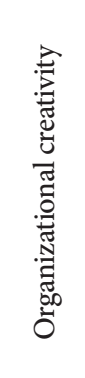 & 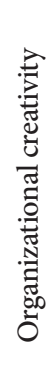 & 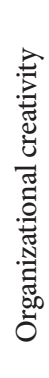 & 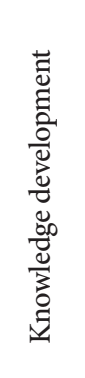 & 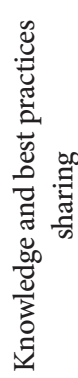 \\
\hline 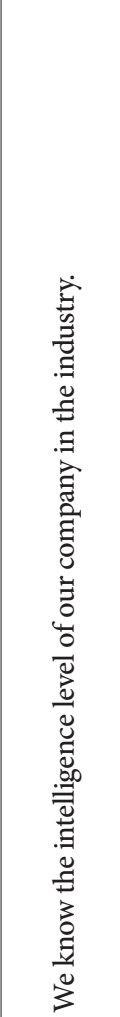 & 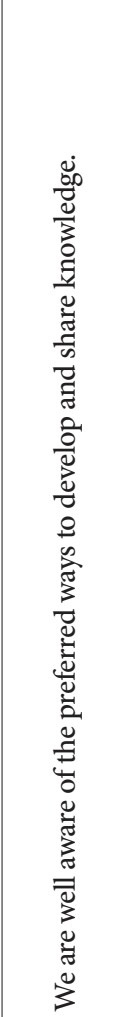 & 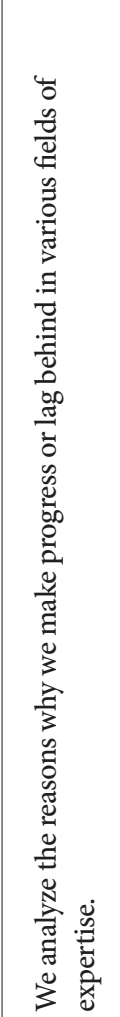 & 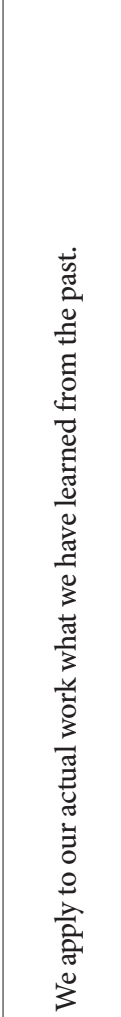 & 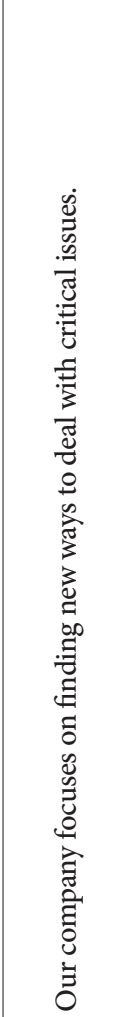 & 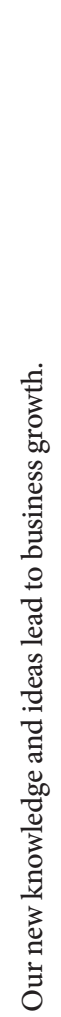 & 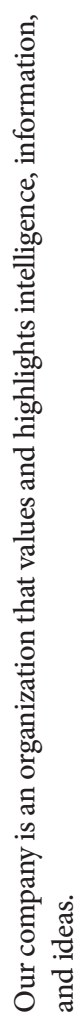 & 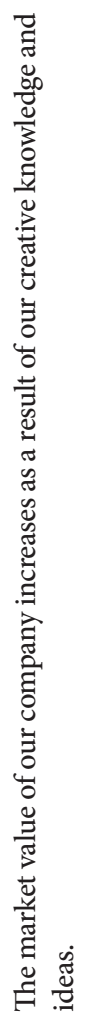 & 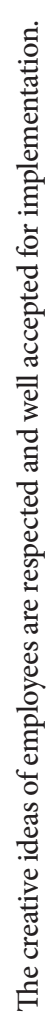 & 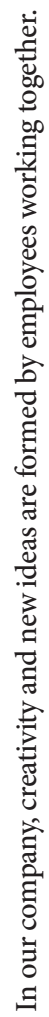 & 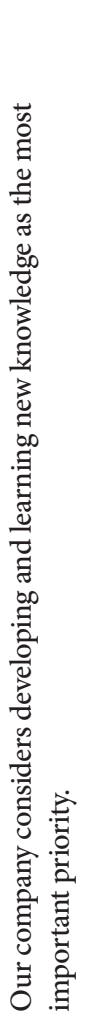 & 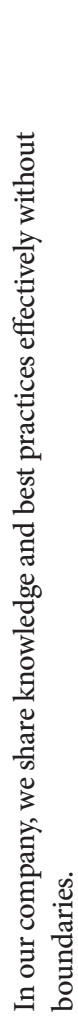 \\
\hline 으 & $\exists$ & $\mathcal{I}$ & $\stackrel{m}{\sim}$ & $\exists$ & $\stackrel{n}{\sim}$ & $\mathscr{0}$ & $\curvearrowright$ & $\stackrel{\infty}{\sim}$ & 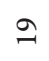 & 가 & $\vec{\sim}$ \\
\hline
\end{tabular}




\begin{tabular}{|c|c|c|c|c|c|c|c|}
\hline 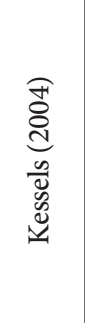 & 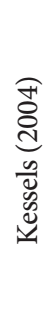 & 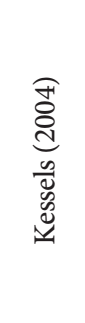 & 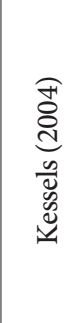 & 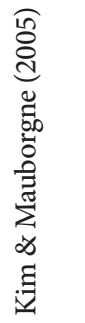 & 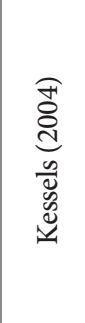 & 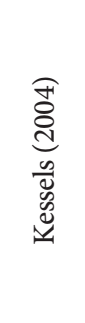 & 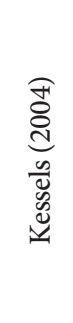 \\
\hline 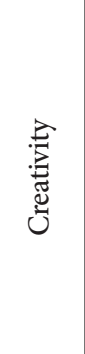 & 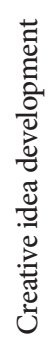 & 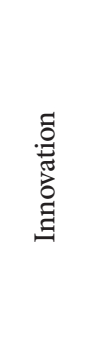 & 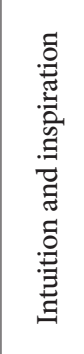 & 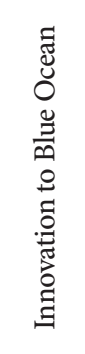 & 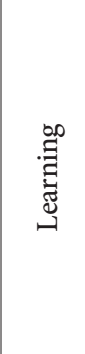 & 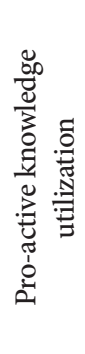 & 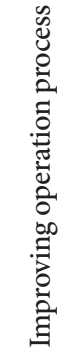 \\
\hline 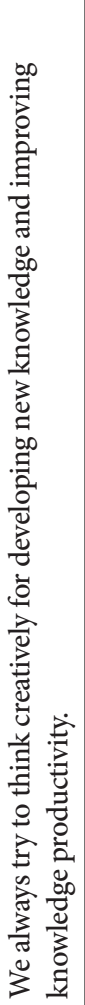 & 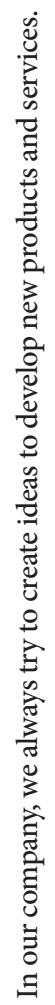 & 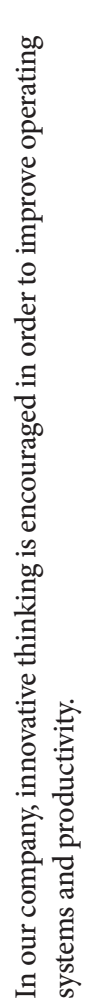 & 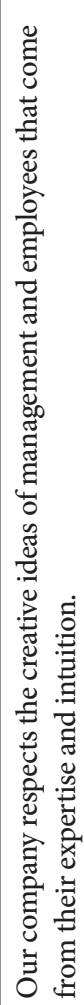 & 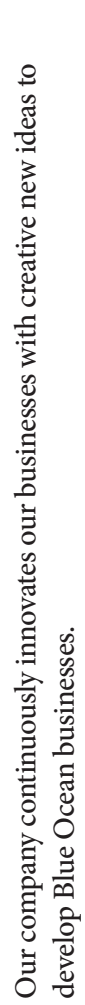 & 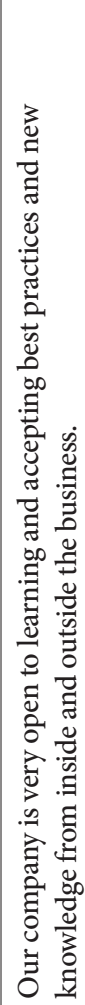 & 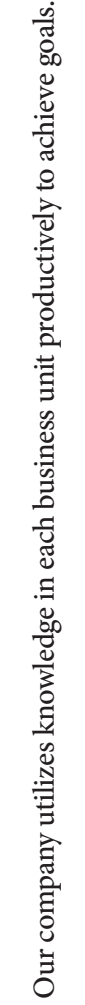 & 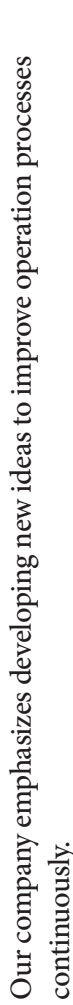 \\
\hline$\tilde{\sim}$ & $\widetilde{\sim}$ & $\stackrel{\sim}{\sim}$ & $\stackrel{\sim}{\sim}$ & ㄱ & $\widehat{\curvearrowright}$ & $\stackrel{\infty}{\sim}$ & ন \\
\hline
\end{tabular}




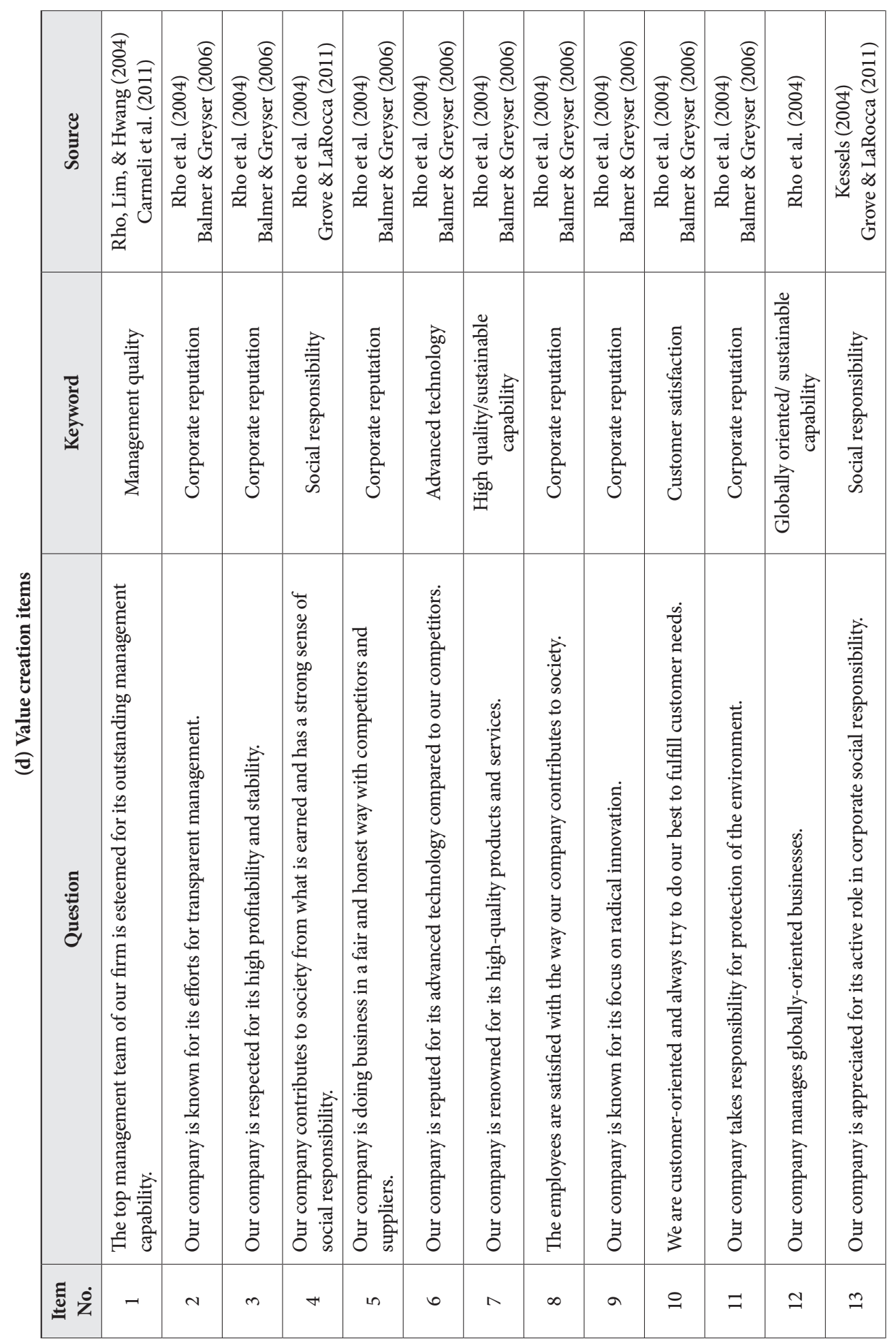




\begin{tabular}{|c|c|c|c|c|c|c|c|c|c|c|c|c|c|c|}
\hline 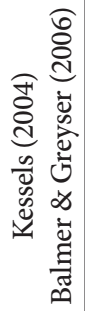 & 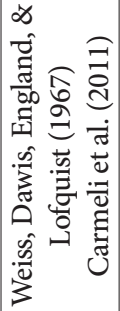 & 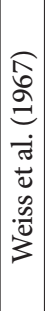 & 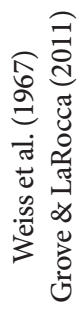 & 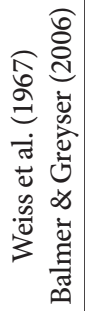 & 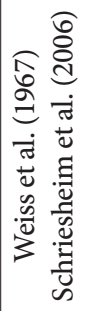 & 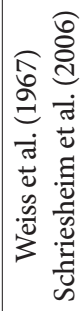 & 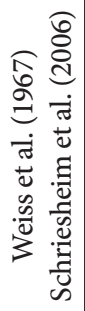 & 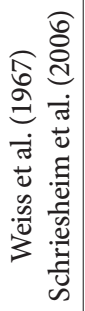 & 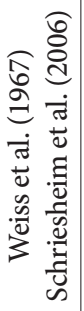 & 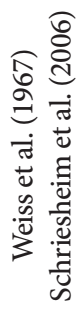 & 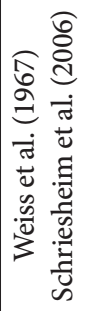 & 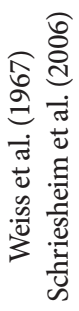 & 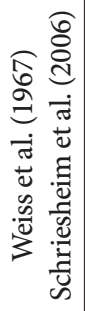 & 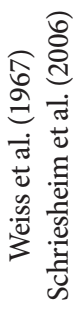 \\
\hline 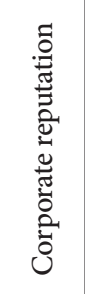 & 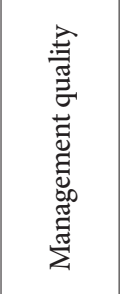 & 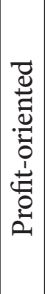 & 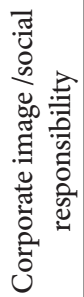 & 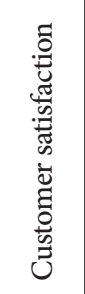 & 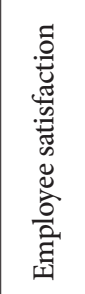 & 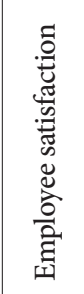 & 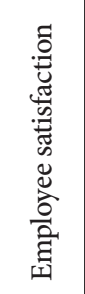 & 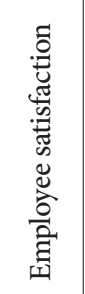 & 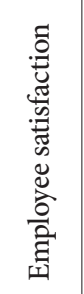 & 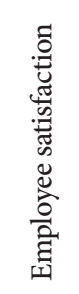 & 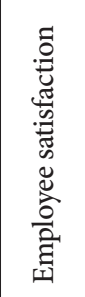 & 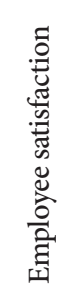 & 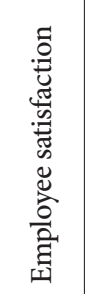 & 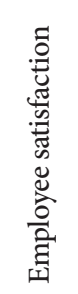 \\
\hline 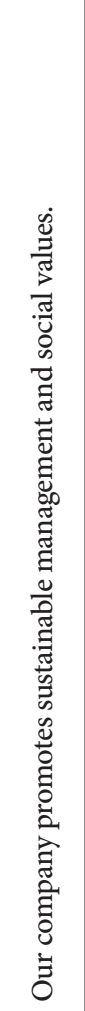 & 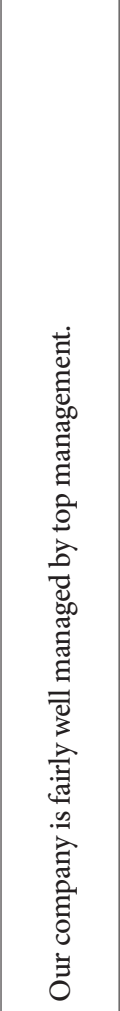 & 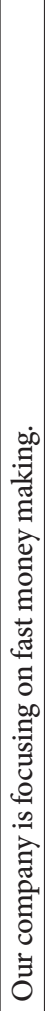 & 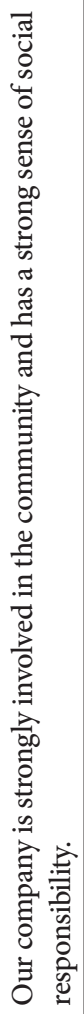 & 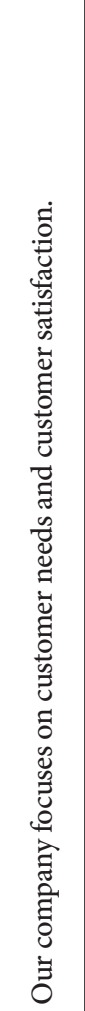 & 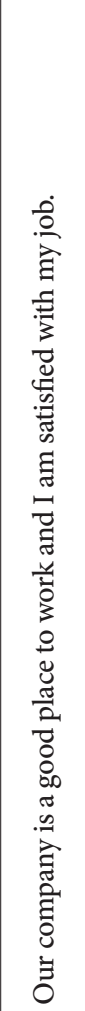 & 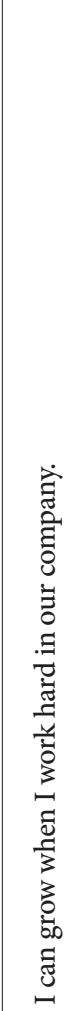 & 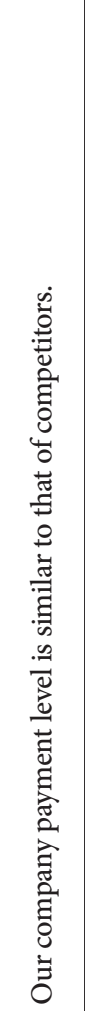 & 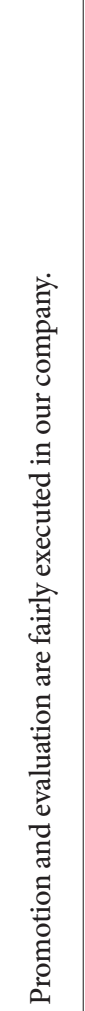 & 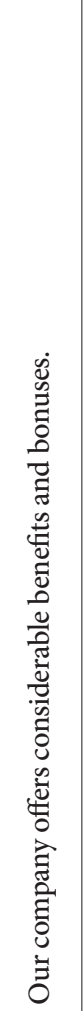 & 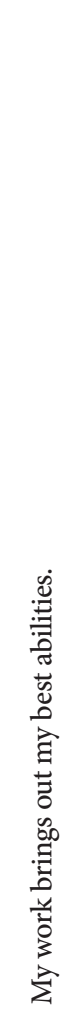 & 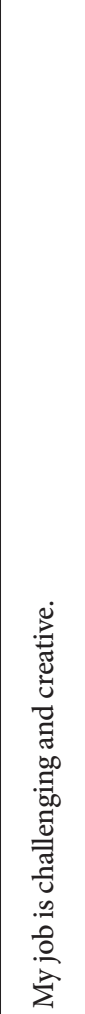 & 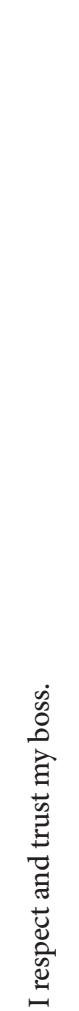 & 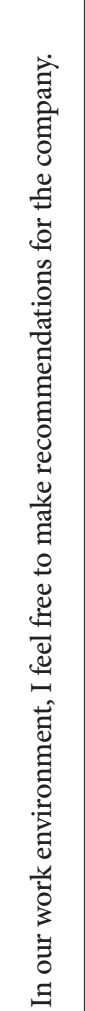 & 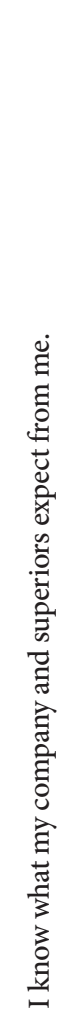 \\
\hline$\exists$ & 느 & 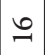 & 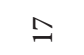 & $\stackrel{\infty}{\stackrel{\infty}{2}}$ & 2 & ¿ & $\bar{\sim}$ & $\tilde{\sim}$ & $\ddot{\sim}$ & $\stackrel{\sharp}{\sim}$ & $\stackrel{\sim}{\sim}$ & $\stackrel{\sim}{\sim}$ & $\hat{~}$ & $\stackrel{\infty}{\sim}$ \\
\hline
\end{tabular}




\subsubsection{Exploratory factor analysis and reliability test}

By means of a factor analysis, the matching of the leadership variables with organizational culture, knowledge productivity, and value creation in the intended model was tested. The loadings for each factor proved to be reliable and appropriate. Only one item related to knowledge productivity (item No. 2) was eliminated due to a low factor loading. Based on the key concepts and the meaning of the clustered items for each characteristic, 14 factors were identified and given appropriate titles, as follows (See Table 3.2):

- Leadership (total 28 items), which consists of four factors: LS1 (people-oriented: 17 items), LS2 (visionary and entrepreneurial: 6 items), LS3 (high challenge-seeking and risk-taking: 2 items), and LS4 (low challenge-seeking and high control: 3 items).

- Organizational culture (total 21 items), which consists of four factors: OC1 (peopleoriented: 13 items), OC2 (high challenge-seeking and innovative: 2 items), OC3 (low challenge-seeking and status quo: 3 items), OC4 (bureaucratic and top-down: 3 items).

- Knowledge productivity (total 29 items), which consists of two factors: KP1 (improvements and innovations of products, services, and work processes: 18 items) and KP2 (increased sustainable capability for future growth: 10 items). One item (item No. 2) was excluded due to low factor loading.

- Value creation (total 28 items), which consists of four factors: VC1 (corporate reputation, image, and CSR: 12 items), VC2 (employee satisfaction with work atmosphere: 9 items), VC3 (employee satisfaction with financial benefits: 3 items), and VC4 (sustainability: 4 items).

The convergent and discriminant validities of the items for leadership style, organizational culture, knowledge productivity, and value creation were proved by a series of exploratory factor analyses in this study. 
Table 3.2 Factor analysis

(a) Leadership style

\begin{tabular}{|c|c|c|c|c|c|}
\hline Item & Questions & LS1 & LS2 & LS3 & LS4 \\
\hline 4 & $\begin{array}{l}\text { Our CEO listens to and respects employees' ideas and } \\
\text { opinions. }\end{array}$ & .752 & .275 & .141 & -.098 \\
\hline 3 & $\begin{array}{l}\text { Our CEO invests enough time and effort into empowering } \\
\text { employees and the organization. }\end{array}$ & .742 & .308 & .041 & -.035 \\
\hline 17 & $\begin{array}{l}\text { Our CEO always maintains integrity and transparent } \\
\text { management. }\end{array}$ & .740 & .175 & .140 & -.146 \\
\hline 16 & $\begin{array}{l}\text { Our CEO invests sufficient time into communication with } \\
\text { management and employees. }\end{array}$ & .735 & .158 & .058 & -.095 \\
\hline 18 & Our CEO is open to accepting change and innovation. & .715 & .261 & .283 & -.142 \\
\hline 10 & $\begin{array}{l}\text { Our CEO tries to motivate employees to do their best with } \\
\text { psychological ownership. }\end{array}$ & .710 & .349 & .119 & -.147 \\
\hline 2 & $\begin{array}{l}\text { Our CEO encourages open communication without } \\
\text { boundaries. }\end{array}$ & .690 & .220 & .160 & -.133 \\
\hline 12 & $\begin{array}{l}\text { Our CEO is doing his/her best to build a creative and } \\
\text { innovative open organization. }\end{array}$ & .670 & .316 & .242 & -.104 \\
\hline 11 & $\begin{array}{l}\text { Our CEO always shares the company vision and goals with } \\
\text { employees. }\end{array}$ & .658 & .366 & .115 & -.101 \\
\hline 20 & $\begin{array}{l}\text { Our CEO prefers to maintain a decentralized organization } \\
\text { with delegation of major activities. }\end{array}$ & .634 & .282 & .137 & .021 \\
\hline 22 & $\begin{array}{l}\text { Our CEO tolerates and accepts dissent and diversity of } \\
\text { employees' decision-making and behaviors. }\end{array}$ & .599 & .485 & -.099 & .010 \\
\hline 1 & $\begin{array}{l}\text { Our CEO delegates authority and responsibilities to } \\
\text { operating executives and managers. }\end{array}$ & .597 & .191 & .219 & -.002 \\
\hline 27 & $\begin{array}{l}\text { Our CEO encourages employee development of creative } \\
\text { ideas. }\end{array}$ & .577 & .413 & .226 & -.217 \\
\hline 9 & We respect and trust our CEO. & .568 & .514 & .199 & -.159 \\
\hline 26 & $\begin{array}{l}\text { Our CEO prefers to take a future-oriented approach for the } \\
\text { company. }\end{array}$ & .559 & .500 & .200 & -.084 \\
\hline 28 & $\begin{array}{l}\text { Our CEO considers human resources development most } \\
\text { important and invests significant amounts of time in it. }\end{array}$ & .540 & .476 & .221 & -.151 \\
\hline 6 & $\begin{array}{l}\text { Our CEO is sometimes directly involved and contributes to } \\
\text { new knowledge/idea development. }\end{array}$ & .519 & .467 & .316 & -.093 \\
\hline 14 & $\begin{array}{l}\text { Our CEO can predict potential risks in the changing } \\
\text { business environment. }\end{array}$ & .279 & .806 & .023 & -.096 \\
\hline 15 & $\begin{array}{l}\text { Our CEO has the ability to develop and implement counter- } \\
\text { measurement strategies to overcome risks. }\end{array}$ & .373 & .740 & .150 & -.045 \\
\hline 8 & Our CEO sometimes shows charismatic leadership. & .239 & .695 & .218 & .010 \\
\hline 5 & $\begin{array}{l}\text { Our CEO has intuition and inspiration from significant } \\
\text { business operation experience. }\end{array}$ & .415 & .589 & .258 & -.161 \\
\hline 25 & $\begin{array}{l}\text { Our CEO considers entrepreneurship very important for } \\
\text { managing the company and its customers. }\end{array}$ & .442 & .508 & .146 & .022 \\
\hline 21 & $\begin{array}{l}\text { Our CEO controls most of the important decisions and } \\
\text { wants to be involved in major activities. }\end{array}$ & .140 & .489 & .123 & .099 \\
\hline
\end{tabular}




\begin{tabular}{|c|l|c|c|c|c|}
\hline 19 & $\begin{array}{l}\text { Our CEO seeks challenges and takes risks to enter into new } \\
\text { business ventures. }\end{array}$ & .358 & .271 & .733 & -.013 \\
\hline 7 & $\begin{array}{l}\text { Our CEO is willing to take risks if necessary for } \\
\text { implementation of new ideas and projects and to achieve } \\
\text { high-level goals and objectives. }\end{array}$ & .313 & .365 & .702 & -.048 \\
\hline 23 & $\begin{array}{l}\text { Our CEO seeks strategies that deviate very little from pre- } \\
\text { existing ones, and attempts to maintain the status quo. }\end{array}$ & .049 & -.052 & -.201 & .795 \\
\hline 24 & $\begin{array}{l}\text { Our CEO prefers to maintain a controlled and centralized } \\
\text { organization. }\end{array}$ & -.191 & .125 & -.021 & .763 \\
\hline 13 & $\begin{array}{l}\text { Our CEO often makes top-down decisions without being } \\
\text { influenced by subordinates' opinions. }\end{array}$ & -.280 & -.179 & .288 & .622 \\
\hline
\end{tabular}

Note: LS1 (People-oriented), LS2 (Visionary and entrepreneurial), LS3 (High challenge-seeking and risk taking), LS4 (Low challenge-seeking and high control).

(b) Organizational culture

\begin{tabular}{|c|c|c|c|c|c|}
\hline Item & Question & OC1 & OC2 & OC3 & OC4 \\
\hline 7 & $\begin{array}{l}\text { In our company, management supports employees to } \\
\text { achieve their objectives and goals. }\end{array}$ & .841 & -.158 & .128 & .050 \\
\hline 8 & In our company, employees' opinions are respected. & .837 & -.079 & .207 & -.022 \\
\hline 9 & $\begin{array}{l}\text { In our company, employees are motivated to participate in } \\
\text { decision-making. }\end{array}$ & .802 & -.083 & .093 & -.032 \\
\hline 6 & $\begin{array}{l}\text { In our company, people are doing their best to manifest the } \\
\text { psychological ownership. }\end{array}$ & .790 & -.176 & .076 & .027 \\
\hline 11 & In our company, employees are respected as human beings. & .768 & -.073 & .204 & -.030 \\
\hline 10 & $\begin{array}{l}\text { Our company has an open culture where people have } \\
\text { freedom to be creative and innovative. }\end{array}$ & .763 & -.073 & .268 & -.173 \\
\hline 4 & $\begin{array}{l}\text { In our company, management and employees share } \\
\text { information, knowledge, and best practices effectively. }\end{array}$ & .755 & -.019 & .277 & -.034 \\
\hline 3 & $\begin{array}{l}\text { In our company, we have boundary-less open and free } \\
\text { communications across levels. }\end{array}$ & .706 & .089 & .409 & -.233 \\
\hline 5 & $\begin{array}{l}\text { In our company, management and employees always share } \\
\text { the company vision, goals, and strategies. }\end{array}$ & .687 & -.199 & .286 & .047 \\
\hline 12 & $\begin{array}{l}\text { In our company, employees are actively involved in learning } \\
\text { new knowledge, information, and ideas both internal and } \\
\text { external to the company. }\end{array}$ & .647 & -.287 & .273 & .095 \\
\hline 13 & $\begin{array}{l}\text { In our company, people are proactive in implementing new } \\
\text { ideas and action plans. }\end{array}$ & .625 & -.157 & .499 & -.002 \\
\hline 1 & $\begin{array}{l}\text { Our company has a non-bureaucratic and boundary-less, } \\
\text { open culture characterized by freedom. }\end{array}$ & .569 & .052 & .501 & -.332 \\
\hline 2 & $\begin{array}{l}\text { Our company organization is decentralized with authority } \\
\text { and responsibilities delegated to each operating business } \\
\text { unit. }\end{array}$ & .467 & -.040 & .408 & .057 \\
\hline 21 & $\begin{array}{l}\text { In our company, people are encouraged to recommend new } \\
\text { ideas freely. }\end{array}$ & .405 & .680 & -.237 & .084 \\
\hline
\end{tabular}




\begin{tabular}{|c|l|c|c|c|c|}
\hline 18 & $\begin{array}{l}\text { Our company is proactive in implementing new ideas and } \\
\text { action plans. }\end{array}$ & .491 & .628 & -.191 & .067 \\
\hline 19 & Our company maintains the status quo. & -.089 & -.045 & .881 & .124 \\
\hline 20 & $\begin{array}{l}\text { Our company prefers to maintain stability to avoid risks and } \\
\text { challenges. }\end{array}$ & -.246 & -.083 & .789 & .157 \\
\hline 16 & Our company maintains a stagnant culture. & .063 & -.267 & .589 & .461 \\
\hline 17 & Our company emphasizes order, rank, and position. & -.042 & .248 & -.095 & .755 \\
\hline 15 & Our company emphasizes following procedures and rules. & .100 & .066 & .249 & .747 \\
\hline 14 & $\begin{array}{l}\text { In our company most of the important decisions are made } \\
\text { from the top down. }\end{array}$ & -.242 & .455 & -.075 & .495 \\
\hline
\end{tabular}

\section{Note: OC1 (People-oriented), OC2 (High challenge-seeking and innovative), OC3 (Low challenge-seeking and status-quo, OC4 (Bureaucratic \& top-down).}

\section{(c) Knowledge productivity}

\begin{tabular}{|c|c|c|c|}
\hline Item & Question & KP1 & KP2 \\
\hline 22 & $\begin{array}{l}\text { We always try to think creatively for developing new knowledge and } \\
\text { improving knowledge productivity. }\end{array}$ & .792 & .323 \\
\hline 19 & $\begin{array}{l}\text { In our company, creativity and new ideas are formed by employees working } \\
\text { together. }\end{array}$ & .755 & .276 \\
\hline 18 & The creative ideas of employees are respected and implemented. & .752 & .367 \\
\hline 16 & $\begin{array}{l}\text { Our company is an organization that highlights intelligence, information, } \\
\text { and ideas. }\end{array}$ & .742 & .318 \\
\hline 4 & $\begin{array}{l}\text { Our open communication contributes to exchange experience, learning, and } \\
\text { knowledge development. }\end{array}$ & .730 & .272 \\
\hline 27 & $\begin{array}{l}\text { Our company is very open to learning and accepting best practices and new } \\
\text { knowledge from inside and outside the business. }\end{array}$ & .722 & .344 \\
\hline 25 & $\begin{array}{l}\text { Our company respects the creative ideas of management and employees that } \\
\text { come from their expertise and intuition. }\end{array}$ & .715 & .259 \\
\hline 17 & $\begin{array}{l}\text { The market value of our company increases due to our creative knowledge } \\
\text { and ideas. }\end{array}$ & .702 & .351 \\
\hline 20 & $\begin{array}{l}\text { Our company considers developing and learning new knowledge as the most } \\
\text { important priority. }\end{array}$ & .701 & .310 \\
\hline 21 & $\begin{array}{l}\text { In our company, we share knowledge and best practices effectively without } \\
\text { boundaries. }\end{array}$ & .683 & .260 \\
\hline 29 & $\begin{array}{l}\text { Our company emphasizes developing new ideas to improve operation } \\
\text { processes continuously. }\end{array}$ & .666 & .347 \\
\hline 24 & $\begin{array}{l}\text { In our company, innovative thinking is encouraged in order to improve } \\
\text { operating systems and productivity. }\end{array}$ & .640 & .313 \\
\hline 28 & $\begin{array}{l}\text { Our company utilizes knowledge in each business unit productively to } \\
\text { achieve goals. }\end{array}$ & .638 & .511 \\
\hline 5 & $\begin{array}{l}\text { In our company, people know what work is meaningful for them and how to } \\
\text { perform such work. }\end{array}$ & .633 & .455 \\
\hline
\end{tabular}




\begin{tabular}{|c|c|c|c|}
\hline 26 & $\begin{array}{l}\text { Our company continuously innovates our businesses with creative new ideas } \\
\text { to develop Blue Ocean businesses. }\end{array}$ & .624 & .417 \\
\hline 6 & $\begin{array}{l}\text { We take sufficient time to think how to apply to our actual work what we } \\
\text { have learned from the past. }\end{array}$ & .573 & .405 \\
\hline 15 & Our new knowledge and ideas lead to business growth. & .568 & .509 \\
\hline 23 & $\begin{array}{l}\text { In our company, we always try to create ideas to develop new products and } \\
\text { services. }\end{array}$ & .556 & .400 \\
\hline 10 & We know the intelligence level of our company in the industry. & .236 & .738 \\
\hline 12 & $\begin{array}{l}\text { We analyze the reasons why we make progress or lag behind in the various } \\
\text { fields of expertise. }\end{array}$ & .475 & .614 \\
\hline 7 & $\begin{array}{l}\text { Our company management and employees have the ability to create } \\
\text { opportunity from turmoil. }\end{array}$ & .359 & .654 \\
\hline 14 & Our company focuses on finding new ways to deal with critical issues. & .507 & .622 \\
\hline 11 & We are well aware of the preferred ways to develop and share knowledge. & .475 & .614 \\
\hline 13 & We apply to our actual work what we have learned from the past. & .369 & .596 \\
\hline 3 & $\begin{array}{l}\text { We try hard to increase our level of expertise and broaden the area of } \\
\text { knowledge. }\end{array}$ & .485 & .580 \\
\hline 1 & $\begin{array}{l}\text { In our company, all the subject matter expertise we need now and in the near } \\
\text { future is available within our organization. }\end{array}$ & .366 & .558 \\
\hline 8 & We try to develop the knowledge and expertise our firm needs. & .538 & .555 \\
\hline 9 & $\begin{array}{l}\text { Our company tries to stimulate people to experiment with new approaches } \\
\text { to solve defined problems. }\end{array}$ & .510 & .550 \\
\hline 2 & We know what problems we are good at solving and those we are not. & .053 & .281 \\
\hline
\end{tabular}

\section{Note: KP1 (Improvements and innovations of products, services and work processes), KP2 (Sustainable development of future growth engine)}

(d) Value creation

\begin{tabular}{|c|l|c|c|c|c|}
\hline Item & \multicolumn{1}{|c|}{ Question } & VC1 & VC2 & VC3 & VC4 \\
\hline 14 & $\begin{array}{l}\text { Our company promotes sustainable management and social } \\
\text { values. }\end{array}$ & .739 & .249 & .209 & .229 \\
\hline 17 & $\begin{array}{l}\text { Our company is strongly involved in the community and } \\
\text { has a strong sense of social responsibility. }\end{array}$ & .713 & .271 & .295 & .136 \\
\hline 13 & $\begin{array}{l}\text { Our company is appreciated for its active role in corporate } \\
\text { social responsibility. }\end{array}$ & .703 & .123 & .264 & .183 \\
\hline 4 & $\begin{array}{l}\text { Our company gives back to society from what we earned } \\
\text { and has a strong sense of social responsibility. }\end{array}$ & .700 & .133 & .451 & .048 \\
\hline 5 & $\begin{array}{l}\text { Our company is doing business in a fair and honest way } \\
\text { with competitors and suppliers. }\end{array}$ & .688 & .326 & .087 & .133 \\
\hline 18 & $\begin{array}{l}\text { Our company focuses on customer needs and customer } \\
\text { satisfaction. }\end{array}$ & .678 & .342 & .042 & .141 \\
\hline
\end{tabular}




\begin{tabular}{|c|c|c|c|c|c|}
\hline 2 & $\begin{array}{l}\text { Our company is known for its efforts toward transparent } \\
\text { management. }\end{array}$ & .671 & .355 & .109 & -.027 \\
\hline 10 & $\begin{array}{l}\text { We are customer-oriented and always try to do our best to } \\
\text { fulfill customer needs. }\end{array}$ & .670 & .327 & .133 & .227 \\
\hline 11 & $\begin{array}{l}\text { Our company takes responsibility for protection of the } \\
\text { environment. }\end{array}$ & .663 & .323 & .038 & .129 \\
\hline 15 & Our company is fairly well managed by top management. & .630 & .313 & .370 & .090 \\
\hline 1 & $\begin{array}{l}\text { The top management team of our firm is esteemed for its } \\
\text { outstanding management capability. }\end{array}$ & .560 & .307 & .444 & .132 \\
\hline 8 & $\begin{array}{l}\text { The employees are satisfied with the way our company treats } \\
\text { us. }\end{array}$ & .548 & .285 & .359 & .158 \\
\hline 26 & I respect and trust my boss. & .253 & .772 & .051 & .131 \\
\hline 27 & $\begin{array}{l}\text { In our work environment, I feel free to make } \\
\text { recommendations for the company. }\end{array}$ & .336 & .769 & .107 & -.019 \\
\hline 28 & I know what my company and superiors expect from me. & .313 & .762 & .171 & .009 \\
\hline 25 & My job is challenging and creative. & .274 & .665 & .399 & .091 \\
\hline 24 & My work brings out my best abilities. & .246 & .643 & .455 & .045 \\
\hline 22 & $\begin{array}{l}\text { Promotion and evaluation are fairly executed in our } \\
\text { company. }\end{array}$ & .265 & .640 & .469 & .098 \\
\hline 20 & I can grow when I work hard in our company. & .354 & .640 & .382 & .022 \\
\hline 19 & $\begin{array}{l}\text { Our company is a good place to work and I am satisfied } \\
\text { with my job. }\end{array}$ & .422 & .629 & .405 & .075 \\
\hline 9 & Our company is known for its focuses on radical innovation. & .465 & .546 & .119 & .175 \\
\hline 21 & Our company payment level is similar to that of competitors. & .272 & .272 & .754 & .017 \\
\hline 23 & Our company offers considerable benefits and bonuses. & .081 & .362 & .740 & .170 \\
\hline 3 & $\begin{array}{l}\text { Our company is respected for its high profitability and } \\
\text { stability. }\end{array}$ & .442 & .117 & .637 & .222 \\
\hline 6 & $\begin{array}{l}\text { Our company is reputed for its advanced technology } \\
\text { compared to our competitors. }\end{array}$ & .124 & .151 & .322 & .780 \\
\hline 12 & Our company manages globally-oriented businesses. & .256 & .070 & .183 & .713 \\
\hline 7 & $\begin{array}{l}\text { Our company is known for its high-quality products and } \\
\text { services. }\end{array}$ & .383 & .197 & .220 & .561 \\
\hline 16 & Our company is known as a profit-oriented firm. & .020 & -.067 & -.147 & .521 \\
\hline
\end{tabular}

Note: VC1 (Corporate reputation and image and CSR), VC2 (Employee satisfaction with work environment), VC3 (Employee satisfaction with financial benefits), VC4 (Sustainability).

Furthermore, to determine the reliability of the results of the analysis, the 
appropriateness of the clustered items to the different factors was examined. Table 3.3 presents the results of the reliability analysis. Cronbach's alpha scores for all 14 factors ranged from 0.605 to 0.953 , indicating an acceptable level of reliability.

Table 3.3 Reliability analysis

\begin{tabular}{|c|l|c|}
\hline Factor & \multicolumn{1}{|c|}{ Questionnaire items } & $\begin{array}{c}\text { Reliability } \\
\text { (Cronbach's } \\
\text { Alpha })\end{array}$ \\
\hline LS1 & $1,2,3,4,6,9,10,11,12,16,17,18,20,22,26,27,28(17$ items $)$ & 0.953 \\
\hline LS2 & $5,8,14,15,21,25(6$ items $)$ & 0.841 \\
\hline LS3 & $7,19(2$ items $)$ & 0.781 \\
\hline LS4 & $13,23,24(3$ items $)$ & 0.617 \\
\hline OC1 & $1,2,3,4,5,6,7,8,9,10,11,12,13(13$ items $)$ & 0.944 \\
\hline OC2 & $18,21(2$ items $)$ & 0.747 \\
\hline OC3 & $16,19,20(3$ items $)$ & 0.779 \\
\hline OC4 & $14,15,17(3$ items $)$ & 0.605 \\
\hline KP1 & $4,5,6,15,16,17,18,19,20,21,22,23,24,25,26,27,28,29(18$ items $)$ & 0.959 \\
\hline KP2 & $1,3,7,8,9,10,11,12,13,14(10$ items $)$ & 0.813 \\
\hline KP3 & $2($ excluded item $)$ & 0.658 \\
\hline VC1 & $1,2,4,5,8,10,11,13,14,15,17,18(12$ items $)$ & 0.937 \\
\hline VC2 & $9,19,20,22,24,25,26,27,28(9$ items $)$ & 0.932 \\
\hline VC3 & $3,21,23(3$ items $)$ & \\
\hline VC4 & $6,7,12,16(4$ items $)$ & \\
\hline
\end{tabular}

\subsubsection{Confirmatory factor analysis}

Table 3.4 provides the overall fit indexes for our study variables. As one progresses from the most restricted model (one-factor) to the least restricted model (fourfactor), one sees that all of the indexes for leadership styles and organizational culture showed incremental improvements in overall fit. All the four-factor models for both leadership style and organizational culture indicated low $x^{2}$ values and $x^{2} / d f$ ratios. Also, the four-factor model for leadership style $\left(x^{2}(d f)=954.626(344), \mathrm{NFI}=\right.$ $0.860, \mathrm{CFI}=0.905, \mathrm{TLI}=0.896, \mathrm{IFI}=.905, \mathrm{RMR}=0.036, \mathrm{RMSEA}=0.068)$ and 
organizational culture $\left(x^{2}(d f)=542.174(184), \mathrm{NFI}=0.888, \mathrm{CFI}=0.923, \mathrm{TLI}=0.911\right.$, $\mathrm{IFI}=.923, \mathrm{RMR}=0.052, \mathrm{RMSEA}=0.071)$ fitted the data significantly better than the one-factor model for leadership style $\left(x^{2}(d f)=1298.140(350), \mathrm{NFI}=0.812, \mathrm{CFI}=\right.$ $0.855, \mathrm{TLI}=0.843, \mathrm{IFI}=.855, \mathrm{RMR}=0.046, \mathrm{RMSEA}=0.084)$ and organizational culture $\left(x^{2}(d f)=1071.564(189), \mathrm{NFI}=0.780, \mathrm{CFI}=0.810, \mathrm{TLI}=0.789, \mathrm{IFI}=.811\right.$, $\mathrm{RMR}=0.088, \mathrm{RMSEA}=0.110)$ and all alternative two-factor models.

Each one-factor model included all four components of each concept (leadership style: LS1, LS2, LS3, and LS4; organizational culture: OC1, OC2, OC3, and OC4). The two-factor model of leadership style was divided as follows: three components (LS1+LS2+LS3, i.e., people-oriented, visionary and entrepreneurial, high challengeseeking and risk-taking) were grouped together, and LS4 (low challenge-seeking and high-control) was kept separate. The two-factor model of organizational culture was divided as follows: two components (OC1+OC2, i.e., people-oriented and high challenge-seeking and high control) were combined, and the other two components (OC3+OC4, i.e., low challenge-seeking and status quo and bureaucratic and topdown) were also combined. Overall, the four-factor models for both leadership style and organizational culture showed the best fit compared to the other alternative models (the one- and two-factor models).

For knowledge productivity and value creation, as one progresses from the most restricted model (one-factor) to the least restricted model (two- or four-factor), one sees that all of the indexes showed incremental improvements in overall fit. Both the two-factor model for knowledge productivity and the four-factor model for value creation indicated low $x^{2}$ values and $x^{2} / d f$ ratios. Also, the two-factor model for knowledge productivity $\left(x^{2}(d f)=914.781(349)\right.$, NFI $=0.886, \mathrm{CFI}=0.926$, TLI $=$ 0.919$, IFI $=0.926, \mathrm{RMR}=0.021, \mathrm{RMSEA}=0.065)$ and the four-factor model for value creation $\left(x^{2}(d f)=1178.687(344), \mathrm{NFI}=0.846, \mathrm{CFI}=0.885, \mathrm{TLI}=0.874, \mathrm{IFI}=\right.$ $0.886, \mathrm{RMR}=0.036, \mathrm{RMSEA}=0.079)$ fitted the data significantly better than the one-factor model for knowledge productivity $\left(x^{2}(d f)=1034.286(350), \mathrm{NFI}=0.871\right.$, $\mathrm{CFI}=0.910, \mathrm{TLI}=0.903, \mathrm{IFI}=0.910, \mathrm{RMR}=0.023, \mathrm{RMSEA}=0.071)$ and value creation $\left(x^{2}(d f)=1939.947(350), \mathrm{NFI}=0.746, \mathrm{CFI}=0.781, \mathrm{TLI}=0.764, \mathrm{IFI}=0.782\right.$, $\mathrm{RMR}=0.046$, RMSEA $=0.108$ ). A good model fit requires that the values of the CFI and TLI must exceed 0.900 , and that the value of the RMSEA should be lower than 0.080 (Lance \& Vandenberg, 2002). Also, values of NFI and IFI over 0.900 and a value of RMR below 0.050 indicate a good fit of the research model.

Each one-factor model included either two or four components (knowledge productivity: KP1 and KP2; value creation: VC1, VC2, VC3, and VC4). The twofactor model of value creation was divided as follows: two components (VC1+VC4, 
i.e., corporate reputation, image, and corporate social responsibility and sustainability) were combined, and the other two components (VC2+VC3, i.e., employee satisfaction with work environment and employee satisfaction with financial benefits) were also combined. Overall, the two-factor model for knowledge productivity and the four-factor model for value creation showed the best fit compared to the other alternative models (the one- or two-factor models). These results verified the discriminate validity of the study variables adopted in this study.

Table 3.4. Confirmatory factor analysis

\begin{tabular}{|c|c|c|c|c|c|c|c|c|c|}
\hline Model & $x^{2}$ & $d f$ & $x^{2} / d f$ & NFI & CFI & TLI & IFI & RMR & RMSEA \\
\hline \multicolumn{10}{|c|}{ Leadership style } \\
\hline Null & 6909.087 & 378 & 18.278 & $\mathrm{~N} / \mathrm{A}$ & N/A & N/A & N/A & .277 & .212 \\
\hline $\begin{array}{l}\text { One- } \\
\text { factor }\end{array}$ & 1298.140 & 350 & 3.709 & .812 & .855 & .843 & .855 & .046 & .084 \\
\hline $\begin{array}{l}\text { Two- } \\
\text { factor }\end{array}$ & 1195.921 & 349 & 3.427 & .827 & .870 & .860 & .871 & .040 & .079 \\
\hline $\begin{array}{l}\text { Four- } \\
\text { factor }\end{array}$ & 954.626 & 344 & 2.804 & .860 & .905 & .896 & .905 & .036 & .068 \\
\hline \multicolumn{10}{|c|}{ Organizational culture } \\
\hline Null & 4859.780 & 210 & 23.142 & N/A & N/A & N/A & N/A & .275 & .240 \\
\hline $\begin{array}{l}\text { One- } \\
\text { factor }\end{array}$ & 1071.564 & 189 & 5.670 & .780 & .810 & .789 & .811 & .088 & .110 \\
\hline $\begin{array}{l}\text { Two- } \\
\text { factor }\end{array}$ & 1049.620 & 188 & 5.583 & .784 & .815 & .793 & .816 & .089 & .109 \\
\hline $\begin{array}{l}\text { Four- } \\
\text { factor }\end{array}$ & 542.174 & 184 & 2.963 & .888 & .923 & .911 & .923 & .052 & .071 \\
\hline \multicolumn{10}{|c|}{ Knowledge productivity } \\
\hline Null & 7989.929 & 378 & 21.137 & N/A & N/A & N/A & N/A & .290 & .228 \\
\hline $\begin{array}{l}\text { One- } \\
\text { factor }\end{array}$ & 1034.286 & 350 & 2.955 & .871 & .910 & .903 & .910 & .023 & .071 \\
\hline $\begin{array}{l}\text { Two- } \\
\text { factor }\end{array}$ & 914.781 & 349 & 2.621 & .886 & .926 & .919 & .926 & .021 & .065 \\
\hline \multicolumn{10}{|c|}{ Value creation } \\
\hline Null & 7644.314 & 378 & 20.223 & N/A & N/A & N/A & N/A & .277 & .223 \\
\hline $\begin{array}{l}\text { One- } \\
\text { factor }\end{array}$ & 1939.947 & 350 & 5.543 & .746 & .781 & .764 & .782 & .046 & .108 \\
\hline $\begin{array}{l}\text { Two- } \\
\text { factor }\end{array}$ & 1455.982 & 349 & 4.172 & .810 & .848 & .835 & .848 & .042 & .091 \\
\hline $\begin{array}{l}\text { Four- } \\
\text { factor }\end{array}$ & 1178.687 & 344 & 3.426 & .846 & .885 & .874 & .886 & .036 & .079 \\
\hline
\end{tabular}




\subsubsection{Qualitative analysis: development of interview guidelines}

The development of the interview guidelines was based on existing research supplemented by items directly related to the research questions of this study. Applying the guidelines shown in Table 3.5, 76 interviews were conducted with executives, managers, and other employees of the four leading Korean companies included in this study.

Before conducting the main series of interviews, four open interviews per company were held with a few executives and staff members in high-ranking positions to improve the interviewer's understanding of each company's leadership style, organizational culture, knowledge productivity, and value creation. The objectives of these pre-study interviews were as follows:

1. To understand the company better and address the key points in the main series of interviews

2. To become aware of potential differences in interviewees' opinions on matters such as management leadership style, organizational culture, and company vision and orientation

During these pre-study interviews, interviewees offered their open and frank opinions on each of the questions, especially those questions related to the leadership of top management and organizational culture of the company. The names of the interviewees and their responses were kept strictly confidential.

Table 3.5 Development of interview guidelines

(a) Questions about leadership style

\begin{tabular}{|c|c|}
\hline Question to CEO & 1. How would you describe your own leadership style? \\
\hline $\begin{array}{l}\text { Question to } \\
\text { employees }\end{array}$ & $\begin{array}{l}\text { 2. What do you think of the leadership style of chairman and CEO of your } \\
\text { company? }\end{array}$ \\
\hline $\begin{array}{l}\text { Follow-up question } \\
\text { subjects }\end{array}$ & $\begin{array}{l}\text { a) Delegation of responsibilities } \\
\text { b) Non-bureaucratic and open communication } \\
\text { c) Empowerment of people and organization } \\
\text { d) Risk taking to enter into new businesses } \\
\text { e) Listening and respecting employeesí opinions and ideas } \\
\text { f) Leading change and innovation }\end{array}$ \\
\hline
\end{tabular}




\section{(b) Questions about organizational culture}

\begin{tabular}{|l|l|}
\hline Questions to all & $\begin{array}{l}\text { 1. How would you describe the culture of your company? } \\
\text { 2. What are its strong points and weak points? }\end{array}$ \\
\hline $\begin{array}{l}\text { a) Non-bureaucratic open culture with the freedom for people to be creative and } \\
\text { innovative } \\
\text { b) Boundary-less open communication } \\
\text { subjects }\end{array}$ & $\begin{array}{l}\text { c) Sharing vision and values within the organization } \\
\text { d) People bring out their best for the company with a strong psychological } \\
\text { ownership } \\
\text { e) Employees can actively and freely recommend new and creative ideas } \\
\text { f) Aggressively seeking change and innovation }\end{array}$ \\
\hline
\end{tabular}

(c) Questions about knowledge productivity

\begin{tabular}{|c|c|}
\hline Questions to all & $\begin{array}{l}\text { 1. How does your company deal with knowledge development? How does } \\
\text { knowledge relate to the productivity of your company? } \\
\text { 2. How would you rate the level of knowledge development and application of that } \\
\text { knowledge for successful corporate performance in your company? }\end{array}$ \\
\hline $\begin{array}{l}\text { Follow-up question } \\
\text { subjects }\end{array}$ & $\begin{array}{l}\text { a) Development of creative knowledge, and improvement of knowledge } \\
\text { productivity } \\
\text { b) Continuous improvement and radical innovation of products, services and } \\
\text { work processes } \\
\text { c) Future growth potential business development and sustainable } \\
\text { capability } \\
\text { d) Respecting employeesí creative new ideas and opinions } \\
\text { e) Securing and developing professional talents and knowledge of the company } \\
\text { which needs now and in the future } \\
\text { f) Effectively sharing of knowledge and ideas in the company }\end{array}$ \\
\hline
\end{tabular}

(d) Questions about value creation

\begin{tabular}{|l|l|}
\hline Questions to all & $\begin{array}{l}\text { 1. Does your company create value successfully? } \\
\text { 2. How does your company achieve its goals for value creation? }\end{array}$ \\
\hline Follow-up question & $\begin{array}{l}\text { a) Vision and future strategy of company management } \\
\text { b) Development of future growth businesses and sustainable growth capability } \\
\text { subjects }\end{array}$ \\
$\begin{array}{l}\text { c) Emplopment and possession of advanced and competitive technology } \\
\text { e) Company reputation and image } \\
\text { g) How does the company meet its corporate social responsibilities }\end{array}$ \\
\hline
\end{tabular}


(e) Questions about relationships among leadership, organizational culture, knowledge productivity, and value creation

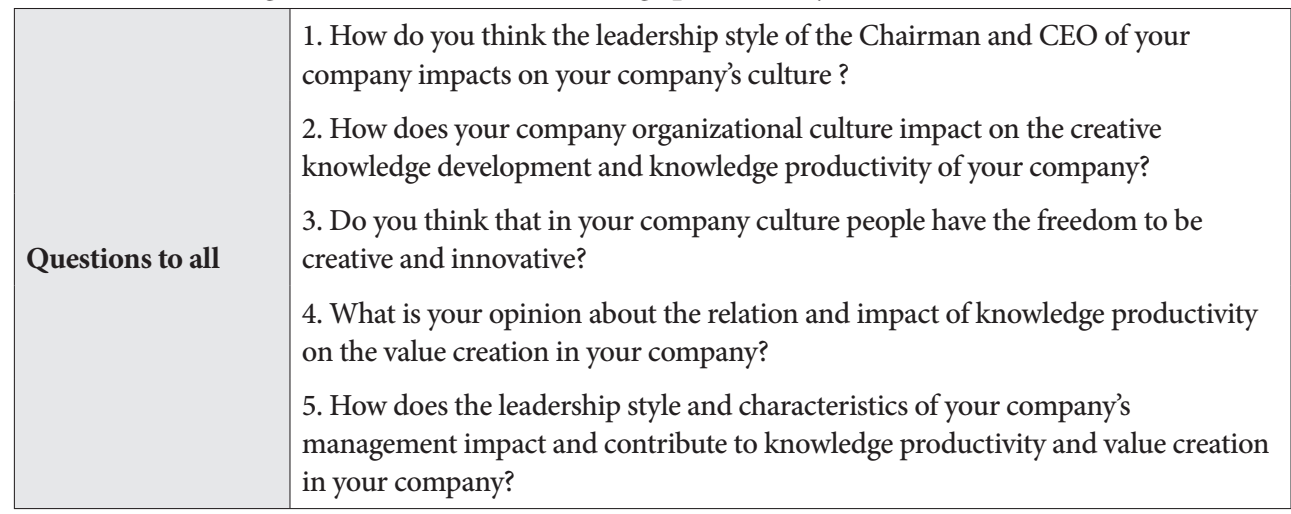

\subsubsection{Variables related to value creation}

The measurement of the variables related to value creation was performed using three methods: a questionnaire, data collection from the participating companies, and data from the Korea Industry Research Institution. Executives, senior managers, and employees responded to the questionnaire items of the survey, which provided data about corporate reputation, image, and CSR (VC1), employee satisfaction with work environment (VC2), employee satisfaction with financial benefits (VC3), and sustainability (VC4). Data on net profit, revenue/sales, and market value for each of the companies were collected from the annual reports of the companies filed with the Korea Stock Exchange that were officially audited in the period of 1990-2010. The Korea Industry Research Institution provided data on net profit, revenue and sales, and market value of the top 100 companies in Korea to facilitate comparison of the sales of each company with the top ten best performing companies in their industry sector. For LG Electronics and Samsung Electronics, sales of each company were compared with those of the top ten Korean electronics companies. In the case of Shinhan Bank, the market share of five major Korean Banks, including Shinhan Bank, in the banking sector in 2010 were compared. As the WoongJin Group included 15 WoongJin companies in different industries, this case could not be compared with the top ten companies in one specific industry. 


\subsection{Case studies on leadership, organizational culture, knowledge productivity, and value creation in four Korean companies}

\subsubsection{Selection criteria}

Four leading companies in Korea participated in the empirical research of this study. The selection was made on the basis of the following criteria:

- Leading company that has achieved sustainable and substantial growth during the past 10 years from $2000-2010$

- Diversified businesses and global activities

- Accessible for the purposes of this research

On the basis of these criteria, the following companies were approached and agreed to participate in this study: LG Electronics, Samsung Electronics, WoongJin Group, and Shinhan Bank. The reasoning behind this selection is provided below.

Obtaining access to these leading companies was challenging, and collecting information on sensitive subjects such as leadership styles of chairmen and CEOs, organizational culture, knowledge productivity, and value creation even more so. For all four companies, it was the first time they had agreed to disclose sensitive internal information for an academic study conducted by an outside researcher.

The case study reports for each company were sent for validation to the participants. On the basis of the report the researcher organized feedback discussions with senior management. In response to the feedback, some minor changes and additions were made in the case reports.

\subsubsection{LG Electronics}

LG Electronics is one of the two leading companies in the consumer electric and electronics industry in Korea. The company is active in global businesses, and 78\% of its sales come from overseas markets. LG Electronics has achieved sustainable growth over the 10-year period examined in this study. At LG Electronics, 120 survey questionnaires were distributed, of which 100 were returned. In this company, the researcher conducted 24 interviews with top management, staff members, and other employees.

\subsubsection{Samsung Electronics}

Samsung Electronics is the leading company in the consumer electric and electronics industry in Korea, achieving sustainable growth over the past 10 years. The company became the world's leading company in its industry and successfully 
operates global businesses in overseas markets ( $83 \%$ of its sales are made in overseas markets). At Samsung, 120 survey questionnaires were distributed, of which 70 were returned. In this company, the researcher conducted 18 interviews with top management, staff members, and other employees.

\subsubsection{WoongJin Group}

The WoongJin Group is a fast-grown leading company in diverse business areas under the leadership of the CEO and founder, S.K. Yoon. This company achieved high growth over more than 10 years. Their rapidly expanding global business generates $21 \%$ of sales from overseas markets. At the WoongJin Group, 120 survey questionnaires were distributed, of which 117 were returned. In this company, the researcher conducted 15 interviews with Chairman S.K. Yoon, top management, staff members, and other employees.

\subsubsection{Shinhan Bank}

Shinhan Bank is one of the two leading banks and financial business groups in Korea. The company achieved a remarkably high growth rate over the past 10 years and expanded its overseas business operations. In 2003, Shinhan Bank merged with Cho-hung Bank, the oldest bank in Korea, established in 1897. At Shinhan Bank, 120 survey questionnaires were handed out, of which 100 were returned. In this company, the researcher conducted 18 interviews with Chairman E.C. Rah, top management, staff members, and other employees. Most respondents held middleand senior-level positions.

\subsection{Designing guidelines for business leaders}

In order to share the research findings and the practical experiences of business leaders in the field, and also to reduce the gap between academic theories and today's fastprogressing practical business management, business leaders and top managers were involved in the empirical part of this study, sharing their opinions and experiences, and reflecting on the research findings. Thirty CEOs who are members of Korean business associations, such as the Korea Management Association, the Federation of Korean Industries, and the Korea Employers Federation, took part in discussions of the concepts to include in the initial version of the guidelines for business leaders in the Korean language. Their comments have been incorporated in the final version, as presented in the guidelines in Chapter 9. These activities may encourage future collaboration and participation of business leaders in academic studies. 


\section{Chapter 4. Findings from the case studies: LG Electronics}

\subsection{General overview}

LG Electronics is one of two leading Korean companies in the consumer electronic and electric industries. When LG Electronics was incorporated in 1958, it was the first manufacturer of electric appliances and consumer electronic products in Korea. Through continuous challenging entrepreneurship and high-quality management provided by three generations of leaders and LG Group chairmen, LG Electronics has developed into a leading global company in the electronics industry. From 1990 to 2009 , company sales increased $980 \%$ and net profit grew $6,200 \%$. In $2010,76 \%$ of the company's total sales of US $\$ 26,100$ million were made in the global market. LG Electronics was therefore selected as a case for this study. A general overview of the company is provided in Table 4.1 .

Table 4.1 General overview

\begin{tabular}{l|l}
\hline $\begin{array}{l}\text { Background of } \\
\text { LG }\end{array}$ & Description \\
\hline Founding & $\begin{array}{l}\text { Founded LG Group in } 1947 \text { as Lucky Chemical Company by In-Hoi Koo, Late } \\
\text { Chairman } \\
\text { Founded LG Electronics in } 1958 \text { as Gold Star Electronics, and changed company } \\
\text { name to LG Electronics in } 1995 \\
\text { B.M. Koo, third generation of the founder, succeeded the leadership position of LG } \\
\text { Group in 1995. As chairman of LG Corp. the holding company of LG Group, he is } \\
\text { leading LG Group companies with the title, Chairman of LG Group. }\end{array}$ \\
\hline $\begin{array}{l}\text { Types of } \\
\text { Industries }\end{array}$ & $\begin{array}{l}\text { LG Electronics } \\
\text { Appliances, Consumer Electronics (Video, Audio, and etc.) }\end{array}$ \\
\hline Mobililiated Communication Equipment \\
companies & $\begin{array}{l}\text { Affiliated companies of LG Electronics both within and outside of Korea } \\
\text { LG Display } \\
\text { LGE USA } \\
\text { LG Brazil } \\
\text { LGE Russia } \\
\text { LGE India } \\
\text { LGE China } \\
\text { 15 more affiliated companies in overseas } \\
\text { Other LG Group Companies } \\
\text { LG Chemical } \\
\text { LG Communication }\end{array}$ \\
& \\
& \\
& \\
&
\end{tabular}




\begin{tabular}{|c|c|c|c|}
\hline & \multicolumn{3}{|c|}{49 more affiliated companies } \\
\hline $\begin{array}{l}\text { Number of } \\
\text { Employees }\end{array}$ & \multicolumn{3}{|c|}{$\begin{array}{l}\text { LG Electronics Total } 87,000 \text { (overseas } 50,000 \text { ) } \\
\text { LG Group Total } 213,000 \text { (overseas } 88,000 \text { ) }\end{array}$} \\
\hline \multirow{13}{*}{$\begin{array}{l}\text { Financial } \\
\text { Status } \\
(2009 / 2010)\end{array}$} & LG Electronics & & \\
\hline & (2009) & KRW & $\mathrm{US}(\$)$ \\
\hline & Sales & 30,513 bil & 26,335 mil \\
\hline & Domestic Sales & 6,665 bil & $5,750 \mathrm{mil}$ \\
\hline & Overseas & 23,848 bil & 20,576 mil \\
\hline & Net Profit & 2,053 bil & $1,771 \mathrm{mil}$ \\
\hline & ROS 6.73\% & & \\
\hline & $\begin{array}{l}\text { Market Value } \\
\qquad(2010)\end{array}$ & $\begin{array}{l}16,484 \text { bil } \\
\text { KRW }\end{array}$ & $\begin{array}{l}14,223 \mathrm{mil} \\
\mathrm{US}(\$)\end{array}$ \\
\hline & Sales & 29,238 bil & $26,105 \mathrm{mil}$ \\
\hline & Domestic Sales & 6,892 bil & $6,153 \mathrm{mil}$ \\
\hline & Overseas & 22,346 bil & 19,951 mil \\
\hline & Net Profit & 635 bil & $567 \mathrm{mil}$ \\
\hline & $\begin{array}{l}\text { ROS } 2.17 \% \\
\text { Market Value }\end{array}$ & 17,068 bil & $15,239 \mathrm{mil}$ \\
\hline
\end{tabular}

Unit; Billion Korean won(KRW), Million US dollar (US(\$))

Note: Net profit in 2010 was negative due to the significant impact of the introduction of Apple's iPhone in 2009 after sustained growth in net profit for 10 years 


\subsection{Quantitative analysis of survey data}

\subsubsection{Demographic characteristics}

Data on LG Electronics was collected from the survey conducted in Korea. In total, 100 respondents from LG Electronics completed the questionnaires (out of 120 questionnaires distributed). The sample characteristics are summarized in Table 4.2 below.

Table 4.2 Characteristics of survey respondents

\begin{tabular}{lccr}
\hline Parameter & Percentage (\%) & Parameter & Percentage (\%) \\
\hline Gender & \multicolumn{3}{l}{ Rank } \\
$\quad$ Male & 81.0 & Employee & 8.0 \\
$\quad$ Female & 19.0 & Assistant manager & 17.0 \\
Age & & Manager & 30.0 \\
$\quad$ <30 years & 9.0 & Senior manager & 33.0 \\
31-40 years & 51.0 & Executive & 12.0 \\
41-50 years & 34.0 & Education level & \\
$>$ 51 years & 6.0 & High school & 1.0 \\
Tenure & & College & 7.0 \\
$<5$ years & 40.0 & Bachelor's degree & 66.0 \\
6-10 years & 25.0 & Master's degree & 22.0 \\
$>$ 11 years & 35.0 & Doctorate degree & 4.0 \\
\hline
\end{tabular}

Among the respondents, $81.0 \%$ were male, which is similar to the ratio of males in the company as a whole (84.0\% of all members of LG Electronics). Ratios of managers $(30.0 \%)$ and senior managers $(33.0 \%)$ are higher than other levels of employment, as more questionnaires were distributed to employees at these levels because they understand and could respond better regarding the four main variables in focus in this research: leadership, organizational culture, knowledge productivity, and value creation. They also had more input about the relations among these variables due to their long work experience within the company. 


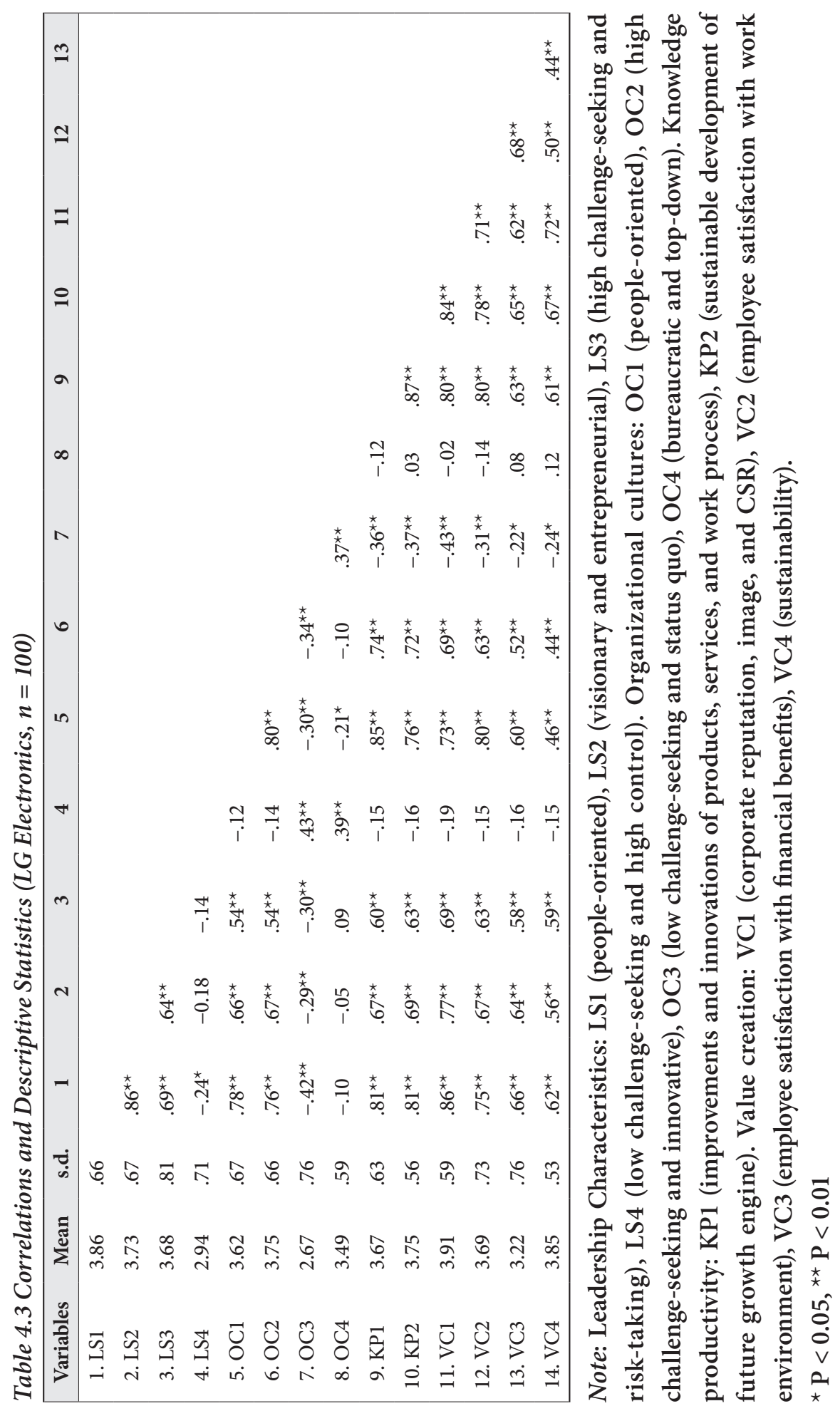




\subsubsection{Relations among key variables}

Statistical analyses were performed using the survey data collected from 100 respondents from LG Electronics. Table 4.3 shows the mean values, standard deviations, and correlations among the variables examined using these data. Financial performance (e.g., revenue and net profit growth, market value increase) is not included in this quantitative analysis, as the financial data are reported separately in section 4.3 .4 below.

The results of this correlation analysis indicate significant and positive relations between the leadership characteristics of LG Electronics: people-oriented (LS1), visionary and entrepreneurial (LS2), and high challenge-seeking and risk-taking (LS3) and knowledge productivity, that is, improvement and innovation of products, services, and work processes (KP1) and sustainable development of future growth engine (KP2). Similarly the leadership characteristics: people-oriented (LS1), visionary and entrepreneurial (LS2), and high challenge-seeking and risk-taking (LS3) were significantly and positively related to the value creation factors, specifically, corporate reputation, image, and CSR (VC1), employee satisfaction with work environment (VC2), employee satisfaction with financial benefits (VC3), and sustainability (VC4).

In addition, the characteristics of the organizational culture of LG Electronics, which is described as people-oriented (OC1) and high challenge-seeking and innovative (OC2), were significantly and positively related to knowledge productivity in terms of improvements and innovation of products, services, and work processes (KP1) and sustainable development of future growth engine (KP2). Two characteristics of the organizational culture of the company: people-oriented (OC1) and high challenge-seeking and innovative (OC2) were significantly and positively related to the value creation factors, corporate reputation, image, and CSR (VC1), employee satisfaction with work environment (VC2), employee satisfaction with financial benefits (VC3), and sustainability (VC4). Finally, knowledge productivity in terms of improvement and innovation of products, services, and work processes (KP1) and sustainable development of future growth engine (KP2) was significantly and positively related to value creation factors, corporate reputation, image, and CSR (VC1), employee satisfaction with work environment (VC2), employee satisfaction with financial benefits (VC3), and sustainability (VC4).

However, the following leadership and organizational characteristics were not part of the leadership style and organizational culture of LG Electronics: low challengeseeking and high-control (LS4) and low challenge-seeking and status quo (OC3) and bureaucratic and top-down control (OC4), respectively. These leadership and 
organizational characteristics were negatively correlated with both knowledge productivity and value creation.

The results of the statistical analysis of the case of LG Electronics indicate that both leadership style (LS1, LS2, and LS3) and organizational culture (OC1 and OC2) of the company were significantly and positively related to both knowledge productivity (KP1 and $\mathrm{KP} 2)$ and value creation (VC1, VC2, VC3, and $\mathrm{VC} 4)$.

\subsection{Qualitative analysis of interview data}

Interviews were conducted with the $\mathrm{CEO}$, three vice presidents, 10 general managers, and 10 managers of LG Electronics (a total of 24 interviewees). Interviews focused on the leadership styles of the LG Group chairman and the CEO of LG Electronics, and on organizational culture, knowledge productivity, and value creation in the LG Electronics Company. Interviewees' answers and opinions generally agreed; they shared many of the same opinions on each of the topics described below.

\subsubsection{Leadership style}

The current chairman of the LG Group, B.M. Koo, who is the third chairman since the founding of LG, succeeded to the leadership position in 1995. CEOs of LG Group companies, including LG Electronics, are proved and experienced professional managers appointed by the group chairman through formal processes, including shareholders' meetings. Interviewees' opinions showed consensus on the leadership styles of the LG Group chairman and the CEO of LG Electronics, as indicated below by the quotations from interviewees.

The Group chairman who is chairman of LG Corp., the group holding company, who owns controlling shares in the holding company, mainly focuses on establishing long-term vision and high-challenging goals for LG Electronics and other LG Group companies. He fully delegates management responsibilities to the CEO of each LG Group company.

The LG Group chairman's management principle is called the "LG Way". It has four principles: (1) to be number one in the industry in which the company operates, (2) to ensure value creation for customers, (3) to respect people of the company as human beings, and (4) to maintain transparency and a high moral standard. The Group chairman periodically reviews the management and performance of each Group company in light of these four principles. 
The CEO of LG Electronics leads the company with his vision and leadership style, while respecting and following the Group chairman's long-term vision and goals, management philosophy, and principles. Therefore, LG Electronics' leadership style is a combination of the Group chairman's leadership and the company CEO's leadership.

Within its two-tops leadership structure, the long-term vision and management principles of LG Electronics are well retained and continued under the Group chairman's sustained leadership, although the CEO of LG Electronics is newly appointed and has assumed his management responsibilities.

LG Electronics follows the global standard for corporate governance systems, utilizing the active role of the board of directors (BOD). The chairman of the LG Group and CEO of LG Electronics respect the decisions of the BOD on major subject matters and issues of the company.

Two-tops leadership structure ${ }^{2}$

The LG Electronics and other LG Group companies operate under a two-tops leadership structure, as described above in the comments of interviewees. The leadership style of LG Electronics is a combination of the Group Chairman's peopleoriented leadership style and his long-term vision, management principles, and philosophy and the LG Electronics CEO's performance-oriented leadership style and his professional management. Although LG Electronics changed CEOs three times within 15 years (1994-2010), LG Electronics' management philosophy, operating principles, organizational culture, long-term vision, and goals were sustained and continued under the leadership of the same LG Group Chairman. The leadership styles of the CEOs differed considerably. The ideal combination of the strengths of

\footnotetext{
${ }^{2}$ Two-tops leadership:

The chairman of LG Corp., the LG Group holding company, is called the LG Group chairman. He leads all LG Group companies, although he is not the chairman or a board member of each subsidiary. He appoints CEOs of LG Group companies through his controlling share ownership of the holding company. CEOs of LG Electronics and LG Group companies officially and practically represent each LG subsidiary, but they all report to the Group chairman. This “two-tops” leadership structure of LG Group companies combines the leadership of the chairman of the LG Group holding company and the leadership of each CEO of LG's affiliated companies, although the holding company and affiliate companies are separate legal entities. Therefore, this twotops leadership structure is different than the concept of a "two-tier" leadership structure, in which two levels exist within one legal entity. In a two-tier leadership structure, the chairman and CEO are in charge of two tiers within the same legal entity. By contrast, in LG, the chairman and CEO of the holding company leads all group companies as chairman of the LG Group. Therefore, this study includes new terminology, "two-tops leadership", for leadership structures the same or similar as that in the LG case.
} 
each "two-tops" leadership style has contributed significantly to the sustained growth and continuous high challenge-seeking entrepreneurship of LG Electronics. Both leaders demonstrate boundary-less, open, non-bureaucratic, and peopleoriented leadership styles, respecting and empowering people of the company.

\section{a. People-orientation}

According to the interviewees, the significant features of the LG Group chairman's leadership style include non-bureaucratic openness and people-oriented characteristics. He respects people and their opinions and ideas, and strongly emphasizes personal development. He considers people as the most important human resources of the LG Group. Under the chairman's people-oriented leadership, the CEO of LG Electronics, like the CEOs of other LG companies, follows the people-oriented management philosophy and principles while strongly advocating performance-oriented business management. This is evidenced in the following quotations from the interviewees.

Under the leadership of the Group chairman, who delegates management responsibilities to the CEOs of LG Group companies, the CEO of LG Electronics also delegated operational responsibilities to each business division leader while maintaining the principles of setting highly challenging goals and performanceoriented management.

The CEO of LG Electronics strongly emphasized global talent development and recruitment while driving the globalization of LG Electronics' businesses.

LG Electronics' leaders and executives respect employees' opinions when making important key business decisions. Under the humanitarian and people-oriented leadership and organizational culture, LG Electronics people have a strong psychological ownership and a high level of employee satisfaction.

\section{b. Vision-building}

Under the two-tops leadership structure, the chairman of the LG Group sets the high challenge-seeking long-term vision and goals of LG Electronics. In addition, the Group Chairman openly shares his vision and goals with the CEO of LG Electronics and key staff members and listens to their opinions.

The long-term vision of LG Electronics is to become the world's best number one excellent company, placing priority on value creation for customers. This vision was established by the Group Chairman with the goal of making LG Electronics the 
world's leading company in the consumer electronics industry. The CEO of LG Electronics outlined the key strategies of the company for achieving this long-term vision and goals through strengthening the company in three major areas: product leadership, market leadership, and people leadership.

The CEO of LG Electronics shares his vision with all members of the company to achieve the company's challenging goals. This vision entails full utilization of the knowledge and capabilities of all the people in the organization. LG Electronics achieved sustained growth and met most of its value creation goals by 2009 (for more detail, see section e and Table 4.7 below).

\section{c. Entrepreneurship}

With its two-tops leadership structure, LG Electronics can effectively develop hightechnology future business projects, taking risks and fostering entrepreneurship, as indicated by the following comments of senior interviewees:

LG Electronics made continuous investments for developing new technology products, such as mobile communication, digital appliances, and digital displays, to maintain leading positions in its core business industries and markets.

The LG Group Chairman and CEO of LG Electronics at that time made a significant challenging and highly risk-taking decision in 1993 to enter into a new high-tech business area, LCD manufacturing, making a significant investment in building new plants and continuous R\&D activities. At the time, LCD was the most advanced type of high-technology display in the world. The company built its first LCD plant in 1995 and continued building plants in Korea, China, and Poland, for a total of 11 plants by 2008. The company continued its R\&D activities and developed the first 52-inch TFT-LCD in the world in 2004 and the first 100-inch TFT-LCD for HDTV in the world in 2006. LG Electronics has continued to invest in developing the most advanced new display technologies. As a result of this entrepreneurial spirit, the LG Display Company, a subsidiary of LG Electronics, became the number one display manufacturer in the world.

This is an example of the entrepreneurial spirit of the two-tops leadership structure of LG Electronics, which combines high challenge-seeking entrepreneurship and the long-term vision of the Group Chairman with the professional management talent and leadership of the CEO of LG Electronics. This combination is good for the 
future growth of the company and new business development.

When the Group Chairman decided to enter into this high-challenging new business and started making strategic plans for its implementation, the CEO of LG Electronics followed the chairman's decision and implemented the plan successfully to achieve the company vision and goals. For making decisions about major projects and strategic plans for implementation, the LG Group Chairman listens to the opinions and ideas of the CEOs, company executives, and the best talent in the area, and tries to make the best use of their knowledge.

\section{d. Risk-taking}

Interviewees' opinions and comments on the subject of risk taking were generally in consensus, as evidenced by the following quotation:

The two-tops leadership structure of LG Electronics, which includes the Chairman of the LG Group and the CEO of LG Electronics and their shared long-term vision for sustainable future growth, could lead to development of new products and businesses for sustainable future growth and globalization with high-challenging entrepreneurship and risk taking.

This leadership approach, which emphasized risk-taking entrepreneurship, has resulted in continuous growth for LG Electronics in global markets, as a result of which the company can now compete with the world's leading companies in the electronics industry. LG Electronics has achieved leading market positions in newly developed world markets, such as South America, India, Russia, Eastern Europe, and China. To achieve this goal, LG Electronics had to take significant risks. In the fast-changing business environment of today, with rapidly advancing hightechnology industries, the leaders of the LG Group and LG Electronics must take significant risks and demonstrate a high-challenging spirit of entrepreneurship to establish high-technology new businesses for future growth. As a result of its entrepreneurship and well-prepared risk management, LG Electronics' core businesses and the new subsidiary company, LG Display, have become world market leaders in their respective industries.

\section{e. Controlling}

The Chairman of the LG Group delegates full management responsibility and authority to the CEO of each LG company. The Group Chairman reviews each company's performance with the CEOs only a few times a year; there is no top-down 
decision-making or direct control. The CEO of LG Electronics also delegates management responsibility and authority to the general managers of each business division, reflecting a bottom-up management style. The CEO and managers of LG Electronics lead the organizations, empowering and motivating people and allowing them significant freedom to do their work without controlling.

The Group Chairman and CEOs of LG Electronics affiliates closely coordinate to make important strategic decisions, which may impact significantly on the vision and sustainable future growth of the company. However, management policies and rules related to integrity and transparency must be followed. Therefore, inflexible tight control in this area is necessary so as to ensure that all the members of the LG Group act with integrity and follow the rules and principles of the LG Group.

\section{f. Leadership style related to the conceptual framework of Chapter 2}

Findings from the empirical analysis of LG Electronics indicate that the leadership style of the Chairman of the LG Group (non-bureaucratic openness and peopleoriented characteristics in combination with high-challenging entrepreneurship) is closer to the A-type leadership style of the conceptual framework of this study, while the leadership style of the CEO of LG Electronics (goal- and performance-oriented, high-challenging, non-bureaucratic openness, and people-oriented) is closer to the B-type leadership style. Therefore, the leadership style of LG Electronics is a combination of the A-type leadership of the LG Group Chairman and the B-type leadership of the CEO of LG Electronics. Table 4.4 summarizes the findings of this case study. 
Table 4.4 Summary of leadership characteristics

\begin{tabular}{|c|c|}
\hline Characteristics & Descriptions \\
\hline People-oriented & $\begin{array}{l}\text { Humanitarian and people-orientation leadership of LG Group chairman } \\
\text { and CEO of the company. Respecting and empowering people. }\end{array}$ \\
\hline Vision-building & $\begin{array}{l}\text { High-challenging vision to build the world's best number one excellent } \\
\text { company through the spirit of value creation for customers. Strategy } \\
\text { for achieving long-term vision through three major types of leadership: } \\
\text { people leadership, product leadership, and market leadership. }\end{array}$ \\
\hline Entrepreneurship & $\begin{array}{l}\text { High challenge-seeking and risk-taking entrepreneurship with two-tops } \\
\text { leadership structure: LG Group chairman and CEO of LG Electronics }\end{array}$ \\
\hline Risk-taking & $\begin{array}{l}\text { Taking risks to achieve high challenge-seeking vision and goals, and to } \\
\text { move into high-technology future oriented new technology businesses. } \\
\text { Well- planned risk management systems. }\end{array}$ \\
\hline Control & $\begin{array}{l}\text { High-level delegation of management responsibilities. Bottom-up } \\
\text { decision-making, no top-down control. However, chairman and CEO are } \\
\text { directly involved in making important strategic decisions. }\end{array}$ \\
\hline Other characteristics & $\begin{array}{l}\text { Two-tops leadership structure; a combination of leadership the LG } \\
\text { Group chairman with his long-term, high-challenging vision, and the } \\
\text { leadership of CEO of LG Electronics, implementing key strategies with his } \\
\text { professional management capability for achieving the vision and goals set } \\
\text { by the Group chairman. }\end{array}$ \\
\hline
\end{tabular}

\subsubsection{Organizational culture}

Most interviewees' opinions demonstrated consensus on the organizational culture of both the LG Group and LG Electronics. Both the former and current chairmen of the LG Group constantly tried their best to establish a boundary-less, open, nonbureaucratic, and people-oriented organizational culture. As a result, the organizational culture of LG Electronics is non-bureaucratic, open, and humanitarian; employees and their opinions are well respected. High challengeseeking, a competitive spirit, and people-oriented harmonized teamwork are the strengths of the culture of LG Electronics. The findings on the organizational culture of LG Electronics from the interviews are similar to those on leadership characteristics as described below.

\section{a. People-orientation}

Interviewees described the fundamental essence of the organizational culture of LG Electronics as “The People Company". The company values people-oriented, humanitarian, harmonized teamwork, but also recognizes the importance of individual capabilities. Respecting people as human beings and the opinions and 
ideas of all members of the organization is essential. Interviewees recognized the importance of human networks and mutual cooperation among the company's organizations. A strong psychological ownership within the employees is part of the people-oriented organizational culture of LG Electronics. Thus, workers feel confident to give their best to achieve the vision and goals of the company.

The people-oriented management philosophy of LG Electronics, in which harmony and strong teamwork are emphasized, promotes the use of "We" instead of " $\mathrm{I}$ " in building a cooperative and harmonized culture as well as labor relations. As a result, LG Electronics won the Grand Award for Labor Management in 2005 as the best labor relations model in Korea. Within this humanitarian organizational culture, LG Electronics employees demonstrate strong psychological ownership and express high employee satisfaction.

\section{b. Challenge-seeking}

The high challenge-seeking spirit of LG Electronics is termed the "LG Way". Four key goals are involved in the LG Way: (1) To become the world's best number one excellent company, seeking top quality (no flexibility on quality); (2) To create value for customers; (3) To respect people as human beings; and (4) To offer transparent and inflexibly ethical management. The leaders of the company have a strong desire and commitment for the future growth of the company and taking acceptable risks. However, one interviewee made an interesting and frank comment: "LG Electronics is just $2 \%$ short of becoming the world's best due to the fact that it has a comfortable culture rather than the toughest competing culture". Some other interviewees also mentioned the potentially negative impact of the company culture, in which harmony among the people is emphasized. The company's result-sharing environment may seem in contrast to a high-challenge seeking approach. Taking risks and maintaining a competitive spirit is essential for the development of new products and new businesses for sustainable future growth.

\section{c. Innovation}

The organizational culture of LG Electronics is open and non-bureaucratic, allowing freedom for people to be creative and innovative. One respondent put it this way:

The management encourages creation of innovative new products and new idea development, and provides significant freedom for creative thinking and imagination. The management has engineered changes and innovation to adapt to the fast-changing and competitive technology environment. There is a strong 
emphasis on technology innovation and creative new product development.

As a result, LG Electronics won the Best Product Innovation Award at the world famous Consumer Electronics Show in Las Vegas for several years, including 16 product innovation awards in 2005, 11 in 2006, 13 in 2008, 14 in 2009, and 15 in 2010. The management of LG Electronics strongly supports product innovation and new technology development to maintain its leading competitive position in this fast-changing technology and design-competitive atmosphere of today's business world.

\section{d. Control}

The management of the LG Group and LG Electronics encourages bottom-up decision-making with employees' active participation and consideration of their opinions through open communication rather than bureaucratic top-down control. The Chairman of the LG Group delegates management responsibility and authority to the CEO of LG Electronics, and the CEO of LG Electronics in turn delegates operating responsibilities to each business division manager. The Chairman of the Group and CEO of the company are selectively directly involved in strategic decision-making and managing important projects. Therefore, executives and managers under the CEO have a significant level of freedom to manage their businesses and do their work responsibly. However, implementation of integrity and transparency policies and the "LG Way" management principles are tightly controlled and applied with no flexibility.

\section{e. Boundary-less}

Since the leadership style of the LG Group Chairman is open and non-bureaucratic, the organizational culture of the LG Group and LG Electronics is very open and boundary-less. Under this open organizational culture, employees have significant freedom to recommend new ideas and opinions. Most opinions of interviewees were in consensus on the subject of organizational culture. They were very proud of the people-oriented, open organizational culture of the company, as evidenced by the following statements.

Our leaders strongly encourage boundary-less open communication among layers, divisions, and business functions.

Our management listens and respects employees' opinions and encourages 
employees to communicate and to recommend their opinions and ideas freely to management, and also promotes bottom-up decision-making. People in our company freely communicate their opinions to senior management.

\section{f. Other observations from the interviews}

By building and managing a non-bureaucratic open organizational culture with significant freedom in which people can be creative and imaginative, LG Electronics has established high knowledge productivity, which is the most important factor for achieving high value creation for the company. One interviewee, however, made a frank comment expressing his concern about the culture of LG Electronics:

Too much humanitarian and open organizational culture with significant freedom leads to a less tenacious competitive spirit for winning. Therefore, LG Electronics is just $2 \%$ short of the number one top position, and our organizational culture accepts the number two position.

A few executive interviewees also expressed concern that the highly humanitarian and people-oriented organizational culture at LG Electronics may reduce the competitive spirit and strong desire to achieve high-performance goals and competitive spirit, which are critical for sustainable future growth in today's fastchanging and high-technology competitive industries. According to these executivelevel interviewees, the management of LG Electronics also recognizes this challenging issue and makes efforts to create tension and foster the competitive spirit. From these views, we may infer that the people-oriented humanitarian open culture of LG Electronics can best be combined with high challenge-seeking entrepreneurship, strong competitiveness, a tenacious spirit, and a tough performance-oriented attitude to achieve the company goal to become the world's best, number one company in its industry.

Under the two-tops leadership structure, with the Chairman of the LG Group and the CEO of LG Electronics, the organizational culture of LG Electronics is closer to the A type defined in the conceptual framework in Chapter 2. Table 4.5 summarizes the findings on the organizational culture of LG Electronics. 
Table 4.5 Summary of organizational culture

\begin{tabular}{l|l}
\hline Characteristics & Descriptions \\
\hline People-oriented & $\begin{array}{l}\text { "The People Company" spirit. Highly humanitarian and people-oriented, } \\
\text { emphasizing harmonized teamwork. Respecting and empowering people. } \\
\text { Strong psychological ownership and high employee satisfaction. }\end{array}$ \\
Challenge-seeking & $\begin{array}{l}\text { High challenge-seeking to become the world's best number one excellent } \\
\text { company with the principle spirit of value creation for customers. }\end{array}$ \\
Innovation & $\begin{array}{l}\text { Non-bureaucratic open culture with sufficient freedom for LG people to be } \\
\text { creative and innovative. Striving hard to develop innovative new products } \\
\text { and technologies. }\end{array}$ \\
Control & $\begin{array}{l}\text { LG Group leader delegates management responsibilities to CEOs of all LG } \\
\text { and operative responsibilities to each business division leader. No top- } \\
\text { down control. Mainly bottom-up decision-making. }\end{array}$ \\
Boundary-less & $\begin{array}{l}\text { LG Group and LG Electronics culture is boundary-less, open, and non- } \\
\text { bureaucratic, enabling people to be creative. }\end{array}$ \\
\hline
\end{tabular}

\subsubsection{Knowledge productivity}

a. Continuous improvement and radical innovation of products, services, and work processes (KP1)

Management of LG Electronics strongly emphasized continuous improvement and radical innovation of products, services, and work processes (KP1), which are essential for successful value creation in the company. Productivity improvement and innovation programs are continuously implemented. Interviewees described a recently implemented special program for process and cost improvement as follows.

The CEO initiated a new program called "il-jal-bub" (best work practices) intended to improve the efficiency of working processes and operating rules. This program involves improvement and innovation programs for work processes by sharing knowledge, experience, and best practices across business divisions throughout the company and also learning best practices from outside companies. For example, waste cost factors are being eliminated throughout all company work processes to improve cost competitiveness.

According to the interviewees, this "il-jal-bub" program promoted greater focus on cost improvement of work processes. The objective of the improvement programs is 
to make LG Electronics a cost competitive and strong company. This program is part of an ongoing effort for improvement and radical innovation of products, services, and work processes (KP1) that will improve knowledge productivity and value creation.

\section{b. Sustainable development of future growth engine business (KP2)}

Some interviewees explained that LG Electronics considers sustainable development of future growth engine business (KP2) to be its most important priority, and therefore the company invests $5 \%$ of total sales into $R \& D$ and new product development. Approximately 10,000 people are involved in $\mathrm{R} \& \mathrm{D}$ and product development in the company.

The former CEO launched a revolutionary innovation program throughout the whole company called "TDR" (Teardown and Redesign). This program effected radical improvement and revolutionary changes in products and work processes, especially in terms of new product development. Respondents provided the following comments:

The TDR program significantly improved and changed products and processes and accelerated new product development of LG Electronics, and also provided solutions and new approaches to major company issues.

Under the open organizational culture of LG Electronics, employees' creative new ideas and recommendations are respected and well accepted for implementation.

The program was implemented throughout the company under cross-business and cross-functional TDR task force teams for effective sharing of knowledge and experience.

\section{c. Other observations}

One interviewee mentioned that the current CEO focuses more on implementing programs toward short-term results oriented for productivity and cost improvement (similar to KP1) within the program called "il-jal-bub" (efficient working rules). However, radical innovation and development of new products for sustainable future growth (similar to KP2) are critical for the company in the context of global high-technology competition. This comment was expressed as a concern arising from the company's greater focus on current aspects rather than future growth 
business development. Findings from the qualitative analysis of the data obtained from the interviews shed new light on the questions raised in the interpretation of the statistical analysis. Table 4.6 summarizes the findings on knowledge productivity of this case study.

\section{Table 4.6 Summary of knowledge productivity}

\begin{tabular}{l|l}
\hline Characteristics & Descriptions \\
\hline $\begin{array}{l}\text { Continuous } \\
\text { improvement and } \\
\text { radical innovation }\end{array}$ & $\begin{array}{l}\text { Strongly emphasis on continuous improvement and radical innovation of } \\
\text { products, services, and work processes (KP1) } \\
\text { Implementing newly launched special program called } \\
\text { "il-jal-bub"(efficient working rules)for improving productivity of work } \\
\text { processes and eliminating waste costs, and utilizing knowledge in the } \\
\text { company }\end{array}$ \\
$\begin{array}{l}\text { Sustainable } \\
\text { development of the } \\
\text { future growth engine } \\
\text { business } \\
\text { (KP2) }\end{array}$ & $\begin{array}{l}\text { Former CEO implemented TDR (Tear-down and Redesigning) program } \\
\text { linking knowledge to create new innovative approaches and solutions for } \\
\text { all work processes. Products innovation and new product development } \\
\text { for future growth. Priority investment for personnel development as } \\
\text { management believes the future of the company depends upon people } \\
\text { and their knowledge. }\end{array}$ \\
$\begin{array}{l}\text { Other observation } \\
\text { Former CEO focused on both KP1 and KP2, and implemented a } \\
\text { special TDR (Teardown and Redesign) program as KP2 is essential for } \\
\text { sustainable future growth in today's global competition and the era of } \\
\text { new high-technology products. } \\
\text { Current CEO focuses more on KP1, implementing productivity } \\
\text { upgrading program called “il-jal-bub" (efficient working rules) for } \\
\text { productivity and cost improvement. }\end{array}$ \\
\hline
\end{tabular}

\subsubsection{Value creation}

By building and managing a people-oriented, non-bureaucratic and open organizational culture with significant freedom in which people can be creative and imaginative, LG Electronics established high knowledge productivity, which is the most important factor for achieving high value creation for the company.

\section{a. Corporate reputation, image, and CSR}

Interviewees stated that the LG Group's management principles are based on transparency, high moral standards, and respecting customers and organization members. The company is well-recognized and respected for its high-quality products and services, high moral standards, and transparent management. The prime objective and management principle of the company, "to be the number one company 
by value creation for customers", is especially well-recognized. Support is provided to maintain the high reputation and image of the company.

The successful combination of the two-tops leadership structure and high management quality of both the Chairman of the LG Group and the CEO of LG Electronics resulted in LG Electronics becoming a top-level global company. The company management is highly respected for its humanitarian, people-oriented approach and high moral standards in combination with challenge-seeking entrepreneurship.

Corporate social responsibility (CSR) is one of the major priorities of both the LG Group and LG Electronics. According to interviewees, employees are proud of the way the company contributes to society. The LG Group and LG Electronics focus continuously on environmental protection and green energy business development. For example, LG Electronics has made significant efforts to develop environmentally-friendly and energy-saving appliances and products. LG Electronics has also implemented and accelerated special joint cooperation programs to support suppliers of parts and components, which are mostly mediumsized and small companies.

Management and labor union representatives of LG Electronics jointly pursued a shift to a program called "Value-Creating Labor-Management Relations" since 1993 based on mutual trust and understanding (Kim, Bae, \& Kwon, 2013). In January 2010, the company labor union declared the "Charter of LGE USR" (Union Social Responsibility) at a special event in which 300 representatives of the labor union and company executives, including the CEO, participated (Kim, 2011; Kim, Bae, \& Kwon, 2013). The book Union Social Responsibility (2011) which is referenced here was written jointly by the executive vice-president of LG Corp., the holding company of the LG Group, the chairman of the labor union of LG Electronics, and a university professor. This declaration of USR was an important turnin

\section{b. Employee satisfaction with work environment and benefits}

Interviewees expressed consensus on the subject of employee satisfaction, as evidenced by the following quotations.

We believe that our company is one of the best places to work, as the leadership style and organizational culture are people-oriented and humanitarian and people are treated with respect.

The company has a work environment in which people have a strong psychological ownership, and do their best by bringing out their best abilities to 
work responsibly for the company.

People in the company believe that their management maintains high principles and has future-oriented company goals. They know that they can grow together with the company when they work hard. The company provides a comparatively high level of compensation, benefits, and a special incentive system related to performance and achievement of company goals.

\section{c. Sustainability}

The management quality of the company is highly respected for its people-oriented approach and high moral standards, which are balanced by its high challengeseeking entrepreneurship. As a result, the company has maintained sustainable high growth in recent decades and preserved its strong reputation for its sustainable growth capability.

\section{d. Financial data on 10-year performance}

Table 4.7, Figure 4.1, and Figure 4.2 respectively show the net profit, sales, and market value of LG Electronics between 1990 and 2010 and a comparison of sales with the top 10 Korean electronics companies. Data on net profit, revenue/sales, and market value of LG Electronics were collected from the annual reports of the company filed with the Korea Stock Exchange. The Korea Industry Research Institution provided data on net profit, revenue and sales, and market value of the top 100 companies, from which the top ten companies in the electronics industry were selected for comparison. LG Electronics overcame the Asian financial crisis of 1998 and the global financial crisis of 2008. In fact, the company recorded increased sales, net profit, ROS, and market value during this research period. Overseas sales grew significantly (225\%) from 2000 to 2010, while domestic sales remained stable.

This indicates that the company focused strongly on its globalization strategy. However, net profit in 2010 was negative due to the introduction of Apple's iPhone to the world market in the third quarter of 2009, which had a significant impact on global mobile communication industries and businesses. 
Table 4.7 Net profit, sales, and market value of LG Electronics (1990-2010) ${ }^{a}$

Unit: billion (KRW), percentage (\%), person (number)

\begin{tabular}{lrrrrrrrr}
\hline & $\mathbf{1 9 9 0}$ & $\mathbf{2 0 0 0}$ & $\mathbf{2 0 0 2}$ & $\mathbf{2 0 0 4}$ & $\mathbf{2 0 0 6}$ & $\mathbf{2 0 0 8}$ & $\mathbf{2 0 0 9}$ & $\mathbf{2 0 1 0}$ \\
\hline Sales & 2,984 & 14,835 & 18,602 & 24,659 & 23,170 & 27,638 & 30,513 & 29,238 \\
\multicolumn{1}{c}{ Domestic } & 1,487 & 4,881 & 6,654 & 5,086 & 5,947 & 6,445 & 6,665 & 6,892 \\
Overseas & 1,496 & 9,954 & 11,947 & 19,573 & 17,223 & 21,193 & 23,848 & 22,346 \\
Sales Profit & 285 & 921 & 1,028 & 1,249 & 534 & 1,226 & 1,614 & $-1,104$ \\
Net profit & 33 & 502 & 497 & 1,546 & 239 & 482 & 2,053 & -635 \\
ROS & $1.11 \%$ & $3.38 \%$ & $2.67 \%$ & $6.27 \%$ & $1.03 \%$ & $1.74 \%$ & $6.73 \%$ & $-2.17 \%$ \\
Employee & 32,536 & 31,774 & 25,024 & 31,614 & 31,201 & 28,659 & 28,597 & 33,242 \\
Market Value & & 3,082 & 5,707 & 8,858 & 9,123 & 15,448 & 16,468 & 17,068 \\
\hline
\end{tabular}

- Market value based on year-end stock price.

- Financial data of overseas operations not included.

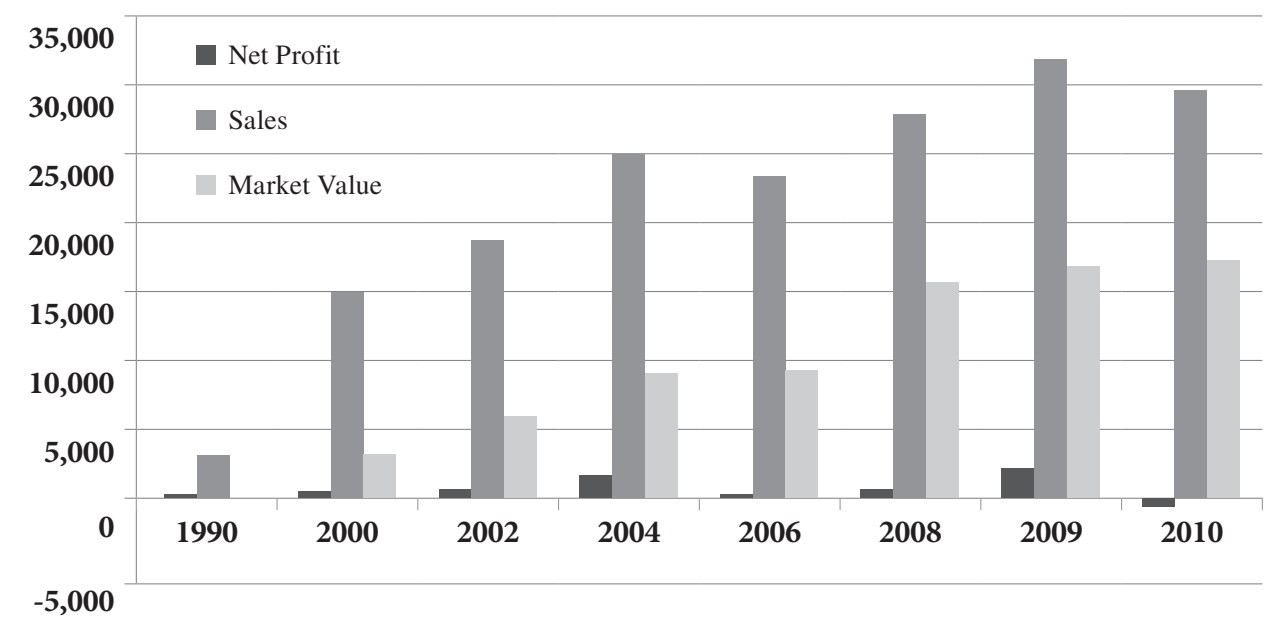

Figure 4.1 Net profit, sales, and market value of LG Electronics (1990-2010)

Unit: billion (KRW)

Note: Negative net profit in 2010 due to the significant impact of Apple's i-Phone introduction to the world market 
The comparison of LG with the top 10 Korean companies is based on the data of the top 100 Korean companies provided by Korea Industry Research Institution.

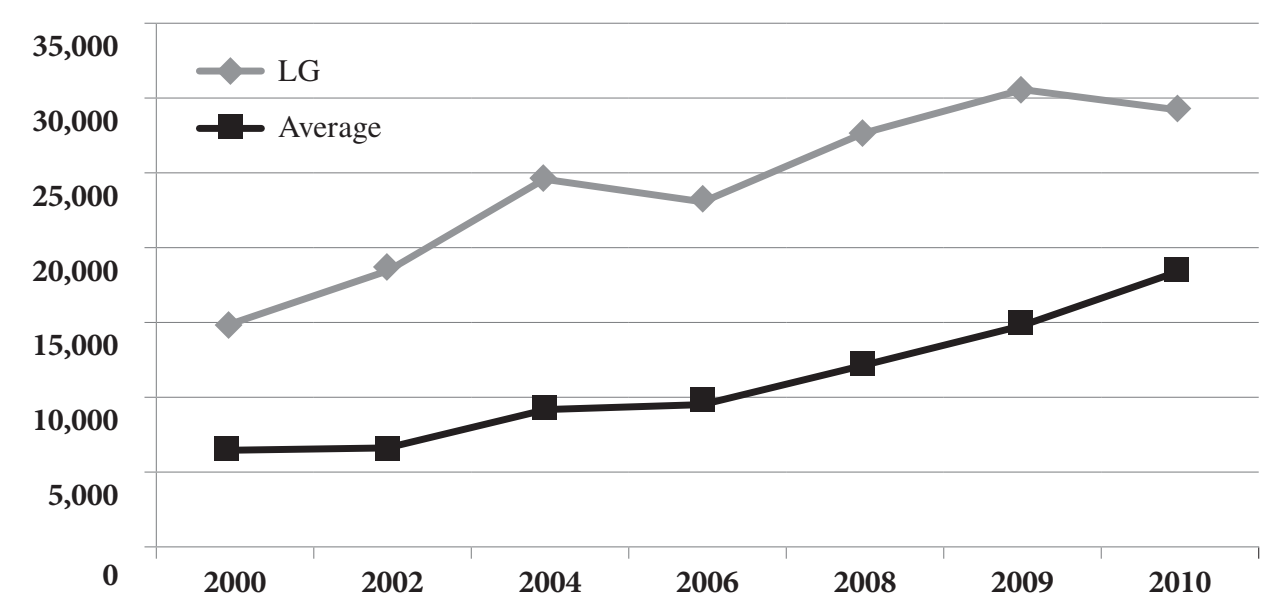

Figure 4.2 Sales of LG Electronics and average sales of top 10 Korean companies other than LGE and including Samsung Electronics (2000-2010)

Unit: billion (KRW)

To conclude the section on value creation at LG Table 4.8 summarizes the findings on value creation. 
Table 4.8 Summary of value creation

\begin{tabular}{l|l}
\hline Characteristics & Descriptions \\
\hline $\begin{array}{l}\text { Corporate } \\
\text { Image, CSR }\end{array}$ & $\begin{array}{l}\text { The company is well-recognized and respected for the high quality of its } \\
\text { products and services, high moral standards, and transparent management. } \\
\text { The principle of management, "to be the number one company by value } \\
\text { creation for customers", is especially well-recognized and helps maintaining } \\
\text { the highly positive reputation and image of the company. }\end{array}$ \\
Employee & $\begin{array}{l}\text { Continuous corporate social activity is an important priority. The LG Group } \\
\text { and LG Electronics focus on contributing to environmental protection and } \\
\text { development of future green energy businesses. }\end{array}$ \\
Sutisfaction & $\begin{array}{l}\text { Highly people-oriented management leadership; non-bureaucratic open } \\
\text { organizational culture that empowers people and creates a high level of } \\
\text { employee satisfaction and psychological ownership. }\end{array}$ \\
Performanciality & $\begin{array}{l}\text { Strong reputation for sustainable future growth capability based on the stable } \\
\text { growth record of the past few decades and quality of the management. } \\
\text { The published financial data shows outstanding performance. Sales, net profit } \\
\text { and market value grew significantly over the past 10 years (2000-2010), except } \\
\text { for net profit in 2010, which was negative due to the significant impact of the } \\
\text { introduction of Apple's iPhone in the world market in the third quarter of } \\
\text { 2009. }\end{array}$ \\
observations & $\begin{array}{l}\text {-Sales growth: 9.8 times (1990-2010)KRW 29,238 bil (2010) } \\
\text {-Net profit growth: 62.2 times (1990-2009) KRW 2,053 bil (2009) } \\
\text {-Market value growth: 5.5 times (2000-2010) KRW 17,068 bil (2010) } \\
\text { LG Electronics achieved sustained growth during the research period (2000- } \\
\text { 2010) based on the competitiveness coming from the strong people power } \\
\text { productive organizational culture. }\end{array}$ \\
\hline
\end{tabular}

\subsection{Conclusion of LG Electronics case study}

LG Electronics achieved sustained growth over the past 20 years, including $980 \%$ sales growth (1990-2010) and 6,221\% net profit growth (1990-2009). However, the net profit in 2010 was negative as a result of the significant negative impact of the introduction of Apple's iPhone to the world market in the third quarter of 2009. Within the past 10 years (2000-2010), LG Electronics achieved 197\% growth in sales and a 554\% increase in market value. In terms of net profit, the company achieved 409\% growth for 9 years (2000-2009); however, net profit in 2010 was unexpectedly negative for the reason explained above. LG Electronics successfully managed continuous growth despite tough global competition in the high-technology electronics and communication industries, becoming a leading company in the 
world electronics industry today.

The main purpose of this empirical research into the LG Electronics company using both qualitative and quantitative analysis was to explore correlations among the key variables (leadership, organizational culture, knowledge productivity, and value creation) based on the conceptual framework of the research model. Identifying the most desirable leadership style and organizational culture for further improving and upgrading knowledge productivity and high value creation is another objective of this study.

Findings from the qualitative analysis, which included interviews with management, executives, and employees, indicate that the leadership characteristics of the company (people-oriented management, visionary entrepreneurship, and high challenge-seeking and risk-taking) aided in communicating a clear vision and giving long-term direction to all organization members. Company leaders created a people-oriented, high-challenging, and innovative organizational culture where people can become creative and innovative and bring out their best capabilities to achieve the vision and goals of the company. Within the LG Electronics organizational culture, advanced knowledge productivity resulted in continuous improvement and innovation of products, services, and work processes, which improved sustainable capability for future growth. Significant and positive correlations were found among three of the main factors examined in this study, (leadership, organizational culture, and knowledge productivity). They were identified as strong bases for high value creation and sustainable future growth. Findings from the quantitative analysis of the survey strongly supported the findings of the qualitative analysis. The results of the quantitative analysis showed that the characteristics of LG Electronics leadership (people-oriented, LS1; visionary and entrepreneurial, LS2; and high challenge-seeking and risk-taking, LS3) were significantly and positively correlated with the characteristics of organizational culture (people-orientated, $\mathrm{OC} 1$; high challenge-seeking and innovative, OC2). These characteristics of leadership and organizational culture positively correlated with knowledge productivity (improvement and innovation of products, services, and work processes, KP1; and continuous radical innovation and improvement leading to sustainable development of future growth engine, KP2).

The characteristics of leadership and organizational culture and the resulting knowledge productivity of LG Electronics were significantly and positively correlated with the key value creation factors (corporate reputation, image, and CSR, VC1; employee satisfaction with work environment, VC2; employee satisfaction with financial benefits, VC3; and sustainability, VC4). Hard data on the financial performance of LG Electronics showed sustainable growth in value creation, 
continuous growth in revenue, net profit, and market value over the 10 -year period of this study, except for the negative net profit in 2010, as explained above. LG Electronics showed outstanding performance compared to the top 10 successful Korean companies in the same industry.

Results of the empirical research on the LG Electronics case using both qualitative and quantitative analysis indicated that the leadership characteristics of LG Electronics (people-oriented, high challenge-seeking, visionary, and entrepreneurial with the company spirit "to be the number one (No. 1) through value creation for customers") created a boundary-less, non-bureaucratic, and innovative organizational culture in which people can be creative and have strong psychological ownership. This management leadership style and organizational culture have improved and advanced knowledge productivity in LG Electronics. In turn, knowledge productivity is significantly and positively related to high value creation and the sustainable growth of the company. This empirical research on the case of LG Electronics supports the conceptual framework of the research model and demonstrates correlations among the four variable factors, namely leadership, organizational culture, knowledge productivity, and value creation, as illustrated in Figure 4.3.

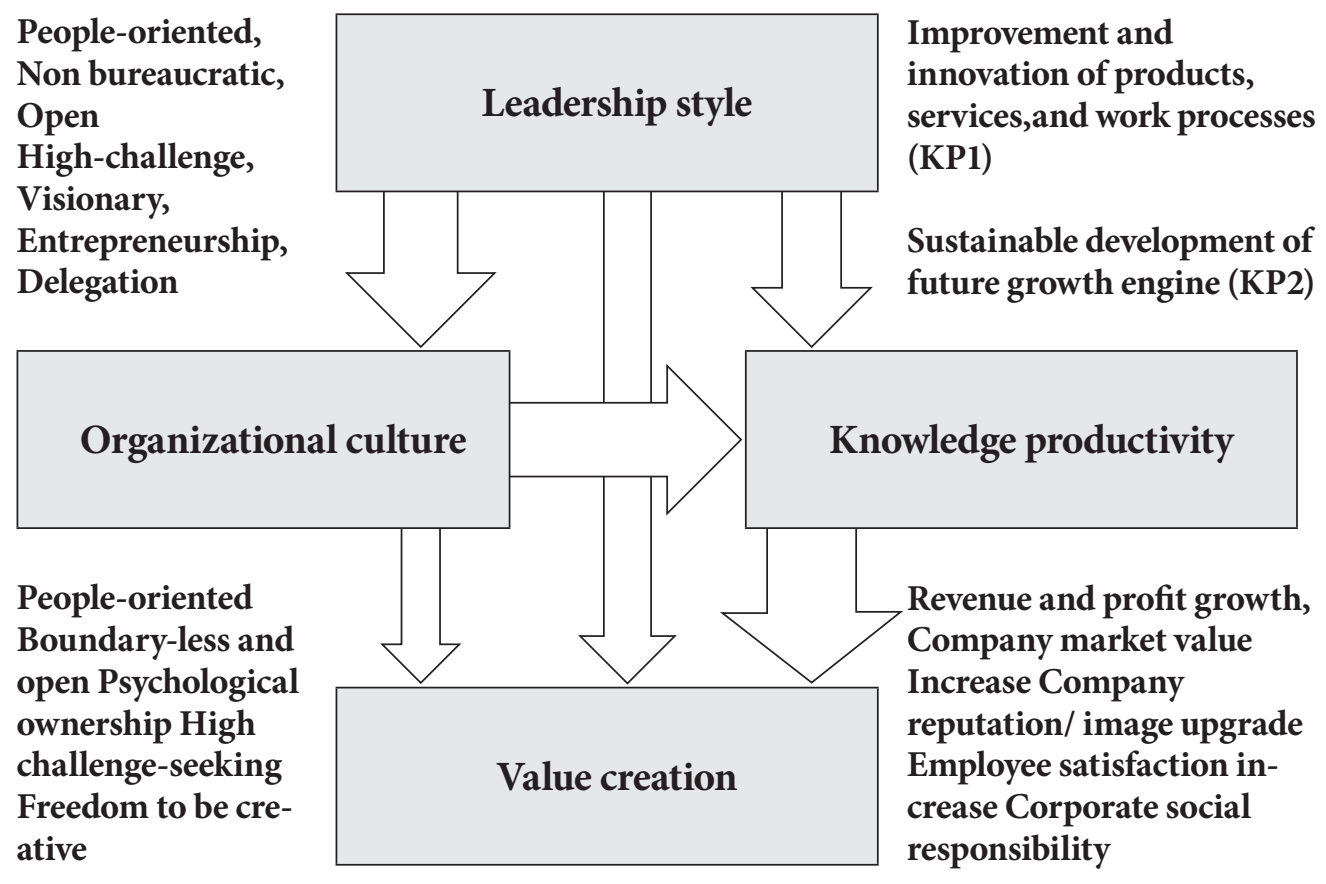

Figure 4.3 Summary of the four main variables of the LG Electronics case study 
Leadership is significantly and positively related to organizational culture (as the thicker arrows indicate in Figure 4.3), organizational culture is significantly and positively related to knowledge productivity (as the thicker arrow shows), and knowledge productivity is significantly and positively related to value creation (as the thicker arrow shows). The leadership of LG Electronics is significantly and positively related to knowledge productivity where organizational culture may act as a mediator, as shown in Figure 4.3, and less direct relation with knowledge productivity. Leadership also is significantly and positively related to value creation where organizational culture and knowledge productivity may act as mediators as shown on the Figure 4.3, and less directly related to value creation. From the case study, the leadership of the LG Group chairman was found to be closer to the A type, while the leadership style of LG Electronics' CEO was closer to the B type in the conceptual framework of the research model. Findings from this empirical research on LG Electronics are summarized in the Table 4.9. These findings support the conceptual framework of this study and provide building blocks for answers to the main research questions. This case study report was sent for validation to the participants. On the basis of the report, the researcher organized feedback discussions with senior management. In response to the feedback, some minor changes and additions were made in the case report.

Table 4.9 Summary of the LG Electronics case in terms of the four main variables

\begin{tabular}{|c|c|}
\hline Characteristics & Descriptions of key common characteristics of the four factors \\
\hline $\begin{array}{l}\text { Leadership } \\
\text { Style }\end{array}$ & $\begin{array}{l}\text { People-oriented and humanitarian, high challenge-seeking and visionary, } \\
\text { entrepreneurial spirit and risk-taking, high-level delegation, but case-by-case } \\
\text { participation in important decisions. Empowering people and organization. } \\
\text { Two-tops leadership structure, LG Group chairman and CEO of LG } \\
\text { Electronics. }\end{array}$ \\
\hline $\begin{array}{l}\text { Organizational } \\
\text { Culture }\end{array}$ & $\begin{array}{l}\text { People-oriented and humanitarian, strong psychological ownership of } \\
\text { employees. Boundary-less and non-bureaucratic open culture with freedom } \\
\text { for people to be creative and innovative. High challenge-seeking. }\end{array}$ \\
\hline $\begin{array}{l}\text { Knowledge } \\
\text { Productivity }\end{array}$ & $\begin{array}{l}\text { Strong capability for continuous improvement and innovation of products, } \\
\text { services, and work processes (KP1). Continuous innovation for sustainable } \\
\text { development of future growth engine business (KP2). Company focusing } \\
\text { more on KP1 than KP2. }\end{array}$ \\
\hline Value Creation & $\begin{array}{l}\text { Sustained high value creation and growth of LG Electronics coming from } \\
\text { strong people-power resulting from the people-oriented and knowledge } \\
\text { productive management and high-challenging entrepreneurship. Continuous } \\
\text { high value creation; stable growth of revenue, net profit, and market value for } \\
\text { the } 10 \text { years of the research period based on financial data. High corporate } \\
\text { reputation, image, and CSR, employee satisfaction with work environment } \\
\text { and financial benefits, and strong sustainable capability. }\end{array}$ \\
\hline
\end{tabular}




\section{Chapter 5. Findings from the case studies: Samsung Electronics}

\subsection{General overview}

Samsung Electronics is the leading company in the Korean electronics industry and also one of the leading electronics companies in the world. When B.C. Lee, the founder of the Samsung Group, incorporated Samsung Electronics in 1969 it was only the third manufacturer of electric appliances and consumer electronics products in Korea. Through the continued high-challenging entrepreneurship of two generations of leadership and the efforts of its professional management team, Samsung Electronics has grown to become a leading global company in its industry. Company sales increased 2,488\%, and net profit grew 18,132\% from 1990 to 2010. Samsung Electronics was selected as a case study for this research for these reasons. A general overview of the company is provided in Table 5.1.

Table 5.1 General overview of Samsung Electronics and the Samsung Group

\begin{tabular}{|c|c|}
\hline $\begin{array}{l}\text { Background } \\
\text { of Samsung }\end{array}$ & Description \\
\hline Founding & $\begin{array}{l}\text { Samsung Group founded in } 1938 \text { as Samsung Trading Company by B.C. } \\
\text { Lee, the late Group Chairman } \\
\text { Samsung Electronics founded in } 1969 \text { by B.C. Lee. }\end{array}$ \\
\hline $\begin{array}{l}\text { Types of } \\
\text { Industries }\end{array}$ & $\begin{array}{l}\text { Samsung Electronics } \\
\text { Main products } \\
\text { - Appliances, Consumer Electronics, Semiconductors, Mobile } \\
\text { Communication Equipment, Displays }\end{array}$ \\
\hline $\begin{array}{l}\text { Affiliated } \\
\text { Samsung } \\
\text { companies }\end{array}$ & $\begin{array}{l}\text { Other Samsung Group Companies (total 62) including: } \\
\text { - Samsung Heavy Industries (shipbuilding) } \\
\text { - Samsung SDI (energy and materials) } \\
\text { - Samsung Techwin Aircraft Engine, } \\
\text { - Samsung Trading } \\
\text { - Samsung Engineering } \\
\text { - Samsung Life Insurance } \\
\text { - Samsung Total Petrochemicals } \\
\text { - Samsung Ever-land } \\
\text { and other } 54 \text { other affiliate companies }\end{array}$ \\
\hline
\end{tabular}




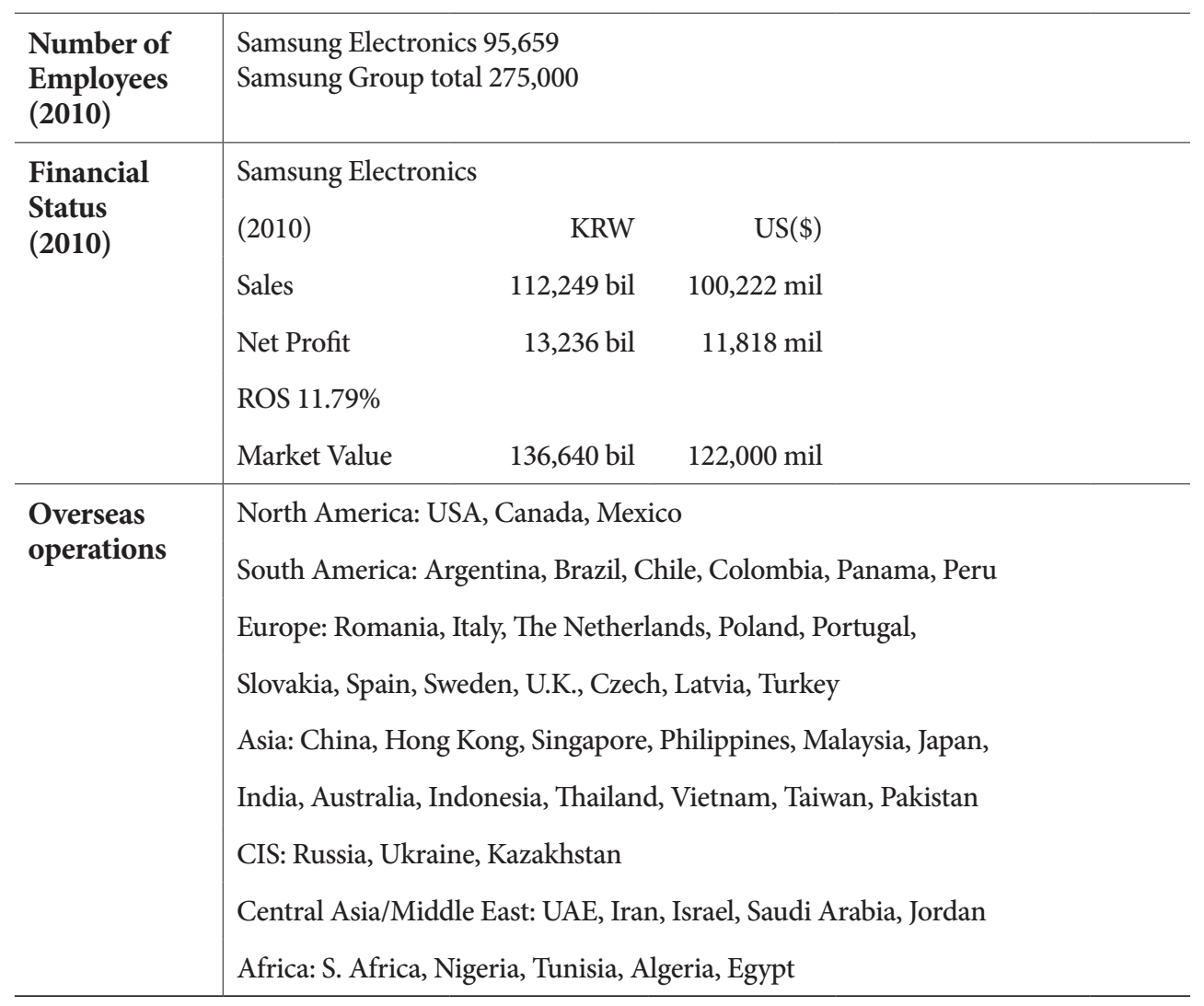




\subsection{Quantitative analysis of survey data}

The following quantitative analysis of the survey results offers an overview of the demographic characteristics and the relations among the key variables.

\subsubsection{Demographic characteristics}

Data on Samsung Electronics was collected from a survey conducted in Korea. In total, 70 respondents from Samsung completed the questionnaire (out of 120 questionnaires distributed). The sample characteristics are summarized in Table 5.2 below.

Table 5.2 Characteristics of survey respondents

\begin{tabular}{lccc}
\hline Parameter & Percentage (\%) & Parameter & Percentage (\%) \\
\hline Gender & \multicolumn{3}{c}{ Rank } \\
Male & 78.6 & Employee & 25.7 \\
Female & 21.4 & Assistant manager & 18.6 \\
Age & & Manager & 30.0 \\
$\quad<$ 30 years & 21.4 & Senior manager & 17.1 \\
31-40 years & 45.7 & Executive & 8.6 \\
41-50 years & 27.1 & Education level & \\
$>$ 51 years & 5.8 & High school & 0.0 \\
Tenure & & College education & 2.9 \\
$\quad<$ years & 30.0 & Bachelor's degree & 80.0 \\
6-10 years & 33.3 & Master's degree & 12.9 \\
$>$ 11 years & 36.7 & Doctorate degree & 4.2 \\
\hline
\end{tabular}

Among the respondents, $78.6 \%$ were males, which is similar to the ratio of males among all employees working at Samsung Electronics. However, the proportions of managers and senior managers were higher $(30.0 \%$ and $17.1 \%$, respectively). The researcher distributed more questionnaires to employees at those management levels, as they could understand and respond better than lower-level employees to questions about the four key variables of leadership, organizational culture, knowledge productivity, and value creation.

Table 5.3 shows the means, standard deviations, and correlations among the variables examined using the survey data collected from 70 respondents from Samsung Electronics. 


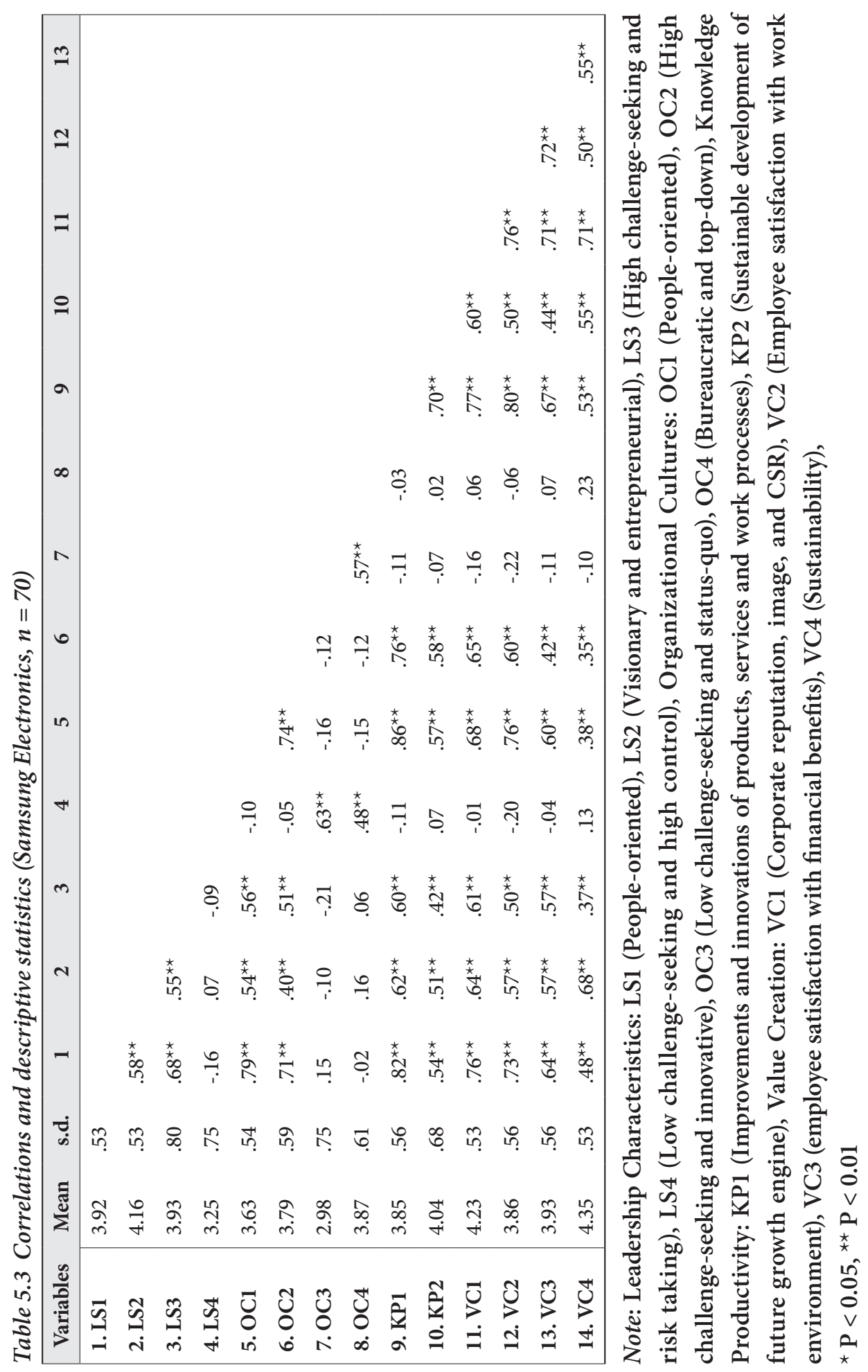




\subsubsection{Relations among key variables}

Table 5.3 shows means, standard deviations, and correlations among the variables in the questionnaire for the employees of Samsung Electronics. Financial performance (revenue and net profit growth, market value increase) is not included in this quantitative analysis, as the financial data are reported separately in section 5.3.4.

The results of the correlation analysis indicate that the leadership characteristics of Samsung Electronics (people-oriented LS1; visionary and entrepreneurial, LS2; and high challenge-seeking and risk taking, LS3) have significantly positive correlations with knowledge productivity, that is, improvements and innovation of products, services, and work processes (KP1) and sustainable development of future growth engines (KP2).

Similarly, the leadership characteristics (people-oriented, LS1; visionary and entrepreneurial, LS2; and high challenge-seeking and risk taking, LS3) have significantly positive correlations with key value creation factors, that is, corporate reputation, image, and CSR (VC1), employee satisfaction with work environment (VC2), employee satisfaction with financial benefits (VC3), and sustainability (VC4). Both characteristics of organizational culture, that is, people-oriented (OC1) and highly challenge-seeking and innovative (OC2), have significantly positive correlations with knowledge productivity (improvements and innovation of products, services, and work processes, KP1; and sustainable development of future growth engines, KP2). In addition, the organizational culture characteristics, that is, people-oriented (OC1) and high challenge-seeking and innovative (OC2), have significantly positive correlations with value creation factors, that is, corporate reputation, image, and CSR (VC1), employee satisfaction with work environment (VC2), employee satisfaction with financial benefits (VC3), and sustainability (VC4). Finally, knowledge productivity factors, that is, improvements and innovation of products, services, and work processes (KP1) and sustainable development of future growth engines (KP2), have significantly positive correlations with value creation, that is, corporate reputation, image, and CSR (VC1), employee satisfaction with work environment (VC2), employee satisfaction with financial benefits (VC3), and sustainability (VC4).

However, the following leadership and organizational culture characteristics are not found in the leadership style and organizational culture of Samsung Electronics: low challenge-seeking and high-control (LS4) and low challenge-seeking and status quo (OC3) and bureaucratic and top-down control (OC4). These characteristics are negatively correlated with both knowledge productivity and value creation.

The results of the statistical analysis of the data from the Samsung Electronics case 
indicate that both its leadership characteristics (people-oriented, LS1; visionary and entrepreneurial, LS2; and high challenge-seeking and risk taking, LS3) and its organizational culture characteristics (people-oriented, $\mathrm{OC} 1$; and high challenge seeking and innovative, OC2) have significantly positive correlations with both knowledge productivity (KP1 and KP2) and value creation (VC1, VC2, VC3, and VC4). This result positively supports the conceptual framework of this study.

\subsection{Qualitative analysis of interview data}

Interviews were conducted with three senior advisors who were successful, respected former CEOs of Samsung Electronics and other leading Samsung Group companies. These managers had worked closely with both the former chairman and the current chairman, and with other executive directors, division general managers, and unit managers of Samsung Electronics. In total, 18 interviews were conducted. These interviews focused on the leadership style of the Chairman of the Samsung Group and the CEO of Samsung Electronics. Interview questions also focused on the organizational culture, knowledge productivity, and value creation of Samsung Electronics. All responses were similar and demonstrated consensus, as summarized below.

\subsubsection{Leadership style}

Interview questions about the leadership styles of the Samsung Group Chairman and the CEO of Samsung Electronics led to a consensus. The current Chairman, K.H. Lee, who succeeded to the Group Chairman position after the founder and former chairman of the Samsung Group, B.C. Lee - his father - in 1987, also followed Samsung's management ideology and philosophy of rational pursuit, seeking the best scientific technologies and development of the best human talent. In 1993, at Samsung's management conference in Frankfurt, Germany, Chairman K.H. Lee announced the "Samsung New Management" program, emphasizing change and innovation and prioritizing quality-oriented management. This announcement included a new vision and long-term goals for all Samsung Group companies, including Samsung Electronics. At the Frankfurt conference, he strongly emphasized the importance of changes and innovation by saying, "Change everything except your wife."

According to the interviewees, the leadership style of Chairman K.H. Lee is creative and charismatic. They also mentioned that the chairman communicates a highly challenging long-term vision and goals for each company, delegating management 
and operational responsibility completely to the CEOs of each Samsung company. His unique intuition and inspiration for the future and long-term goals for Samsung Group companies and Samsung Electronics are respected and followed by Samsung people.

Chairman Lee leads Samsung companies and each CEO through the Samsung Group's special "Future Strategy Planning Office", which closely evaluates the management and performance of the CEOs of each Samsung company, reporting the results directly to the Group Chairman. This organization was started under the former chairman as the "Group Secretarial Organization", but recently the name was changed to the "Future Strategy Planning Office" to emphasize its role as a think-tank of the Samsung Group to support the Group Chairman.

\section{Two-tops leadership structure of Samsung}

Respondents frequently mentioned the two-tops leadership structure that is in place at Samsung Electronics. As explained earlier, the management leadership structure of Samsung Electronics and other Samsung Group companies is a "two-tops leadership" structure combining the strengths and leadership of the Group Chairman, who owns the controlling shares of the Samsung Group, and the strengths and leadership skills of the CEOs, the professional managers of each Samsung Group company. In the case of Samsung Electronics, two-tops leadership is a combination of the long-term high-challenging vision and management principles of the Group Chairman and the professional management capability and leadership of the CEO of Samsung Electronics working together to achieve the vision and goals for the company.

One of the most important strengths of the two-tops leadership structure is the consistency of management principles and philosophy. The high-challenging longterm vision and goals of the Group Chairman are consistent even when the CEO of the company or the professional management team is changed. As an example of the success of the two-tops leadership model, former Vice Chairman and CEO of Samsung Electronics, J.Y. Yoon, managed Samsung Electronics for 12 years (19962008) with his own unique leadership style and high-challenging vision while following Group Chairman K.H. Lee's long-term vision and high-challenging goals and respecting the principles, philosophy, and spirit of Samsung New Management. This two-tops leadership structure enabled Samsung Electronics to become a top global electronics company. In addition, Vice-Chairman and CEO J.Y. Yoon was selected by Harvard Business Review in 2009 as "the No. 2 most successful CEO in the World." This two-tops leadership structure is a management leadership model 
adopted by many successful major diversified Korean corporations in which controlling shares are owned by founder-chairmen or succeeding chairmen.

\section{a. People- orientation}

Interviewees, including executives and managers, explained that Samsung's peopleoriented management philosophy and corporate culture value human resources highly and put a high priority on talent development.

The founder of the Samsung Group, B.C. Lee, advocated a "People Management" philosophy. When describing his time allocation methods, he said "I invested $\mathbf{8 0 \%}$ of my time in finding top talent and in people development." Samsung's successful people management philosophy and its priority of developing the best people for building the best company continued through two generations of Group Chairmen, from the founder, B.C. Lee, to today's Chairman K.H. Lee. Chairman Lee emphasized that "In this digital era, we are in a brain war, and we are fighting with peoples' brains. Therefore, Samsung should develop top global talent to lead the company in the 21st century."

Samsung's people-oriented management philosophy and spirit attracted the very talented people to manage Samsung Electronics. Samsung employees are called "Samsung men." They are strongly loyal to Samsung and committed to following and implementing Samsung's spirit, vision, and principles. This Samsung spirit has enabled Samsung Electronics to become one of the top leading companies in the world today. Samsung made significant investments in human resources development, especially for people in the high technology industries. Samsung currently operates 12 human resource development institutions and operations in Korea. In addition, all Samsung companies run their own talent development programs simultaneously for all employees, executing the lifelong learning principle of the Samsung Group.

During the last few years, Samsung has recruited global top talent from many other countries in various professional fields, especially people with strong technology and marketing capabilities. Global talent recruiting has accelerated internal competition among the top-level employees and strongly motivated selfdevelopment. According to one senior management interviewee, "Samsung's top talent has world-class specialized skills and capability. They also have strong loyalty to the company and high moral standards."

\section{b. Vision-building}

The Samsung Group's long-term vision was firmly established by founding 
Chairman B.C. Lee and current Chairman K.H. Lee. All Samsung Group companies and Samsung people share the vision and do their best to achieve it. One senior executive interviewee summarized how Group Chairman Lee's future-oriented visionary leadership style had progressed Samsung's vision as follows.

"In the fast-changing and increasingly complicated business environment, his long-term view and creative vision for building future growth are super penetrative and differentiated from other leaders, and he takes significant risks for development of future-oriented new products and new businesses for sustainable growth. An example is Samsung's semiconductor business."

"He has very special intuition and inspiration, which determines the Samsung Group's future direction. Samsung people, including the CEOs of all the subsidiary companies, respect and follow the Chairman's long-term vision and goals for the future of Samsung."

A former senior executive of Samsung Electronics and CEO of an affiliate company of Samsung Electronics who was interviewed for this study summarized the progress and changes in the Samsung Group leaders' long-term and high-challenging visions, management principle, and philosophy through the two generations of leadership during the past several decades. Table 5.4 provides this summary. 
Table 5.4 Progress of Samsung Group leader's long-term vision and management principle(1938-2010)

\begin{tabular}{|c|c|}
\hline Period & Progress \\
\hline 1938 to 1987 & $\begin{array}{l}\text { Samsung Group led by B.C. Lee, founder and Chairman } \\
\text { - Founding Spirit and Vision, and management principle } \\
\text { - Patriotic business first } \\
\text { - Talent development } \\
\text { - Pursuit of rationale and principle }\end{array}$ \\
\hline 1987 to present & Samsung Group led by K.H. Lee, Chairman \\
\hline 1988 & $\begin{array}{l}\text { Declaration of "New Samsung Foundation" by K.H. Lee, Chairman at the } 50 \\
\text { Years Samsung Anniversary } \\
\text { - Respecting people } \\
\text { - Delegation for self-control management } \\
\text { - Importance of technology }\end{array}$ \\
\hline 1993 & $\begin{array}{l}\text { Declaration of "New Management Spirit" by K.H. Lee, chairman } \\
\text { - Start Changes and Innovation from me and myself } \\
\text { - Challenge for "World Best" and "World Top Position" } \\
\text { - Change to "quality-based management" from "quantity-based } \\
\text { management" } \\
\text { - Increased investment in technology development up to 10\% of } \\
\text { total revenue } \\
\text { Developed and secured basic technologies through the leadership of the } \\
\text { Chief Technology Officer, CTO and CEO }\end{array}$ \\
\hline 2006 to present & Declaration of Creative Management by K.H. Lee, chairman \\
\hline
\end{tabular}

The CEOs of all Samsung companies set their own visions and goals for their businesses following the Group Chairman's long-term vision, management principles, and guidelines. Then those visions and goals are shared with their employees. Samsung Electronics' CEO and Vice-Chairman J.Y. Yoon set the following high-challenging goals for the company. These goals reflect the vision of the Group Chairman.

- Building a base for a world leading company

- Building an integrated digital company 
- Attaining a top global position in the semiconductor industry

- Attaining a top global position in the mobile communications and appliance industries

\section{c. Entrepreneurship and challenge-seeking}

The high challenge-seeking vision and entrepreneurship of Chairman Lee strongly empowered and motivated CEOs and executives of all Samsung Group companies, especially Samsung Electronics, to make Samsung the world's best modern electronics company. For example, Samsung Electronics entered into the hightechnology semiconductor industry by taking significant risks in terms of both technology and investment.

As a result, Samsung Electronics achieved 2,490\% (24.9 times) growth in sales, $18,130 \%$ (181.3 times) growth in net profit, and $11,170 \%$ (111.7 times) growth in market value in 20 years (1990-2010) (Source: Financial data of Samsung Electronics), making Samsung Electronics the world leading company in the semiconductor, mobile communication, and appliance industries. Samsung's management continued with high-challenging innovation and improvements, investing 1,500 billion Won (approx. US\$1.4 billion) for process innovation and new product development since 1995 in order to build the base that is today's Samsung Electronics. For supporting business growth in high-technology industries, Samsung Electronics made significant investments in R\&D of up to $10 \%$ of total revenue, and increased the $\mathrm{R} \& \mathrm{D}$ team by $20 \%$ each year. Over 50,000 researchers were employed as of 2010.

\section{d. Risk-taking}

Through a combination of challenge seeking, risk-taking, the visionary leadership of the Group Chairman, and the professional management capability and entrepreneurship of Samsung Electronics' CEO, Samsung made large-scale investments in order to develop future-oriented new products and businesses in high technology industries, such as, in the semiconductor and mobile communications industries. As a result of high risk-taking entrepreneurial management decisions, Samsung Electronics became the world leader in both these industries. In the case of Samsung Electronics, the Group Chairman mostly took high-risk entrepreneurial decisions. The role of the CEO was to focus on successful implementation and risk management rather than risk-taking and high-challenging decision-making. 


\section{e. Controlling}

According to the interviewees, Group Chairman K.H. Lee fully delegated management responsibility and authority to the CEOs of each Samsung-affiliated company, including Samsung Electronics, and did not involve himself directly in company operations. However, he leads Samsung Group companies through the unique secretarial systems operation called the "Future Strategy Planning Organization", which evaluates the performance of each of the Samsung-affiliated companies and reports to the Group Chairman, as mentioned earlier.

Samsung's group management employed a unique system, which combined delegation of management authority and responsibility and indirect control through the Future Strategy Planning Office. This operation is organized by the highly talented and experienced senior people selected from the various Samsung Group companies. It also supports and assures implementation of the Group Chairman's vision and long-term strategic goals in each subsidiary.

Under the two-tops leadership structure of the Samsung Group, the organizational culture of Samsung Electronics is also a two-tops culture, combining a strong goaloriented and high performance-seeking work environment following the Group Chairman's leadership principles and high-challenging long-term vision and boundary-less open culture, in which people are motivated and empowered people under the leadership of the CEO of Samsung Electronics. The leadership culture of Samsung Electronics is similar to the B type of the leadership framework in Figure 5.3.

The leadership style of the Samsung Group Chairman can be characterized as follows: strong, charismatic, paternalistic, and sovereign, with a high-challenging long-term vision and strong goal orientation for the Samsung Group companies. While concentrating on long-term strategy development, the Chairman fully delegates management responsibility and authority to each CEO without direct participation or top-down control. The Group Chairman's communication style is also very special; he favors selective face-to-face direct communication with key executives, but rarely engages in direct communication with middle and lower-level managers. However, most Samsung people share and respect and follow the Chairman's vision, goals, spirit, and principles. The Group Chairman's leadership can be described as a combination of type A (full delegation to CEO) and type B (developing long-term vision and strategy) in the leadership framework of this study (Figure 5.3). Table 5.5 summarizes the findings of the leadership characteristics of Samsung. 
Table 5.5 Summary of leadership characteristics

\begin{tabular}{l|l}
\hline Characteristics & Descriptions \\
\hline People-oriented & $\begin{array}{l}\text { People-oriented management philosophy: develop the best people for } \\
\text { building the best company, motivation and empowerment of people. } \\
\text { Leading continuous innovation and change throughout the company. }\end{array}$ \\
Vision-building & $\begin{array}{l}\text { High-challenging vision for building the world's top integrated digital } \\
\text { company with the spirit of quality-based management, especially in the } \\
\text { semiconductor, mobile communications, and appliances industries. }\end{array}$ \\
Entrepreneurship & $\begin{array}{l}\text { Combination of Group chairman's high-challenging long term visionary } \\
\text { entrepreneurship and willingness to take risks, and highly performance- } \\
\text { oriented professional management of the CEO of Samsung Electronics. }\end{array}$ \\
Risk taking & $\begin{array}{l}\text { Taking risks for development of high-technology future oriented new } \\
\text { businesses. } \\
\text { Combination of high-level delegation of authority and responsibility } \\
\text { and well organized performance evaluation and reporting systems. } \\
\text { Delegation and team leadership with clear role setting for divisions and } \\
\text { teams. } \\
\text { Two-tops } \\
\text { leadership structure }\end{array}$ \\
$\begin{array}{l}\text { Unique two-tops leadership structure; a combination of the long-term } \\
\text { high-challenging vision and management principles of the Group } \\
\text { Chairman and professional management capability and leadership } \\
\text { of the CEO of Samsung Electronics and his own vision and goals for } \\
\text { leading the company and implementing strategy. }\end{array}$ \\
\hline
\end{tabular}

\subsubsection{Organizational culture}

According to senior executive interviewees who had spent most of their working lives with Samsung, Samsung has a very strong organizational culture. The principle of Samsung's management spirit (high-challenging, goal-oriented, seeking to be number one, and best compensation for the best performance and best people) was started and built by the founder and former chairman, B.C. Lee, and continued by the current chairman, K.H. Lee.

In keeping with the unique Samsung culture, Chairman K.H. Lee developed his vision and management philosophy, which prioritizes quality management, creativity, design, and customer orientation. Under the umbrella of the Samsung Group's organizational culture, each of the Samsung companies has its own distinct culture. Samsung's principal spirit and main values are as follows: (1) to respect people as the major assets of the company and give them opportunities to do their best; (2) to seek excellence, endless passion, and challenge to become the world's best; (3) to embrace change and innovation for the survival of the company; (4) to 
seek co-prosperity, taking the role of corporate citizen for the good of the nation, society, and all people; and (5) to prioritize integrity. A senior advisor and former CEO of a Samsung company noted "Recently, Samsung has tried to change its culture to be more open and flexible, to adapt to the fast-changing environment and to accept diversity and various opinions and ideas of employees of various functions and layers". The Group Chairman continually emphasizes his key message to all Samsung people: "Without continuous change and innovation, even Samsung may not survive. With such a strong drive toward change and innovation, Samsung Electronics was able to grow into the company we know today". The main characteristics of the organizational culture of Samsung Electronics are summarized below based on the interviews.

\section{a. People- orientation}

Most of the interviewees' comments show a consensus about the people-oriented management principle of Samsung.

Samsung considers people as the most important resources of the company, and respects people and provides opportunities to do their best.

The company strongly motivates people with the best compensation for the best people for high performance. Samsung people are doing their jobs with a strong psychological ownership with clear roles set for each function and position.

Following its people-oriented management goals and principles, Samsung Electronics implemented continuous investments in people and talent development for decades. At the same time, Samsung actively recruited global top talent from outside of Korea.

The Samsung Group's culture and environment provide support for implementing integrated human resources development and human resources management programs empowering people do their best to meet the company's vision and goals. Samsung Electronics and each of the Samsung group companies run their own talent development programs simultaneously with the Group-level programs so that all employees follow the lifelong learning principle of Samsung Group management.

\section{b. Challenge-seeking}

Most interviewees mentioned the strongly goal-oriented Samsung culture.

The Group Chairman sets a high challenge-seeking vision and goals for the 
Samsung Group and Samsung Electronics, and shares his vision and goals with all executives and members of Samsung.

In combination with the long-term vision of the Samsung Group Chairman, the CEO of Samsung Electronics sets high-challenging goals and implementation plans for the company and for each business division.

Highly motivated people take goal-oriented, challenging action and utilize their best capabilities to achieve the goals of the company. Samsung has a special Samsungstyle performance evaluation and compensation system, which motivates people to do their best for achieving company goals.

\section{c. Innovation}

According to a senior interviewee, Samsung Electronics implemented PI management, a special process innovation program focusing on 3Ps (people, products, processes) to follow the Group Chairman's management principle of quality-oriented management, which he emphasized at the Frankfurt conference. A few interviewees mentioned that the management of Samsung Electronics has tried to change its organizational culture to become more open and boundary-less, enabling people to become more innovative and creative.

The Samsung Group's leader constantly emphasized continuous change and innovation of products, services, and work processes.

Once creative and innovative new ideas and new business plans are developed and accepted by the management, Samsung's organizations implement the accepted plans effectively and rapidly, as Samsung's organizational culture includes productive teamwork systems and a strong capability for rapid implementation.

\section{d. Controlling}

Interviewees' opinions on the managing and controlling aspect of Samsung's organizational culture were generally in consensus. One respondent mentioned that

The chairman delegates management responsibility to the CEO of Samsung Electronics and other Samsung-affiliated companies. The CEO of Samsung Electronics delegates operating responsibilities to each business division leader. Samsung operates very effective and precisely organized controlling functions 
and systems, and clearly sets the roles of each organization.

Another described Samsung's "well-combined delegation of management responsibility and performance-monitoring and evaluation systems". He also mentioned that “today's leader of Samsung Electronics tries to build a more open and non-bureaucratic organizational culture for empowering people and for building a highly effective knowledge-productive organizational culture". The CEO of Samsung Electronics manages the company with his own leadership style, open and boundary-less communication, empowering and motivating people while following the Chairman's direction to achieve his long-term vision and goals.

\section{e. Boundary-less}

A few interviewees mentioned that the company's organizational culture should be changed further to become more open and to accept people's opinions and ideas even more openly and freely to foster creativity. An inflexible one-way culture still exists, and creative opinions of low-level employees are not yet efficiently communicated to the management levels. Samsung Electronics' management therefore desires to build a more open culture. As one interviewee explained, "Samsung's organizational culture has been changing to become more open and boundary-less, and less top-down".

\section{f. Other observations from the interviews}

The two-tops leadership structure of Samsung has created a strong organizational culture. As previously explained, the management and leadership style of Samsung Electronics and other Samsung Group companies is a unique "two-tops leadership" system, combining fundamental Samsung principles, management philosophy, high-challenging long-term vision of the Group Chairman, and the leadership of the professional management, the CEO of Samsung Electronics, with his vision and goals for the company. The organizational culture of Samsung Electronics under this two-tops leadership structure has created a strong, goal-oriented, hard-working atmosphere with tension to achieve the company goals. Table 5.6 summarizes the findings of this study concerning organizational culture for Samsung. 
Table 5.6 Summary of organizational culture

\begin{tabular}{|c|c|}
\hline Characteristics & Descriptions \\
\hline People-oriented & $\begin{array}{l}\text { People-oriented culture and top priority for human resources and } \\
\text { talent development with life-long learning culture. Strong psychological } \\
\text { ownership of employees as a result of effective people empowerment. }\end{array}$ \\
\hline Challenge- seeking & $\begin{array}{l}\text { High challenge-seeking vision and goals of Group Chairman are shared } \\
\text { by the organization members and being implemented most effectively by } \\
\text { the CEO and leaders of each business divisions. }\end{array}$ \\
\hline Innovation & $\begin{array}{l}\text { Seeking continuous change and innovation of all works processes, } \\
\text { products and services for sustainable growth. }\end{array}$ \\
\hline Controlling & $\begin{array}{l}\text { Unique two-tops controlling and management system. Delegation } \\
\text { of management responsibilities to each business leader. Effective } \\
\text { combination of efficient top-down and bottom-up decision making. }\end{array}$ \\
\hline Boundary-less & $\begin{array}{l}\text { Changing culture toward more open and boundary-less to foster a more } \\
\text { creative and knowledge productive organizational culture to utilize } \\
\text { people's brains and knowledge more effectively. }\end{array}$ \\
\hline
\end{tabular}

\subsubsection{Knowledge productivity}

Continuous improvement and radical innovation of products, services, and work processes (KP1) (Kessels et al., 2011) are essential to the success of Samsung Electronics. The goal-oriented company vision, in which seeking to be number one is emphasized, accelerated creative knowledge and new idea development. Samsung's leadership philosophy and principles of management (continuous change, innovation, and continuous improvement of products and processes) built today's strong company. For example, J.Y. Yoon, former CEO and vice chairman of Samsung Electronics, once burnt the entire mobile phone stock at a factory when a quality problem arose just to follow Samsung's philosophy of quality management. This case demonstrated the strong Samsung culture of learning by doing.

Continuous high challenging development of future oriented new products and new businesses (similar as KP2) (Kessels et al., 2011) enabled Samsung Electronics employees to learn, improve, and innovate for sustainable future growth. The Group leader requires fundamental change and continuous innovation for corporate survival. The company initiated the "Knowledge Factory" concept programs to further effective new knowledge development and sharing of newly developed knowledge and ideas within the company for building a knowledge-productive organization.

A few interviewees mentioned that Samsung Group management places high priority on lifelong learning programs for human resources development. In total, 12 human 
resources development institutions are operated by the Samsung Group. In addition, all Samsung Group companies run their own training and talent development programs simultaneously for all employees. They emphasized that these development programs based on the lifelong learning principle enhanced knowledge productivity in the Samsung Group. However, knowledge productivity has not yet reached the company's goal; therefore, further efforts and more focus on knowledge productivity are needed to meet the high-challenging goals of the Group leader.

Former Chairman B.C. Lee, the founder of the Samsung Group, and current chairman K.H. Lee both have the unique characteristic of thinking and analyzing continuously until they find causes and solutions for the main challenging issues. They overcome difficulties and create opportunities with their analytical style.

Chairman K.H. Lee is continuously thinking and asking "why". This thinking habit, questioning "why", and analyzing reasons and solutions became the most systematic and creative thinking tool of Samsung management. Executives of Samsung had to be prepared to answer those fundamental questions.

A senior interviewee mentioned that most CEOs of Samsung companies (including Samsung Electronics) probably have the world's best capabilities for developing and implementing action plans to achieve the high-challenging vision and goals of the company, as given by the Group Chairman. Table 5.7 summarizes the findings of this section.

Table 5.7 Summary of knowledge productivity

\begin{tabular}{l|l}
\hline Characteristics & Descriptions \\
\hline $\begin{array}{l}\text { Continuous } \\
\text { improvement and radical } \\
\text { innovation } \\
\text { (KP1) }\end{array}$ & $\begin{array}{l}\text { Group leader and Samsung Electronics management strongly driving } \\
\text { "continuous changes and innovation" and "continuous improvement } \\
\text { of products and processes". Strong culture for learning by doing. }\end{array}$ \\
$\begin{array}{l}\text { Sustainable development } \\
\text { of future growth engine } \\
\text { (KP2) }\end{array}$ & $\begin{array}{l}\text { Group leader strongly emphasizes radical changes and continuous } \\
\text { innovation for survival and sustainable growth. Efficient knowledge } \\
\text { sharing and productive knowledge utilization for future growth. }\end{array}$ \\
$\begin{array}{l}\text { Other observations } \\
\text { Life-long learning programs for human resources development } \\
\text { with "Knowledge Factory" concept of Group chairman. Top priority } \\
\text { for best talent and human resources development result in a high } \\
\text { knowledge-productive organization. }\end{array}$ \\
\hline
\end{tabular}




\subsubsection{Value creation}

\section{a. Corporate reputation, image, and CSR}

Samsung Electronics maintains the highest corporate reputation and image in Korea and in the world, offering high-quality products and services and sustaining high growth in revenue, net profit, and market value as a result of successful management. According to a senior interviewee, the Group Chairman's leadership gave clear direction and long-term vision to Samsung people, demanding continuous challenges for high value creation of Samsung Group companies, including Samsung Electronics.

Other interviewees explained that Samsung continuously fostered a strong work environment where people could perform to the best of their capabilities to achieve the vision and goals of the company. The Group Chairman appointed top quality professional management to the CEO positions and provided sufficient time and support for implementing their business plans to achieve the company goals and objectives. A strong goal-oriented performance evaluation system supported the achievement of significant growth in sales, profit, and market value during the past decades. As a result, the company maintained the highest reputation and corporate image, and investors and the market show confidence in the quality of management. Regarding corporate social responsibility (CSR), as part of the Samsung Group's and Samsung Electronics' important management principles and spirit, the company contributes to society and humanity by providing the best products and best services with the best people and technology. Samsung Electronics continuously invests to support major culture and sports programs and other social programs. Samsung Electronics implemented special collaboration and joint cooperation programs with cooperative firms of value chain (suppliers of parts and components).

b. Employee satisfaction with work environment and financial benefits

Employee satisfaction at Samsung Electronics is very high. However, the work environment is not easy, as workers must do their best to meet the high performance goals of the company. The company strongly motivates people with high-level financial benefits and compensation based on performance. Samsung people strive to do their best for the company vision with a strong psychological ownership.

\section{c. Sustainability}

The company achieved sustained high growth in sales, net profit, and market value during the research period (from 2000 to 2010), as Table 5.5 shows. According to an executive interviewee, sustainable capability is aided by the strong two-tops 
leadership structure of Samsung Electronics, which is a combination of the highchallenging leadership of the Group Chairman and the professional management capability of the CEO of Samsung Electronics.

\section{d. Financial data on 10-year performance}

Table 5.8, Figure 5.1, and Figure 5.2 respectively show the information about the sales, net profit, and market value of Samsung Electronics from 1990 to 2010 and the comparison of sales with the top ten Korean companies in the electronics industry. Data on net profit, revenue/sales, and market value of Samsung Electronics were collected from the annual reports of the company filed with the Korea Stock Exchange. The Korea Industry Research Institution provided data on net profit, revenue, sales, and market value of the top 100 companies, from which the top ten companies in the electronics industry were selected for comparison.

Although Samsung Electronics felt the significant negative impact of the global financial crisis in 2008, the company recorded stable growth in sales and showed a positive performance in terms of net profit and return on sales. In fact, Samsung Electronics sales in the global market grew significantly from 2000 to 2010, while domestic sales were stable. This indicates that Samsung management strongly focused on globalization. 
Table 5.8 Net profit, sales, and market value of Samsung Electronics (1990-2010)

Unit: billion (KRW), percentage (\%), person (number)

\begin{tabular}{lrrrrrrrr}
\hline & $\mathbf{1 9 9 0}$ & $\mathbf{2 0 0 0}$ & $\mathbf{2 0 0 2}$ & $\mathbf{2 0 0 4}$ & $\mathbf{2 0 0 6}$ & $\mathbf{2 0 0 8}$ & $\mathbf{2 0 0 9}$ & $\mathbf{2 0 1 0}$ \\
\hline Sales & 4,511 & 34,283 & 39,813 & 57,632 & 58,972 & 72,953 & 89,772 & 112,249 \\
-Domestic & & 10,903 & 11,075 & 10,036 & 10,748 & 13,656 & 14,973 & \\
-Overseas & & 23,380 & 28,738 & 47,595 & 48,224 & 59,396 & 74,798 & \\
Operation profit & & 7,435 & 7,478 & 12,016 & 6,933 & 4,134 & 6,348 & 14,924 \\
Net profit & 73 & 6,014 & 7,051 & 10,786 & 7,916 & 5,525 & 9,649 & 13,236 \\
ROS & $1.62 \%$ & $17.54 \%$ & $17.71 \%$ & $18.72 \%$ & $13.42 \%$ & $7.57 \%$ & $10.75 \%$ & $11.79 \%$ \\
Employee & 43,500 & 43,996 & 48,421 & 61,899 & 85,813 & 84,462 & 85,085 & 95,659 \\
Market Value & 1,205 & 23,895 & 47,958 & 66,358 & 90,294 & 66,432 & 117,692 & 134,640 \\
\hline
\end{tabular}

- Samsung Electronics was listed in 1975

- Market Value based on year-end stock price

- Financial data based on HQ operations only, overseas operations not included

Figure 5.1 Net profit, sales, and market value of Samsung Electronics (1990-2010)

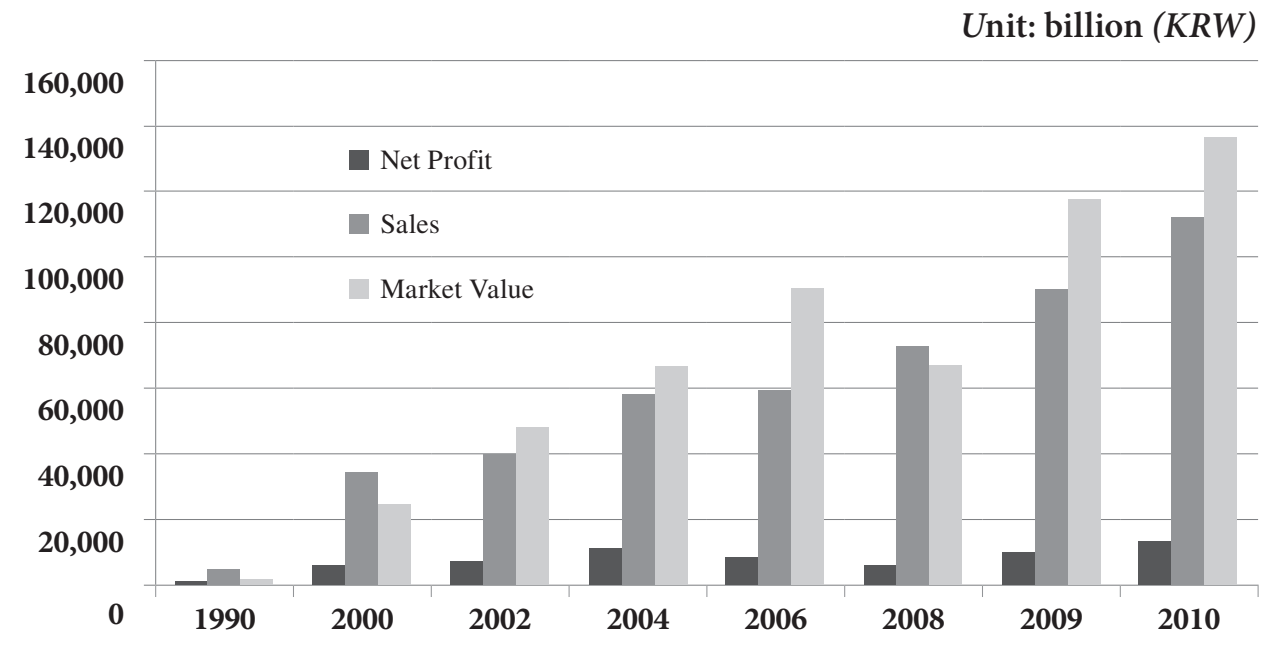

Figure 5.1 provides data regarding the net profit, sales, and market value of Samsung Electronics from 1990 to 2010. All indicators improved continually except in 2008 due to the impact of global financial crisis in that year. 
Figure 5.2 Sales of Samsung Electronics compared with the average sales of the top 10 Korean companies, including LG Electronics and excluding Samsung Electronics (20002010).

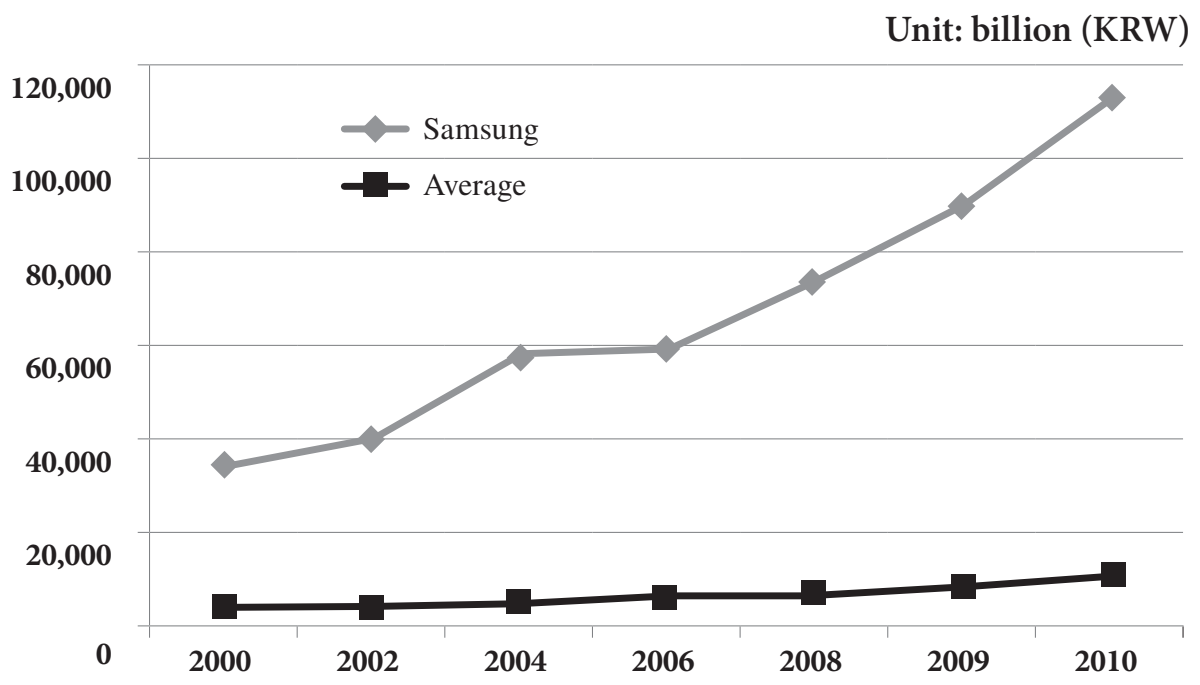

Figure 5.2 shows the relative increase in sales of Samsung Electronics over the period (2000-2010) compared to those of the average top 10 Korean electronics companies for the same period. Samsung's sales were three times higher than the average sales of the top 10 Korean electronics companies (except Samsung) in 2000, and ten times higher in 2010. Table 5.9 summarizes the findings of this section. 
Table 5.9 Summary of value creation

\begin{tabular}{l|l}
\hline Characteristics & Descriptions \\
$\begin{array}{l}\text { Management } \\
\text { quality }\end{array}$ & $\begin{array}{l}\text { Group chairman's leadership gave clear direction and significant impact to the } \\
\text { people demanding continuous challenges for value creation. }\end{array}$ \\
$\begin{array}{l}\text { Corporate social } \\
\text { responsibility }\end{array}$ & $\begin{array}{l}\text { Continuing corporate social service activities. Special collaboration and joint } \\
\text { cooperation programs with cooperative firms of value chain (suppliers of } \\
\text { parts and components). Substantial contribution to social culture activities. }\end{array}$ \\
$\begin{array}{l}\text { Employee } \\
\text { satisfaction }\end{array}$ & $\begin{array}{l}\text { High level employee satisfaction with good compensation system based on } \\
\text { performance. Highly motivated people. }\end{array}$ \\
$\begin{array}{l}\text { Corporate } \\
\text { reputation and } \\
\text { image }\end{array}$ & $\begin{array}{l}\text { Highest reputation and image in Korea and in the world with high quality of } \\
\text { products and services, and continuous high growth in market value. }\end{array}$ \\
$\begin{array}{l}\text { Performance } \\
\text { Other } \\
\text { observations }\end{array}$ & $\begin{array}{l}\text { Outstanding performance based on financial data records: } \\
\text { sales, net profit and market value grew significantly as a result of successful } \\
\text { management. } \\
\text {-Sales growth: 24.9 times (1990-2010) KRW 112,249 Bil } \\
\text {-Net profit growth: 181.3 times (1990-2010) KRW 13,236 Bil } \\
\text {-Market value growth: } 5.7 \text { times (2000-2010) KRW 136,640 Bil } \\
\text { goal-oriented leadership gave strong pressure on CEOs, executives, and } \\
\text { managers to do their best to achieve high-challenging performance goals. }\end{array}$ \\
\hline
\end{tabular}

\subsection{Conclusion of Samsung Electronics case study}

Samsung Electronics achieved sustained high growth from 1990 to 2010: 2,488\% growth in sales, $18,132 \%$ growth in net profit, and $11,173 \%$ increase in market value. During the 10-year research period (2000-2010), Samsung Electronics achieved significant high value creation, $327 \%$ growth in sales, $220 \%$ increase in net profit, and $564 \%$ growth in market value.

Samsung Electronics has continuously grown, despite tough global competition in the high-technology electronics and communication industries, to become a leader in the world electronics industry today. Several years ago, Samsung Electronics' CEO mentioned that his long-term challenging goal was to catch up to the world 
leaders and top Japanese electronics companies. Today, Samsung Electronics is ahead of those target companies. It has become the world leading company in the electronics industry.

The main purpose of this empirical research on Samsung Electronics was to explore relationships among key variables (leadership, organizational culture, knowledge productivity, and value creation) using both qualitative analysis and quantitative analysis based on the conceptual framework of the research model. Another goal was to define desirable leadership styles for improving and upgrading knowledge productivity and achieving high value creation. The findings of the qualitative analysis, which involved interviews with management, executives, and managers, indicated that Samsung's people-oriented leadership spirit and philosophy originated in the founder of Samsung, the late B.C. Lee, who valued people's creative knowledge and talent as the most important assets of the company. Continuing this people-oriented leadership spirit, the current Samsung chairman led radical innovation and change, communicating a challenging vision and goals and building a highly knowledge-productive organizational culture. Samsung's high-challenging leadership and organizational culture and high knowledge productivity became a strong base for sustained high value creation and sustained growth of Samsung Electronics.

Through effective communication systems, the Samsung Group leader's highchallenging vision and goals are effectively shared with all Samsung Electronics people, creating a unique, high-challenging, innovative, and strong performanceoriented organizational culture where people bring out their best capability to achieve company goals and performance objectives. In this knowledge-productive organizational culture, advanced and high knowledge productivity continuously improved and innovated products, services, and work processes (KP1) of the company, establishing strong sustainable capability and accelerated sustainable development of future growth engine(KP2), which became a strong base for Samsung Electronics' high growth and sustainable value creation.

The findings from the quantitative analysis of survey data for Samsung Electronics indicate that the four major factors, the leadership styles of the Samsung Group chairman and Samsung Electronics' CEO, organizational culture, knowledge productivity, and value creation are positively correlated. These findings also support the findings of the qualitative analysis of the interview data.

These leadership and organizational culture characteristics are positively related to knowledge productivity (improvement and innovation of products, services, and work processes, KP1; and sustainable development of future growth engine, KP2. 
These leadership characteristics, organizational culture characteristics, and knowledge productivity of Samsung Electronics have significantly positive relationships with the following key value creation factors: corporate reputation, image, and CSR (VC1), employee satisfaction with work environment (VC2), employee satisfaction with financial benefits (VC3), and sustainability (VC4). Financial performance data of Samsung Electronics, which result from value creation, also shows continuous stable growth of sales, net profit, and market value for the past 10 years (2000-2010). Samsung Electronics shows outstanding performance compared to the successful top 10 Korean companies in the same industry during the same period. This Samsung Electronics case study indicates a strong correlation between the combination of certain leadership characteristics (high-challenging, visionary, valuing entrepreneurship and taking risks, and people-oriented) with high knowledge productivity and value creation.

Under the unique two-tops leadership structure of Samsung, although the Group Chairman delegated management responsibilities to the CEOs of Samsung companies, including Samsung Electronics, his high-challenging vision and strong, goal-oriented, performance-driving leadership direction are well respected and shared by the CEO of Samsung Electronics and other company executives. All CEOs and executives are willing to put in their best effort with professional management capabilities to achieve the Chairman's vision and performance goals. The dynamic working environment for achieving the Chairman's vision and performance goals resulted in fast growth and continuous improvement in market leadership position due to high performance. The Group Chairman's indirect control through a special staff organization called the "Future Strategy Planning Organization" (formerly the Group Secretarial Office) is a unique Samsung Group management system.

However, a few senior executive interviewees expressed their concern that for sustainable future growth and creation of new innovative business ideas in hightechnology competitive global markets, the current strong performance-driven organizational culture and work environment my hinder people from becoming more creative and innovative for future growth. According to the interviewees, the $\mathrm{CEO}$ and senior management of Samsung Electronics also recognize this issue. Therefore they are trying to create a more open, boundary-less organizational culture with freedom for people to be creative and innovative. 
High challenging, Visionary, Charismatic Empowering people, Delegation, Entrepreneurship

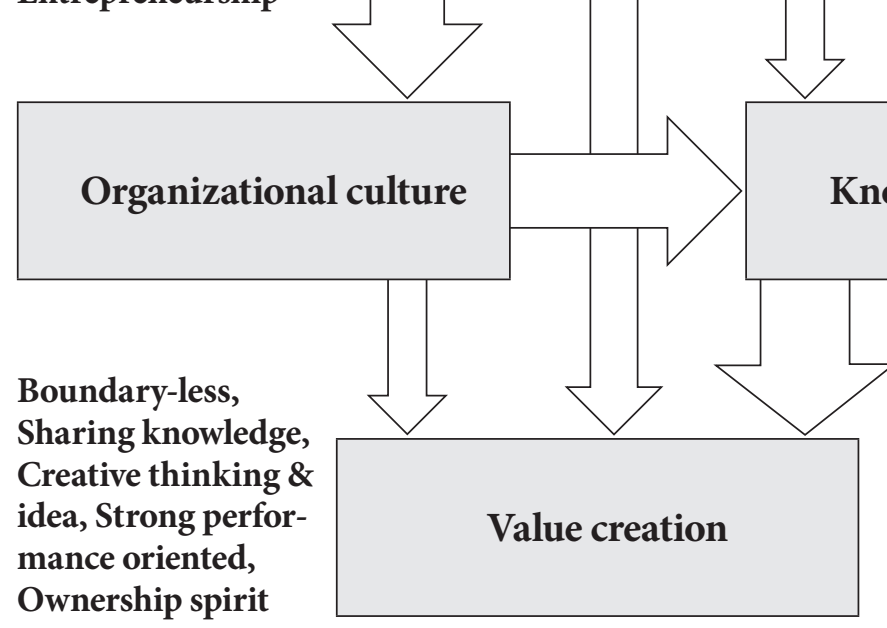

Continuous improvement \& innovation of products, services, work processes(KP1)

Sustainable development of future growth engine(KP2)

Figure 5.3 Summary of the related four main variables of the Samsung Electronics case study

In the case of Samsung Electronics, significant interactions are evident among the four main variables, as shown in Figure 5.3. Leadership style has a significantly positive relation with organizational culture (as the thicker arrow shows), organizational culture has a significantly positive relation with knowledge productivity (as the thicker arrow shows), and knowledge productivity has a significantly positive relation with value creation (as the thicker arrow shows). Leadership style impacts knowledge productivity more significantly through organizational culture, and also has a case-by-case direct impact on knowledge productivity depending on the subject matter and the leader's understanding. Leadership style impacts value creation significantly through organizational culture and knowledge productivity, although this impact is indirect.

The leadership style of the chairman of the Samsung Group is close to the A type leadership of the research model, while that of the CEO of Samsung Electronics is close to the B type leadership of the research model. Samsung is an effective combination of those two leadership styles, A and B. From the findings of the empirical research on the Samsung Electronics case, we learn that Samsung 
Electronics' leadership characteristics (people-oriented, visionary, entrepreneurial, highly challenging and risk taking) and organizational culture characteristics (people-oriented, high challenge-seeking, innovative, and performance-oriented) are closely correlated. Samsung Electronics' leadership characteristics, high knowledge productivity, high value creation, and sustained growth capability are significantly and positively correlated. These research findings provide building block for the answers to the main research questions of this study. Table 5.10 summarizes the findings of this case study.

This case study report was sent to the participants for validation. On the basis of the report, the researcher organized feedback discussions with senior management. In response to the feedback, some minor changes and additions were made in the case report.

Table 5.10 Summary of the Samsung Electronics case in terms of the four main variables

\begin{tabular}{l|l}
\hline Characteristics & Descriptions of key common characteristics of the four factors \\
\hline $\begin{array}{l}\text { Leadership } \\
\text { Style }\end{array}$ & $\begin{array}{l}\text { People-oriented: developing the best people for the best company. } \\
\text { Vision for building the world's leading integrated digital company. } \\
\text { High challenge-seeking and risk-taking entrepreneurship. } \\
\text { Two-tops leadership structure: Combination of Group chairman's high } \\
\text { challenging long term vision and professional management leadership of the } \\
\text { best CEO. }\end{array}$ \\
$\begin{array}{l}\text { Organizational } \\
\text { Culture }\end{array}$ & $\begin{array}{l}\text { People-oriented culture with high priority for human resources and talent } \\
\text { development. Delegation of responsibility with unique indirect control } \\
\text { system. High challenge-seeking and strong goal and performance-oriented } \\
\text { culture under the two-tops leadership structure. Seeking continuous changes } \\
\text { and innovation. Strong learning culture. }\end{array}$ \\
$\begin{array}{l}\text { Knowledge } \\
\text { Productivity }\end{array}$ & $\begin{array}{l}\text { Group leader's strong desire for advanced knowledge productivity for building } \\
\text { top competitive leading company, and active development of future oriented } \\
\text { new products for sustainable growth. Demanding continuous radical change, } \\
\text { innovation, and improvement of products, services and work processes. }\end{array}$ \\
Value Creation & $\begin{array}{l}\text { Achieved most successful sustained growth and high value creation for the } \\
\text { past 10 years. Bypassed world leading top competitors and became the world } \\
\text { top leading company in the electronics industry today. }\end{array}$ \\
\hline
\end{tabular}





\section{Chapter 6. Findings from the case studies: WoongJin Group}

\subsection{General overview}

The WoongJin Group has a unique history of growth and business diversification. It started as an education and publication business in 1980 and expanded into many different areas, such as healthcare, food and beverage, and the chemical, finance, and construction industries. Recently, the Group made a significant investment in the high-technology solar energy industry. The founder and chairman of the Group is a highly people-oriented, high-challenging, entrepreneurial leader who has created an open and innovative organizational culture in which people are empowered to do their best to achieve company goals with a strong psychological ownership. Under the high-challenging visionary entrepreneurship of the founder and leader and the empowered professional management team, the WoongJin Group has grown into a top 30 company in Korea in the past 30 years. Sales grew 3,630\% and net profit increased $4,880 \%$ from 1990 to 2010 . The WoongJin Group was therefore selected as a case study for this research. A general overview of the company is provided in Table 6.1.

Table 6.1 General overview

\begin{tabular}{l|l}
\hline $\begin{array}{l}\text { Background } \\
\text { of WoongJin }\end{array}$ & Description \\
\hline Founding & $\begin{array}{l}\text { Founded education business in } 1980 \text { as Heim International by Seok-Keum } \\
\text { Yoon, current chairman. Changed company name to WoongJin ThinkBig in } \\
\text { 1983. Since then, WoongJin continued to grow and expand into several different } \\
\text { industries, becoming a highly successful medium-to-large-sized business group. }\end{array}$ \\
\hline $\begin{array}{l}\text { Types of } \\
\text { industries } \\
\text { and } \\
\text { subsidiary } \\
\text { companies }\end{array}$ & $\begin{array}{l}\text { WoongJin Holdings (Total: 15 companies) } \\
\text { Woongjin ThinkBig (Education/Publication) } \\
\text { Booxen (Education/Publication) } \\
\text { WoongJin Coway (Environment/Healthcare) } \\
\text { WoongJin Foods (Food and beverage) } \\
\text { WoongJin Chemical (Materials) } \\
\text { WoongJin Capital (Finance/Service) } \\
\text { WoongJin ST (Finance/Service) } \\
\text { Kukdong Construction (Construction/Leisure) } \\
\text { WoongJin Playdoci (Construction/Leisure) } \\
\text { WoongJin Energy (Solar energy) }\end{array}$ \\
\hline
\end{tabular}




\begin{tabular}{|c|c|c|c|}
\hline $\begin{array}{l}\text { Number of } \\
\text { Employees } \\
(2010)\end{array}$ & $10,144(2010)$ & & \\
\hline \multirow[t]{7}{*}{$\begin{array}{l}\text { Financial } \\
\text { status } \\
(2010)\end{array}$} & $\begin{array}{l}\text { WoongJin Group } \\
(2010)\end{array}$ & KRW & $\mathrm{US}(\$)$ \\
\hline & Sales & 5,373 bil & $4,797 \mathrm{mil}$ \\
\hline & Domestic sales & 4,434 bil & 3,959 mil \\
\hline & Overseas sales & 938 bil & $838 \mathrm{mil}$ \\
\hline & Net profit & 244 bil & $218 \mathrm{mil}$ \\
\hline & ROS $4.55 \%$ & & \\
\hline & Market value & 6,069 bil & $5,418 \mathrm{mil}$ \\
\hline $\begin{array}{l}\text { Overseas } \\
\text { operations }\end{array}$ & \multicolumn{3}{|c|}{$\begin{array}{l}\text { U.S.A., China, Hong Kong, Japan, Malaysia, Indonesia, India, UAE, } \\
\text { Cambodia, Vietnam, Netherlands }\end{array}$} \\
\hline
\end{tabular}




\subsection{Quantitative analysis of survey data}

\subsubsection{Demographic characteristics}

Data on the WoongJin Group was collected from a survey conducted in Korea. In total, 117 respondents from the WoongJin Group completed the questionnaires (out of 120 questionnaires distributed). The sample characteristics are summarized in Table 6.2 below.

Table 6.2 Characteristics of survey respondents

\begin{tabular}{lccc}
\hline \multicolumn{1}{c}{ Parameter } & Percentage (\%) & \multicolumn{1}{c}{ Parameter } & Percentage (\%) \\
\hline Gender & \multicolumn{3}{c}{ Rank } \\
$\quad$ Male & 82.9 & Employee & 16.2 \\
$\quad$ Female & 17.1 & Assistant manager & 6.8 \\
Age & & Manager & 27.4 \\
$\quad<$ 30 years & 17.9 & Senior manager & 16.2 \\
31-40 years & 31.6 & Executive & 33.3 \\
41-50 years & 36.7 & Education level & \\
$\quad>\mathbf{5 1}$ years & 13.8 & High school & 0.9 \\
Tenure & & College & 0.9 \\
$\quad<$ years & 33.3 & Bachelor's degree & 78.6 \\
6-10 years & 23.9 & Master's degree & 16.2 \\
$>$ 11 years & 42.8 & Doctorate degree & 3.4 \\
\hline
\end{tabular}

Among the respondents, $\mathbf{8 2 . 9 \%}$ were male, which is similar to the proportion of males among all employees of the WoongJin Group. The proportions of managers (27.4\%) and senior managers (16.2\%) are higher because more questionnaires were distributed to managers, as they could understand and respond better regarding the four key variables (leadership, organizational culture, knowledge productivity, and value creation). 


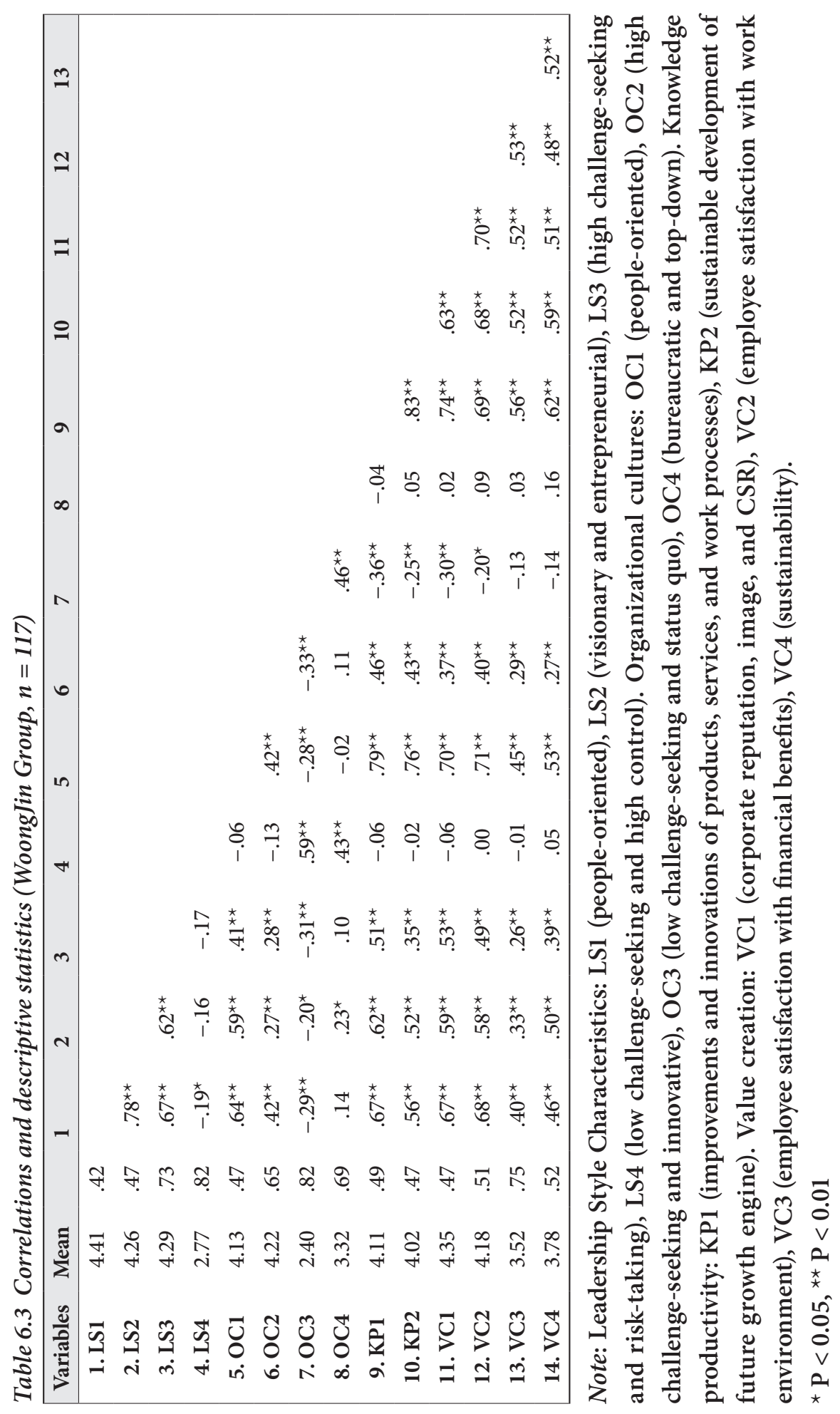




\subsubsection{Relations among key variables}

Statistical analysis was performed using the survey data collected from 117 respondents of the WoongJin Group. Financial performance (e.g., revenue and net profit growth, market value increase) is not included in this quantitative analysis, as the financial data are reported separately in section 6.3.4. Table 6.3 shows means, standard deviations, and correlations among the variables examined using the survey data collected from these respondents.

The results of the correlation analysis indicate that the leadership characteristics of the WoongJin Group (people-oriented, LS1; visionary and entrepreneurial, LS2; and high challenge-seeking and risk-taking, LS3) have significantly positive correlations with knowledge productivity in terms of improvements and innovation of products, services, and work processes (KP1) and sustainable development of future growth engines (KP2). No positive relationship was found between leadership characteristics (low challenge-seeking and high-control, LS4) and knowledge productivity. Similarly, the leadership characteristics (people-oriented, LS1; visionary and entrepreneurial, LS2; and high challenge-seeking and risk-taking, LS3) have significantly positive correlations with the value creation factors (corporate reputation, image, and CSR, VC1; employee satisfaction with work environment, VC2; employee satisfaction with financial benefits, VC3; and sustainability, VC4). No correlation was found between the last leadership characteristic (low challengeseeking and high-control, LS4) and value creation. In addition, organizational culture characteristics (people-oriented, OC1; and high challenge-seeking and innovative, OC2) have significantly positive correlations with knowledge productivity in terms of improvement and innovation of products, services, and work processes (KP1) and sustainable development of future growth engines (KP2). However, significantly negative correlations were seen between two organizational culture characteristics (low challenge-seeking and status-quo, OC3; and bureaucratic and top-down control, OC4) and knowledge productivity. Also, significant positive relationships were observed between the two other organizational culture characteristics (people-oriented, OC1; and high challengeseeking and innovative, OC2) and the value creation factors (corporate reputation, image, and CSR, VC1; employee satisfaction with work environment, VC2; employee satisfaction with financial benefits, VC3; and sustainability, VC4). Finally, significantly positive correlations were found between knowledge productivity in terms of improvements and innovations of products, services, and work processes (KP1) and sustainable development of future growth engines (KP2) and all four value creation factors (corporate reputation, image, and CSR, VC1; employee 
satisfaction with work environment, VC2; employee satisfaction with financial benefits, VC3; and sustainability, VC4).

However, several leadership and organizational culture characteristics are not evident in the Woongjin Group: low challenge-seeking and high-control (LS4), low challenge-seeking and status quo (OC3), and bureaucratic and top-down control (OC4). These leadership and organizational culture characteristics were negatively correlated with both knowledge productivity and value creation.

The results of the statistical analysis of the WoongJin Group case indicate that both its leadership characteristics (LS1, LS2, and LS3) and its organizational culture characteristics (OC1 and $\mathrm{OC} 2$ ) were significantly and positively correlated with both knowledge productivity (KP1 and KP2) and value creation (VC1, VC2, VC3, and VC4). These results positively support the conceptual framework of this study.

\subsection{Qualitative analysis of interview data}

Interviews were conducted with the chairman, two presidents, three managing directors, four general managers, and five managers of the WoongJin Group, for a total of 15 interviewees. Questions on the following subjects were included: management leadership, organizational culture, knowledge productivity, and value creation. Their responses generally showed consensus on these subjects, with the exception of a few opinions, depending upon the business and industry of the WoongJin Group companies.

\subsubsection{Leadership style}

Interviewees' opinions about the leadership style of Group Chairman S.K. Yoon were in consensus. They stated that his visionary and challenge-seeking entrepreneurship had created a unique, open, and energizing organizational culture that can be called "Sinbaram Munhwa" (Exciting Wind-Blowing Culture), where people are highly motivated and empowered and enjoy their work with strong psychological ownership. Other comments were as follows.

Our chairman has endless passion for developing and growing futuristic businesses, demonstrating strongly charismatic leadership with an open mind and respecting organization members and their opinions.

He is always thinking positively. His vision and goals for the company and management principles are widely shared and well accepted by WoongJin people, 
as we respect him from the heart.

Our leader likes direct open communication with employees at various levels. Most importantly, he invests significant time in boundary-less communication. He listens to the people in the company and respects their opinions.

Because of his long business experience in the field as the founder of most of the WoongJin businesses, his inspiration and insights into WoongJin businesses, combined with the passion and psychological ownership of the highly empowered WoongJin people, the WoongJin Group has become a highly respected success model of people-oriented management.

The interviewees described Chairman Yoon's leadership style as open, highly visionary, endlessly challenge-seeking, strongly charismatic, and highly peopleoriented.

\section{a. People-orientation}

Interviewees characterized the Chairman's leadership style as unique, peopleoriented, humanitarian, high-challenging, and charismatic. WoongJin's open organizational culture has benefited from this leadership style. One respondent stated that "Our Chairman's trademark message to all WoongJin people is 'To-ToSarang', which means 'love and love always', embracing fellow workers, colleagues, and customers as partners, and cooperating with all people”. “To-To-Sarang" has become the slogan of WoongJin's people-oriented organizational culture and teamwork mentality. The leader prioritizes sharing his vision and dream among all WoongJin people and working together to realize them.

Another word unique to WoongJin, "Sinbaram-Kyungyung" (Exciting WindBlowing Management), means a management style that is exciting, like the wind blowing, a style that makes people enjoy and be excited by working together with their fellow workers and customers. Under this unique people-oriented organizational culture and leadership, WoongJin employees are highly excited and empowered. They enjoy their work with a strong psychological ownership, sharing their vision of the company with fellow co-workers and joining the leadership of the company to realize their shared dream. One employee celebrated the fact that the Chairman "trusts people and respects their opinions, and fully delegates responsibility". Other comments were as follows. 
These unique "WoongJin Way" programs were initiated by chairman Yoon and executed continuously throughout the WoongJin Group companies, and came to represent WoongJin's culture and working environment.

Our leader has in-depth understanding of each employee's talent and character, and utilizes human resources and people talent in the right way. His motto is "the right person for the right place". He respects people as human beings and values people's opinions.

Although he fully delegated responsibilities to the CEOs of each WoongJin company, they respect and follow the Chairman's long-term vision and goals and WoongJin's management principle and philosophy.

These interviewees' comments and opinions indicate that under the unique peopleoriented, open, and organizational culture created by the Chairman's leadership, WoongJin people are highly empowered, motivated, and innovative. The Chairman values delegation of authority and responsibility. However, every WoongJin company is managed under a WoongJin-style two-tops leadership structure combining the leadership strengths of the Group Chairman and those of the CEOs of each WoongJin company.

\section{b. Vision-building}

According to a few senior interviewees, the chairman of the WoongJin Group always seeks high-challenging visions to share with all organization members.

Chairman Yoon always sees the big picture, the long-term, high-challenging vision and goals for the company, which he has shared with every member of the company effectively, and people in WoongJin accept and share the vision as their own. He always thinks positively in his approach.

His vision and goals are very practical and achievable, as he has significant intuition and insight from his long experience of founding and managing all WoongJin's businesses.

With such intuition and insight, he can foresee and forecast the future direction for WoongJin businesses in the fast-changing and difficult business environment, and we respect and trust his judgment. 
In order to share the high-challenging company vision and WoongJin way of thinking and working with all WoongJin people most effectively and directly, Chairman Yoon himself lectures regularly to all company executives and managers in human resources development programs. Through these continuous communication efforts, the WoongJin Group's vision and goals are successfully shared and fostered. These lectures have become the power behind WoongJin.

\section{c. Entrepreneurship}

Chairman Yoon founded an education company in 1980 with a small capital fund of $\$ 60$ thousands and only 7 employees. This small company grew to become today's WoongJin Group, which recorded $\$ 4.2$ billion of annual revenue and employed 9,470 employees in 2009 as a result of the founder's endless high-challenging entrepreneurship, continuous change, and innovation. Respondents provided the following comments about entrepreneurship in the WoongJin Group.

Our high challenge-seeking entrepreneurship-oriented leader enjoys developing and creating new businesses and new opportunities while taking acceptable risks.

He is constantly seeking a better way and emphasizing creative and innovative ways of thinking and new approaches. He encourages people in the company to have self-confidence and to take positive approaches to achieve objectives and goals.

From his long experience of founding and managing all WoongJin businesses, the Chairman himself, with his intuition and inspiration, often comes up with creative new ideas, which he then passes to the responsible CEOs to support the business leaders.

\section{d. Risk taking}

Several interviewees mentioned the Chairman's high-challenging entrepreneurship and willingness to take risks to enter into future-oriented new businesses, such as high-technology polysilicon manufacturing for solar power.

Our leader expanded the business into various different industries by taking significant risks, as he himself had self-confidence in the growing businesses and ability to manage risks, and all those businesses in different industries became 
successful.

Recently he made a significantly large project decision taking the risk to start manufacturing of a high-technology material, polysilicon, for the future growth of solar energy in the power generation industry with an investment of US\$1.0 billion. With this high-risk investment, WoongJin completed building a new high-technology plant and started manufacturing operations within 18 months.

The leader made a high-risk decision to enter a future growth business. He made that decision after careful review and evaluation of potential risks so as to secure confidence in the risk management plan.

\section{e. Control}

WoongJin has two-tops leadership and management structure, a well-balanced combination of the Chairman's long-term futuristic vision and management experience and the relatively young CEOs' passion and professional management skills. WoongJin employees had the following things to say about the company's management style.

Our Chairman delegates management responsibilities completely to the CEO of each WoongJin company. However, as the chairman, he gives clear directions and long-term goals to the CEOs of each company. Those CEOs manage each company business, respecting and following the Chairman's long-term directions and goals.

Our chairman does not control the business directly; however, he regularly holds open conversations with each CEO, and shares his thoughts and opinions for the businesses with them, indirectly managing and controlling through open conversations.

\section{f. Other observations from the interviews}

Chairman Yoon's way of doing business is respected by WoongJin employees. It has become the standard principle for the business practices of the WoongJin Group. Each company selects suppliers and subcontractors through open and transparent processes; they are never selected based on the chairman's personal relations and contacts.

Our chairman maintains a consistent leadership style and management principle and provides direction with a policy of integrity and transparency. 
He never hired people with private connections, such as relatives and people from his home town; he only hired people based on talent and capability through transparent processes. Therefore, our people highly respect him and we are proud of being WoongJin family members.

The leadership style of the Group Chairman is open and non-bureaucratic, strongly people-oriented, empowering people and the organization. Although authority is delegated to each CEO, the Group Chairman selectively participates in key decisionmaking. Findings from the empirical research indicated the leadership style of the Group Chairman is very close to the B-type leadership in the conceptual framework of the research model. The leadership styles of the CEOs of WoongJin Group companies are also close to the B-type leadership, as they are strongly influenced by the Group chairman. Table 6.4 summarizes the findings of this case study on leadership.

Table 6.4 Summary of leadership characteristic

\begin{tabular}{l|l}
\hline Characteristics & Descriptions \\
\hline People-oriented & $\begin{array}{l}\text { People-oriented and charismatic leadership style of chairman. Trusts people } \\
\text { and fully delegates responsibility. Empowering and energizing people. } \\
\text { Strong psychological ownership. }\end{array}$ \\
Entrepreneurship & $\begin{array}{l}\text { Highly challenging long-term vision and goals with a big picture for } \\
\text { the future of the company. Sharing vision with all company employees } \\
\text { effectively. Leading continuous innovation and changes throughout the } \\
\text { company. } \\
\text { challenging business opportunities while taking acceptable risks. }\end{array}$ \\
Risk-taking & $\begin{array}{l}\text { Taking risks for moving into new businesses for future growth. } \\
\text { Well-organized risk management system and operation experience. }\end{array}$ \\
$\begin{array}{l}\text { High-level delegation of authority and responsibility. Two-tier leadership } \\
\text { structure with effective combination of highly challenging leadership of the } \\
\text { Group Chairman and passion and energy of strongly empowered younger } \\
\text { CEOs. }\end{array}$ & $\begin{array}{l}\text { Group Chairman invests significant time and effort for empowering and } \\
\text { education of employees. }\end{array}$ \\
\hline
\end{tabular}




\subsubsection{Organizational culture}

The founder of the WoongJin Group, Chairman Yoon, has created a people-oriented, humanitarian, unique, open organizational culture in which employees are highly empowered and energized and enjoy their work with a strong psychological ownership. One respondent provided the following comment about the organizational culture of WoongJin: "Our chairman constantly emphasizes creative thinking, change, innovation, and challenges for sustainable growth of businesses in the fast-changing competitive environment". Interviewees explained the company's special "Sinbaram" organizational culture, which means "Exciting Wind-Blowing Culture", where employees are excited and enjoy working together with fellow workers, partners, and customers.

\section{a. People-orientation}

WoongJin has a special people-oriented and exciting open culture with two unique cultural concepts: "Sinbaram" and "To-To-Sarang". "Sinbaram" (Exciting Wind-Blowing Culture), 신바람문화 in Korean, is a word that describes an organizational culture in which employees are highly excited, motivated, and empowered to enjoy their work. "To-To-Sarang (Love and Love Always Culture), 또또사랑 in Korean, promotes a loving mind in the organization, showing love toward the company, fellow workers, customers, and partners. Under the unique people-oriented organizational culture of "Sinbaram" and "To-To-Sarang", people in the WoongJin Group share the vision and dreams of the company, enjoying teamwork together. One interviewee described the unique WoongJin culture as follows:

Our culture is family-oriented, and we call our company people the WoongJin family. The paternalistic and family-oriented culture tightened our internal unity and solidarity, but sometimes, too much family-oriented relationship can become a hurdle to open and candid communication, as people hesitate to deliver straightforward negative messages to others and management, between coworkers and team members.

WoongJin strongly emphasizes continuous lifelong learning for selfdevelopment, and offers various human resources development and training programs. Some special programs are run in cooperation with universities, such as the WoongJin MBA program for executive development. 


\section{b. Challenge-seeking}

From the start of WoongJin as a small company, high challenge-seeking and positive thinking characterized its culture. The vision and goals of the company are achieved under the motto "Goal-oriented and Can-Do Thinking". A senior executive interviewee explained the history of WoongJin's high-challenging culture. As the responsibility for management of each business is fully delegated, each business leader is challenged to achieve the company goals and objectives. One respondent described the organizational culture thus:

Our culture is both creative and dynamic, and we are not afraid of challenges in new areas. At the same time, many important new business ideas and projects were initiated by the chairman's intuition and entrepreneurship, and CEOs and executives executed those projects following the chairman's idea, as we respect and trust our leader's inspiration and judgment.

\section{c. Innovation}

According to an executive interviewee, Chairman Yoon has been conveying the following advice to the people in the WoongJin Group regarding innovation:

We should think repeatedly about the same issue until we find a new solution and a new idea. Medium-sized companies could not succeed in competition without creative ideas. We should develop differentiated new products and services which other companies do not have yet. In our organization, anyone can freely recommend a new idea to the company and management, and when the new idea is both creative and workable, it will be accepted and implemented.

\section{d. Control}

Although the Chairman fully delegates management responsibility and authority to the CEOs of WoongJin Group companies, those managers of WoongJin companies manage their businesses following the Chairman's leadership and his long-term vision and goals because they respect their leader from the heart. The Chairman's communication style is to hold regular open conversations with each CEO and other responsible executives to review business practices and to share opinions and ideas frankly. This is an effective two-tops leadership structure of WoongJin Group management.

\section{e. Boundary-less}

Respondents described the Chairman's leadership style and boundary-less organizational culture of the WoongJin Group companies.

Our culture is open and boundary-less and emphasizes open communication and 
open discussion at meetings for the effective sharing of knowledge and ideas. But people sometimes hesitate to be frank and straightforward with negative comments, as they do not want to damage family-oriented relations. However, our leader respects people and listens to our opinions and ideas without boundaries. We can have comfortable meetings and open discussions with our chairman.

\section{f. Other observations from the interviews}

WoongJin's culture is very special. People in the company respect and follow their charismatic and highly ethical leader from their hearts in a similar way that some people follow a religious leader. There is a strong family-oriented culture of solidarity and interpersonal relationships as people are respected and treated. In newly merged firms, existing labor unions changed and harmonized themselves after they joined the WoongJin family. Table 6.5 summarizes the findings of this section.

Table 6.5 Summary of organizational culture

\begin{tabular}{|c|c|}
\hline Characteristics & Descriptions \\
\hline People-oriented & $\begin{array}{l}\text { WoongJin-style people-oriented culture. Strong psychological ownership } \\
\text { of empowered people. "Sinbaram Munhwa" (Exciting Wind-Blowing } \\
\text { Culture) in which people are highly motivated and empowered, enjoying } \\
\text { their work with passion. } \\
\text { "To-To-Sarang Culture", which means "love and love always" among fellow } \\
\text { workers, colleagues, customers, and partners. }\end{array}$ \\
\hline Challenge seeking & $\begin{array}{l}\text { High challenge-seeking vision and goals of Group Chairman are effectively } \\
\text { shared with all WoongJin people, and are implemented highly effectively } \\
\text { by leaders and team members of each business company. }\end{array}$ \\
\hline Innovation & $\begin{array}{l}\text { Seeking continuous change and innovation in all work processes, products, } \\
\text { and services for sustainable growth and competitiveness. }\end{array}$ \\
\hline Control & $\begin{array}{l}\text { Delegation of management responsibility to CEO of each business. Two- } \\
\text { tops leadership structure and management system of Group Chairman and } \\
\text { CEOs of all WoongJin companies. Effective combination of efficient top- } \\
\text { down and bottom-up decision-making. }\end{array}$ \\
\hline Boundary-less & $\begin{array}{l}\text { Highly boundary-less and highly open culture, moving toward more } \\
\text { open knowledge-sharing to create a knowledge-productive organizational } \\
\text { culture that utilizes people's skills and knowledge more effectively. }\end{array}$ \\
\hline
\end{tabular}




\subsubsection{Knowledge productivity}

a. Continuous improvement and radical innovation of products, services, and work processes (KP1)

Knowledge productivity is essential to the success of the WoongJin Group of companies. An active learning culture emphasizes continuous study and selfdevelopment for building a creative thinking organizational culture for continuous improvement and innovation. To accomplish this, the company runs various human resources development programs and organizes innovation-oriented learning programs, such as the customized MBA program for WoongJin executives and managers, the Core Value Innovation Seminar, Innovation Meeting, and Imagination Ocean Meeting to share best practices of innovation across subsidiary companies and business operations. One respondent stated "Our chairman strongly emphasizes that innovation is accepting and implementing new ideas, thinking, and raising questions repeatedly for continuous changes and innovation". There is a strong learning culture in the WoongJin Group, especially for "learning by doing", throughout each company and business.

\section{b. Sustainable development of future growth engines (KP2)}

Most of WoongJin's businesses geared toward future growth were initiated and initially led by the Group Chairman, who has a superior intuition for attractive growth opportunities from his unique experience. He constantly tries to empower and motivate WoongJin people to think in different and creative ways to achieve sustainable company growth. Highly challenging leadership and an open organizational culture motivate radical innovation and new business development for the sustainable future growth of WoongJin companies. For example, WoongJin recently made a significant investment in building new environmental protectionoriented solar energy businesses, including a project involving high-technology polysilicon manufacturing.

Other observations from the interviews related to the key words extracted from previous literature are as follows. WoongJin's people-oriented, high challengeseeking, innovative culture has resulted in a highly knowledge-productive organization, which has made it possible for WoongJin to grow many different businesses both rapidly and successfully. A knowledge-productive organizational culture that fosters development of leading innovations and radical improvement is the main growth engine driving WoongJin forward. A summary of the findings of this study on knowledge productivity is provided in Table 6.6. 
Table 6.6 Summary of knowledge productivity

\begin{tabular}{l|l}
\hline Characteristics & Descriptions \\
\hline $\begin{array}{l}\text { Continuous } \\
\text { improvement and } \\
\text { radical innovation } \\
\text { (KP1) }\end{array}$ & $\begin{array}{l}\text { The Group Chairman and CEOs of each WoongJin Group company } \\
\text { encourage continuous change and innovation, and continuous } \\
\text { improvement of products, services, and work processes. Strong learning } \\
\text { culture, especially for action learning (i.g., learning by doing) throughout } \\
\text { the organization. }\end{array}$ \\
$\begin{array}{l}\text { Sustainable } \\
\text { development of } \\
\text { future growth } \\
\text { engine(KP2) }\end{array}$ & $\begin{array}{l}\text { Strongly emphasizing aggressive changes and continuous innovation for } \\
\text { sustainable growth. Efficient knowledge-sharing in an open organizational } \\
\text { culture and productive knowledge utilization, which contribute to } \\
\text { sustainable future growth. High-challenging, visionary, and risk-taking } \\
\text { leadership enables significant major decision-making and launching of } \\
\text { new high-technology businesses for future growth, such as a polysilicon } \\
\text { manufacturing project for solar energy development, an environmentally } \\
\text { friendly business. }\end{array}$ \\
Other observations & $\begin{array}{l}\text { Strong learning culture and top priority for best talent and human } \\
\text { resources development. Highly knowledge-productive organization. }\end{array}$ \\
\hline
\end{tabular}

\subsubsection{Value creation}

a. Corporate reputation, image, and CSR

WoongJin's people-oriented and high-challenging entrepreneurial leadership created a highly knowledge-productive organizational culture which became a strong base for continuous high growth and high value creation in WoongJin and improved the reputation and image of the company. According to one interviewee, continuous high growth and the unique people-oriented management leadership and organizational culture significantly improved WoongJin's image and reputation. The Chairman of the WoongJin Group is one of the most admired business leaders in Korea, as WoongJin Group revenue increased 3,600\% and net profit increased $4,880 \%$ over a period of 20 years (1990-2010).

WoongJin's role as a corporate citizen and its social responsibilities are part of the spirit and philosophy of the WoongJin Group. The Group invests continuously in environmental protection programs, and WoongJin employees volunteer for social service work. WoongJin also donated and built the Research Center at Seoul National University to support the education and development of future scientists and engineers for Korea.

\section{b. Employee satisfaction with work environment and benefits}

The comments and opinions of interviewees on the subject of employee satisfaction 
indicate a consensus.

We feel high-level employee satisfaction with a strong psychological ownership as a result of the people-oriented leadership style and organizational culture, and high levels of transparency and integrity of people management in all the WoongJin organizations.

WoongJin's unique organizational culture, "Sinbaram" (Exciting Wind-Blowing Culture) and "To-To-Sarang" (Love and Love Again Culture) empowered people and significantly increased employee satisfaction.

\section{c. Sustainability}

The WoongJin Group demonstrated sustainable high growth over a period of recent 20 years, diversifying business aggressively into 15 affiliated companies in seven different industries, such as education, manufacturing of food and beverages, hightechnology polysilicon for solar energy, financial services, and construction. According to an interviewee, the highly capable WoongJin Group management successfully overcame the most difficult business conditions during the financial crisis in Korea and Asia in 1998. In fact, the financial crisis became a terrific growth opportunity for WoongJin construction and polysilicon manufacturing for solar energy. These businesses may impact financial stability depending upon future trends, as WoongJin made significant investments in these new businesses recently.

\section{d. Other observations from the interviews}

In terms of size, the WoongJin Group ranks 30th in Korea. Thus, it belongs to the medium- to large-sized group of businesses. However, the company image and reputation are unparalleled as a result of its people-oriented management and organizational culture, and the high ethical standards of its leader.

e. Financial data on 10-year performance

Table 6.7 and Figure 6.1 show the sales, net profit, and market value of the WoongJin Group between 1990 and 2010. These data were collected from each of the WoongJin Group companies. Market value data are based on five listed companies among the 15 companies within the WoongJin Group. 
Table 6.7 Sales, Net Profit, and Market Value of WoongJin Group (1990-2010) ${ }^{a}$

Unit: billion (KRW), percentage (\%), person (number)

\begin{tabular}{|c|c|c|c|c|c|c|c|c|}
\hline & 1990 & 2000 & 2002 & 2004 & 2006 & 2008 & 2009 & 2010 \\
\hline Sales & 148 & 1,069 & 1,783 & 2,003 & 2,345 & 4,583 & 4,745 & 5,373 \\
\hline Domestic & 148 & 1,069 & 1,781 & 1,994 & 2,325 & 3,736 & 3,966 & 4,434 \\
\hline Overseas & 0 & 0.3 & 2 & 8 & 20 & 766 & 801 & 938 \\
\hline Operational profit & 11 & 90 & 160 & 157 & 154 & 288 & 459 & 486 \\
\hline Net profit & 5 & 52 & 72 & 139 & 101 & 89 & 275 & 244 \\
\hline ROS & $3.38 \%$ & $4.86 \%$ & $4.10 \%$ & $7.00 \%$ & $4.30 \%$ & $1.94 \%$ & $5.81 \%$ & $4.55 \%$ \\
\hline Employee & 885 & 4,691 & 5,935 & 7,028 & 8,076 & 10,506 & 9,995 & 10,144 \\
\hline Market value & & 87 & 300 & 611 & 2,569 & 3,026 & 4,658 & 6,069 \\
\hline
\end{tabular}

Market value is based on year-end stock price of five listed companies among the 15 companies of the WoongJin Group. No market value data is available for 1990, as WoongJin only became a listed company in 1996. The first listed company, WoongJin ThinkBig, was listed in 1996.WoongJin was founded in 1980.

Financial data based on fiscal year (01.01-12.31)

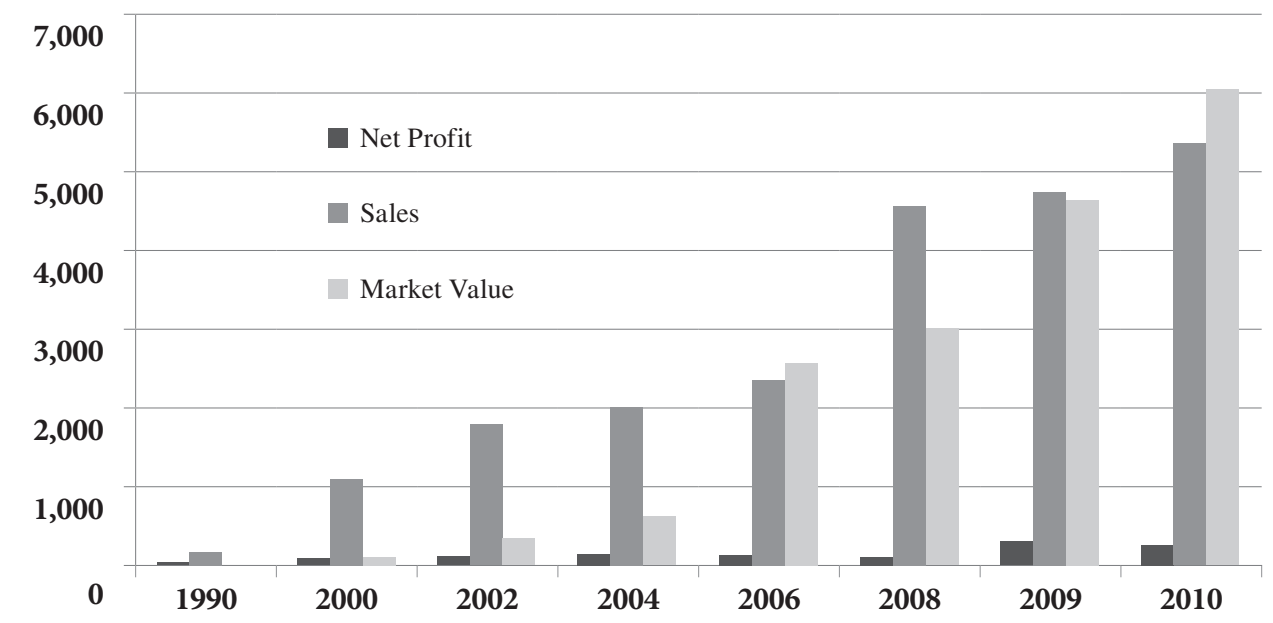

Figure 6.1 Net profit, sales, and market value of WoongJin Group. Market value is based on five listed WoongJin Group companies among 15 companies. (1990-2010)

Unit: billion (KRW)

Figure 6.1 shows net profit, sales, and market value of the WoongJin Group from 1990 to 2010. All listed indicators continually increased despite the global financial crisis in 1998. Sales and market value exhibited especially rapid growth since 2006. 
The WoongJin Group case included in total 15 WoongJin companies in different industries. Therefore, this case could not be compared with the top ten companies in one specific industry. Sales of the WoongJin Group in Table 6.7 reflect total sales of all 15 affiliated companies.

Table 6.8 Summary of value creation

\begin{tabular}{|c|c|}
\hline Characteristics & Descriptions \\
\hline $\begin{array}{l}\text { Corporate } \\
\text { reputation, images, } \\
\text { and CSR }\end{array}$ & $\begin{array}{l}\text { Continuous high growth and unique people-oriented management } \\
\text { leadership and organizational culture significantly improved WoongJin's } \\
\text { image and reputation. Its strong entrepreneurship and high- challenging } \\
\text { leadership and organizational culture are widely recognized and respected } \\
\text { in both industry and society. } \\
\text { Corporate citizen role and social responsibilities are important principles } \\
\text { and philosophy of WoongJin. The company continuously invests in } \\
\text { environmental protection programs, and WoongJin employees volunteer } \\
\text { for these environmental programs and other social services. }\end{array}$ \\
\hline $\begin{array}{l}\text { Employee } \\
\text { satisfaction }\end{array}$ & $\begin{array}{l}\text { High-level employee satisfaction with strong psychological ownership } \\
\text { as a result of people-oriented leadership and organizational culture. } \\
\text { In particular, WoongJin's unique organizational culture, "Sinbaram” } \\
\text { (Exciting Wind-Blowing Culture) and "To-To Sarang" (Love and Love } \\
\text { Again Culture), strongly empower people. }\end{array}$ \\
\hline Sustainability & $\begin{array}{l}\text { WoongJin Group achieved sustainable high growth for } 20 \text { years (1990- } \\
\text { 2010) diversifying business aggressively in seven different industries. Such } \\
\text { aggressive diversification into new businesses may impact sustainability } \\
\text { depending upon the future trends of the industries as WoongJin made } \\
\text { significant investment in the new businesses recently. }\end{array}$ \\
\hline $\begin{array}{l}\text { Financial } \\
\text { Performance }\end{array}$ & $\begin{array}{l}\text { Outstanding performance based on hard data records. Sales, net profit } \\
\text { and market value grew significantly as a result of successful management. } \\
\text { Market value based on } 5 \text { listed companies among } 15 \text { companies of } \\
\text { WoongJin Group } \\
\text {-Sales growth: } 36.3 \text { times (1990-2010) KRW 5,373 bil } \\
\text {-Net profit growth: } 48.4 \text { times (1990-2010) KRW } 244 \text { bil } \\
\text {-Market value growth: } 69.8 \text { times (2000-2010) KRW 6,069 bil }\end{array}$ \\
\hline
\end{tabular}

\subsection{Conclusion of WoongJin Group case study}

The WoongJin Group achieved sustained high growth over the past 20 years (from 1990 to 2010), 3,630\% growth in sales, and 4,880\% increase in net profit. Over the 10 years encompassing the research period of this study (2000-2010), WoongJin achieved significantly high value creation, including a 503\% increase in sales, $469 \%$ 
growth in net profit, and 6,976\% increase in market value. The WoongJin Group grew continuously despite tough competition in the industries it serves. It became a leading business group in selected markets in Korea.

The main purpose of this empirical research into the WoongJin Group using both qualitative and quantitative analysis was to explore relations among four key factors, leadership style, organizational culture, knowledge productivity, and value creation, based on the conceptual framework of the research model, and to define desirable leadership style and organizational culture for improving and upgrading knowledge productivity and achieving high value creation.

The findings from this empirical research into the WoongJin Group indicate that the Group's high-challenging and innovative entrepreneurship and people-oriented leadership created WoongJin's unique organizational culture, a boundary-less, open, and non-bureaucratic "Sinbaram" (Exciting Wind Blowing Culture) in which people can become more creative and innovative, and can feel a strong psychological ownership. This management leadership style and organizational culture improved and advanced the knowledge productivity of the WoongJin Group. Thus, the three key variables in focus, leadership, organizational culture, and knowledge productivity, are closely related, and they form the basis for sustainable growth and value creation of the WoongJin Group.

Findings from the qualitative analysis of interviews with the WoongJin Group's Chairman, CEOs, executives, and managers of WoongJin companies indicate that the WoongJin Group Chairman and CEOs' high-challenging entrepreneurship and people-oriented leadership provided clear vision and long-term direction to all WoongJin people and created a people-oriented and high-challenging organizational culture in which people can bring out their best capabilities to achieve the vision and goals of the WoongJin Group. In this organizational culture, people become more creative and innovative, using their knowledge and ideas more effectively, increasing knowledge productivity, and improving and innovating products, services, and work processes continuously. At the same time, these creative ideas help to build sustainable capability and develop new businesses for future growth.

Findings from the quantitative analysis of the survey strongly support the findings and conclusions of the qualitative analysis. The results of the quantitative analysis show that the WoongJin Group leadership characteristics (people-oriented and innovative, LS1; visionary and entrepreneurial, LS2; and high-challenge-seeking and risk-taking, LS3) were significantly and positively correlated with the organizational culture characteristics (people-oriented, OC1; high-challenge-seeking and 
innovative, OC2). These leadership and organizational culture characteristics were significantly and positively correlated with knowledge productivity (improvement and innovation of products, services, and work processes, KP1 and sustainable development of future growth engines, KP2). All these leadership characteristics, organizational culture characteristics, and knowledge productivity of the WoongJin Group were significantly and positively correlated with the following value creation factors: corporate reputation, image, and CSR (VC1), employee satisfaction with work environment (VC2), employee satisfaction with financial benefits (VC3), and sustainability (VC4). Financial data on the performance of the WoongJin Group resulting from value creation also demonstrated continuous stable growth of revenue, net profit, and market value over the 10 years examined in this research.

Findings from the empirical research using both qualitative and quantitative analysis clearly indicate strong relations among the four main valuables, namely, leadership, organizational culture, knowledge productivity, and value creation, and also support the conceptual framework of this research model, as shown in the Figure 6.2.

The leadership characteristics of the WoongJin Group (people-oriented and highchallenging visionary entrepreneurship) had a significant and positive impact on both knowledge productivity and value creation. The people-oriented, high challenge-seeking and innovative organizational culture also related positively with both knowledge productivity and value creation in the WoongJin Group. Although the Group Chairman delegates management responsibility to each CEO of the WoongJin Group companies, his long-term vision and management principles are well respected and implemented by CEOs and executives of each WoongJin Group company. 
Non-bureaucratic, open, Empowering people, Delegation and participation Visionary, Charismatic High-challenging Entrepreneurship
Improvement and innovation of products, services, and work processes (KP1)

Sustainable development of future growth engine (KP2)

\section{)}

People-oriented Sinbaram, exciting people Boundary-less, open Ownership spirit Creative thinking and ideas Freedom to be creative

Leadership style

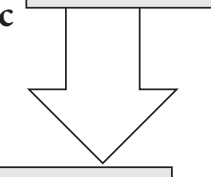

\section{Organizational culture}

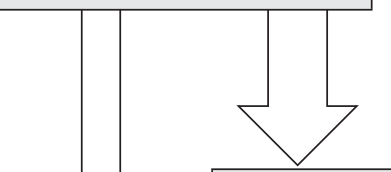

Knowledge productivity

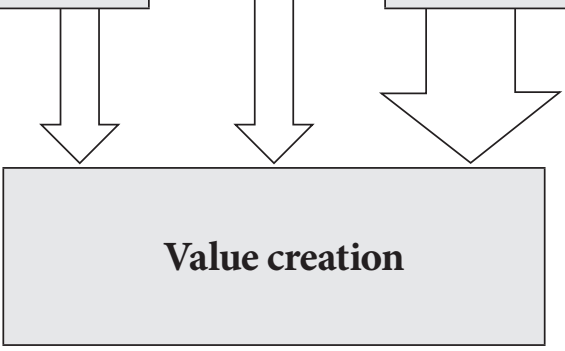

Revenue and profit growth Company market value increase Company reputation and image upgrade. Employee satisfaction increase. CSR

Figure 6.2 Summary of the related four main variables of the WoongJin Group case study

In the WoongJin Group case, significant interactions were found among the four main variables (Figure 6.2). Leadership style had a significant and positive relation with organizational culture (thick arrow), organizational culture had a significant and positive relation with knowledge productivity (thick arrow), and knowledge productivity had a significant and positive relation with value creation (thick arrow). Leadership style was significantly and positively related to knowledge productivity through organizational culture, and also directly related to knowledge productivity, as the Chairman has influential intuition and inspiration from his substantial experiences of business operations and management. The leadership style of the WoongJin Group was significantly and positively related to value creation in connection with organizational culture and knowledge productivity, and also directly related to value creation. The leadership style of the WoongJin Chairman and CEO of WoongJin Group companies was found to be close to the B-type leadership described in this research model.

As a result of this empirical research into the WoongJin Group using qualitative and quantitative analysis, we can conclude that for the WoongJin Group, the four main 
variables can be described as follows: (1) people-oriented, visionary, and highchallenging leadership; (2) innovative and challenge-seeking, empowering and open organizational culture; (3) high knowledge productivity, all of which are significantly and positively correlated with (4) high value creation and sustained future growth capability.

These findings provide clear building blocks for answering to the main research questions of this study, and support the conceptual framework of this research.

The case study report of the WoongJin Group was sent to the participants for validation. On the basis of the report, the researcher organized feedback discussions with senior management. In response to the feedback, some minor changes and additions were made in the case report.

In 2013, after the period (2000-2010) examined herein, WoongJin faced significant financial difficulties as a result of the stagnation of the construction industry in Korea and the global solar energy industry due to the negative impact of the depressed world economy. WoongJin's leadership attempted to overcome the financial crisis by aggressive restructuring of WoongJin Group businesses. WoongJin's high reputation for transparency and management integrity provided a strong basis for overcoming financial difficulties, as creditor banks trusted WoongJin's leadership and management. This WoongJin case indicated that trustworthy and transparent management aids in risk management and overcoming crises. Table 6.9 summarizes the findings of this case study. 
Table 6.9 Summary of the WoongJin Group case in terms of the four main variables

\begin{tabular}{l|l}
\hline Variables & Descriptions of key common characteristics of the four factors \\
\hline Style & $\begin{array}{l}\text { People-oriented and charismatic leadership. High challenge-seeking } \\
\text { entrepreneurship moving into new businesses and new opportunities while } \\
\text { taking acceptable risks. Emphasizing creative and innovative ways of thinking } \\
\text { and new approaches. Effective combination of two-tops leadership structure: } \\
\text { chairman's high-challenging visionary entrepreneurship and each CEO's } \\
\text { professional management skills. }\end{array}$ \\
$\begin{array}{l}\text { Organizational } \\
\text { Culture }\end{array}$ & $\begin{array}{l}\text { People-oriented culture. Strong psychological ownership of the empowered } \\
\text { people. Unique WoongJin style: "Sinbaram" (Exciting Wind-Blowing Culture), } \\
\text { through which employees are highly motivated and empowered and sharing } \\
\text { vision and dreams, and enjoy their work with passion. Open, boundary-less } \\
\text { culture in which responsibility is delegated. }\end{array}$ \\
$\begin{array}{l}\text { Knowledge } \\
\text { Productivity }\end{array}$ & $\begin{array}{l}\text { Group chairman demanding continuous changes, improvement, and } \\
\text { innovation of products, services, and work processes for sustainable growth. } \\
\text { Active learning culture and top priority for best talent and human resources } \\
\text { development, making a highly knowledge-productive organization. High- } \\
\text { challenging and open organizational culture motivates continuous innovation } \\
\text { and new business development for the future growt }\end{array}$ \\
Value Creation & $\begin{array}{l}\text { Achieved highly successful sustained growth and high value creation for the } \\
10 \text { years case study period. High level of employee and customer satisfaction } \\
\text { and excellent company reputation. Active in meeting its corporate social } \\
\text { responsibilities. }\end{array}$ \\
\hline
\end{tabular}




\section{Chapter 7. Findings from the case studies: Shinhan Bank}

\subsection{General overview}

The Shinhan Bank is one of the top two leading banks in Korea. When the bank was founded in 1982, it operated only three branches with 270 employees. By 2010, Shinhan had grown to be a major financial business group in Korea, operating 12 affiliated financial companies including the Shinhan Bank as the result of the continued high-challenging entrepreneurship of Shinhan's management team. Total assets of Shinhan Bank increased from 10,046 to 234,314 BKW (billion Korean Won), which is a growth rate of $2,332 \%$ from 1990 to 2010 . Its market value increased from 1,273 to $25,085 \mathrm{BKW}$, an increase of $1,970 \%$ during the same period. Net profit increased from 99 to $1,648 \mathrm{BKW}$, an increase of 1,665\% from 1990 to 2010. From 1990 to 2008, before the impact of the world financial crisis of 2008, the Shinhan Bank grew 1,463\%. Thus, the Shinhan Bank was selected as a case study for this academic research. A general overview of the company is provided in Table 7.1.

Table 7.1 General overview of the Shinhan Bank and Shinhan Financial Group

\begin{tabular}{l|l}
\hline $\begin{array}{l}\text { Background of } \\
\text { the Shinhan } \\
\text { Financial Group }\end{array}$ & Description \\
\hline Founding & Founded in 1982 as Shinhan Bank \\
\hline $\begin{array}{l}\text { Types of } \\
\text { industries } \\
\text { and subsidiary } \\
\text { companies }\end{array}$ & $\begin{array}{l}\text { Shinhan Bank } \\
\text { Banking and related financing businesses } \\
\text { Shinhan Financial Group (holding company) }\end{array}$ \\
& $\begin{array}{l}\text { Shinhan Card } \\
\text { Shinhan Investment Corp. } \\
\text { Shinhan Capital } \\
\text { Shinhan Life Insurance } \\
\text { Jeju Bank } \\
\text { Shinhan Private Equity } \\
\text { Shinhan Credit Information } \\
\text { Shinhan BNP Paris Assets Management } \\
\text { Shinhan Macquarie Financial Advisory } \\
\text { Shinhan Data System }\end{array}$ \\
\hline
\end{tabular}




\begin{tabular}{|c|c|c|c|c|}
\hline $\begin{array}{l}\text { Total number } \\
\text { of employees } \\
(2010)\end{array}$ & \multicolumn{4}{|c|}{$\begin{array}{l}\text { Shinhan Financial Group 18,803 } \\
\text { Shinhan Bank 10,832 }\end{array}$} \\
\hline $\begin{array}{l}\text { Financial } \\
\text { status } \\
(2010)\end{array}$ & $\begin{array}{l}\text { Shinhan Bank } \\
(2010) \\
\text { Total assets } \\
\text { Preprovision } \\
\text { profit } \\
\text { Net profit } \\
\text { ROA } \quad 0.77 \% \\
\text { ROE } \quad 11.45 \% \\
\text { Market value }\end{array}$ & $\begin{array}{c}\text { KRW } \\
234,314 \text { bil } \\
\text { 3,363 bil } \\
1,648 \text { bil } \\
\\
25,085 \text { bil }\end{array}$ & $\begin{array}{r}202,222 \mathrm{mil} \\
2,902 \mathrm{mil} \\
1,422 \mathrm{mil} \\
21,649 \mathrm{mil}\end{array}$ & US(\$) \\
\hline $\begin{array}{l}\text { Overseas } \\
\text { operations }\end{array}$ & $\begin{array}{l}\text { U.S.A, U.K. Ca } \\
\text { China, Hong K } \\
\text { India, Vietnam } \\
\text { Kazakhstan (5 }\end{array}$ & $\begin{array}{l}\text { Mexico, Ger } \\
\text { Japan, Singał } \\
\text { abodia, Uzbe } \\
\text { cations in } 14\end{array}$ & ries) & \\
\hline
\end{tabular}




\subsection{Quantitative analysis of survey data}

\subsubsection{Demographic characteristics}

Data on Shinhan Bank was collected from a survey conducted in Korea. In total, 100 respondents from Shinhan Bank completed the questionnaires (out of 120 questionnaires distributed). The sample characteristics are summarized in Table 7.2 below.

Table 7.2 Characteristics of Survey Respondents

\begin{tabular}{lccc}
\hline \multicolumn{1}{c}{ Parameter } & Percentage (\%) & Parameter & Percentage (\%) \\
Gender & \multicolumn{2}{c}{ Rank } \\
Male & 99.0 & Manager & 40.0 \\
Female & 1.0 & Senior manager & 30.0 \\
Age & & Executive & 30.0 \\
$\quad<$ 30 years & 9.0 & & \\
31-40 years & 30.0 & Education level & \\
41-50 years & 61.0 & High school & \\
$>$ 51 years & 0.0 & College & 0.0 \\
Tenure & & Bachelor's degree & 73.0 \\
$<$ 5 years & 13.0 & Master's degree & 23.0 \\
6-10 years & 18.0 & Doctorate degree & 0.0 \\
$>$ 11 years & 69.0 & & \\
\hline
\end{tabular}

Males made up the majority of respondents (99\%), although only $59 \%$ of all members of the Shinhan Bank are male, as more questionnaires were distributed to employees at the middle management and senior levels of Shinhan Bank, most of whom are male. Senior-level managers have a better understanding of and can respond better to questions about the four main variables utilized in this study (leadership, organizational culture, knowledge productivity, and value creation). Thus, the respondents were all managers, general managers, or executives. 


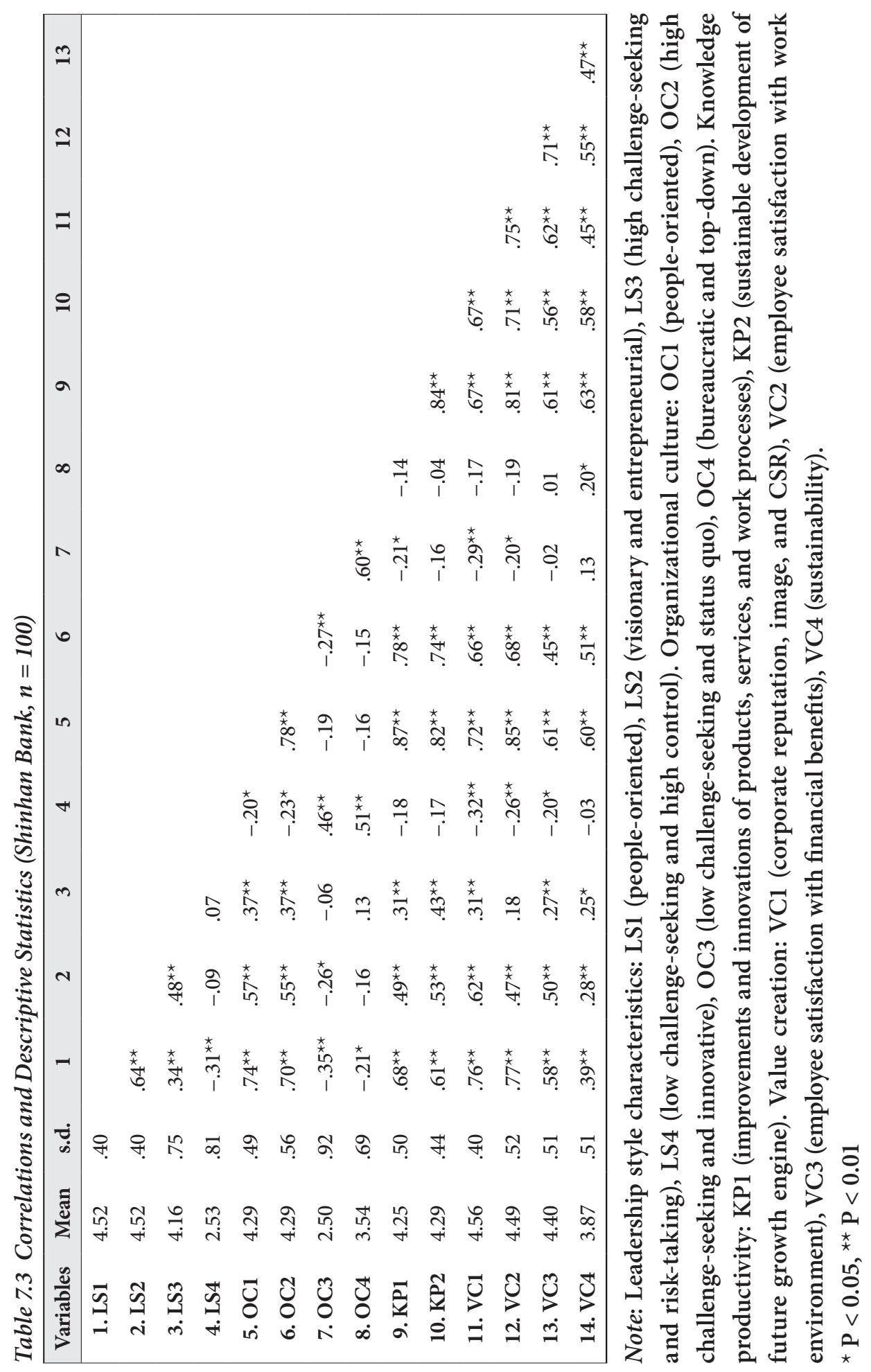




\subsubsection{Relations among key variables}

Table 7.3 shows means, standard deviations, and correlations among the variables in the questionnaire for the employees of Shinhan Bank. Financial performance (e.g., revenue and net profit growth, market value increase) is not included in this quantitative analysis, as the financial data are separately reported in section 7.3.4. The results of the correlation analysis indicate that significant and positive relationships exist between the following leadership characteristics: people-oriented (LS1), visionary and entrepreneurial (LS2), and high challenge-seeking and risk-taking (LS3) and knowledge productivity, that is, improvement and innovation of products, services, and work processes (KP1) and sustainable development of future growth engines (KP2). No positive relationship was found between low challenge-seeking and high controlling leadership (LS4) and knowledge productivity. Similarly, significantly positive relationships were observed between two leadership characteristics: peopleoriented (LS1) and visionary and entrepreneurial (LS2) and all value creation factors: corporate reputation, image, and CSR (VC1), employee satisfaction with work environment (VC2), employee satisfaction with financial benefits (VC3), and sustainability (VC4). Significantly positive relationships were found between high challenge-seeking and risk-taking leadership (LS3) and all VC factors except for employee satisfaction with work environment (VC2). On the other hand, significantly negative relationships were found between low challenge-seeking and high control leadership (LS4) and value creation in terms of corporate reputation, image, and CSR (VC1), employee satisfaction with knowledge productivity in terms of improvement and innovation of products, services, and work processes (KP1), and also with value creation in terms of corporate reputation and image (VC1), employee satisfaction with work environment (VC2), and employee satisfaction with financial benefits (VC3). Significantly positive relationships were seen between organizational culture characteristics of Shinhan Bank (people-oriented, OC1 and high challenge-seeking and innovative, OC2) and knowledge productivity, that is, improvement and innovation of products, services, and work processes (KP1) and sustainable development of future growth engines (KP2). By contrast, low challenge-seeking organizational culture (OC3) was significantly and negatively related to knowledge productivity in terms of improvement and innovation of products, services, and work processes (KP1) and also to value creation in terms of corporate reputation and image (VC1) and employee satisfaction with work environment (VC2).

Significantly positive relationships were found between two organizational culture characteristics: people-oriented (OC1) and high challenge-seeking and innovative organizational culture (OC2) and all value creation factors, that is, corporate 
reputation, image, and CSR (VC1), employee satisfaction with work environment (VC2), employee satisfaction with financial benefits (VC3), and sustainability (VC4). However, significantly negative relationships were seen between the organizational culture characteristic, low challenge-seeking and status quo (OC3), and two value creation factors, that is, corporate reputation, image, and CSR (VC1) and employee satisfaction with work environment (VC2). No significant relationship was observed between bureaucratic and top-down organizational culture (OC4) and knowledge productivity or value creation. Finally, knowledge productivity (improvement and innovation of products, services, and work processes, KP1 and sustainable development of the future growth engine, KP2) was significantly and positively related to value creation in terms of corporate reputation, image, and CSR (VC1), employee satisfaction with work environment (VC2), employee satisfaction with financial benefits (VC3), and sustainability (VC4).

The results of the correlation analysis of the Shinhan Bank case indicated significantly positive relations between one organizational culture characteristic, bureaucratic and top-down control (OC4), and value creation in terms of sustainability (VC4). This significantly positive correlation between OC4 and VC4 in the Shinhan case differs from the findings in the cases of the other three companies. The banking industry in Korea can generally be characterized as more conservative, less willing to take risks, and more used to top-down and centralized control than other industries. In the case of Shinhan Bank, effective management of financial risks aided in protecting and sustaining banking and other financial businesses during the Asian financial crisis, or "IMF crisis", of 1998 and the more recent global financial crisis of 2008. Thus, the survey respondents from Shinhan Bank expressed positive opinions about conservative and top-down control of the organizational culture due to its positive impact on corporate sustainability. The results of the statistical analysis of the Shinhan Bank case indicate that both its leadership style (LS1, LS2, and LS3) and its organizational culture (OC1 and OC2) were significantly and positively related to both knowledge productivity (KP1 and KP2) and value creation (VC1, VC2, VC3, and VC4).

\subsection{Qualitative analysis of interview data}

Interviews were conducted with the president, two vice presidents, two managing directors, nine general managers, and team leaders of Shinhan Bank. In total, 14 interviewees were asked questions on subjects related to leadership style, organizational culture, knowledge productivity, and value creation of Shinhan Bank 
and the Shinhan Financial Group. Interviewees' answers were generally in consensus on those subjects, except for a few different views, as summarized below.

\subsubsection{Leadership style}

Leaders of the Shinhan Financial Group, the holding company, and Shinhan Bank are professionals who do not own majority controlling shares in the company. Thus, the corporate governance structure of Shinhan differs from those of the other three companies examined in this research. In the case of Shinhan, ownership and management are separate, as the share ownership structure of the holding company is diversified, and there is no majority controlling ownership. However, the chairman of the holding company plays a similar role to that of the Group Chairman of the other leading Korean companies selected for this study. E.C. Rah, chairman of the Shinhan Financial Group, served the company for 33 years, working with the Shinhan Bank for 10 years as CEO and the Shinhan Financial Group for 9 years as chairman. According to a few senior interviewees, the leadership style of chairman E.C. Rah, is practical and self-confident with a strong psychological ownership. He is known for his open-minded leadership, ability to listen, respect for employees' opinions, and ability to take the initiative toward change and innovation. The CEO of Shinhan Bank leads the company, sharing the vision and goals with the chairman and following people-oriented management principles. Therefore, Shinhan-style leadership and organizational culture can be maintained over a long period of time, although the CEO of the bank may change. The following are some selected statements from the interviewees.

His leadership style is softly charismatic, a combination of charismatic character for leading businesses and people-oriented humanitarian leadership, empowering people to have a strong psychological ownership.

The chairman constantly maintains a fair and transparent human resources management policy based on fairly evaluated performances and capabilities. He provides fair opportunities for employees based on performance and capability; which universities employees graduated from and their personal networks are not important for his style of people management.

He strictly adheres to the management principles of the company, working for customers, employees, and shareholders and for society, not for personal benefit. Therefore, people in the company respect and trust him as a role model of the 
principles. He seeks stable growth without taking high risks, but sometimes makes high challenge-seeking and high risk-taking decisions, such as the merger with Cho-hung Bank, one of the oldest and largest banks in Korea, in 2003.

Based on the interviewees' opinions and statements, the characteristics of the leadership style at Shinhan are described as follows.

\section{a. People- orientation}

Most interviewees' opinions were in consensus on the leadership style of the chairman. According to them, the chairman respects and trusts subordinates. He prefers boundary-less, open communication directly with employees rather than communicating through layers and staff systems, and he listens to and respects employees' opinions. The quotations below illustrate this.

He fully delegates management responsibilities to CEOs of the bank and affiliated companies and staff. However, he involves himself directly in major issues related to decision-making and long-term direction and goals of the bank and affiliated companies.

As he has a warm humanitarian personality and respects employees as human beings, employees trust and respect him. Such people-oriented humanitarian leadership characteristics empowered and motivated Shinhan people to have a strong psychological ownership.

Our chairman has implemented very fair HR systems in all Shinhan Bank and Shinhan affiliate companies. Such fair and transparent performance evaluation and HR systems strongly motivated people.

\section{b. Vision building}

By leading the Shinhan Bank for 10 years as CEO and the Shinhan Financial Group for 9 years as chairman, the leader's long-term vision and goals to build a leading bank and financial business group and the strategy for realizing this vision and objective became the base of Shinhan's success today, according to a senior executive interviewee. Responses were in consensus as indicated by the following statements.

Our chairman takes initiative in his leadership role, providing a highchallenging vision for meeting the goals of the company and a long-term strategy for the future of the company to build the top leading finance group in Korea. He 
uses open and boundary-less two-way communication for sharing his vision and goals with all executives, team members, and employees.

He leads continuous innovation and changes throughout the company. He believes that if an organization is not seeking changes and innovation, that organization is dead.

\section{c. Entrepreneurship}

According to interviewees' explanations, the leader believes in high challengeseeking entrepreneurship to build the number one leading bank in Korea. He made important decisions for big deals, such as merging with the Cho-hung Bank in 2003 and acquiring the LG Card Company in 2007.

Other statements also strongly support the sustainable entrepreneurship and balanced decision-making of the chairman and management team.

The chairman promotes a strong psychological ownership, as he participated in management of the Shinhan Bank from the early stage of its establishment.

Our chairman has strong capability for making the most reliable decisions for critical major projects and key issues. With his inspiration and intuition, he has managed Shinhan financial businesses for 33 years from the beginning of the Shinhan Bank.

He always tried to understand key factors deeply and precisely, and openly listened to people's opinions before he made major decisions. Once a decision is made, he fully concentrates on implementation of the decision with his unique leadership style and strong execution and driving power.

He considers field activities and performance most important for evaluation and promotion.

\section{d. Risk-taking and risk management}

Executive interviewees explained how Shinhan's leaders make important decisions, taking and managing risks. As Shinhan Bank maintained stable risk management, the organization was able to overcome significant difficulties in the two financial crises in 1998 and 2008 successfully, while other banks in Korea experienced serious negative impacts from those crises. 
Our leader seeks stable and sustainable growth rather than taking high risks for rapid growth. However, in order to secure important strategic opportunities for high growth, such as merging with the Cho-hung Bank and acquisition of the LG Card Company, the leader made high-challenging strategic decisions, taking risks. However, before making such important strategic decisions and taking risks, he conducted an in-depth professional evaluation of the potential risks and was well prepared for managing potential risks. As a result, such critical decisions provided important momentum for high growth.

\section{e. Controlling}

Responses of interviewees on the subject of control were in consensus. The chairman fully delegates management responsibilities to each CEO of the Shinhan Financial Group companies. The chairman has no direct control, although he is involved in major strategic decision-making such as establishing the long-term vision and goals and managing strategic development for the Shinhan Financial Group. He is also involved in final decision-making on major issues and important projects, such as entering into new business areas and mergers and acquisitions. He is a very openminded and non-bureaucratic leader. However, he is not flexible about implementing Shinhan's management principles and its integrity and transparency policies.

Shinhan leaders place high priority on building a non-bureaucratic, open organizational culture with boundary-less communication by benchmarking the GE model. By the decision of the chairman, Shinhan Bank learned from GE the "Work-Out Town Meeting" program and implemented it throughout the organization to build an open organizational culture. With such continuous efforts of the chairman and leadership team, Shinhan's communication and knowledge-sharing systems became very open and boundary-less.

\section{f. Other observations from the interviews}

The chairman places special emphasis on revenue and operations in the business fields, providing more incentives and promotion opportunities to those employees who are directly involved in sales and customer services. One interviewee stated it as follows:

Our leader's principal philosophy is respecting field operations serving to customers. This philosophy has become a strong base for Shinhan's successful growth. 
g. Connection to the conceptual framework of this study

The findings from the qualitative analysis indicate that Chairman Rah's leadership style is close to the B Type described in the conceptual framework of the research model. This means that his leadership style is people-oriented, non-bureaucratic, open, and empowering, and he delegates management responsibilities to the CEO of each company of Shinhan Group. However, he decides to participate directly on a case-by-case basis for major decisions using intuition and inspiration based on 33 years of experience managing banking and financial businesses. The leadership style of the CEO of Shinhan Bank is also close to the B Type. The characteristic organizational culture of Shinhan is strongly influenced by the leaders.

\section{h. Shinhan style of two-tops leadership}

Shinhan Financial Group, the holding company of Shinhan Bank, does not have a majority controlling shareowner. Therefore, Shinhan's ownership and management are separate, and its corporate governance system differs from those of the other three leading Korean companies in this study. However, the chairman of the holding company occupies a similar role as the Group Chairmen of the other three leading Korean companies selected for this study. In these executive roles, he was fully trusted by influential shareholders. He developed the long-term strategies, vision, and goals of Shinhan Bank and affiliated companies by sharing ideas and opinions with their CEOs and executives. The chairman and CEOs shared the vision and goals with all Shinhan executives and employees. The chairman, on behalf of shareholders of the holding company, selected and appointed the CEO of the Shinhan Bank and the CEOs of other affiliated companies, and fully delegated management responsibilities to them. The CEO of the Shinhan Bank respects and follows the long-term vision and goals and management principles developed by the chairman and shared with all employees. The two-tops leadership structure of Shinhan appears to be an effective combination of the leadership of the Chairman and the leadership of the CEO of the Shinhan Bank and other affiliated companies. A summary of the respondents' statements on leadership in the Shinhan Financial Group and Shinhan Bank is provided in Table 7.4. 
Table 7.4 Summary of leadership characteristics in the Shinhan Group

\begin{tabular}{|c|c|}
\hline Characteristics & Descriptions \\
\hline People-oriented & $\begin{array}{l}\text { Respecting and trusting employees and open communication with } \\
\text { employees; chairman and CEO listen to employees' opinions } \\
\text { Such people-oriented humanitarian leadership empowered and motivated } \\
\text { people to have a strong psychological ownership. }\end{array}$ \\
\hline Vision-building & $\begin{array}{l}\text { Taking initiative in a leadership role for building the top leading bank and } \\
\text { financial business group in Asia, and sharing the vision and goals with all } \\
\text { employees. Leading continuous innovation and changes throughout the } \\
\text { company. }\end{array}$ \\
\hline Entrepreneurship & $\begin{array}{l}\text { High challenge-seeking entrepreneurship to build the top leading bank and } \\
\text { financial group. Strong ability to make reliable decisions for major projects } \\
\text { with his inspiration and } 33 \text { years of management experience. }\end{array}$ \\
\hline Risk-taking & $\begin{array}{l}\text { Making important decisions, taking risks for major merger and acquisition } \\
\text { deals for corporate growth, such as merging with the Cho-hung Bank } \\
\text { and acquisition of the LG Card Company. Seeking stable and sustainable } \\
\text { growth rather than taking high risks for rapid growth. }\end{array}$ \\
\hline Controlling & $\begin{array}{l}\text { Fully delegating management responsibilities to CEOs of Shinhan } \\
\text { Financial Group companies and heads of operations. No direct top-down } \\
\text { control. However, selectively involved in major strategic decisions. }\end{array}$ \\
\hline $\begin{array}{l}\text { Other } \\
\text { characteristics }\end{array}$ & $\begin{array}{l}\text { Strong emphasis on field activities, providing more incentives and } \\
\text { promotion opportunities to field workers who are directly involved in sales } \\
\text { and profit generation. }\end{array}$ \\
\hline
\end{tabular}

\subsubsection{Organizational culture}

According to a few senior interviewees, Shinhan people believe that the Shinhan Bank was built by ordinary people, like Shinhan employees. They are proud of Shinhan and its culture today, which they further developed with strong loyalty to their company. The following are key comments from interviewees regarding the organizational culture in the Shinhan Group.

Shinhan culture is unique and extraordinary. It was created by ordinary people. It emphasizes respect and allows equal opportunities to every Shinhan employee. Anyone who makes an important contribution to the company, he or she can have a fair opportunity for promotion. We love our company and we have a strong psychological ownership for the company. We are proud of our Shinhan culture today. 
Shinhan Bank and Shinhan's affiliate companies follow a specific vision and management principles, which they call the "Shinhan Way". All Shinhan managers and employees share the Shinhan Way and have adopted it as their vision. Key principles of the Shinhan Way are as follows: (1) top priority on creating value for customers; (2) practice business the "right way" and fulfill social responsibilities; (3) value and develop people talent; and (4) create synergy effects within the Shinhan Group. The requirements for implementation of the Shinhan Way are as follows: (1) customer-oriented and acknowledging social responsibility; (2) respecting each other and openly communicating; (3) creative thinking and leading change; (4) high-challenging and seeking excellence to attain the number one position; and (5) psychological ownership with pride as a Shinhan member.

When the Shinhan Bank was established in 1982, it was a small bank with only 270 employees and 3 branches. In order to survive, grow, and compete with all the other existing big banks in Korea, the Shinhan Bank had only one choice at that time: to manage its banking business differently than the other banks. While other banks were managing their organizations in bureaucratic and top-down controlling ways, not considering customer satisfaction important at that time, the Shinhan Bank operated in a significantly different way. It prioritized boundary-less and nonbureaucratic open communication and close teamwork, emphasizing customer satisfaction as the top priority. It implemented a special compensation system from the start: high compensation based on high performance and capability. Shinhan people can share vision and values in this open organizational culture. Today, Shinhan's typical strong organizational culture is different from those of most other banks in Korea.

\section{a. people-orientation}

A special, people-oriented organizational culture is characteristic of the Shinhan Group. Interviewees provided the following opinions and information about the people-orientation of the Shinhan Group.

Our company considers relationships among our people and interpersonal skill and teamwork to be most important. We think our working relationships and teamwork are evidence of a family-oriented culture. Our management respects employees as co-workers and listens to their opinions openly.

Our leaders encourage and motivate people in the company to recommend new ideas freely for improvement of businesses and new business development, and 
the leaders openly accept the best ideas for implementation.

We have boundary-less open communication and discussions to listen to employees' opinions when the company needs to make important decisions. Through various open communication channels, our opinions are well listened to and regarded, and we are actively participating in Shinhan business operations. We have a strong people-oriented and humanitarian organizational culture. Our leadership has empowered people to have a strong psychological ownership for the company. We feel strong loyalty to the company and are proud to work for Shinhan. As a result, employees' satisfaction level is very high and the turnover rate is very low (less than $1 \%$ ).

The company invests important amounts toward education and various talent development programs for building people power. Shinhan operates a fair HRM system, providing equal opportunities to all employees based on fair evaluation of performance and capability. Shinhan people therefore have a strong psychological ownership and loyalty to the company as a result of those programs.

\section{b. Challenge-seeking}

According to the interviewees, a high challenge-seeking, strong frontier spirit and customer-centered thinking are the basis of Shinhan culture.

We are seeking our goals and objectives through entrepreneurship to become a global leading bank. We have an offensive and aggressive approach for developing new markets and entering into new businesses. Our people hate to be defeated by the competition. We must win any competitions, as we have strong driving power.

Shinhan people have their own confident opinions on how to do their work better. We have very open discussions and debates at our meetings before we make decisions. Through such open discussions and debates, we share everyone's opinions and ideas and select the best ones. Once we have made a decision, we all share the decision and do our best teamwork for successful implementation. This is our strong point.

Our corporate culture strongly emphasizes field operations such as sales and marketing, which take high priority. Therefore, proven performance and capability of sales and marketing is the key to becoming an executive of Shinhan. 


\section{c. Innovation}

The Shinhan culture prioritizes seeking continuous change and innovation, and motivates employees to suggest creative new ideas and plan for continuous improvement in order to make the company better. Management openly listens when employees suggest new ideas and opinions. When these ideas and suggestions are accepted and implemented, they are shared with all employees immediately. Such effective sharing of new ideas and best practices throughout the organization motivates employees to produce better ideas and seek new approaches continuously while they are working in order to improve the company.

\section{d. Controlling}

In the Shinhan Group, employees have a high level of self-regulation and autonomy. Managers have much less direct control, as the management responsibilities of each business are fully delegated to those in responsible positions. Managers and employees actively participate in decision-making and implementation. Shinhan has a unique two-tier management structure. The chairman fully delegates management responsibilities to CEOs of Shinhan Bank and all affiliated companies. However, he directly participates in strategic decision-making and establishing of the company's long-term vision and goals. Some interviewees described it this way:

From the early stages of the Shinhan Bank, our top management emphasized strong teamwork through differentiated managing of the organization, creating a non-bureaucratic open organizational culture with bottom-up decisionmaking and an open discussion and participation-based culture which was quite different from the culture of other major banks in Korea during that period. It may take more time to collect opinions of all participants and build consensus for making decisions, but employees' psychological ownership is inspired by this participation, and employees fully support the decisions, as their opinions and suggestions are well reflected in the decisions.

Shinhan's culture is closer to a horizontal culture with lower-level control as compared to a vertical culture with high-level top-down control.

\section{e. Boundary-less}

Active boundary-less communication and teamwork are characteristic of Shinhan companies. Sharing information and knowledge among employees across various layers and organizations is prioritized. Most decisions are made through boundary- 
less open discussions and exchanging opinions among the concerned organizations and workers. One interviewee summarized it this way:

There are lots of formal and informal meetings in our company for making decisions and planning effective implementation. Through this active open communication culture, our management and senior-level leaders well remember most working-level peoples' names and understand their characters and abilities. This has created Shinhan's unique family-oriented environment and a strong psychological ownership.

\section{f. Other observations from the interviews}

According to a senior interviewee, the company respects employees' teamwork and considers it the most important capability to achieve company goals and maintain the company's reputation and image. When the company hires new employees, teamwork capability and ability to get along with other people are considered important qualifications. Table 7.5 summarizes the findings of this section.

\section{Table 7.5 Summary of organizational culture for Shinhan Group}

\begin{tabular}{l|l}
\hline Characteristics & Descriptions \\
\hline People-oriented & $\begin{array}{l}\text { Strong people-oriented humanitarian organizational culture. Respecting } \\
\text { employees as co-workers. Typical family-oriented culture. Fair and } \\
\text { transparent HMR systems based on performance and capability. } \\
\text { Considering employeesí teamwork and relationships is most important. } \\
\text { Empowering people to have a strong psychological ownership and loyalty } \\
\text { to the company. }\end{array}$ \\
Innovation & $\begin{array}{l}\text { Highly challenging frontier spirit, seeking the vision and goals for } \\
\text { building a global leading bank. Aggressively entering into new businesses } \\
\text { and markets. Strong customer-centered spirit and approach. Strong } \\
\text { fighting spirit, hating to be defeated by the competition. }\end{array}$ \\
$\begin{array}{l}\text { Seeking continuous change and innovation. Motivating employees to } \\
\text { suggest creative new ideas and plans for improvement and innovation, } \\
\text { and openly listening to their opinions and ideas. When employeesí new } \\
\text { ideas and suggestions are accepted for implementation, they are shared } \\
\text { with all organizations and people effectively. }\end{array}$ \\
$\begin{array}{l}\text { High-level self-regulation and autonomy and minimum control, } \\
\text { as management responsibilities are fully delegated. Typical two- } \\
\text { tier management structure. Chairman directly participates in } \\
\text { making strategic decisions and establishing long-term vision and } \\
\text { goals. Motivating employees to participate in decision-making and } \\
\text { implementation actively. }\end{array}$
\end{tabular}




\begin{tabular}{l|l} 
Boundary-less & $\begin{array}{l}\text { Boundary-less communication and active teamwork culture, sharing } \\
\text { information and knowledge across various layers and organizations } \\
\text { within the company. Frequent formal and informal open meetings for } \\
\text { making decisions and efficient teamwork for implementation. }\end{array}$ \\
Other observations & $\begin{array}{l}\text { Company considers employeesí teamwork capability to be most } \\
\text { important. When the company hires new employees, teamwork capability } \\
\text { is considered an important qualification. }\end{array}$
\end{tabular}

\subsubsection{Knowledge productivity}

a. Continuous improvement and innovation of products, services, and work processes (KP1) The leaders of the Shinhan Financial Group and Shinhan Bank strongly and constantly emphasize improvement and innovation of Shinhan's financial products, quality of services, and work processes to make Shinhan a leading bank in Korea and Asia. For doing this, the company provides strong support and invests in employees' education and self-development programs and on-the-job training for continuous knowledge improvement and fostering of creativity. It encourages and motivates employees to create new ideas for continuous improvement and innovation of work processes and quality of products and services with a special incentive program. Shinhan Bank implemented a 6-sigma program throughout the company to improve management quality of all operations and systems, including work processes and customer service, challenging all workers to achieve the level of zero-defects. Through these programs, the company's competitiveness improved significantly. As a result, Shinhan became the leading bank in Korea. A senior interviewee made the comment that

Shinhan grew fast and became the most successful leading bank in Korea in 28 years. Thus, our people have high pride in their achievement. However, we always think we have still not done enough to achieve our high-challenging goal. Our people are always working hard with a strong psychological ownership for continuous self-development and creating knowledge and new ideas for continuous improvement and innovation to achieve our ultimate goal.

Another senior interviewee mentioned the CoP (Community of Practice) (Lee, Suh, \& Hong (2010), which is also a very important feature of the Shinhan Group. He described it as follows:

Our people share knowledge, ideas, information, and best practices through 
CoPs, which include internal community networks. Each individual joins one or two CoPs, and approximately $700 \mathrm{CoPs}$ are in operation in our company.

In order to solve various problems our company faces while we are working, finding and gathering ideas from various different field employees is important and the CoP networks are very effective to collect those ideas. Furthermore, teamwork through open communication in Communities of Practice is important for making decisions and executing them.

In addition, Shinhan has implemented a KM (Knowledge Management) Score program since 1998. The company checks and calculates KM Scores to show how well employees are sharing knowledge, developing new knowledge, and applying newly developed knowledge into the practical management systems in the company.

\section{b. Sustainable development of future growth engine (KP2)}

Shinhan people and culture have a strong capability to overcome crisis and change adversity into new growth opportunities. The head of one department explained the following example.

When the Shinhan Bank merged with the Cho-hung Bank, which was one of the top three banks in Korea, having a long banking business history of over 100 years, many people worried about the merger, as the majority of Cho-hung Bank people strongly objected to a merger by a young bank such as Shinhan. However, Shinhan people and leaders successfully overcame these significant difficulties through the approach of boundary-less open communication and sharing opinions by implementing a special "Work-Out Town Meeting" program for Shinhan and Chohung people together. After merging of the two banks, Shinhan became one of the top two banking firms in Korea. This case of Shinhan's peacefully and successfully merging with Cho-hung Bank became a case study model for academic research in universities, such as Harvard Business School. The basis of the Shinhan Way is continuous high challenge-seeking for sustainable future growth.

Other interviewees explained Shinhan's new challenge to expand banking businesses to global markets.

As the domestic market provides limited opportunity for future growth, Shinhan management adopted a challenging long-term goal and plans for expanding Shinhan business into foreign countries to establish global banking operations. 
The inspiration and intuition of our chairman Mr. Rah played an important role in the long-term plan. As a result, the company operates many subsidiaries in many different countries, such as China, Vietnam, Japan, Australia, and Canada. Not only have local subsidiaries been established in many different countries, but global banking network systems have also been established.

We did our best, but it is not easy to set up local subsidiary operations in those foreign countries, since there are many different rules and regulations and local government approval must be obtained. Therefore, we need to implement our long-term plan to build a global leading financial company.

Another observation from the interviews revealed that Shinhan established a special online network for knowledge sharing called the Knowledge Management Folder, in which Shinhan people can freely participate and share knowledge and ideas. Shinhan people maintain close relationships and formal and informal networks, openly sharing knowledge and ideas. Shinhan people normally invest significant private time after business hours to maintain these close and friendly teamwork relationships with co-workers. This close networking culture enhances knowledge sharing and knowledge productivity for Shinhan companies. A summary of the findings of this study on knowledge productivity is provided in Table 7.6.

\section{Table 7.6 Summary of knowledge productivity in the Shinhan Group}

\begin{tabular}{l|l}
\hline Characteristics & Descriptions \\
\hline $\begin{array}{l}\text { Continuous } \\
\text { improvement and } \\
\text { (KP1) }\end{array}$ & $\begin{array}{l}\text { Strong support for and investment in employees education and self- } \\
\text { development programs and on-the-job training for continuous knowledge } \\
\text { improvement and fostering creativity. Encouraging and motivating } \\
\text { employees to create new ideas for continuous improvement and } \\
\text { innovation of work processes and quality of products and services with a } \\
\text { special incentive program. Implemented the 6-sigma program throughout } \\
\text { the company to improve management quality of all operation systems. } \\
\text { Each individual joins one or two CoPs activities, and approx. 700 CoPs are } \\
\text { in operation. }\end{array}$ \\
$\begin{array}{l}\text { Sustainability } \\
\text { development of } \\
\text { future growth engine } \\
\text { (KP2) }\end{array}$ & $\begin{array}{l}\text { sustainable growth. Shinhan people have strong capability to overcome } \\
\text { crisis and change them into new growth opportunities. } \\
\text { Shinhan management, with their inspiration and intuition, continuously } \\
\text { works on the long-term goal to expand Shinhan into foreign countries and } \\
\text { establish global banking operations. }\end{array}$ \\
Other observations & $\begin{array}{l}\text { Shinhan opened a special online site (Knowledge Management Folder) } \\
\text { for knowledge sharing where Shinhan people freely participate and share } \\
\text { knowledge and ideas. Close networking culture enhances knowledge } \\
\text { sharing and knowledge productivity. }\end{array}$ \\
\hline
\end{tabular}




\subsubsection{Value creation}

\section{a. Corporate reputation, image, and CSR}

Shinhan has maintained a strong reputation and image as a sound and sustainable growing top financial business in Korea with high risk management capability. The company has a well-established, strong image of field service and customer-oriented operations. Interviewees expressed consensus in their opinions on the company's special relationship with customers:

Shinhan emphasizes a customer-oriented sales mentality. Wherever and whenever customers want, we are ready for them. By building such special customer relationships through sales activities, our company is closer to its customers and respects them. Shinhan maintained customer-oriented management principles and culture as a top priority from the beginning.

According to the interviewees, Shinhan actively participates in corporate social activities. For example, the company organized and operates a CSR and culture management team for active participation in CSR activities, which improved Shinhan's corporate image. A senior interviewee provided his opinion on CSR activities:

For sustainable management, Shinhan made significant efforts to build a warm and people-oriented company image to the public. The company founded the Shinhan Scholarship Foundation to help and support education of students from low-income families and students who are the child head of the family. In order to support and promote culture, Shinhan opened and operates art and culture exhibition halls.

These social activities are consistent with the management principle and philosophy of Shinhan. They have improved social awareness and the company reputation and image of Shinhan as a corporate citizen. In addition, many employees volunteered to join CoPs and social service activities to contribute to society. They must participate in such community service work at least once a year, and the company encourages employees to use part of their paid annual holidays for social service work. 


\section{b. Employee satisfaction with work environment and benefits}

Interviewees' opinions are in consensus on this subject. Although most of the people in the company have intense workloads, they are highly satisfied with their jobs. They also have a strong psychological ownership and loyalty to the company. Employees are proud of working for Shinhan, as the company culture is very humanitarian and people-oriented, respecting employees and giving them equal opportunities. Thus, they are able to concentrate on their work without concerns about working conditions. Employees are satisfied with the company work environment and financial compensation levels.

\section{c. Sustainability}

Shinhan's management quality, effective leadership, and "people power" of the organization members allowed the company to achieve sustained high growth since it was established in 1982. From 1990 to 2010, total assets grew 2,332\%, net profit grew $1,665 \%$, and market value grew $1,970 \%$. According to senior interviewees, Shinhan's leadership was constantly seeking a high-challenging, long-term vision to make Shinhan a global leading bank.

However, the leader seeks stable and sustainable growth rather than taking high risks for rapid growth. Shinhan's management maintained a stable risk management approach and was well prepared for potential risks. As a result, Shinhan Bank maintained sustained growth throughout the financial crises in 1998 and 2008, while other banks experienced severe negative impacts on performance. Interviewees expressed their confidence in the sustainable capability of Shinhan Bank management.

\section{d. Financial data on 10-year performance}

Table 7.7, Figure 7.1, and Figure 7.2 respectively show the net profit, total assets, and market value of Shinhan Bank from 1990 to 2010, and a comparison in terms of market share of the top five major Korean banks in 2010. Data on net profit, total assets and market value of Shinhan Bank were collected from the annual reports of the company filed with the Korea Stock Exchange. The Korea Industry Research Institution provided financial data of the top 100 companies, from which the top five banks in the finance industry were selected for comparison of market share. 
Table 7.7 Net profit, total assets, and market value of Shinhan Bank (1990-2010)

Unit: billion (KRW), percentage (\%), person (number)

\begin{tabular}{lrrrrrrrr}
\hline & $\mathbf{1 9 9 0}$ & $\mathbf{2 0 0 0}$ & $\mathbf{2 0 0 2}$ & $\mathbf{2 0 0 4}$ & $\mathbf{2 0 0 6}$ & $\mathbf{2 0 0 8}$ & $\mathbf{2 0 0 9}$ & $\mathbf{2 0 1 0}$ \\
\hline Total assets & 10,046 & 53,186 & 58,889 & 71,759 & 177,007 & 249,509 & 233,537 & 234,314 \\
PPP & 148 & 1,599 & 1,060 & 1,446 & 2,893 & 2,856 & 2,387 & 3,363 \\
Net profit & 99 & 372 & 595 & 844 & 1,431 & 1,446 & 748 & 1,648 \\
ROA & $1.64 \%$ & $0.85 \%$ & $1.05 \%$ & $1.15 \%$ & $1.08 \%$ & $0.71 \%$ & $0.34 \%$ & $0.77 \%$ \\
ROE & $9.06 \%$ & $12.24 \%$ & $19.79 \%$ & $22.48 \%$ & $17.66 \%$ & $12.69 \%$ & $5.89 \%$ & $11.45 \%$ \\
Employee & 3,241 & 4,241 & 4,377 & 4,820 & 10,741 & 10,998 & 10,340 & 10,832 \\
Market value & 1,273 & 5,135 & 3,625 & 7,472 & 18,124 & 11,767 & 20,390 & 25,085 \\
\hline
\end{tabular}

The Shinhan Bank and Cho-hung Bank merged in 2003 Thus, data from 2006 to 2010 also included Cho-hung Bank. Market value: Based on the data of the Shinhan Financial Group, the holding company in which Shinhan Bank is included as an affiliate. PPP: Pre-provision profit. ROA: return on assets, ROE: return on equity. Shinhan Bank experienced a negative impact on ROA and ROE from the global financial crisis in 2008.

Figure 7.1 Total assets and net profits of Shinhan Bank (1990-2010)

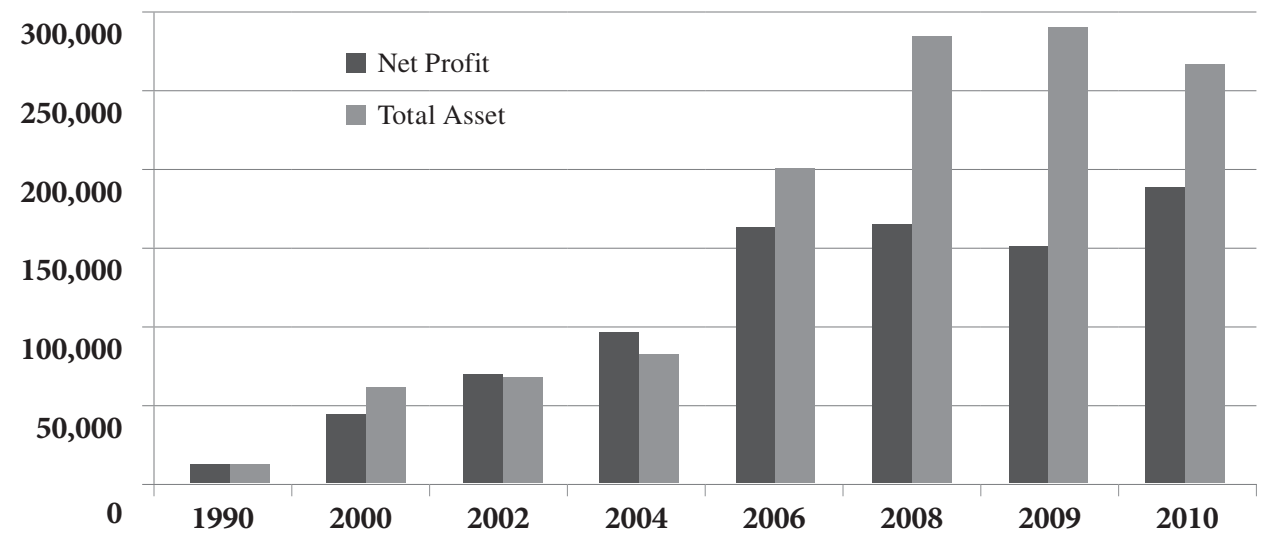

Figure 7.1 shows net profit and total assets of the Shinhan Bank between 1990 and 2010. Both indicators increased continuously despite the global financial crisis. 
Figure 7.2 Market shares of the banking sector in the financial industry in Korea in 2010

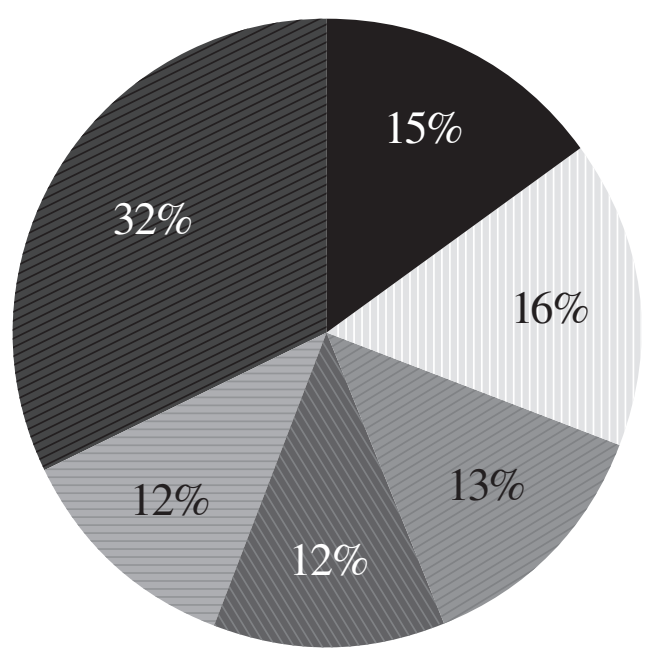

Shinhan

Woori

Kookmin

SC First

Hana

Others

Figure 7.2 provides information regarding the market share of the banking sector in the financial industry in 2010 for five major Korean banks: Shinhan, Woori, SC First, Kookmin, and Hana. The cumulative share for all other banking institutions in Korea is also represented.

These five major banks have $68 \%$ of the market share of the banking sector in the Korean financial industry. The Shinhan Bank is reported as having the second-highest market share (15\%). 
Table 7.8 Summary of value creation for Shinhan Group

\begin{tabular}{|c|c|}
\hline Characteristics & Descriptions \\
\hline $\begin{array}{l}\text { Corporate } \\
\text { reputation, image, } \\
\text { and CSR }\end{array}$ & $\begin{array}{l}\text { Maintaining high reputation and image through sound and sustainable } \\
\text { growth, becoming a leading bank in Korea. } \\
\text { Establishing a strong tradition of active field service and customer- } \\
\text { oriented operations. }\end{array}$ \\
\hline Management quality & $\begin{array}{l}\text { Active participation in corporate social activities. Shinhan organized and } \\
\text { operates a CSR and culture management team. The company founded the } \\
\text { Shinhan Scholarship Foundation to support education of students from } \\
\text { low-income families and students who are the child head of the family. } \\
\text { Encouraging employees to participate in volunteer social service work } \\
\text { during their annual vacation. } \\
\text { Shinhan management maintained the principle of employees' } \\
\text { psychological ownership within the company, called the Shinhan Way, } \\
\text { working for customers, employees, and shareholders. People of the } \\
\text { company respect and trust the leader as a role model of the management } \\
\text { principle of Shinhan. }\end{array}$ \\
\hline $\begin{array}{l}\text { Employee } \\
\text { satisfaction }\end{array}$ & $\begin{array}{l}\text { Employees are highly satisfied with their jobs, compensation, } \\
\text { opportunities, and work environment, especially the open and progressive } \\
\text { organizational environment. Strong psychological ownership of } \\
\text { empowered Shinhan people. }\end{array}$ \\
\hline Other observations & $\begin{array}{l}\text { Shinhan restructured its corporate governance system; as a result, } 11 \\
\text { affiliated financial businesses (including Shinhan Bank) are under the } \\
\text { umbrella of the holding company, Shinhan Financial Group. Shinhan } \\
\text { Bank expanded global operations. } 51 \text { overseas operations in } 14 \text { foreign } \\
\text { countries. Long-term goal is to become a global financial company and } \\
\text { play a leading role in Asia. }\end{array}$ \\
\hline Performance & $\begin{array}{l}\text { Outstanding performance records based on financial data. Total assets, } \\
\text { net profit, and market value grew significantly as a result of successful } \\
\text { management. } \\
\text {-Total asset growth: } 23.3 \text { times (1990-2010) KRW } 234,314 \text { bil (2010) } \\
\text {-Net profit growth: } 16.6 \text { times (1990-2010) KRW 1,648 bil (2010) } \\
\text {-Market value growth: } 19.7 \text { times (1990-2010) KRW 25,085 bil (2010) }\end{array}$ \\
\hline
\end{tabular}

\subsection{Conclusion of Shinhan Bank case study}

The Shinhan Bank achieved sustained high growth during the period from 1990 to $2010,2,332 \%$ growth in total assets, a 1,665\% increase in net profit, and $1,970 \%$ growth in market value. During the research period (2000-2010), value creation of 
the Shinhan Bank was significant, as evidenced by a $441 \%$ increase in total assets, $443 \%$ growth in net profit, and $449 \%$ increase in market value, except in 2008 . Due to the negative impact of the global financial crisis in 2008, net profit, ROA, and ROE declined significantly in 2009. Recovery occurred in 2010. Since the Shinhan Bank was established in 1982, it grew continuously due to its high-challenging leadership and people-oriented, empowering organizational culture, becoming one of the top two leading banks in Korea within 28 years.

The main purpose of this empirical research on the case of the Shinhan Bank using both qualitative and quantitative analysis was to explore correlations among key variables (leadership, organizational culture, knowledge productivity, and value creation) based on the conceptual framework of the research model. By this method, an effective leadership style may be defined and the optimal organizational culture identified for improving and upgrading knowledge productivity and high value creation. The Shinhan Bank is a special success story to study due to its sustained high growth and rapid rise to success.

Findings from the qualitative analysis of interviews with Shinhan executives and managers indicated that the Shinhan leader's leadership style (e.g., softly charismatic, highly people-oriented, high-challenging, visionary, and entrepreneurial) has created a typical, open, empowering, people-oriented, and challenging organizational culture in which Shinhan employees want to do their best to achieve the vision and goals of the company with a strong psychological ownership and creative thinking. In this organizational culture, knowledge productivity has flourished because the management respects people's knowledge and ideas. Most staff members and employees are actively and effectively sharing information, knowledge, and ideas through the boundary-less and open programs offered by the organization. This is reflected in the correlations between Shinhan's management leadership style and organizational culture, which are significantly and positively related to knowledge productivity. As a result, Shinhan was able to achieve sustained high growth and high value creation for the 10 years examined in this study.

Findings from the quantitative analysis strongly supported the findings and interpretation of the qualitative analysis. The results of the quantitative analysis showed that the Shinhan Group and Shinhan Bank's leadership characteristics (people-oriented and innovative, LS1; visionary and entrepreneurial, LS2; and high challenge-seeking, and risk taking, LS3) had significantly positive relationships with 
characteristics of organizational culture (people-oriented, OC1; high challengeseeking and innovative, OC2). These leadership and organizational culture characteristics had significantly positive relationships with knowledge productivity (improvement and innovation of products, services, and work processes, KP1; sustainable development of future growth engines, KP2). All these leadership characteristics, organizational culture characteristics, and knowledge productivity of the Shinhan Bank had significant and positive relationships with the key value creation factors (corporate reputation, image, and CSR, VC1; employee satisfaction with work environment, VC2; employee satisfaction with financial benefits, VC3; and sustainability, VC4). Financial data on the performance of the Shinhan Bank demonstrate its successful value creation and show continuous and stable growth of total assets, net profit, and market value for the 10 years of the research period (2000-2010). The results of this empirical research, in which both qualitative and quantitative analysis methods were used, strongly supported the conceptual framework of the research model.

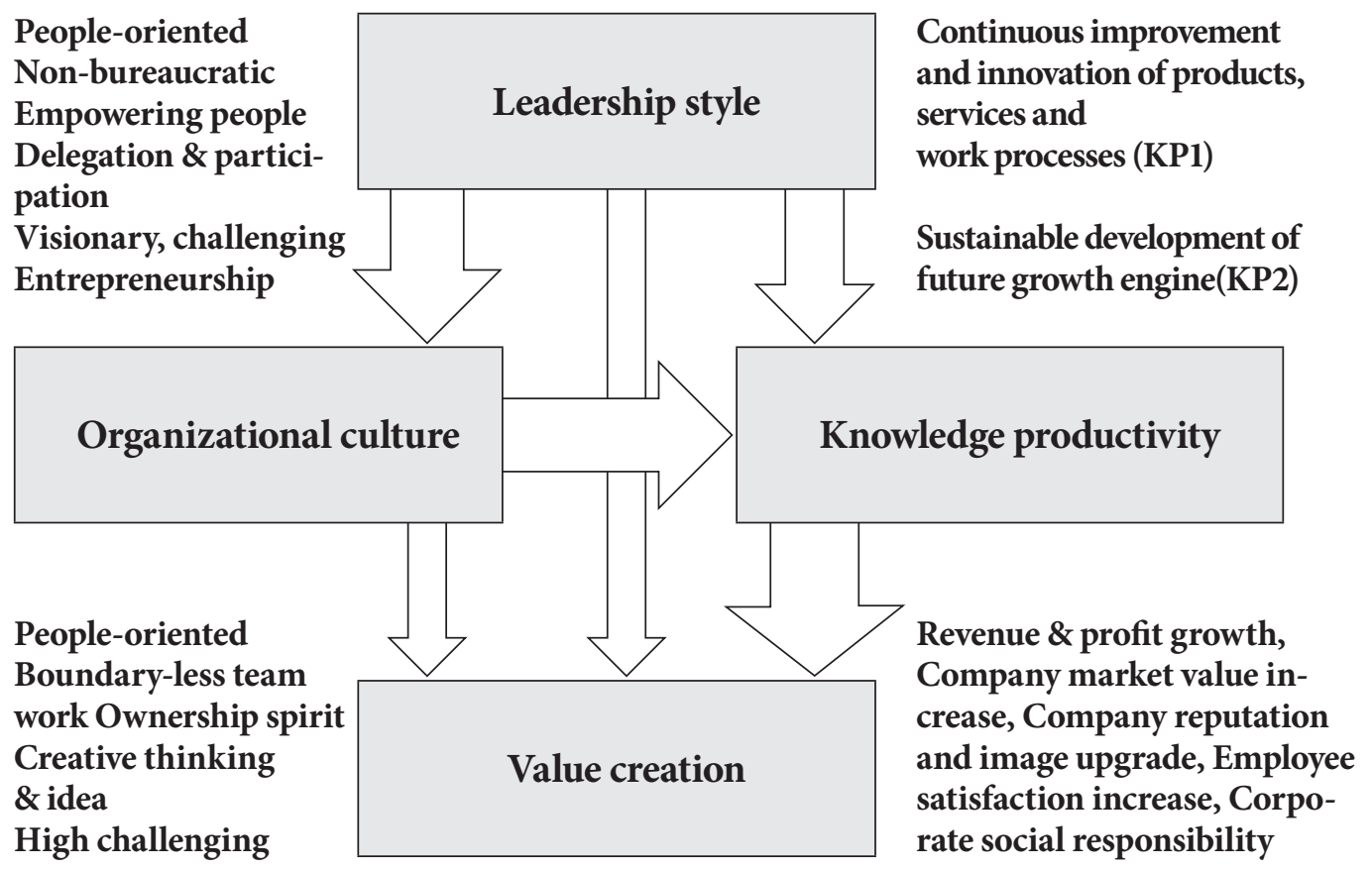

Figure 7.3 Summary of the relations between the four main variables in the Shinhan Bank case study 
In Figure 7.3, powerful interactions among the four main variables are observed in the Shinhan Bank case.

Leadership style was significantly and positively related to organizational culture (thick arrow, top left), organizational culture was significantly and positively related to knowledge productivity (thick arrow, middle), and knowledge productivity was significantly and positively related to value creation (thick arrow, bottom right). Leadership style was significantly related to knowledge productivity through organizational culture, and also directly related to knowledge productivity. As the leader, the chairman provided strong intuition and inspiration based on his many years of business operations and management experience.

Leadership style was significantly and positively related to value creation through organizational culture and knowledge productivity. The leadership style of the Chairman of the Shinhan Financial Group and the CEO of the Shinhan Bank are close to the B-type leadership described in this research model.

As a result of the empirical research into the Shinhan Bank, we can observe strong relationships among the four main factors: (1) Shinhan's unique people-oriented, visionary entrepreneurship and high-challenging leadership style; (2) its creative and strong teamwork as a result of its people-oriented open organizational culture; (3) its high knowledge productivity; and (4) high value creation resulting in sustained future growth capability. These results provided building blocks for answering the main research questions of this study. Table 7.9 summarizes the findings of this case study.

The case study reports of each company were sent for validation to the participants. On the basis of the reports, the researcher organized feedback discussions with senior management. In response to the feedback, some minor changes and additions were made in the case reports. 
Table 7.9 Summary of Shinhan Bank case in terms of the four main variables

\begin{tabular}{l|l}
\hline Variables & Descriptions of key common characteristics of the four factors \\
\hline Leadership & $\begin{array}{l}\text { Strong people-oriented and softly charismatic leadership. High challenge- } \\
\text { seeking entrepreneurship with a long-term goal to become one of the top 10 } \\
\text { Asian banks and financial businesses groups. Empowering people and the } \\
\text { organization. }\end{array}$ \\
$\begin{array}{l}\text { Organizational } \\
\text { culture }\end{array}$ & $\begin{array}{l}\text { People-oriented humanitarian culture. Strong psychological ownership of } \\
\text { empowered people enjoying their work with passion. Open, boundary-less } \\
\text { teamwork capability and sharing knowledge and ideas. }\end{array}$ \\
$\begin{array}{l}\text { Knowledge } \\
\text { productivity }\end{array}$ & $\begin{array}{l}\text { Leader strongly demanding continuous changes and improvement of work } \\
\text { processes and services for sustainable growth. Active learning culture } \\
\text { and top priority for developing talent and human resources, making a } \\
\text { highly knowledge-productive organization. High-challenging and open } \\
\text { organizational culture motivating continuous innovation. }\end{array}$ \\
Value creation & $\begin{array}{l}\text { Achieved important successful sustained growth and high value creation for } \\
\text { the past 10 years. High employee and customer satisfaction and reputation. } \\
\text { Active participation in corporate social activities. }\end{array}$ \\
\hline
\end{tabular}




\section{Chapter 8. Cross-case analysis of similarities and differences among the four companies}

\subsection{Introduction}

This chapter presents a cross-case analysis of the results from the case studies into the four Korean companies. Section 8.2 presents the findings of the quantitative analysis. Section 8.3 presents the findings of the qualitative analysis of the data from the interviews conducted with executives and managers of the same four companies to shed more light on the nature of the relationships among the four main variables. The concluding Section 8.4 offers a summary of the findings from the four case studies.

\subsection{Quantitative analysis of the survey data}

\subsubsection{Demographic characteristics}

In total, 387 respondents from the four companies completed the questionnaires (out of 480 questionnaires distributed). The sample characteristics are summarized in Table 8.1 below.

Table 8.1 Characteristics of survey respondents

\begin{tabular}{lllc}
\hline \multicolumn{1}{c}{ Parameter } & Percentage (\%) & \multicolumn{1}{c}{ Parameter } & Percentage (\%) \\
\hline Gender & & Rank & \\
Male & 85.8 & Employee & 11.6 \\
Female & 14.2 & Assistant manager & 9.8 \\
& & Manager & 31.8 \\
& & Senior manager & 24.3 \\
Age & & Executive & 22.5 \\
$<\mathbf{3 0}$ years & 14.0 & & \\
31-40 years & 38.7 & & \\
41-50 years & 40.5 & Education level & \\
$>\mathbf{5 1}$ years & 6.8 & High school & \\
Tenure & & College & 1.6 \\
$<5$ years & 29.7 & Bachelor's degree & 2.6 \\
6-10 years & 24.3 & Master's degree & 74.2 \\
$>\mathbf{1 1}$ years & 46.0 & Doctorate degree & 18.9 \\
\hline
\end{tabular}


The majority of the respondents were highly educated, experienced male managers. The rank and educational level of sample is important for the questions about leadership characteristics of chairmen, CEOs, and senior executives. Senior-level respondents were better equipped to answer questions on subject matter related to the four major variables examined in this study. Their distance from the strategic discussions on top issues of the company and issues on knowledge productivity and value creation is very short. The sample also showed that the social top structure of most Korean companies is still very much dominated by male managers. The statistical analysis of the data on the combined four companies, the mean values, standard deviations, and correlations among the variables are listed in Table 8.2. 


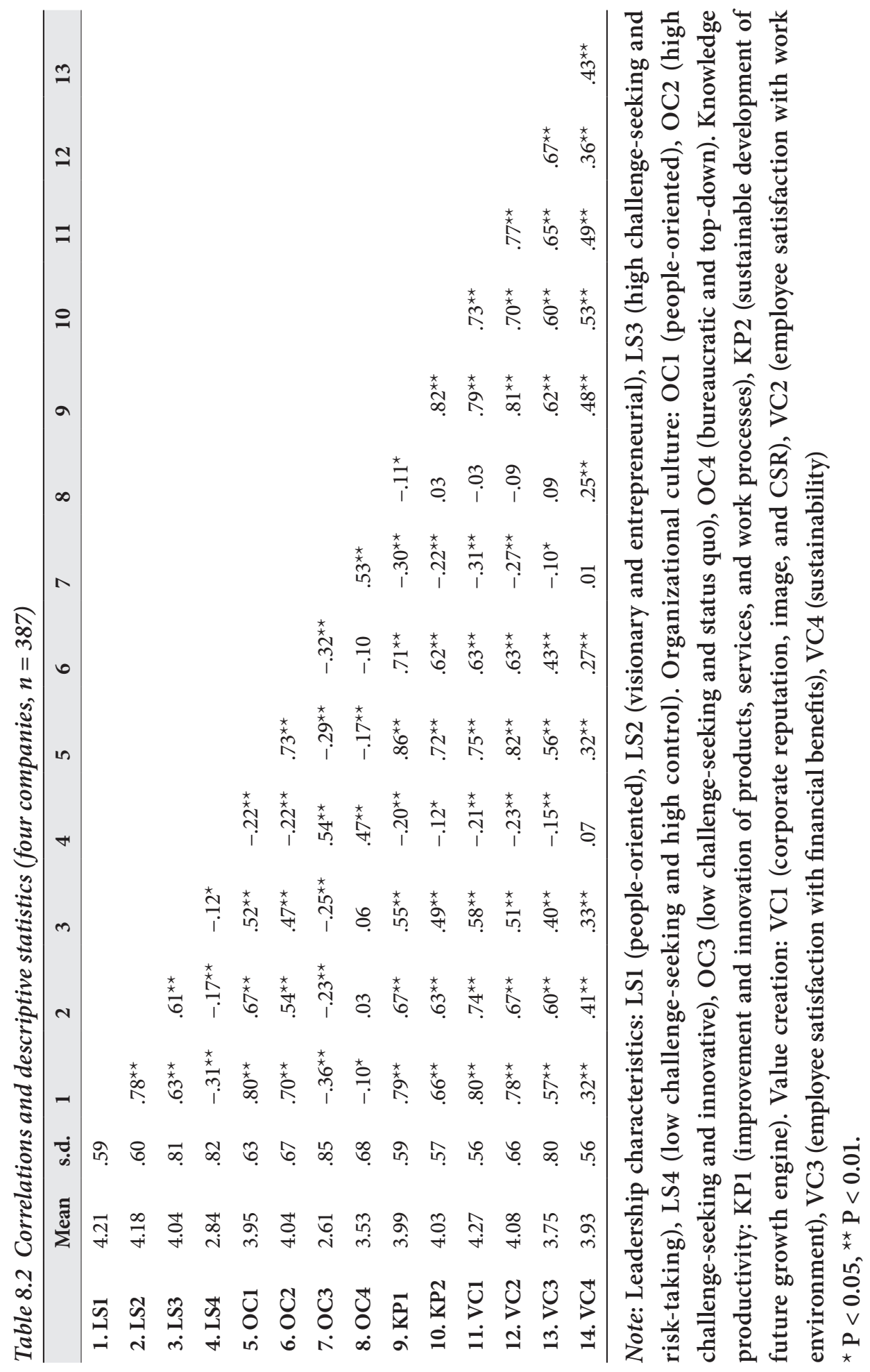




\subsubsection{Relations among key variables}

Table 8.2 shows the means, standard deviations, and correlations among the key variables. The results of the analysis indicated that significant and positive relationships exist between leadership characteristics (people-oriented, LS1; visionary and entrepreneurial, LS2; and high challenging-seeking and risk-taking, LS3) and characteristics of organizational culture (people-oriented, $\mathrm{OC1}$; and high challengeseeking and innovative, OC2). Significantly negative relationships were found between the leadership characteristic (low challenge-seeking and high control, LS4) and the organizational culture characteristics (people-oriented, $\mathrm{OC1}$; and high challengeseeking and innovative, OC2). By contrast, significantly positive relationships were found between the particular leadership characteristic (low challenge-seeking and high control, LS4) and the two organizational culture characteristics (low challengeseeking and status-quo, OC3; and bureaucratic and top-down, OC4).

Significant and positive relationships were identified between three leadership characteristics (people-oriented, LS1; visionary and entrepreneurial, LS2; and highly challenge-seeking and risk-taking, LS3) and knowledge productivity (improvement and innovation of products, services, and work processes, KP1; and sustainable development of future growth engines, KP2). On the other hand, a significantly negative correlation was identified between low challenge-seeking and highly controlling leadership (LS4) and improvement and innovation of products, services, and work processes (KP1) and sustainable development of future growth engines (KP2).

In addition, significant and positive relationships were found between three leadership characteristics (people-oriented, LS1; visionary and entrepreneurial, LS2; and high challenge-seeking and risk-taking, LS3) and the value creation factors (corporate reputation, image, and CSR, VCl; employee satisfaction with work environment, VC2; employee satisfaction with financial benefits, VC3; and sustainability, VC4). However, significantly negative correlations were found between low challenge-seeking and high-controlling leadership (LS4) and the value creation factors (corporate reputation, image, and CSR, VC1; employee satisfaction with work environment, VC2; and employee satisfaction with financial benefits, VC3).

Significantly positive correlations were detected between people-oriented organizational culture (OC1) and high challenge-seeking and innovative organizational culture (OC2) and the knowledge productivity factors (improvement and innovation of products, services, and work processes, KP1; and sustainable development of future growth engines, KP2). Conversely, significantly negative 
correlations were found between low challenge-seeking and status quo organizational culture (OC3) and the knowledge productivity factors (improvement and innovation of products, services, and work processes, KP1; and sustainable development of future growth engine, KP2). Significantly negative correlations were found between bureaucratic and top-down organizational culture (OC4) and the knowledge productivity factor (improvement and innovation of products, services, and work processes, KP1).

Significant and positive correlations were seen between people-oriented organizational culture (OC1) and high challenge-seeking and innovative organizational culture (OC2) and the value creation factors (corporate reputation, image, and CSR, VC1; employee satisfaction with work environment, VC2; employee satisfaction with financial benefits, VC3; and sustainability, VC4). Significantly negative correlations were found between low challenge-seeking and status quo organizational culture (OC3) and the value creation factors (corporate reputation, image, and CSR, VC1; employee satisfaction with work environment, VC2; and employee satisfaction with financial benefits, VC3). No significant correlations were observed between bureaucratic and top-down organizational culture (OC4) and the value creation factors (corporate reputation, image, and CSR, VC1; employee satisfaction with work environment, VC2; and employee satisfaction with financial benefits, VC3). However, a significantly positive correlation was found between topdown organizational culture (OC4) and sustainability (VC4) in this correlation analysis of the four companies. The results of the correlation analysis of each of the four companies in Chapter 4 indicated that in the cases of LG Electronics, Samsung Electronics, and WoongJin Group, no significant correlations were evident between bureaucratic and top-down organizational culture (OC4) and the value creation factors (corporate reputation, image, and CSR, VCl; employee satisfaction with work environment, VC2; employee satisfaction with financial benefits, VC3; and sustainability, VC4). However, in the case of Shinhan Bank, a significant and positive correlation was identified between bureaucratic and top-down organizational culture (OC4) and one value creation factor (sustainability, VC4), unlike in the other three companies. Also in the Shinhan case, no significant correlations were found between bureaucratic and top-down organizational culture (OC4) and other value creation factors (corporate reputation, image, and CSR, VC1; employee satisfaction with work environment, VC2; and employee satisfaction with financial benefits, VC3), as in the other three companies' cases.

The differences in results of the correlation analysis between Shinhan Bank and the other three companies in the relationship between bureaucratic and top-down 
organizational culture (OC4) and sustainability (VC4) could be interpreted and understood as follows. Korean financial companies, especially banks, are characterized by a more conservative and less risk-taking culture, and are more used to top-down central control. Like the Shinhan Bank, they managed financial risks very effectively and protected the sustainability of their banking and other financial businesses during the 1977 Asian financial crisis (IMF Crisis) and the 2008 global financial crisis.

Finally, significantly positive correlations were observed between knowledge productivity (improvement and innovation of products, services, and work processes, KP1; and sustainable development of future growth engine, KP2) and the value creation factors (corporate reputation, image, and CSR, VC1; employee satisfaction with work environment, VC2; employee satisfaction with financial benefits, VC3; and sustainability, VC4).

The four leading Korean companies included in this study share commonalities in leadership and organizational culture. They are people-oriented, high challengeseeking and risk-taking, innovative, visionary, and entrepreneurship-oriented. Those commonalities in leadership and organizational culture created knowledgeproductive organizations, which enabled the achievement of high value creation and sustainability.

\subsection{Qualitative analysis of interviews data}

We conducted in-depth interviews with management, executives, managers, and employees of the four companies from 2009 to 2010. A qualitative analysis of the interview data from the four companies may shed additional light on the nature of the relationships among the main variables, thus allowing us to learn more about characteristics of leadership that have a positive impact on knowledge productivity leading to the achievement of high value creation.

\subsubsection{Leadership and organizational culture}

The results of this empirical research indicated that leadership characteristics and organizational culture are significantly related. This observation supports the claim of Schein (2004) that "culture and leadership are two sides of the same coin" (2004, p. 22). The first three leadership characteristics (people-oriented, visionary and entrepreneurship-oriented, and highly challenge-seeking and risk-taking) are similar to the organizational culture styles (people-oriented and highly challenge- 
seeking and innovative). During the interviews, respondents found it difficult to separate aspects of leadership from characteristics of culture clearly. The leaders of each company are deeply embedded in the culture of their respective organizations, and are part of their creation and constant recreation. For this reason, the results of the cross-case analysis on leadership and organizational culture are combined here for all companies, and the findings for organizational culture are included in this leadership section.

The results of the qualitative analysis revealed that although differences exist in the leadership styles and organizational cultures of the four companies, important commonalities among the key characteristics can be found; they are peopleoriented, visionary, and entrepreneurial, and high challenge-seeking, risk-taking, and innovative. These key characteristics of leadership and organizational culture were significantly and positively correlated with knowledge productivity and value creation in the four companies. Knowledge productivity was also significantly and positively correlated with value creation. Many interviewees were very clear about the importance of continuous improvement and innovation. They stressed the need for open information sharing, learning, and creative thinking. Therefore, creating an organizational culture that promotes knowledge productivity is an important mission and responsibility of business leaders today.

These leaders try to empower and motivate their people by creating non-bureaucratic and open organizational cultures with considerable freedom. They see the need for people in the organization to become more creative and innovative, demonstrating a strong psychological ownership and doing their best to achieve the company's vision and goals. These findings are in the line with the research of Avey et al. (2012) who claimed that individuals with psychological ownership feel more enthusiastic about working for the organization's targets, feel more accountable to the target, and experience a greater sense of belongingness to the organization.

Although the chairmen and CEOs in the four companies delegate management responsibilities to each business and division leader, in major strategic decisionmaking and managing of important projects, they also participate either directly or indirectly through management organization and controlling systems. No examples of low challenge-seeking, bureaucratic, and highly controlling leadership characteristics were found in any of the cases examined in this study.

\section{a. Leading people and organizations by not controlling}

During the interviews, leaders often mentioned that the ways of leading people and 
organizations have changed and progressed during the past few decades, from the traditional way of bureaucratic top-down controlling and managing to the nonbureaucratic, open, and participative way of leading. Leaders of the four companies examined here prioritize leading and empowering people and organizations rather than controlling. The common ways of leading and empowering in these four companies are as follows:

1) Respecting people in the organization as co-workers and fellow partners, and value their opinions and ideas, not just as employees or hired people.

2) Sharing vision and goals with all organization members through boundary-less open communications. Leaders invest a great deal of time and effort in communication with organization members. Communication has become a critical factor for leading both people and organizations.

3) Delegating management responsibilities in line with a clearly shared vision and goals, and clearly delegating tasks to followers combined with equitable fair performance evaluation and compensation systems.

Thus, the success of these companies is closely related to effective open communication and sharing of visions and goals without controlling people, which can actually move an organization forward successfully and effectively. These findings are close to the research of Bass (1990) who emphasized idealized influence, inspirational motivation, and individualized consideration as the characteristics of transformational leadership in contrast to transactional leadership, which is based on a controlling organizational culture.

b. Commonalities and differences in leadership and organizational culture among the four companies

While the four companies have commonalities of leadership and organizational culture, the interviews also revealed specific characteristics in each case. Both commonalities and differences are summarized below.

\section{Commonalities}

Common characteristics of leadership and organizational culture in the four sample companies are people-orientation, vision, and entrepreneurship-orientation. In addition, they are high challenge-seeking, risk-taking, and innovative. These characteristics were positively related to knowledge productivity and value creation. 


\section{Two-tops leadership}

The leadership structures in the four selected Korean companies can be described as two-tops leadership combining the strengths of the leadership of the Group Chairman, who holds an influential leading shareholder position, with the strengths of the professional managers (CEOs), who lead each company under the Group Chairman's leadership. The major roles of the Group Chairman are to build a longterm vision and goals, develop strategies, and make high-challenging decisions, taking risks for development of future oriented new businesses to lead the global market position. At the same time, the CEOs of these companies offer performanceoriented professional management talent to achieve business goals within relatively short periods of time following the Group Chairman's long-term vision, goals, management principles, and spirit. The four companies included in this study have two-tops leadership structures in principle; however, each company has a slightly different style of two-tier leadership depending upon the leadership style of the Group Chairman and the type of ownership. Most large group companies in Korea have a similar leadership structure, which in this study is called the "two-tops leadership" structure.

\section{Differences}

The leadership style and organizational culture of LG Electronics is strongly peopleoriented with a focus on building an excellent company by following the Group Chairman's leading principle of "Value Creation for Customers". The leadership style and organizational culture characteristics of Samsung Electronics are peopleoriented and strongly performance-oriented as a result of a typical combination of the Group Chairman's high-challenging long-term vision and goal-oriented entrepreneurship and the CEO's proven professional management capability. This combination turned Samsung Electronics into a world leading digital company.

The WoongJin Group Chairman is strongly people-oriented. He created the important WoongJin-style "Sinbaram" (Exciting Wind Blowing) organizational culture, in which people are empowered to be highly motivated and enjoy their work. All WoongJin Group companies are involved in a friendly teamwork-building movement called "To-To-Sarang", which means "love and love together", involving fellow workers, colleagues, customers, and partners. In this unique WoongJin-style "Sinbaram" and "To-To-Sarang" leadership and organizational culture, people do their best with passion and a strong psychological ownership. 


\section{A special case of Shinhan leadership}

The Chairman of the Shinhan Financial Group, the holding company, was CEO of Shinhan Bank, and held both professional top management positions for more than 19 years, although he had no influential share ownership. The leader's softly charismatic, highly people-oriented and challenging vision and entrepreneurship created a strongly goal- and performance-oriented organizational culture. In this organizational culture, Shinhan people have a strong psychological ownership and do their best to achieve the vision and goals of the company. This "Shinhan people power" allowed the Shinhan Bank to achieve sustainable high growth and become a leading bank in Korea. This is a different type of two-tops leadership structure, which is a combination of the leadership characteristics of the chairman of the group holding company, the Shinhan Financial Group, and the leadership characteristics of the CEO of all Shinhan-affiliated companies, including Shinhan Bank. In this case, the chairman and the CEOs are professional managers who do not own controlling shares in the company.

\section{c. Conclusion}

The leadership styles and organizational cultures of each of the four companies described above share a common principle and spirit, which is related to peopleoriented and high- challenging visionary entrepreneurship. These commonalities among the leaders of the four companies and their organizational cultures became a special source of strength by which those companies established their successful positions in their respective industries.

Bass $(1985,1990)$ described the main characteristics of transformational leadership, as a people-oriented leader who transforms and motivates followers through idealized influence, intellectual stimulation, and individual consideration. In addition, such a transformational leader encourages followers to come up with creative ideas and new ways to challenge the status quo and alter the environment to support success. The leadership of these four companies, in which people are empowered and their ideas are respected, is closely connected to the creation of knowledge-productive organizational cultures and sustainable growth. Table 8.3 provides a summary of the commonalities among the four companies in terms of leadership and organizational culture. 
Table 8.3 Summary of commonalities of leadership and organizational culture characteristics of the four companies

\begin{tabular}{l|l}
\hline Characteristics & Descriptions \\
\hline People-oriented & $\begin{array}{l}\text { People-oriented, respecting organization members } \\
\text { and their ideas. Empowering and motivating people to have strong } \\
\text { psychological ownership. }\end{array}$ \\
$\begin{array}{l}\text { Entrepreneurial } \\
\text { Challenging for high vision and goals for building top leading company } \\
\text { in the industry. Sharing vision and goals with organization members } \\
\text { through open communication. }\end{array}$ \\
$\begin{array}{l}\text { Challenge-seeking } \\
\text { and risk-taking }\end{array}$ & $\begin{array}{l}\text { Strong entrepreneurial spirit to achieve high vision and goals. Leading } \\
\text { High challenge-seeking and risk-taking for development of future } \\
\text { oriented new businesses to lead the market position . }\end{array}$ \\
Control & $\begin{array}{l}\text { Delegation of management responsibilities to each business leader. } \\
\text { Two-tops leadership } \\
\text { term vision-oriented and risk-taking leadership of Group Chairman and } \\
\text { performance and goal-oriented leadership of CEO of each company under } \\
\text { the Group Chairman. }\end{array}$ \\
Boundary-less & $\begin{array}{l}\text { Boundary-less communication and teamwork, sharing knowledge and } \\
\text { information within the organization across layers and divisions. }\end{array}$ \\
\hline
\end{tabular}

\subsubsection{Knowledge productivity}

\section{a. Commonalities}

Leaders of the four companies strongly emphasized and promoted continuous improvement and innovation of products, services, and work processes (KP1), and also encouraged radical innovation and development of creative new ideas for sustainable development of future growth engine (KP2) and moving into new business areas by taking risks. People-oriented leadership of the four companies strongly promoted life-long learning programs, which enhanced knowledge productive organizations. The quantitative analysis indicated that leadership and knowledge productivity in all four companies were strongly related. However, the interviews with the leaders revealed that the priority of KP2 and taking risks to implement it differed among those companies.

In the interviews, leaders had clear opinions about how the combination of peopleoriented values and high challenges created a culture that is favorable for continuous 
improvement and radical innovation. Thus, just pushing for performance without considering the engagement and creativity of people may not lead to innovation.

\section{b. Differences}

Although the four leading companies have important commonalities with regard to the knowledge productivity factors KP1 and KP2, as mentioned above, each of the four companies has its own characteristics when it comes to knowledge productivity. Some examples are described below.

LG Electronics emphasized continuous improvement and innovation of products, services, and work processes, which is similar in concept to KP1. The previous CEO of the company implemented a special program called TDR (Tear-down and Redesign), a radical innovation method for future growth, new product development, and new business development, which is similar in concept to KP2. However, driving radical innovation for new products and new business development for future growth (similar to KP2) was not a top priority of the recent leader, who focused more on a short-term, profit-oriented cost reduction program called "il-jal-bub" (which means "doing your work better"). Therefore, the company missed critical timing for developing competitive new products on time in response to the introduction of Apple's new iPhone in 2009. This had a significant negative impact on sales and performance, and resulted in a negative net profit in 2010 for the first time in the company's history.

On the other hand, the Samsung Group's leader strongly demanded continuous radical changes, innovations, and improvements of products, services, and work processes (KP1) and also strongly promoted sustainable development of future growth engine (KP2). As a result, Samsung Electronics effectively overcame the potential negative impact of the introduction of Apple's new iPhone to the world market, and managed to turn the potential risks into a radical growth opportunity. As a result, Samsung Electronics grew rapidly in market share and became the world leader in the smart phone industry in 2010.

WoongJin Group companies are committed to continuous changes and radical innovations of products, services, and work processes (KP1), new business development for future growth (KP2), and taking risks. Their aggressive leadership and high challenge-seeking accelerated innovation promoted new business development for future growth. Recently, the company has made significant investments, taking even more risks to enter into a new business area: hightechnology polysilicon manufacturing in the newly developed solar energy industry. Shinhan's leader focused strongly on boundary-less information and knowledge 
sharing within the company through the Shinhan Way open teamwork program across departments, divisions, and hierarchical layers, emphasizing continuous improvement and innovation of services and work processes. Respecting organization members and their knowledge and ideas is the main characteristic of a people-oriented organizational culture. This is how the company created a knowledge-productive organizational culture with "Shinhan People Power".

\section{c. Conclusion}

The analysis of interviews repeatedly indicated that the common characteristics of knowledge productivity of the four companies (continuous improvement and innovation of products, services, and work processes, KP1; radical innovation and development of creative new ideas for sustainable development of future growth engine, KP2), and their various specific characteristics described above became the special strengths of each company, making them successful and leading in their respective industries. Table 8.4 summarizes the commonalities regarding knowledge productivity among the four companies.

Table 8.4 Summary of commonalities of knowledge productivity in the four companies

\begin{tabular}{l|l}
\hline Characteristics & Descriptions \\
\hline $\begin{array}{l}\text { KP1. Improvement and } \\
\text { innovation of products, } \\
\text { services, work processes }\end{array}$ & $\begin{array}{l}\text { Empowering people to take a creative approach to new knowledge } \\
\text { and idea development, strongly emphasizing continuous } \\
\text { improvement and innovation of products, services, and work } \\
\text { processes. }\end{array}$ \\
$\begin{array}{l}\text { KP2. Sustainable } \\
\text { development of future } \\
\text { growth engine }\end{array}$ & $\begin{array}{l}\text { Leadership taking risks for development of future growth engine } \\
\text { businesses and moving into new business areas. Strong motivation } \\
\text { and encouraging people to be innovative and creative, challenging } \\
\text { for sustainable future growth. }\end{array}$ \\
Other observations & $\begin{array}{l}\text { People-oriented and high challenge-seeking visionary leadership } \\
\text { characteristics of the four companies led to knowledge-productive } \\
\text { organizational cultures focusing on high value creation and } \\
\text { sustainability. People-oriented leadership promoting life-long } \\
\text { learning programs, which enhanced knowledge productive } \\
\text { organizations. }\end{array}$ \\
\hline
\end{tabular}

\subsubsection{Value creation}

Both financial data on performance and non-financial data were used for the evaluation of value creation. Financial performance data included sales, net profit, 
and market value of the four companies for the 10 years of the research period. Nonfinancial factors included corporate reputation, image, and CSR, employee satisfaction with work environment, employee satisfaction with financial benefits, and sustainability.

\section{a. Commonalities}

The results of the qualitative analysis and financial performance data showed successful value creation and sustainable growth in all four companies. The results of the quantitative analysis of the four companies indicated strong relations between leadership characteristics organizational culture knowledge productivity value creation factors, such as corporate reputation, image, and CSR, employee satisfaction with work environment and financial benefits, and sustainability.

The financial data on performance of the four companies indicated that high value creation was successfully achieved over the 10 years from 2000 to 2010 in terms of revenue and profit growth, market value increases, and overcoming the world financial crisis that started in 2008. During this period, value creation and growth of the four companies were higher than the average of the top 10 Korean companies in their industries, except for the special and unexpected case of LG Electronics in 2010.

Findings from the interviews indicated that the corporate reputation, image, and CSR of the four companies are highly recognized in their industries. Employee satisfaction with the work environment and financial benefits in the four companies were also very high. As a result, employees in the four companies have a strong psychological ownership and are proud of their membership in the respective companies.

The cross-case analysis on value creation of the four companies clearly indicated that leadership, organizational culture, and knowledge productivity in the four companies were closely and positively related to the achievement of high value creation and contributed to building sustainability and future growth capability. These results are supported by the financial data from the four companies on performance in the past 10 years. Results of the quantitative analysis indicated that low challenge-seeking, high top-down control, status quo and bureaucracy were significantly and negatively correlated with both knowledge productivity and value creation. Interview results consistently indicated that those leadership and organizational culture characteristics did not apply to the four companies.

\section{b. Differences}


Although the findings of this study indicated high levels of achievement of the major value creation factors, each company had its own particular approach and different strengths, which strongly supported and contributed to the successful value creation of each particular company. LG Electronics recorded continuous high value creation, stable growth of revenue, and increased net profit and market value over the 10-year research period, except in 2010. High ethical standards, people-oriented leadership, and high-challenging entrepreneurship are well-respected in the industry and society. These became a sound base for value creation and the growth of LG Electronics.

Samsung Electronics' strong performance-driven work environment under the Group Chairman's high-challenging, strong goal-oriented leadership provided a clear mission to Samsung's CEOs, executives, and managers to achieve exceptionally high performance goals. Through continuous high value creation, stable growth in revenue, and increased net profit for the 10 -year research period, Samsung overtook the world's leading competitors to become the leading company in the global electronics industry.

The WoongJin Group achieved very successful sustained growth and high value creation over the 10 -year research period with increased revenue of $3,100 \%$ and net profit growth of $54,900 \%$ over the 20 years (1990-2010) of its existence. As a result of its people- oriented and customer-first leadership and organizational culture, both employee and customer satisfaction reached very high levels. However, a potential downturn in the global solar energy industry and depression in the domestic construction industries may impact the sustainability of WoongJin, as the company made significant investments into these future-oriented new businesses.

Shinhan Bank sustained high growth and high value creation over the past 10 years and became a leading bank in Korea and Asia. Shinhan Bank maintains its high reputation and image through sound and sustainable growth and a high level of employee and customer satisfaction, according to the interviewees. The high level of value creation at Shinhan Bank is related to a combination of high challengeseeking, a well-developed system of risk management, and the typical Shinhan "People Power".

\section{c. Summary}

Although each of the four companies had their own approach and particular 
strengths, the value creation factors examined in this study (corporate reputation, image, and CSR, employee satisfaction with work environment and financial benefits, and sustainability) were significantly and positively related to the leadership styles (people-oriented, visionary and entrepreneurial, and high challenge-seeking and risk-taking) in all four companies. Knowledge productivity within the four companies was similarly positively correlated with value creation. The data on financial performance of the four companies over the 10 years from 2000 to 2010 strongly supported the results of the findings from the qualitative and quantitative analyses. Table 8.5 provides a summary of the commonalities among the four companies in terms of value creation.

Table 8.5 Summary of commonalities of value creation in the four companies

\begin{tabular}{|c|c|}
\hline Characteristics & Descriptions \\
\hline Management quality & $\begin{array}{l}\text { Strength of two-tops leadership: Chairman's high-challenging long- } \\
\text { term vision and goal-oriented leadership in combination with CEO's } \\
\text { performance-oriented professional management leadership led companies } \\
\text { to achieve high value creation and sustainable growth. }\end{array}$ \\
\hline $\begin{array}{l}\text { Corporate } \\
\text { reputation, image, } \\
\text { and } \\
\text { CSR }\end{array}$ & $\begin{array}{l}\text { High reputation and image with high-quality products and services, and } \\
\text { sustained high growth. } \\
\text { Fulfilling CSR through active participation of these companies in } \\
\text { corporate social citizenship activities enhanced reputation and image of } \\
\text { each company. }\end{array}$ \\
\hline $\begin{array}{l}\text { Employee } \\
\text { satisfaction }\end{array}$ & $\begin{array}{l}\text { High level of employee satisfaction with good compensation and benefit } \\
\text { systems based on performance and people-oriented work environment in } \\
\text { an open organizational culture. }\end{array}$ \\
\hline Sustainability & $\begin{array}{l}\text { Strong sustainable growth capabilities and distinctive strengths of each of } \\
\text { the four companies. }\end{array}$ \\
\hline $\begin{array}{l}\text { Financial } \\
\text { performance }\end{array}$ & $\begin{array}{l}\text { Outstanding performance records based on financial hard data on sales, } \\
\text { net profit, and market value of the four companies. Achieved continuously } \\
\text { high growth over the past } 10 \text { years (2000-2010). }\end{array}$ \\
\hline
\end{tabular}

\subsection{Summary of the findings from the cross case analysis}

This study focused on the relationships among leadership, knowledge productivity, and value creation in four leading Korean companies that achieved high value creation and sustainable growth over a long period, especially the research period (2000-2010). In this research, specific leadership characteristics related to building a knowledge-productive organizational culture and achieving knowledge productivity 
(including innovation and organizational learning) for high value creation and sustainable company growth were identified.

Findings from case studies of the four successful leading Korean companies indicated that these leadership styles were close to the A type (non-bureaucratic and open, high-challenging and visionary entrepreneurship, empowering people, delegation) and B type leadership styles (non-bureaucratic and open, high challenging and visionary entrepreneurship, charismatic, empowering people, delegation and participation), as described in the conceptual framework of this study in Section 2.9 of Chapter 2. From the empirical research, we can conclude that C type leadership (bureaucratic and charismatic, visionary entrepreneurship, topdown, and delegation) and $\mathrm{D}$ type leadership (bureaucratic, charismatic and imperialistic, entrepreneurial, top-down), as described in the leadership typology of the conceptual framework in Section 2.9 of Chapter 2, were not found in the four selected companies.

In the Korean economic development era under the military government during the second half of the 1960s and through the 1970s and 1980s, the most successful business leaders who founded today's leading conglomerates, the large group companies in Korea (the so-called "Chaebols") (Chang, 2012) exhibited mostly C or D type leadership styles with high-challenging entrepreneurship, strong charisma, and bureaucratic and top-down control. The "Chaebols" are similar to the "Keiretsu" networks in Japan in terms of the composition of interfirm groupings and the ties binding companies to one another (cross-shareholding, interlocking directorates) (Lincoln, Gerlach, \& Ahmadjian, 1996). However, controlling shares of "Chaebols" are mostly owned by the founders' families. The leadership styles and organizational culture of companies in Korea have evolved and changed during the past three decades during the nation's economic development and industrialization, which paralleled the democratization of Korean society. The leadership styles and organizational culture have become people-oriented and humanitarian, nonbureaucratic and open, with more delegation of responsibility and less top-down control. Respecting people in business organizations as human beings and their knowledge and ideas is closer to A- and B-type leadership styles. These leadership styles are favorable for building knowledge-productive organizations and achieving sustainable high levels of value creation. In knowledge-productive, creative organizational cultures, organization members continuously improve and innovate businesses with a strong psychological ownership and passion, thereby achieving high value creation for the company. Table 8.6 provides a summary of the cross-case analysis. 


\begin{tabular}{|c|c|c|c|c|}
\hline & 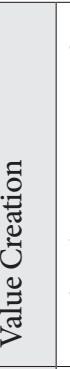 & 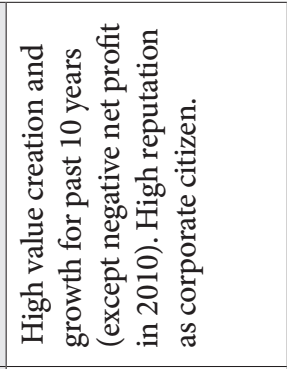 & 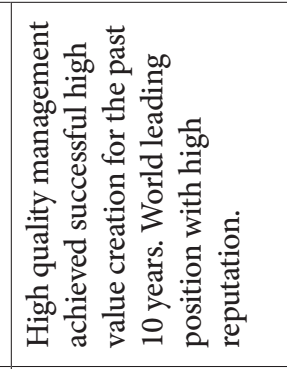 & 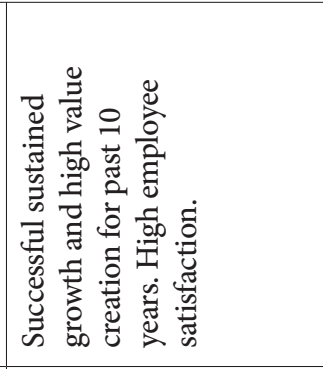 \\
\hline & 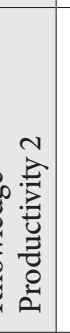 & 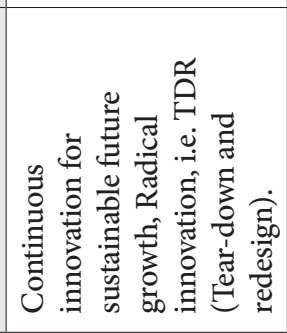 & 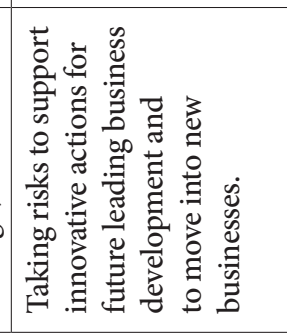 & 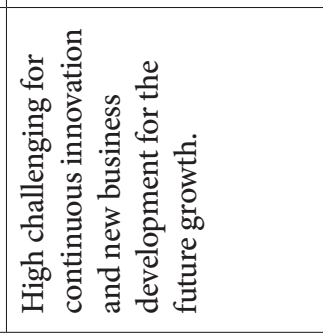 \\
\hline & : & 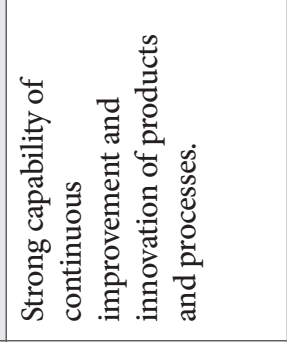 & 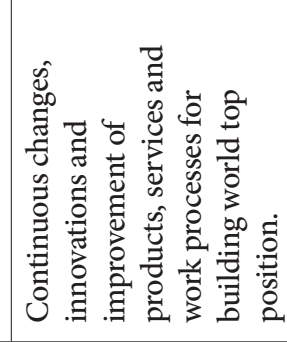 & 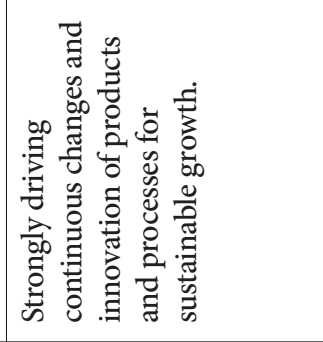 \\
\hline & 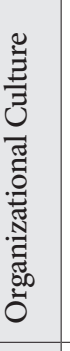 & 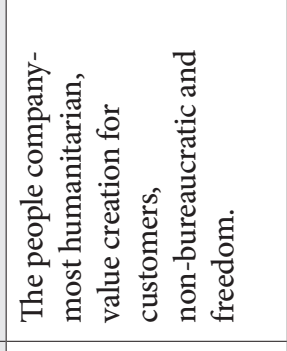 & 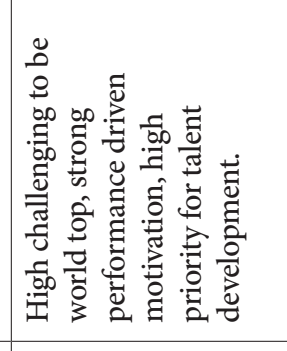 & 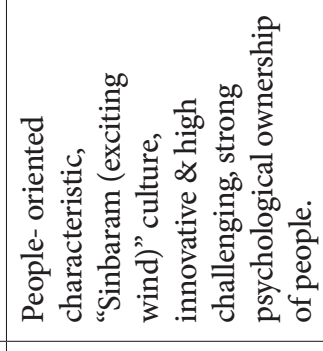 \\
\hline & 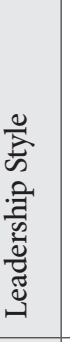 & 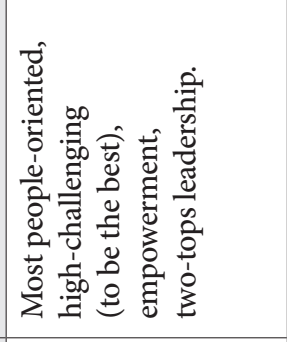 & 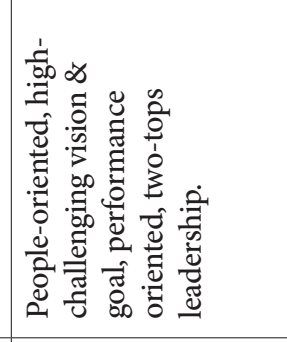 & 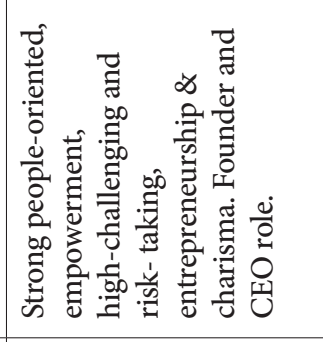 \\
\hline & & 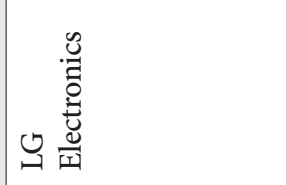 & 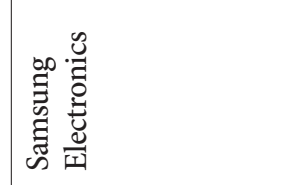 & 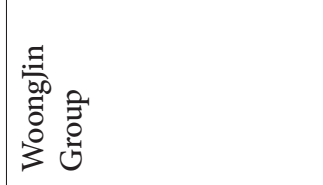 \\
\hline
\end{tabular}




\begin{tabular}{|c|c|c|}
\hline 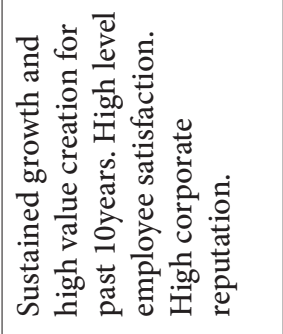 & 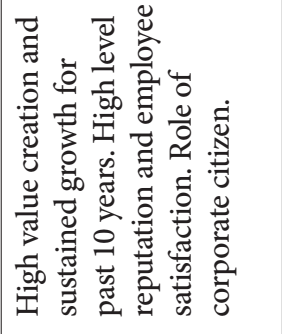 & \\
\hline 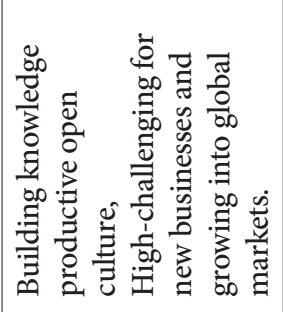 & 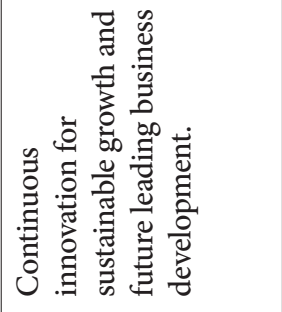 & 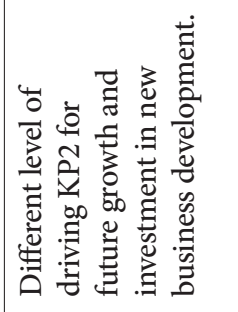 \\
\hline 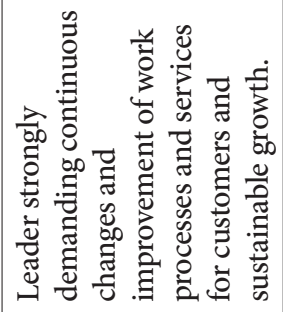 & 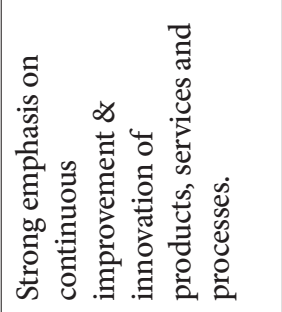 & 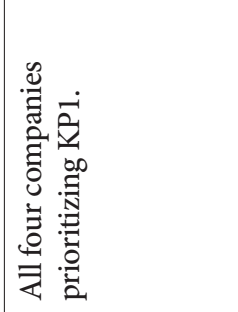 \\
\hline 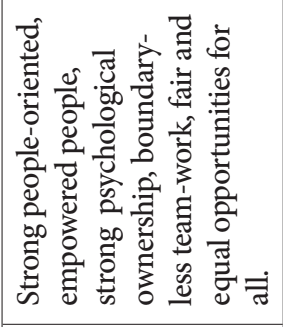 & 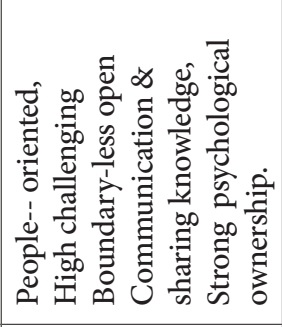 & 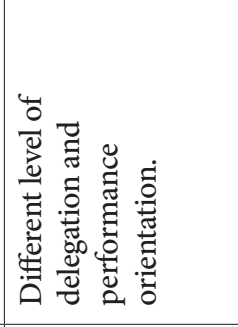 \\
\hline 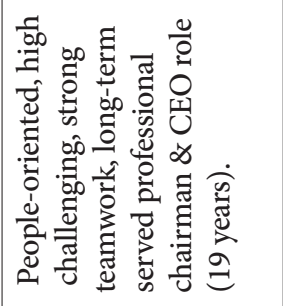 & 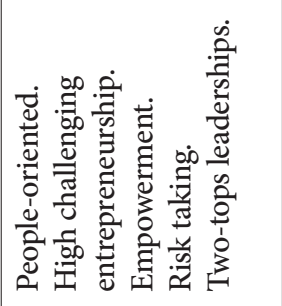 & 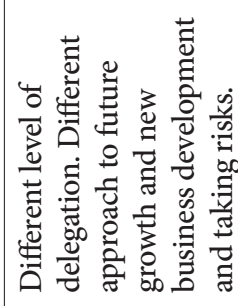 \\
\hline 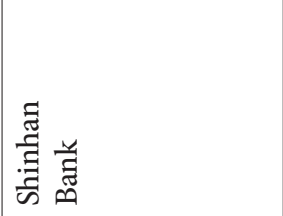 & 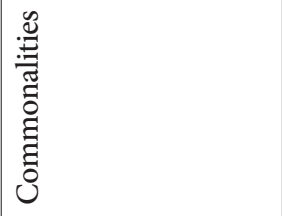 & 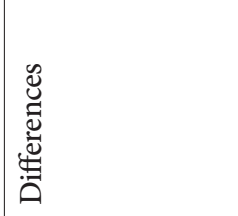 \\
\hline
\end{tabular}





\section{Chapter 9. Conclusion and discussion}

\subsection{Introduction}

In this chapter, the main research questions of this study were answered based on the findings from the literature review and the empirical research on four major Korean companies. The main research questions of this study are: (1) How do the characteristics of leadership relate to organizational culture, knowledge productivity, and value creation of the company? (2) How do organizational culture, knowledge productivity, and value creation interact? and (3) What leadership style is favorable for building a knowledgeproductive organizational culture and achieving sustainable high value creation?

On the basis of the answers to these questions, a revised conceptual framework is presented in this chapter, as well as guidelines for business leaders. In addition to providing responses to the main research questions, conclusions and critical reflections on the research approach are provided, and some directions and questions for future research are suggested.

\subsection{Objectives of this study}

Value creation is considered one of the most important objectives for managing a business today. In this research, value creation in the context of business management is a concept encompassing revenue and profit growth, increased company market value, increased employee and customer satisfaction, and improved corporate reputation, image, and fulfilled CSR. Companies that have achieved value creation in all these areas have done so as a result of successful business management.

The objectives of this research were to explore the relationships among leadership, organizational culture, knowledge productivity, and value creation, and to understand those leadership styles that are associated with successful high value creation within a company. As leadership styles and organizational cultures have changed and evolved significantly over recent decades in our new knowledge-based society, this research also aimed to understand how a knowledge-productive organizational culture and high value creation depend on successful leadership. Another objective of this study was to offer practical guidelines for business leaders in the areas of leadership, organizational culture, and knowledge productivity necessary to achieve high value creation in today's rapidly changing and advancing 
businesses. It is a way to narrow the gap between academic research in these domains and the day-to-day activities of business leaders.

\subsection{Answers to the research questions}

This section brings together the main research findings in the previous four case studies that were conducted for the purpose of answering the initial three research questions.

\subsubsection{How do the characteristics of leadership relate to organizational culture, knowledge productivity, and value creation of the company?}

\section{Conclusion 1. Leadership and organizational culture}

As organizational culture depends heavily upon the leadership styles of top management, especially those of the founder, chairman, and CEO (Schein, 1985; Schein, 1992; Schein, 2004), an effective leadership style is crucial for the creation of a knowledge-productive and people-empowering organization, and ultimately to the achievement of high value creation. Brown et al. (2008) claimed that CEO leadership plays an important role in developing vision and shaping an organizational culture. The research of Taormina (2007) showed that flexible and open leadership behaviors are more positively correlated with innovative culture than controlling leadership behaviors. García-Morales, Jimenez-Barrionueve, and Gutierrez-Gutierrez (2012) also found that transformational leadership influenced organizational performance positively through learning and innovation within organizations.

The results of our study on four leading Korean companies clearly indicate that leadership characteristics and organizational culture are significantly correlated, as shown in Figure 9.1. The characteristics of leadership and organizational culture identified in the factor analysis were given similar labels in Figure 9.1. The commonalities of the leadership characteristics (people-oriented, delegating, and empowering people, visionary and entrepreneurial, high challenge-seeking and risk taking) among the four companies are conceptually similar to the organizational culture characteristics (people-oriented, high challenge-seeking, and innovative) of the four companies. This supports the claim of Schein (2004) that "culture and leadership are two sides of the same coin" (2004, p. 22).

From studying those companies that achieved successful value creation, we learn that their common leadership characteristics allowed the firms to create knowledgeproductive and innovative organizational cultures with similar characteristics. Commonalities of the organizational culture among the four companies are that 
they are people-oriented, high challenge-seeking, and innovative. The two-tops leadership structures are also similar among the four companies, combining strengths of the leadership of the Group Chairman and strengths of the professional managers (CEOs) who lead each company under the Group Chairman's leadership. Most large business groups in Korea have similar two-tops leadership structures.

Several interviewees from the four companies emphasized that people-oriented leadership and organizational culture and boundary-less and open communication accelerated knowledge sharing and knowledge productivity in their companies. Thus, these factors are positively related to value creation. The four companies each have their own people-oriented organizational cultures, which provide a strong base for their high knowledge productivity and sustained value creation. Our findings are similar to those of the research by Taormina (2007) showing that flexible leadership behaviors are positively correlated with and stronger predictors of innovative culture than controlling leadership behaviors. Jung et al. (2008) also claimed that freedom within the organization and a boundary-less open culture are important for fostering creativity and innovation. By contrast, controlling leadership behaviors are more positively correlated with and stronger predictors of bureaucratic culture than flexible leadership behaviors.

Leadership characteristics such as low challenge-seeking and high control, and organizational culture characteristics such as low challenge-seeking and status-quo, bureaucratic, and top-down control could not be found in the four companies of this study.

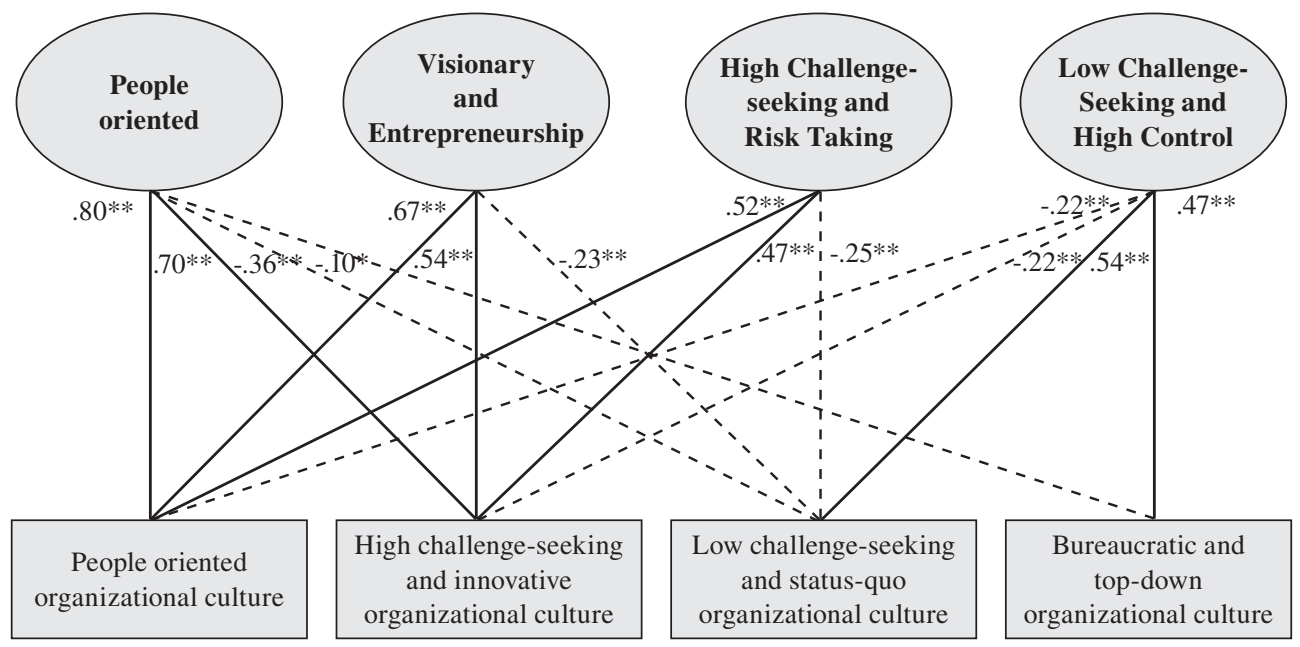

Figure 9.1 Correlation of leadership characteristics and organizational culture Note: ${ }^{*} p<.05,{ }^{*} p<.01$ ( - positive relationship, ..... negative relationship) 


\section{Conclusion 2. Leadership and knowledge productivity}

In today's advanced knowledge economy, one of the most critical roles of leadership is to create a knowledge-productive organizational culture in order to achieve high value creation. The quantitative analysis of the surveys of the four leading Korean companies identified the following common leadership characteristics: peopleoriented (LS1), visionary and entrepreneurial (LS2), and high challenge-seeking and risk-taking (LS3). These leadership characteristics correlated significantly and positively with the following knowledge productivity factors: improvement and innovation of products, services, and work processes (KP1) and sustainable development of future growth engine (KP2). Leadership characteristics have become more humanitarian and people-oriented, respecting organization members and their knowledge and ideas. These findings from the quantitative analysis (as shown in Figure 9.2) are in line with Kessels et al. (2011), who emphasized the connection between people-oriented leadership styles, learning development, and knowledge productivity. Recent studies by Yang (2007), Von Krogh, Nonaka, and Rechsteiner (2012) also found that people oriented leadership roles like innovator, mentor, or facilitator were found to be positively related to knowledge sharing in organizations

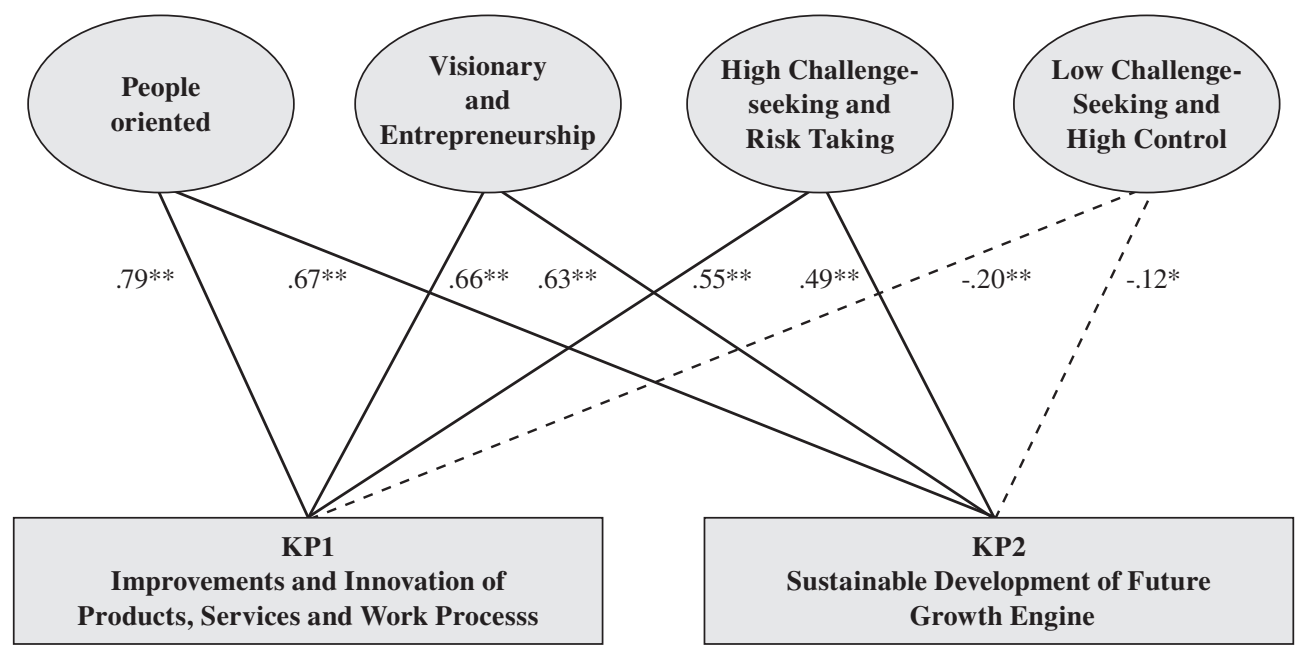

Figure 9.2 Correlation of leadership characteristics and knowledge productivity Note: ${ }^{*} p<.05,{ }^{* *} p<.01$ (- positive relationship, ..... negative relationship)

\section{Future growth engine development}

The power of sustainable growth was evident in the four Korean companies researched in this study. The terminology "Future Growth Engine” (“미래성장동력” in 
Korean) is commonly used concept in Korea (Bae et al., 2010; Kim \& Chung, 2007). It means "newly developed business and industry that will ensure the future growth of companies as well as the economy and industries of the country". For developing new businesses for sustainable future growth, certain leadership characteristics are important, such as high challenge seeking and risk taking, visionary, and entrepreneurship-oriented. The "future growth engine" is similar to the concept of knowledge productivity (KP2), which means the sustainable development of improvement and radical innovation in the future (Kessels, 1996; Kessels \& Keursten, 2002; Kessels et al., 2011).

For managing businesses, development of future oriented business is critical to securing sustainable growth, especially in light of the intense competition in today's high-technology industries. To maintain a leading position in a market, a company should invest continuously in development of technologies, new products, and businesses by taking risks, even though their success cannot be guaranteed. Without continuous development of new products and businesses for sustainable future growth, a company can lose its market position to competitors who make successful investments in this area. Developing sustainable future growth businesses requires three key elements for success: 1) leaders with high challenge-seeking entrepreneurship and a strong willingness to take risks (Mischel, 1973; Nahavandi \& Malekzadeh, 1993); 2) high knowledge productivity and strong support from leadership for radical innovation, creative turmoil, and reflective skills (Kessels, 1996); and 3) professional management and teamwork skills with strong psychological ownership.

Under the typical two-tops leadership structure, which includes the high challengeseeking, risk-taking entrepreneurship of the Group Chairman and the professional management and implementation capability of the CEOs, the four leading Korean companies included in this study successfully developed future growth engine businesses and seem to have mastered these three key elements for success.

\section{Conclusion 3. Leadership and value creation}

Value creation is considered as one of the most important objectives for the leaders of businesses and institutions, and for economic development. Through value creation, a company can meet stakeholders' expectations, such as those of investors who place their trust in the capabilities of the leaders of the company. Value creation enables sustainable growth of the company and allows the company to fulfill its CSR. Therefore, value creation should be regarded as a most important "shared vision and dream" (Shin \& Zhou, 2003) of all organization members and 
stakeholders, and the main responsibility and role of top management in the business world. This research has explored how leadership characteristics and value creation in business organization are related, and described the interaction of organizational culture and knowledge productivity between leadership and value creation (see Figure 9.3).

Data on the financial performance of the four Korean companies revealed that they all achieved exceptionally high value creation and sustainable growth over the 10 years of the study period. Previous empirical studies showed a positive relationship between transformational leadership, employee creativity, and organizational innovation (Gumusluoglu \& Ilsev, 2009), employee innovation as influenced by knowledge, skills, and abilities (Pieterse et al., 2010), and employee job satisfaction and leader effectiveness (Piccolo et al., 2012). These conclusions are in line with the recent empirical study of Song, Kolb, Lee, and Kim (2012), who found that transformational leadership has a directly positive impact on organizational knowledge creation and, as a mediator, an indirectly positive influence on organizational knowledge creation through employees' work engagement. Chang and Lee (2007) and Sarros et al. (2008) also claimed that transformational leadership better reflects the people-oriented and intellectually stimulating environment. The four cases in this research indicate that in such an environment a knowledgeproductive organizational culture can be created.

In addition, Jin and Yeo (2011) claimed that corporate reputation and image, important intangible values of a company, are inextricably linked to the reputation and image of the company's leadership. Findings based on the interviews in our research indicated that the reputation and image of the leaders of these four companies were high and regarded as very important. The leaders of the four companies adopted specific management principles, which include transparency and integrity policies and fulfillment of CSR, which are closely related to the corporate reputation and image, and also related to employee satisfaction with the company (Berson, Oreg, \& Dvir, 2008). 


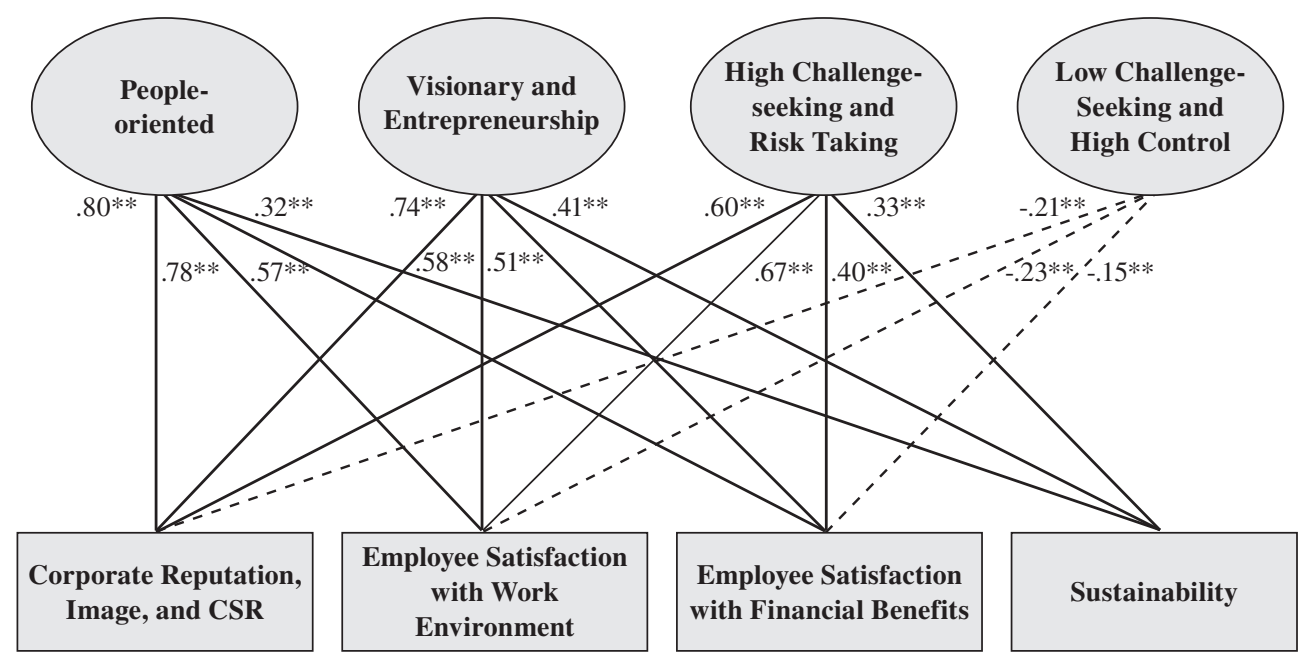

Figure 9.3 Correlation of leadership characteristics and value creation Note: ${ }^{\star} p<.05,{ }^{* *} p<.01$ (-positive relationship, ...... negative relationship)

\subsubsection{How do organizational culture, knowledge productivity, and value creation interact?}

\section{Conclusion 4. Organizational culture and knowledge productivity}

What type of organizational culture can maximize knowledge productivity? The results of the quantitative analysis of the four companies identified the following two commonalities of organizational culture: people-oriented (OC1) and highly challenge-seeking and innovative (OC2). These organizational culture characteristics were significantly and positively correlated with the two knowledge productivity concepts: continuous improvement and innovation of products, services, and work processes (KP1) and sustainable development of future growth engine (KP2), as shown in Figure 9.4.

Analysis of the data from the interviews revealed that the four companies continuously invested substantial time and effort in human resources and talent development programs. They all cherished the principle of lifelong learning. An emphasis on learning by doing, participating in communities of practice, mentor systems linking experienced colleagues with new employees, frequent participation in the programs offered by their corporate academies, and creating a favorable learning climate in the workplace contributed to the establishment of a strong learning culture. This learning culture combined with a high challenge-seeking, 
creative, and innovative spirit enabled efficient knowledge sharing and productive knowledge utilization to encourage sustainable future growth. These characteristics are similar to those studied by Kessels et al. (2011) in relation to innovative practices in western companies. The strong learning cultures of the four Korean companies, in which a high priority was placed on the development of the best talent and human resources, formed the basis of their knowledge-productive organizational cultures. In a study by Zheng, Yang, and McLean (2010), knowledge management effectiveness mediated the relationship between organizational culture and organizational performance. Although the concepts of knowledgement management and knowledge productivity are slightly different, their results are consistent with the findings in this study, and with conclusions 4 and 5.

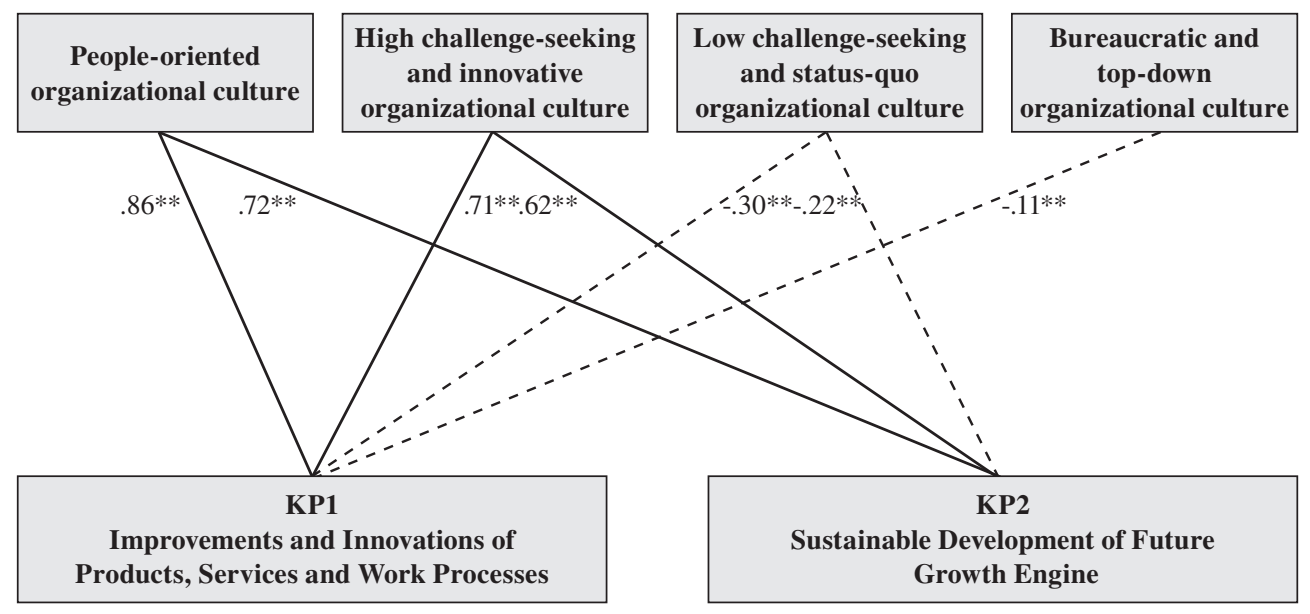

Figure 9.4 Correlations of organizational culture and knowledge productivity Note: ${ }^{\star} p<.05,{ }^{* *} p<.01$ ( - positive relationship, ..... negative relationship)

\section{Conclusion 5. Knowledge productivity and value creation}

The knowledge economy and knowledge revolution, as forecasted and described by Drucker (1993, 1999), have developed amazingly rapidly in the twenty-first century. Knowledge has therefore become the most important asset in most companies today. Knowledge productivity refers to the way in which individuals, teams, and units across an organization achieve knowledge-based improvements and innovations. It involves the development of new knowledge in the workplace that can generate continuous improvement and radical innovations of products, services, and operating processes (Kessels, 2004). It has become one of the critical 
elements in the process of value creation. Financial capital, natural resources, and physical labor will remain as important factors for production and value creation. However, companies' capacity to transform knowledge into competencies for both gradual improvement and radical innovation is essential for value creation and the development of future growth businesses (Drucker, 1993). As value creation is the main objective and responsibility of leaders of business enterprises and institutions, it is vital to understand not only the process of improving knowledge productivity, but also how to implement and apply knowledge in the day-to-day practices of field business operations.

The results of the quantitative analysis of the four companies identified the facts that the knowledge productivity factors (KP1 and KP2) were found to be significantly and positively correlated with the main value creation factors: corporate reputation, image and CSR (VC1), employee satisfaction with work environment (VC2), employee satisfaction with financial benefits (VC3), and sustainability (VC4), as shown in Figure 9.5.

As an example, a senior manager interviewed at Samsung Electronics explained that the Chairman had strongly emphasized the creative use of knowledge since 2006. Therefore, the $\mathrm{CEO}$ and executives of Samsung Electronics managed business operations by placing high priority on continuous improvement and innovation of the products, services, and work processes of the company (KP1), and also the sustainable development of future growth engine (KP2). This enabled Samsung Electronics, particularly in regard to its mobile communication products, to become the most competitive company in its industry in the world. The Samsung Chairman's emphasis on the creative use of knowledge contributed to the high value creation of the company. We also found similar drivers for radical innovation in the three other companies.

Knowledge productivity requires an effective lifelong learning climate that encourages boundary-less sharing of knowledge, creative thinking, and imagination, and an entrepreneurial spirit not only at the top, but at all levels within companies and institutions (Kessels et al., 2011). During the interviews, respondents from each company often mentioned that their leaders strongly emphasized lifelong learning and talent development programs. They consistently promoted continuous improvement and innovation, as in the Shinhan case, in which strong support for learning was provided and the company invested in employee education, selfdevelopment programs, and on-the-job training. Each of the four companies in this study also encouraged radical innovation and the development of creative new ideas for the development of future growth engine businesses similar to KP2. For example, LG Electronics' TDR (Tear-down and Redesign) program encouraged radical innovations and development of new products for sustainable future growth. 
Leadership plays a major role in building an organizational culture that encourages knowledge productivity, which is essential to achieve high-level value creation (Makri \& Scandura, 2010).

From the literature review and empirical research in this study, we find support for the proposition that knowledge productivity is the twenty-first century growth engine for value creation. This conclusion indicates the future direction for knowledge-based companies and societies.

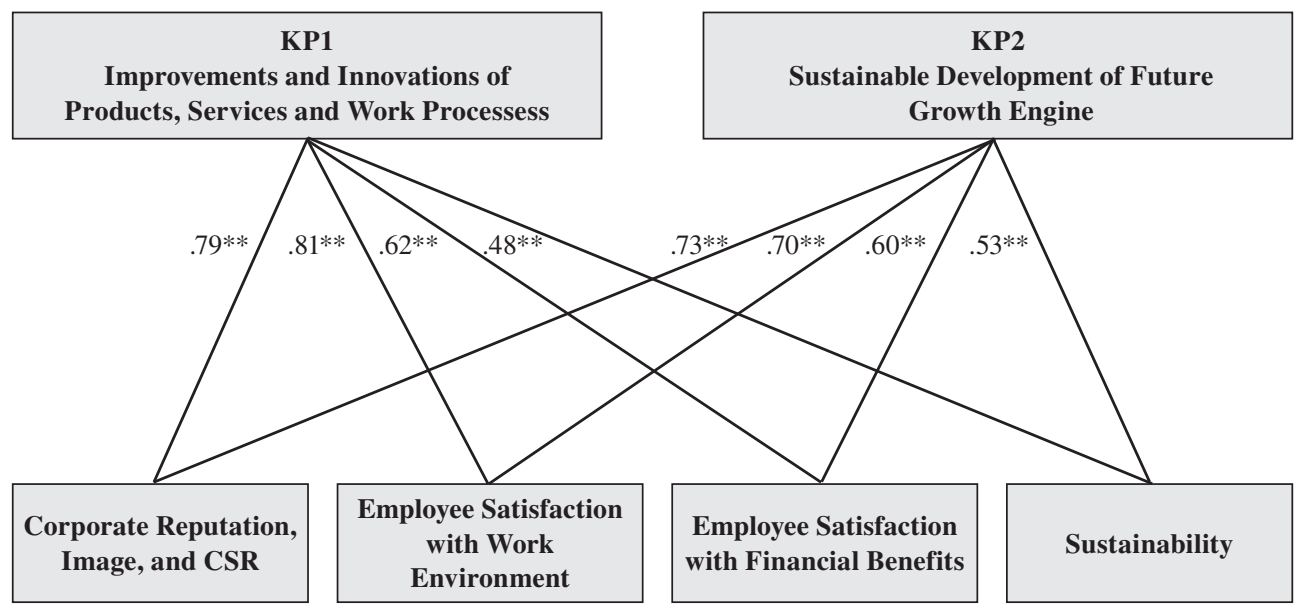

Figure 9.5 Correlations between knowledge productivity and value creation.

Note: ${ }^{*} p<.05,{ }^{*} p<.01$ (- positive relationship)

Knowledge productivity: The twenty-first century growth engine for value creation Conclusion 5 above summarizes a proposition that in a twenty-first century advanced knowledge economy, knowledge productivity plays a critical role in value creation not only for business corporations, but also for society and national economies, by advancing future knowledge development. This raises the following questions, which are related to the main research questions of this study:

How can existing and new knowledge be utilized in productive and innovative ways to achieve high value creation and sustainable development of future growth businesses? And what type of leadership is favorable for creating a knowledgeproductive organizational culture? 
Knowledge productivity, the corporate curriculum, and lifelong learning as related concepts have been studied in The Netherlands (Kessels, 1996; 2001; Van Lakerveld, 2005; Stam, 2007; De Jong, 2010; Kessels et al., 2011) and other parts of Europe and Asia (Harrison \& Kessels, 2004; Garvey \& Williamson, 2002; Yusof, Masrek, Noordin, \& Johare, 2012), but unlike the term "knowledge management", they have not yet been widely introduced into the management field. Therefore, research in this field is vital in order to assess the practical utility of knowledge productivity and the soundness of the theoretical bases of previous research. Findings from this case study in Korean companies clearly indicate that knowledge productivity is significantly and positively correlated with value creation. Thus, this study offers valuable information to address the above questions.

Practical applications of the findings of this study in the management of real business operations will help them to maximize value creation in their companies and institutions. For this reason, future research on subjects related to knowledge productivity should focus more on practical approaches and applications of knowledge productivity in industries and business management, and also on linking knowledge productivity and human resource development to economic development in various countries.

Future research should extend the concept of building a knowledge-productive organizational culture to building knowledge-productive industries, societies, and countries. New approaches to knowledge productivity can be applied to a wide variety of economic, industrial, and business contexts, including science and technology. Knowledge productivity may then be considered the twenty-first century growth engine for value creation in many areas of a knowledge-based society. This will shed light on how closely learning, knowledge development and application, improvement, innovation, and economic value creation are connected.

\subsubsection{What leadership style is favorable for creating} a knowledge-productive organizational culture and achieving sustainable high value creation?

\section{Conclusion 6. Favorable leadership styles for sustainable value creation}

Achieving increased value creation and sustainable company growth is the most important responsibility and challenge for business leaders today. In this study, we found that knowledge productivity in terms of gradual improvement and radical innovation of work processes, products, and services suggested by Kessels et al. (2011) was strongly related to value creation in successful companies. Building a 
knowledge-productive organizational culture and leading and empowering organization members to become more innovative and creative aid in developing and implementing high knowledge productivity. This conclusion finds support in the recent empirical study of Song, Kolb, Lee, and Kim (2012), where transformational leadership seems to have a positive impact on organizational knowledge creation. Similarly, a recent empirical study by Nguyen and Mohamed (2011) found a moderating effect of organizational culture on the positive relationship between transformational leadership and knowledge management

The findings in this study indicate that one of the most important leadership characteristics is people orientation. Leaders must respect organization members as human beings, and also respect their opinions and ideas (Oldham \& Cummings, 1986). Leaders can empower and motivate people by leading their organizations in a non-bureaucratic and open way, and allowing significant freedom so that there are no limits on people's imagination and creative thinking. Under such leaders, people become more creative and innovative, exhibit strong psychological ownership (Bae et al. 2010), and do their best to achieve the company's vision and goals. The findings of this study are similar to the results of a previous empirical study by Zhang and Bartol (2010). They found that empowering leadership positively influenced employee creativity by increasing employees' intrinsic motivation (i.e., autonomy and competence). Wang and Cheng (2010) also found that benevolent leadership, which is close to the people-oriented leadership style identified here, had a positive impact on employee creativity.

Important common characteristics of the leaders of the four companies are that they are visionary and entrepreneurial, high challenge-seeking and risk-taking, and peopleoriented. All these characteristics are important for knowledge-intensive development of future growth businesses and achievement of sustainable capability. The leadership styles of the four companies were associated with knowledge-productive organizational cultures, which may have enabled the companies to achieve high value creation. The findings of this study are consistent with the results of another empirical study by Davis, Bell, Payne, and Kreiser (2010), who found a positive relationship between an entrepreneurial orientation of the leader and firm performance.

The results of this study strongly support the initial conceptual framework of the research, in which the relationships among leadership, organizational culture, knowledge productivity, and value creation were revealed. The empirical findings enable the characterization of these relationships to be improved, as shown in the revised conceptual model in Figure 9.6. 


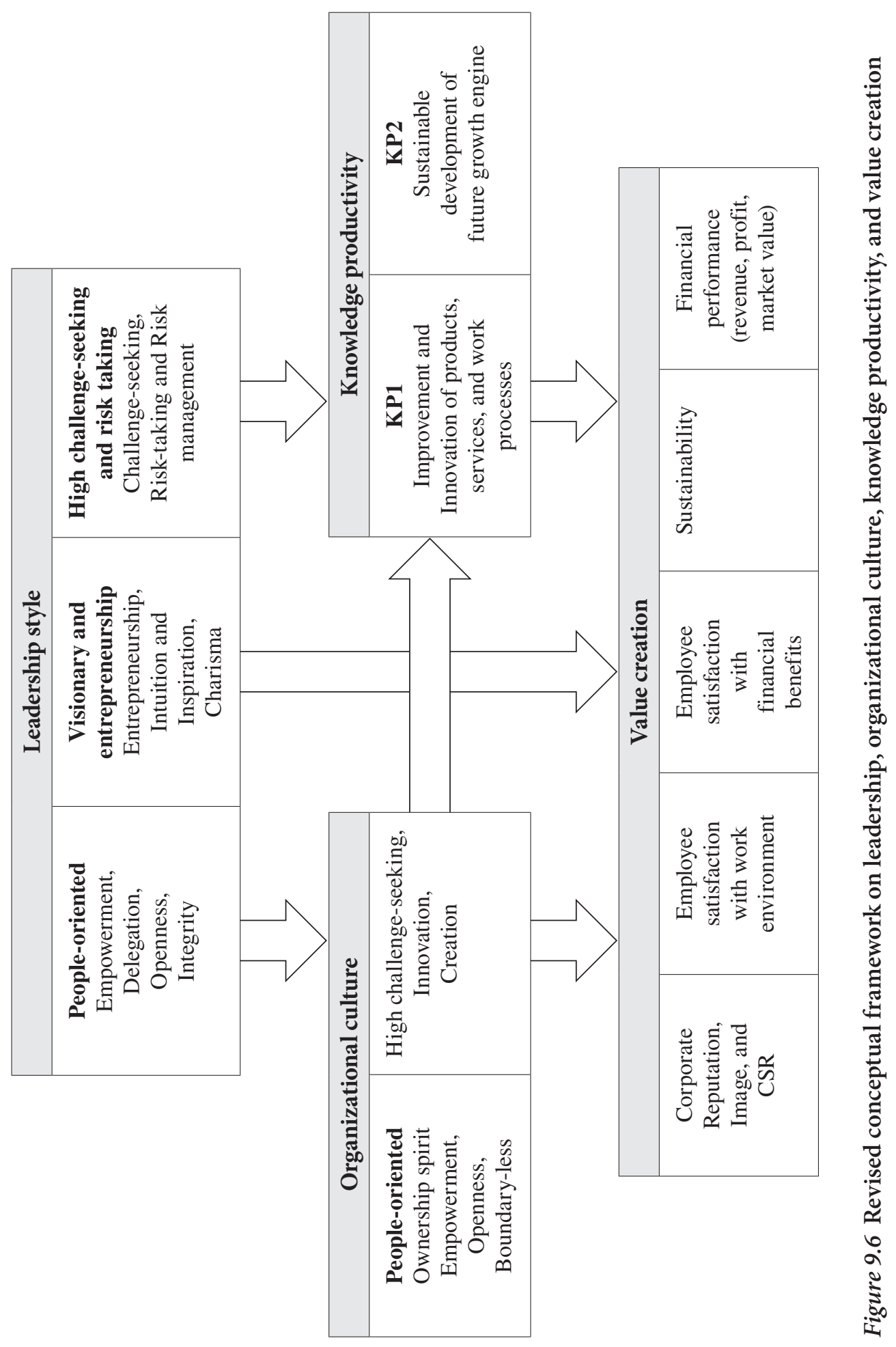


When we compare the responses to the three research questions with the initial framework on four leadership styles (A, B, C, and D) presented in Chapter 1, there seems to be evidence that in the four companies studied, characteristics of Types $A$ and $\mathrm{B}$ were predominantly found.

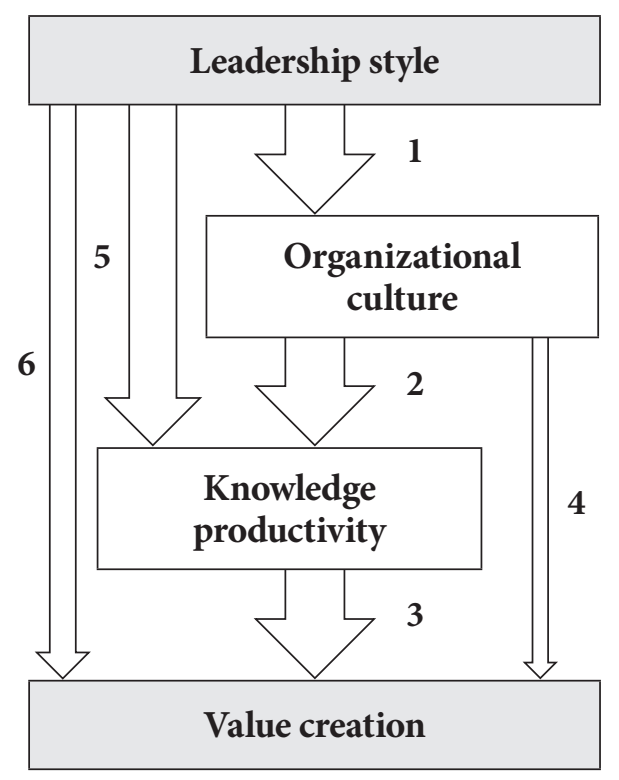

Figure 9.7 Four types of leadership leading to value creation

From a leadership perspective there are roughly six approaches to influence value creation:

Approach 1 Leadership related to organizational culture

Approach 2 Organizational culture related to knowledge productivity

Approach 3 Knowledge productivity related to value creation

Approach 4 Organizational culture related to value creation

Approach 5 Leadership directly contributes to knowledge productivity depending upon subject matter

Approach 6 Leadership directly -> contributes to value creation

The contributions of leaders to organizational culture, knowledge productivity, and value creation differ depending upon their leadership style (A, B, C, or D). The following description explains how A, B, C, and D type leaders approach value creation in relation 
with organizational culture and knowledge productivity. In addition, the leaders of the four companies and their respective leadership styles are described below.

A type leadership:

1) Strongly 1-2-3 \& 1-4 with a selective 5 approach

2) Leadership characteristics: people-oriented, non-bureaucratic and open, charismatic, delegation, visionary and high-challenging entrepreneurship

Group chairmen of the following two companies can be regarded as A type

- LG Group (LG Electronics), - Samsung Group (Samsung Electronics)

B type leadership:

1) Mainly 1-2-3 \& 1-4 with an active 5 approach

2) Leadership characteristics: people-oriented, non-bureaucratic and open, charismatic, delegation, innovative, visionary and high-challenging entrepreneurship

The chairmen of the WoongJin Group and Shinhan Financial Group can be regarded as B type. The CEOs of LG Electronics, Samsung Electronics, Shinhan Bank, and WoongJin Group companies can be regarded as B type. They demonstrate strong performance and action-oriented characteristics, CEOs are less charismatic than their Group chairmen.

A- and B-type leaders are similar in approaches and characteristics. However, A-type leaders take a selective 5 approach, while B type leaders take a more active 5 approach in demonstrating entrepreneurship.

C type leadership:

1) Less 1-2-3 \& 1-4 with active 5 and 6 approaches

2) High challenging entrepreneurship, bureaucratic, limited delegation, charismatic

D type leadership:

1) Limited 1-2-3 \& 1-4 mainly 5 and 6 approaches

2) Bureaucratic, top-down control, charismatic, maintaining status-quo

Findings of the case studies;

In this study no leaders were identified demonstrating $\mathrm{C}$ or $\mathrm{D}$ type leadership in the 
four companies. The leadership styles of the four companies mainly show A and/or B type characteristics.

\subsubsection{Evolution of leadership style in Korea}

Leadership styles in Korea have evolved and changed over the last three decades. Fastprogressing economic development, industrialization, and democratization of Korea have brought significant changes to leadership and organizational culture in Korean businesses (Park, 2009). The leadership and organizational culture have become more people-oriented and humanitarian, less bureaucratic and more open, delegating responsibilities and encouraging active participation. Top-down control is now rare. Leaders now value, respect, and empower people within their organizations. Bureaucratic and charismatic top-down control now mainly belongs to the past. Today's people-oriented leadership and organizational culture allow employees the freedom to be creative and innovative with strong psychological ownership, as the findings of this empirical research on the four companies confirmed.

Through the economic development era in Korea initiated by the military government during the decades from the 1960s to the early 1990s, the most successful business leaders were those who founded today's leading Korean companies. They did so without experience of advanced technologies in their respective industries. These were $\mathrm{C}$ or $\mathrm{D}$ type leaders with a strong sense of entrepreneurship, high-challenging spirit, and a willingness to take risks. Examples include B.C. Lee, founder of the Samsung Group, who initiated Samsung's electronics and semiconductor businesses with no existing technological base or experience, and J.Y. Chung, founder of the Hyundai Group, who started shipbuilding and automobile manufacturing industries from nothing and with no previous experience.

During that period in Korea, in which rapid economic and industrial development occurred under the military government, $C$ and $D$ type leaders could start and lead new businesses, taking high risks in difficult situations with no technological background. Three times the "five-year economic development plan" was implemented in Korea, spanning 15 years of economic development, during which the Korean economy and its industries developed and advanced (Park, 2009). During this time, the economic base progressed from agriculture to light industry, then to manufacturing of heavy machinery, and eventually to high-technology industries. Politically, the Korean government changed from a military government to a democratic and open society. Human rights became more recognized and respected, and the living standard of the Korean people improved significantly. 
These major changes to the economy, industry, political, and civil society accelerated fundamental changes in leadership style and organizational cultures in the business world.

In recent decades, when the electronics, information, and communication industries grew to become leading Korean industries, leadership styles and organizational cultures in leading Korean companies changed and progressed even more rapidly. The leadership style in most leading Korean companies today is more people-oriented and humanitarian than Korean organizations were in the past. However, the highchallenging entrepreneurship and risk-taking characteristics of previous generations have been retained, acting as drivers for sustained growth. Major Korean enterprises and industries were originally developed and managed mostly by the then $\mathrm{C}$ type leadership (top-down decision and control, charismatic and bureaucratic, visionary and high-challenging entrepreneurship, and taking risks) and sometimes in combination with $\mathrm{D}$ type leadership characteristics during the earlier stage of economic and industrial development. During the stage of advancing economy and industry, the leadership styles of business leaders have changed, mostly from C and D types to $\mathrm{A}$ and $\mathrm{B}$ types.

Thus, as this study confirms, leadership styles, which are people-oriented, delegating and empowering, and high-challenging visionary entrepreneurship, have been identified as favorable for achieving high levels of both knowledge productivity and value creation. Characteristics of the $A$ and $B$ type leadership styles discussed in this study are close to the concepts of transformational leadership (Bass, 1985; Bass, 1993) combined with strategic leadership (Nahavandi \& Malekzadeh, 1993; 1998), as identified in previous studies.

\subsubsection{Traditional concept of employee vs. co-worker and fellow worker}

The translation of the word "employee" into Korean, Chinese, and Japanese, 종업원, 從業員 (all three countries used the same Chinese characters), is associated with the meaning of obeying and following the orders of an employer in a similar way to how a master gives orders to servants. The term "employee" in English was translated into Chinese characters several decades ago during the era when Asian society was generally bureaucratic, and top-down control and obedience-based structures dominated. The rather dictatorial image of this translated word in Korean, Chinese, and Japanese does not reflect the concept of the employee who has psychological ownership and shows team spirit in today's knowledge-based society and peopleoriented organizational culture. In the phrase "employee's psychological ownership", the word "ownership" means something different from what is commonly known as 
share ownership. Under people-oriented leadership and in an organizational culture in which organization members are respected as human beings and their knowledge and ideas are valued, workers are empowered and have psychological ownership, team spirit, strong commitment, and devotion to the company, calling it "my company" or "our company" (Kwak \& Kim, 2012) although they are not shareholders.

Especially in the decades during which Korea was under military control, employees had to follow and obey employers and bosses through top-down, one-way instruction. In today's Korea, society and culture are highly people-oriented and human rights are respected. Therefore, the traditional meaning of this word in the Korean language, which implies obeying and following the employer in a slave-like way, does not reflect the situation in modern Korean society and the organizational cultures in many Korean businesses. Today, the literal meaning of the word "employee" in the Korean, Chinese, and Japanese languages may even be perceived as insulting to people working for a company, especially to knowledge workers whose knowledge, experiences, and ideas are most important valuable assets to the company. Some leading Korean companies have already decided to avoid using the term "employees" (종업원) in the Korean language; instead, they use terms such as "co-worker", "colleague", and "fellow worker".

From a western perspective it may be difficult to understand the strong relationships between employees and the companies studied in this research project. This may raise the question as to how people can develop psychological ownership and loyalty without holding shares in the company. According to recent research with a Korean sample, employees' psychological ownership was affected by organization leaders' empowerment and the degree to which employees participated in decision-making (Kao \& Kao, 2007; Cho, Kim, \& Park, 2011). When leaders respect the members of the company as human beings and value their opinions and ideas, people in the organization do not think of themselves as mere employees who were hired by the company just to perform tasks. They can develop a sense of psychological ownership (in Korean "Juin-Eisik"), and see themselves as valuable team members working together for the company goals (Kwak \& Kim, 2012). Employees' psychological ownership, as influenced by these factors, showed positive relationships with their job satisfaction, job performance, and organizational commitment. Also, other recent studies found a relationship between employees' loyalty and its antecedents in a Korean context. According to these studies, employees' loyalty was positively 
influenced by the psychological contract between employer and employee (Kim \& Cho, 2013), trust, and harmonious relationships between leaders and organization members (Kwon \& Choi, 2014). Based on these empirical findings, we can conclude that holding shares in the company is not a prerequisite for enhanced psychological ownership of Korean employees.

This loyalty to the company sometimes goes even further; for example, employees may choose to spend their own private time on social projects for the company, even giving up part of their holidays. Roh and Yoo (2013) investigated the impact of Korean employees' perceptions of the socially contributive activities of their companies on employee attitude. The findings showed that involvement in CSR activities was positively associated with what the authors call employees' “organizational citizenship behavior and commitment" (Roh \& Yoo, 2013). Furthermore, corporate social investment activities of Korean companies such as building houses for the poor, ultimately had a positive effect on the companies' market value (Bae, Kim, \& Kim, 2008). To sum up, the participation of employees in CSR activities encourages a spirit of volunteerism and self-sacrifice on the part of employees and also seems to influence the market value of those companies in a positive way.

Although labor unions have been very active in many Korean companies in recent years, in the four companies in this study, cooperative labor relations have prevailed. Management and employees (including labor union representatives) of the four leading Korean companies during the study period maintained trusting cooperative relations with no noticeable labor disputes, unlike other companies. In the case of LG Electronics, management and labor union representatives jointly pursued a program called "labor-management relations for value creation", establishing USR (union social responsibility) of the company for planning of joint social activities (Kim, Bae, \& Kwon, 2013). From the interviews in the case study of Samsung, we learn that the people-oriented management of Samsung (e.g., respecting organization members as human beings, providing equal opportunities for talent development and promotion, and providing fair compensation based on performance), seems to be at the root of a strong sense of psychological ownership, and therefore the need to organize a labor union has not been felt. Also in the Korean context, integrity of management, transparency in decision-making, and fairness in promotion and financial rewards are highly valued in the workplace. As a result of such strategic practices, a strong bond between the company and employees was established not only at the top level, 
but also at lower levels of employees.

According to the findings of this study, common characteristics of leadership and organizational culture in the four companies include highly challenging visionary entrepreneurship, people orientation, and empowerment of and respect for organization members as human beings, along with their knowledge and ideas. In organizations with these leadership and organizational culture characteristics, empowered employees can develop a strong sense of psychological ownership. Managers and employees in such companies understand that their hard work and efforts benefit all stakeholders, including shareholders, employees, customers, the national economy, and society as a whole. They feel proud about their jobs and are committed to do their best to achieve the vision and goals of the company.

\subsubsection{Guidelines for business leaders}

One of the ambitions of this research project is to narrow the gap between the academic research on leadership and value creation on the one hand, and the adoption of the findings in the day-to-day practice of business leaders on the other. The previously stated research questions focus on this objective. In the following section, a set of guidelines is proposed for business leaders on how to build a culture favorable for knowledge productivity, sustainable value creation and sustainable growth in their corporations. The basis for the guidelines followed from the literature review and conclusions 1 through 6 , as reported in this study. The preliminary version of the guidelines was reviewed and discussed with thirty leading CEOs and opinion leaders, members of Korean business associations such as the Korea Management Association, the Federation of Korean Industries, and the Korea Employers Federation. Their comments have been incorporated in the following guidelines for business leaders.

Guideline 1. Set value creation as the top priority of the company, to be regarded as the "shared vision and dreams" of all members of the organization (Conclusion 1, Conclusion 3).

a. As explained in Chapter 1, value creation enables employees to have a vision and dreams for the future and encourages them to do their best with a strong sense of psychological ownership and team spirit (Shin \& Zhou, 2003; Jung et al., 2008). Value creation means that the company meets stakeholders' expectations. Value creation allows the company to contribute to society by meeting its corporate social responsibility (Husted \& Allen, 2007). Most importantly, value creation 
enables sustainable growth of the company. Therefore, value creation should be regarded as part of the "shared vision and dreams" (Shin \& Zhou, 2003; Shipman, Byrne, \& Mumford, 2010) of all organization members and other stakeholders (Conclusion 1, Conclusion 3).

b. The leader should also ensure that the main factors examined in this study (leadership, organizational culture, and knowledge productivity) and all company functions and action plans are positively and effectively related to the company's value creation (Conclusion 6, Figure 9.6).

c. To foster value creation, the leader must take on a new leadership role, creating a harmonious organizational culture in which all the members of the organization adopt a vision of value creation as their "shared dream" (Conclusion 1, Conclusion 3).

Guideline 2. Implement people-oriented leadership practices.

a. Respect members of the organization as human beings and fellow workers, and also respect their knowledge and ideas (Oldham \& Cumming, 1986; Harrison \& Pelletier, 1997; Chadwick et al., 2008) (Conclusion 1, Conclusion 6).

b. Empower people in the organization to have a vision and dreams for the future with strong psychological ownership (Tosi et al., 2004) (Conclusion 3, Conclusion 6).

c. Encourage a non-bureaucratic, open culture and active delegation of responsibilities with bottom-up decision-making. Emphasize boundary-less, open communication, especially between leader and subordinates (Jung et al., 2008; Denison, 2000; Quinn \& McGrath, 1985) (Conclusion 1).

Guideline 3. Create a knowledge-productive and innovative organizational culture (Conclusion 1, Conclusion 2, Conclusion 5, Conclusion 6).

a. Provide sufficient freedom for people to be creative and innovative (Conclusion 4, Conclusion 6).

b. Promote boundary-less sharing of information, knowledge, and ideas among organization members as part of the company's wealth creation strategy, respecting and accepting different ideas and opinions with a flexible open mind.

c. Lead the company to preserve a competitive position in today's global economy using differentiation convergence strategies (Kim \& Mauborgne, 2005) by implementing continuous improvement and promoting radical innovation of 
products, services, and work processes (Kessels et al., 2011).

d. Create a lifelong learning culture and invest in the continuous development of human resources and talent (Kessels, 2004; Jung et al., 2008) (Conclusion 2, Conclusion 4).

e. Encourage organization members to have pride and develop a spirit of professionalism in the domains in which they carry responsibility.

Guideline 4. Prioritize high-challenging vision and goals that include seeking new future growth opportunities, taking risks, and effectively adapting to the rapidly changing business environment. Invest sufficient time and effort into sharing the company's vision and goals with all organization members (Conclusion 2, Conclusion 3).

a. The leader must ensure that all members of the organization share the highchallenging vision and goals for future growth as their "shared dream" (Shin \& Zhou, 2003) (Conclusion 3), investing sufficient time and effort in communicating the vision and goals (Conclusion 4).

b. Organize and operate risk management systems and establish guidelines for successful implementation of high-challenging future oriented business projects, taking risks while minimizing the negative impacts that might result from these risks (Conclusion 1).

c. Understand and accept mistakes when organization members did their best while attempting to meet challenging goals.

Guideline 5. Encourage activities related to corporate social responsibility (CSR) (Conclusion 3).

a. Encourage employees to participate in social activities for the good of the community.

b. Emphasize the company's role and reputation in society, as this not only reinforces the responsibility of the company toward society, but also increases the commitment, engagement, and psychological ownership of the employees.

c. From the broad perspective, take a positive and proactive approach toward CSR for contributing to value creation for the nation, global society, and mankind (Porter \& Kramer, 2011), which in turn will also contribute to sustainable growth of the company (Du, Bhattacharya, \& Sen, 2010; Husted \& Allen, 2007).

d. Stimulate continuous awareness about the use of renewable energy, water, and 
other resources and find production methods that contribute to sustainability and environmental protection. A future-oriented, environmental friendly technology fuels continuous improvements and radical innovations as it instigates knowledge productivity.

Guideline 6. Emphasize transparency, integrity, and honesty as an inflexible part of policy, thereby creating a safe and trustworthy work environment while maintaining a strong corporate reputation and image (Berson, Oreg, \& Dvir, 2008). Instead of imposing rules, an atmosphere should be created that allows learning and discussion of moral and integrityrelated questions and dilemmas (Conclusion 3).

\subsection{Research relevance}

In this section, the academic and practical relevance of this study, as well as its methodological weaknesses, are discussed. It concludes with recommendations for future research directions.

\subsubsection{Academic relevance}

The main objectives of this research project were to contribute to the theories of leadership, relating organizational culture, knowledge productivity, and value creation. Leadership styles and organizational cultures have dramatically evolved and advanced in recent years, especially in Korea. In previous academic research, the intricate relationships among leadership, organizational culture, knowledge productivity, and value creation have not very often been studied. This study shed new light on the relationship between knowledge productivity and value creation, as well as the critical role of leadership.

\subsubsection{Practical relevance}

This research project was intended to reduce the gap between academic theories and practical management in business fields. The cases of four leading Korean companies (Samsung Electronics, LG Electronics, Woong-Jin Group, and Shinhan Bank) were examined to define and theorize leadership styles and organizational culture in practical ways. The main conceptual framework of this research was developed based on the author's 30 years' experience of advanced management with a leading global company (GE) and in-depth understanding of the four leading Korean companies. The concepts presented in this study were developed in close 
collaboration with members of the corporate sector, and the guidelines presented herein were intended to be practical and adoptable by business leaders. To validate the initial conceptual framework, a survey and a series of interviews were conducted with executives and managers of the four companies. The resulting data provided the basis for answering the research questions and developing a set of practical guidelines to be adopted by business leaders. The senior leaders of the four companies as well as top executives from the Korean business world (who are mostly members of the Korean Management Association) discussed the research findings and commented on the guidelines. Conclusions of this study and the guidelines for business leaders presented in this study therefore reflected opinions of business leaders and constitute a practical outcome of this research project, thus contributing to narrow the gap between academic research and the business world.

\subsubsection{Relevance for society}

The findings and conclusions of this research suggest that highly empowered people within organizations become creative and do their best with strong psychological ownership to achieve high value creation and fulfill the vision of the company. Companies adopting this people-oriented approach and exhibiting knowledgeproductive characteristics can influence industries and society in a positive way. Through high value creation in combination with corporate social responsibility (CSR), companies can contribute to society not only by acting as good corporate citizens, but also by improving sustainability.

\subsection{Critical review of this research}

Several fundamental questions provided the starting point for this research. The main questions are: How do the characteristics of leadership relate to organizational culture, knowledge productivity, and value creation? And, can we offer guidelines for business leaders to make use of these research findings in their day-to-day practice? However, there are some limitations in answering the questions of this study, as outlined below.

\subsubsection{Generalization}

In this study, four leading Korean companies were used as case study models for the empirical research to enable understanding of the relationships among the main concepts in highly successful companies. Therefore, the results may not be necessarily generalized to all other Korean and foreign companies. Successful 
leading companies achieving high value creation were selected deliberately to identify the leadership and organizational culture characteristics for creating a knowledge-productive organizational culture. Thus, low-performing companies were not included in this research. In future research, comparing high- and lowperforming companies may provide a clearer view of the distinctive factors that determine success or failure of a company.

In future empirical research with the objective of developing more generalized and globalized conclusions, a broad sample should be used including companies exhibiting high-, medium-, and low-level performance and also companies from many different regions and countries. However, the approach in this study did allow an in-depth exploration of the various research concepts and learning from management practices in each of the successful enterprises.

\subsubsection{Reliability}

The results of the exploratory and confirmative factor analyses showed that the questionnaire items were grouped differently depending on the characteristics of the included variables. All variables showed acceptable reliability (Cronbach's alpha), and most items represented their factors well.

\subsubsection{Validity}

Despite some minor inconsistencies, the results of the factor analysis accorded and fitted with the original intentions of the research model of this study, which built on a rich, literature base, thereby increasing the validity of the variables in the quantitative analysis. The interview results were read back to the interviewees to ensure that the analysis was based on valid contributions. Furthermore, the research findings, conclusions, and guidelines were discussed with business leaders and selected members of the Korean Management Association to improve the validity of this study.

\subsubsection{Methodological issues}

The results of the correlation analysis showed positive or negative relationships between characteristics of the variables. However, these results do not allow inference of causal relationships. This is an important limitation of this study in terms of answering the question as to what leadership characteristics lead to value creation. However, the findings from previous research and the opinions expressed during the interviews provide an important and additional basis for the conclusions drawn here. Future research will need to identify the causal relationships among the 
main variables, suggesting the need for a more elaborate research design and methods for analysis.

The mediating effects of the four variables were not examined in this study. Among the four main variables, two may be mediators between the other variables. Organizational culture may be a mediator between leadership and knowledge productivity, as well as between leadership and value creation. In addition, knowledge productivity may be a mediator between leadership and value creation, as well as between organizational culture and value creation. In future research, a more elaborate analysis should be conducted in order to identify the mediating or moderating effects of the main variables.

\subsection{Directions for future research}

This final section on directions for future research includes suggestions for advanced cooperation between the academic world and business leaders to reinforce the validity and practicality of research in the domain of leadership and value creation in a knowledge economy, including the concept of creating shared value (CSV) (Porter \& Kramer, 2011).

\subsubsection{Leadership and organizational culture}

During recent decades, leadership styles and organizational culture in the business world have changed and progressed substantially, especially in the newly developed country of Korea. As a result, leadership styles and organizational culture in today's business world differ considerably from those of the past. Previous research has mostly been based on the leadership and organizational culture characteristics prevalent in the period from the 1970 s to 2010 , mainly in western contexts. Therefore, theories from such research in earlier decades may not adequately reflect the leadership and organizational culture characteristics of today. Important gaps may exist between earlier academic research and today's real-time field operations. This is a topic that is often discussed among business leaders, who find it difficult to relate the results of those academic studies to their daily business practice. This is one of the main subjects often discussed at conferences and meetings of the Korea Professional Management Academy, which the researcher currently serves as the chairman.

To focus on today's advanced modern management leadership and organizational culture models, future research projects should also involve business leaders and top management sharing their experiences and knowledge. This is an important prerequisite to further reduce the gap between academic theories and leadership 
practice in the field.

\subsubsection{Knowledge productivity}

Future research on subjects related to knowledge productivity should focus on practical approaches and applications of knowledge productivity in industry and field business management settings. Future research should also focus on linking knowledge productivity to industrial and economic development at the national level. Knowledge productivity will play an increasingly important role in the knowledge society as the twenty-first century growth engine for value creation and sustainable future growth, probably not only in the business world, but also in areas such as economics, science, technology development, health care, and social sciences.

Studies on the relationships between leadership, knowledge productivity and value creation are sparse. However, business leaders expect that knowledge productivity will play an increasingly important role in our knowledge society as the twenty-first century growth engine for value creation and sustainable future growth. It is worthwhile to investigate further how learning, knowledge development, incremental improvement, radical innovation and economic value creation interrelate. These aspects are directly related to human resource development, and indicate that HRD is central for leadership in these successful companies. Therefore, future research on subjects related to the concept of knowledge productivity should focus not only on practical approaches and applications in industry and field business management settings, but also on linking human resource development and knowledge development.

\subsubsection{Creating Shared Value}

In the context of this research, value creation in business management encompasses the concepts of: (a) revenue and net profit growth; (b) increasing corporate market value; (c) increasing satisfaction of employees and customers; (d) improving corporate reputation and image; and (e) fulfilling CSR. CSR contributes to the value creation of companies mainly by improving corporate reputation and image and increasing satisfaction of employees and customers. It also involves in the area of environmental protection for the society, which can create future growth business opportunities. This study stressed the importance of CSR for stimulating innovation (Guideline 5 and in specific $5 \mathrm{~d}$ ).

Recently, the concept of creating shared value (CSV) was introduced by Porter and 
Kramer (2011). They defined shared value as operating policies and practices that enhance the economic competitiveness of a company while simultaneously advancing the economic and social conditions of the communities in which it operates. Companies prioritizing CSV focus on identifying and expanding the connections between societal and economic progresses.

As a value creation factor, CSR mainly emphasizes on improving corporate reputation and image by contributing to society, while CSV more proactively involves in the company's competitive position and creating economic value by creating social value. To accomplish this value creation, companies should leverage their unique resources and expertise.

For these reasons, future research exploring the relationships among leadership, organizational culture, knowledge productivity, and value creation need to consider including the concept of CSV as another main factor within the domain of value creation. 


\section{Summary in English}

\section{Leadership, Organizational Culture, Knowledge Productivity and Value Creation in Four Successful Korean Companies}

\section{Toward guidelines for people-oriented business leaders}

\section{Introduction}

This study explores the relationships between leadership characteristics, organizational culture, knowledge productivity and value creation in leading Korean corporations. The empirical part of this study is based on the selection of four highly successful and leading companies, namely LG Electronics, Samsung Electronics, Woong-Jin Group and the Shinhan Bank.

In knowledge-intensive organizations, it is important to understand what kind of leadership is needed to build knowledge productivity, achieve continuous improvement and radical innovation and ensure high value creation. However, investigating these critical elements in successful companies is a delicate matter. For the first time, leaders of the four companies included in this study agreed to participate in empirical research on these issues. From a literature search related to the main topics, a conceptual framework was developed. This was followed by a survey among 387 leaders and senior managers and additional interviews with senior-level executives and managers of these companies. The results indicate that a strongly people-oriented, highly challenging and entrepreneurial style of leadership with open, boundary-less communication and knowledge sharing is strongly related to value creation, sustainability and future growth engine development in these four companies. In collaboration with business leaders, the research findings have been translated into guidelines for leadership promoting value creation.

\section{Problem statement and research questions (Chapter 1)}

Value creation is widely considered to be one of the most important objectives for leaders of businesses and institutions to contribute to economic development. This objective of this study is to explore the relationship between leadership characteristics and value creation and describes the interaction of organizational 
culture and knowledge productivity and their connections to leadership and value creation.

Substantial changes have occurred in business environments in recent years; of these changes, the shift from capital, raw materials and physical labour as the main means of production (Bukowitz \& Williams, 2002; Drucker, 1993) to the development and application of knowledge may be one of the most important. In a knowledgeproductive organization, management and employees accelerate improvements and innovations and develop new opportunities for growth. All these factors are crucial for high value creation. The leadership characteristics that encourage building of a knowledge-productive and people-empowering organizational culture that fosters high value creation must therefore be identified. These assumptions provide the starting point for this research.

The main research questions addressed in this study are as follows:

1. How do the characteristics of leadership relate to organizational culture, knowledge productivity and value creation in companies, especially in successful leading Korean companies?

2. Is it possible to design a set of guidelines for leadership on the basis of the answers to question 1, in order to achieve high value creation in knowledge-productive organizations?

\section{Conceptual framework (Chapter 2)}

Through value creation, a company can meet stakeholders' expectations, such as those of investors who place their trust in the capabilities of company management. Value creation allows employees to have visions and dreams for the future and encourages them to do their best for the company with a strong ownership spirit (Weiss et al., 1967). Value creation enables sustainable growth of the company and allows the company to contribute to society by fulfilling its corporate social responsibility (Husted \& Allen, 2007). Value creation is not only a matter of revenue, profit growth and market value; it also relates to corporate reputation and customer and employee satisfaction. Therefore, value creation should be considered the main responsibility of top managers and leaders in the business world (Rho, Lim, \& Hwang, 2004). In the context of this research, value creation encompasses the 
concepts of: (a) revenue and net profit growth; (b) increasing company market value; (c) increasing satisfaction of employees and customers; (d) improving corporate reputation and image; and (e) fulfilling corporate social responsibility.

A knowledge-productive organization is one in which continuous improvement and radical innovation of products, services and work processes can be observed (Kessels, Verdonschot, \& De Jong, 2011). Producing knowledge in a company can be seen as an ongoing learning process, integrated into the day-to-day work environment, in which staff members at all levels can participate (Kessels \& Keursten, 2002). Such a learning process focuses not only on the development of subject matter expertise and enhanced problem solving, leading towards improvements and innovations, but also on reflective skills, open communication and interaction, and the motivation and engagement of staff members. This second aspect of knowledge productivity enables companies to develop the capability to be innovative in the future (Kessels, 2001; Kessels, 2004; Kim \& Mauborgne, 2005).

An organizational culture in which open communication is prioritized contributes to learning and enables the exchange of knowledge and experience. Such an organizational culture may motivate people to be innovative and creative, encourage them to feel a real sense of accomplishment, and bring out their best capabilities, fostering an ownership spirit which aids in achieving the vision and goals of the company (Alimo-Metcalfe et al., 2008; Harrison \& Pelletier, 1997; Hutchings \& Michailora, 2004; Jung, Wu, \& Chow, 2008; Shin \& Zhou, 2003).

The selection of Korean leading companies for this research project is inspired by the following considerations. The four companies have a special leadership style, known as "Two-tops Leadership", which is characterized by people-oriented, highly challenging and risk-taking entrepreneurship and an organizational culture that focuses on knowledge productivity and high value creation. It is the kind of leadership and organizational culture that contributed to the successful industrialization of and economic growth in Korea in recent decades. Another reason is that research in the domains of leadership, organizational culture, knowledge productivity and value creation is mostly based on models of Western countries. Research in this area that includes Korean cases is rare. The four selected leading Korean companies have achieved sustainable and substantial growth during the research period (2000-2010), diversifying their businesses and expanding global business activities. This research is intended to shed light on how these successful leading Korean companies developed their characteristic leadership styles and organizational culture, which are obviously favourable for knowledge productivity 
and high value creation.

An important aspect of organizational culture in Korean companies is the "ownership spirit" of the employees, which in the Korean language can be transcribed as “주인의식" (Juin-Eisik) (Jung et al., 2008; Shin \& Zhou, 2003). This term is commonly used in the business community in Korea to describe the mindset and spirit of employees who love their company and their work, who are willing to do their best for the company with a sense of loyalty as strong as that of the owner of the company. When leaders respect and empower their employees as human beings and value their opinions and ideas, they can encourage this ownership spirit (Tosi et al., 2004). In this study, the phrase "ownership spirit" is unrelated to the concept of share ownership. Juin-Eisik (ownership spirit) is closely linked with a sense of responsibility, a sense of mission that enables employees to love and enjoy their work. Employees with ownership spirit trust their leaders and the company.

Effective leaders communicate a challenging vision and value entrepreneurship (Shin \& Zhou 2003; Tsui et al. 2006) within the organization. They share their vision and values with all members of the organization in a boundary-less and open way (Slater, 1998; Slater, 1999). We expect that the role of leaders in developing a knowledge-productive culture is closely related to their attitude toward challenges, risk-taking and entrepreneurship and their methods of control (Nahavandi \& Malekzadeh, 1993). As knowledge development is inherently a learning process for staff members, a favourable climate conducive to learning is required (Kessels, 2001). Therefore, it is expected that leaders that are people-oriented and encourage openness, participation, empowerment, trust and respect will contribute to the creation of a learning culture favourable to knowledge productivity, including continuous improvement and radical innovation (Chadwick, Barnett, \& Dwyer, 2008; Hutchings \& Michailora, 2004; Jung et al., 2008; Oldham \& Cummings, 1986; Shin \& Zhou, 2003; Trice \& Davis, 1993).

Recently, Carmeli, Schaubroeck and Tishler, (2011) stressed the role of empowering leadership behaviour, which enhances team potency. Such leadership behaviour shapes the context for information exchange, joint decision-making and collaboration. It nurtures confidence among team members and has positive implications for firm performance. Makri and Scandura (2010) were among the first to relate creative leadership at the CEO level to the development of social and human capital and knowledge development throughout the company.

Leaders can influence value creation indirectly by developing a strong organizational culture. The longitudinal study by Wilderom, Van den Berg and Wiersma (2012) offered evidence for the relationship between organizational culture and firm 
performance and charismatic leadership characteristics. In a knowledge economy, leaders may directly influence value creation by openly focusing on knowledge productivity. The purpose of this study is to explore and understand the leadership characteristics by which a strong, knowledge-productive organizational culture is created, one that leads the company to achieve high value creation and sustainable growth.

To investigate the relationships among the main variables of the conceptual framework, the following detailed questions are addressed:

1) How do the characteristics of leadership relate to organizational culture, knowledge productivity and value creation of the company?

2) How do organizational culture, knowledge productivity and value creation interact?

3) What leadership style is favourable for building a knowledge-productive organizational culture and achieving sustainable high value creation?

4) Is it possible to design a set of guidelines for leadership on the basis of the answers to questions 1, 2 and 3 in order to achieve high value creation in knowledgeproductive organizations?

\section{Methods and procedure (Chapter 3)}

To address these research questions, data were collected related to the major concepts in the framework in four leading Korean companies, namely Samsung Electronics, LG Electronics, Shinhan Bank and the Woong-Jin Group. To learn about the relationships among the main variables presented in the conceptual framework, these four very successful Korean companies were deliberately selected, as they provide examples of continuous value creation over the last 10 years. Data collection was performed using a survey questionnaire and a series of semistructured interviews. The results were evaluated in feedback discussions for validation. Each company was described in a separate case study report. The results of the cross-case analysis of the four companies served as the basis for developing guidelines for business leaders who wish to facilitate a knowledge-productive culture and enhance value creation within their organizations.

Over the last ten years, the knowledge-intensive companies that participated in this study have created value far above the average in their respective industries, 
according to the financial data of the top 100 Korean companies provided by Korea Institute for Industrial Economics \& Trade, or KEIT (2011). Therefore, it is worthwhile to examine the leadership characteristics in these companies and learn how these characteristics are related to organizational culture, knowledge productivity and value creation. Obtaining access to the senior-level executives and managers of these leading companies was challenging, and collecting information on sensitive subjects such as leadership styles of chairmen and CEOs, organizational culture, knowledge productivity and value creation even more so. For all four companies, it was the first time that they had agreed to disclose sensitive internal information on leadership and value creation for an academic study conducted by outside researchers.

\section{Instrument development}

For data collection, a new survey instrument was developed based on an elaborate literature review, combining elements from previous research with new items to fit the conceptual framework of this study.

The survey questionnaire consists of a total of 106 items: 28 items on leadership (including empowerment, communication, delegation, integrity, entrepreneurship, inspiration, charisma, challenge seeking, risk taking and risk management), 21 items on organizational culture (including people orientation, ownership spirit, empowerment, challenge seeking, boundary-lessness, open communication and innovation), 29 items on knowledge productivity (including learning, improvement, innovation and future growth engine) and 28 items on value creation (including reputation, image, corporate social responsibility, employee satisfaction, sustainability and financial performance). The items were transformed into a questionnaire with items scored on a five-point scale from (1) I fully disagree to (5) I fully agree. A pilot version of the questionnaire was distributed in one of the four companies. On the basis of the results of the pilot survey, some items were removed and others were refined. The survey questionnaire was developed in both English and Korean; however, the Korean version was distributed to the four participating Korean companies.

\section{Data collection and response}

The human resources departments of each company were supportive in organizing the distribution of the survey questionnaires and collecting the survey data. In total, 480 questionnaires were distributed to executives, managers and other employees of 
the four companies, and 387 respondents returned their completed questionnaires anonymously. For the quantitative analysis, all 387 survey responses from the four companies were usable (Samsung Electronics: 70, LG Electronics: 100, Shinhan Bank: 100, Woong-Jin Group: 117). The overall response rate to the questionnaire was $84 \%$. This high response rate may have been influenced by the personal approach to the respondents by the researcher and the help of the senior managers and HR staff members in organizing the data collection. All respondents were full-time executives, senior managers, managers and staff members of the four companies included in the study.

\section{Factor analysis and reliability test}

Convergent and discriminant validity of the items for leadership style, organizational culture, knowledge productivity and value creation was proved by a series of exploratory factor analyses. The loadings for the majority of the $\mathbf{1 4}$ factors proved to be reliable and appropriate. Only one item related to knowledge productivity was eliminated due to a low factor loading.

The factors and their respective variables are as follows. Leadership (28 items) consists of four factors: LS1 (people-oriented: 17 items), LS2 (visionary and entrepreneurial: 6 items), LS3 (high challenge-seeking and risk-taking: 2 items) and LS4 (low challenge-seeking and high control: 3 items). Organizational culture (21 items) consists of four factors: OC1 (people-oriented: 13 items), OC2 (high challenge-seeking and innovative: 2 items), OC3 (low challenge-seeking and status quo: 3 items) and OC4 (bureaucratic and top-down: 3 items). Knowledge productivity (28 items) consists of two factors: KP1 (improvements and innovations of products, services and work processes: 18 items) and KP2 (increased sustainable capability for future growth: 10 items). Value creation (28 items) consists of four factors: VC1 (corporate reputation, image and corporate social responsibility: 12 items), VC2 (employee satisfaction with work atmosphere: 9 items), VC3 (employee satisfaction with financial benefits: 3 items) and VC4 (sustainability: 4 items). Furthermore, an analysis of reliability was conducted to determine the appropriateness of the clustered items for each factor. To determine the reliability of the results of the analysis, the appropriateness of the clustered items to the different factors was examined. Cronbach's alpha scores for all 14 factors ranged from 0.605 to 0.953 , indicating an acceptable level of reliability.

The results of a confirmatory factor analysis verified the discriminate validity of the variables adopted in this study. 


\section{Interview guidelines}

In addition to the survey questionnaire, a set of interview guidelines was developed. These guidelines formed the basis for additional talks with executives, managers and other employees in the four companies. Before the main series of interviews was conducted, four open interviews per company were held with a few executives and staff members in high-ranking positions to improve the understanding of each company's leadership style, organizational culture, knowledge productivity and value creation, and to facilitate selection of key points on company vision and orientation to conduct the main series of interviews more effectively. The names of the interviewees and their responses were kept strictly confidential.

\section{Variables related to value creation}

Data collection for the variables related to value creation was performed using three methods: a questionnaire ( 28 items), data available from the participating companies (e.g., annual reports) and the financial data of the top 100 Korean companies between 2000 and 2010 provided by the Korea Institute for Industrial Economics and Trade (KEIT) (2011). Executives, senior managers and employees responded to the survey by completing the questionnaire items, thus providing data about corporate reputation, image and corporate social responsibility (VC1), employee satisfaction with work environment (VC2), employee satisfaction with financial benefits (VC3) and sustainability (VC4). Data on net profit, revenue/sales and market value for each of the companies were collected from the annual reports of the companies filed with the Korea Stock Exchange that were officially audited in the period of 1990-2010. KEIT also provided data on net profit, revenue and sales and total assets of the top 100 companies in Korea to facilitate comparison of each company to the best-performing companies in their industry sector.

\section{Designing guidelines for business leaders}

In order to share the research findings with business leaders and also to reduce the gap between academic theory and day-to-day business management, active involvement of business leaders and top managers was solicited in this study. Practical guidelines for business leaders were developed on the basis of the research findings. Thirty CEOs who are members of Korean business associations, such as the Korea Management Association, the Federation of Korean Industries and the 
Korea Employers Federation, took part in a series of discussions on the conceptual version of the guidelines in the Korean language. Their comments have been incorporated in the final version of the guidelines for value creation in the Discussion section. Their participation in this study may encourage future collaboration and participation of business leaders in academic research in Korea.

\section{Case study reports}

For each of the four companies, a separate case study was conducted including the results of the quantitative analysis (i.e., the survey), qualitative interpretation of the interviews and the financial performance data provided by the Korea Industry Research Institution. The case study reports for each company were sent for validation to the participants. On the basis of their response, the researcher organized feedback discussions with senior management. As a result, some minor changes and additions were made to the case reports.

\section{LG Electronics (Chapter 4)}

LG Electronics is one of the two leading companies in the consumer electric and electronics industry in Korea. The company is active globally; $78 \%$ of its sales come from overseas markets. LG Electronics achieved sustainable growth over the 10 -year period examined in this study. At LG Electronics, 120 survey questionnaires were distributed, of which 100 were returned. In this company, the researcher conducted 24 interviews with top management, senior staff members and other employees.

The main findings in the LG Electronics case study can be summarized as follows:

The leadership style can be characterized as people-oriented and humanitarian, high challenge-seeking and visionary, and risk-taking with an entrepreneurial spirit. Senior leaders show a high level of delegation, but participate in making important decisions. In the two-tops leadership structure in this company, the LG Group chairman and CEO of LG Electronics share responsibilities.

The culture is people-oriented and humanitarian, fostering strong psychological ownership on the part of employees. The company's boundary-less and nonbureaucratic open culture offers freedom for people to be creative and innovative, resulting in a high challenge-seeking work environment. LG managers developed a strong capability in the company for continuous improvement and innovation of 
products, services and work processes (KP1), as well as for continuous innovation for sustainable development of future growth engine business (KP2). The company seems to focus more on KP1 than KP2.

LG Electronics shows sustained high value creation and growth based on strong people power, resulting in stable growth of revenue, net profit and market value during the 10 years of the research period. The company enjoys a high corporate reputation and a good image, and invests in corporate social responsibility (CSR). Employee satisfaction with the work environment and financial benefits is high.

\section{Samsung Electronics (Chapter 5)}

Samsung Electronics is the leading company in the consumer electric and electronics industry in Korea, achieving sustainable growth over the 10-year period examined in this study. Samsung became the world's leading company in its industry during this period. It successfully operates global businesses in overseas markets. At Samsung, 120 survey questionnaires were distributed, of which 70 were returned. In this company, the researcher conducted 18 interviews with top management, senior staff members and other employees.

The main findings in the Samsung Electronics case study can be summarized as follows:

The leadership can be characterized as people-oriented, focusing on developing the best people for the best company. The vision for building the world's leading integrated digital company is the driving force; high challenge-seeking and risktaking entrepreneurship are also characteristic of Samsung. The two-tops leadership structure of this company combines the Samsung Group chairman's highly challenging long-term vision with the professional management leadership of the CEO of Samsung Electronics. Samsung's people-oriented culture places high priority on human resources and talent development. The management delegates responsibility with a unique indirect control system, seeking continuous changes and innovation. The company has a strong learning culture.

The group leader has a strong desire to achieve advanced knowledge productivity for building a top, competitive, leading company and actively developing futureoriented new products for sustainable growth. His vision involves continuous radical change, innovation and improvement of products, services and work 
processes. The company successfully achieved sustained growth and high value creation for the past 10 years, bypassing its competitors to become the world's leading company in the electronics industry today.

\section{The WoongJin Group (Chapter 6)}

The WoongJin Group is a fast-growing, leading company in diverse business areas. This company achieved high growth over the 10 -year period examined in this study. Their rapidly expanding global businesses generate $21 \%$ of sales from overseas markets. At the WoongJin Group, 120 survey questionnaires were distributed, of which 117 were returned. In this company, the researcher conducted 15 interviews with Chairman S.K. Yoon, top management, senior staff members and other employees.

The main findings in the WoonJin Group case study can be summarized as follows:

The people-oriented and charismatic leadership and high challenge-seeking entrepreneurship of the leaders allow the company to move into new business areas and take advantage of new opportunities while also taking acceptable risks. The effective two-tops leadership structure combines the group chairman's highchallenging visionary entrepreneurship and each CEO's professional management skills, emphasizing creative and innovative ways of thinking and new approaches.

The people-oriented culture at WoongJin facilitates strong psychological ownership and empowerment of employees. The unique WoongJin style, "Sinbaram" (Exciting Wind-Blowing Culture), highly motivates employees to share the vision and dreams of the company's leaders, so that they enjoy their work with passion. In the open, boundary-less culture at WoongJin, responsibility is widely delegated.

The group chairman demands continuous changes, improvements and innovation of products, services and work processes for sustainable growth. The active learning culture and prioritization of talent and human resources development result in a highly knowledge-productive organization. The highly challenging and open organizational culture motivates employees toward continuous innovation and new business development for the company's future growth. The company achieved highly successful and sustained growth and high value creation for the 10 years of the study period. This financial success goes with a high level of employee and 
customer satisfaction and an excellent company reputation. The company is active in meeting its corporate social responsibilities.

\section{Shinhan Bank (Chapter 7)}

Shinhan Bank is one of the two leading banks and financial business groups in Korea. The company achieved a remarkably high growth rate and expanded its overseas business operations over the 10 -year period examined in this study. At Shinhan Bank, 120 survey questionnaires were distributed, of which 100 were returned. In this company, the researcher conducted 18 interviews with Chairman E.C. Rah, top management, senior staff members and other employees. Most respondents held middle- and senior-level positions at the time of the interviews.

The main findings in the Shinan Bank case study can be summarized as follows:

The bank has a strong people-oriented and softly charismatic leadership, characterized by high challenge-seeking entrepreneurship with a long-term goal to become one of the top 10 Asian banks and financial businesses groups. The peopleoriented humanitarian culture yields strong psychological ownership of empowered employees who enjoy their work with passion. An emphasis on open, boundary-less teamwork facilitates sharing of knowledge and ideas.

The leader strongly demands continuous changes and improvement of work processes and services for sustainable growth. The active learning culture and prioritization of talent development and human resources result in a highly knowledge-productive organization. The highly challenging and open organizational culture motivates employees toward continuous innovation. The bank achieved important successful sustained growth and high value creation for the past 10 years, accompanied by high reputation and employee and customer satisfaction. The bank participates actively in corporate social activities.

The four aforementioned case reports formed the basis for the cross-case analysis in this study.

\section{Results of the cross-case analysis (Chapter 8)}

Chapter 8 presents the characteristics of the respondents, the main correlations between the 14 factors related to the four variables (leadership, organizational culture, knowledge productivity and value creation) and a summary of the cross-case analysis. 


\section{Characteristics of the sample}

The majority of respondents were highly educated, experienced managers. As in most Korean companies, the social structure at the top executive level is still very much dominated by male executives and managers.

\section{Relationships between the main variables}

As expected, the relationships between the various leadership characteristics and the factors that constitute organizational culture are very strong. The first three leadership characteristics (people-oriented, visionary and entrepreneurshiporiented and highly challenge-seeking and risk-taking) are similar to the organizational culture styles (people-oriented and highly challenge-seeking and innovative). During the interviews, respondents found it difficult to separate aspects of leadership from characteristics of culture clearly. The leaders of each company are deeply embedded in the culture of their respective organizations, and are part of the creation and constant recreation of value.

The results of the qualitative analysis revealed that although differences exist in the leadership styles and organizational cultures across the four companies, important commonalities among the key characteristics can be found; they are all peopleoriented, visionary and entrepreneurial and high challenge-seeking, risk-taking and innovative. These key characteristics of leadership and organizational culture were significantly and positively correlated with knowledge productivity and value creation in the four companies. Knowledge productivity was also significantly and positively correlated with value creation. Many interviewees were very clear about the importance of continuous improvement and radical innovation. They stressed the need for open information and knowledge sharing, learning and creative thinking. They also emphasized that creating an organizational culture that promotes knowledge productivity is an important mission and responsibility of business leaders today.

I found differences in the results of the correlation analysis between Shinhan Bank and the other three companies in the relationship between bureaucratic and topdown organizational culture (OC4) and sustainability (VC4), which could be interpreted and understood as follows. Korean financial companies, especially banks, are characterized by a more conservative and less risk-taking culture, and are more used to top-down, central control. Like Shinhan Bank, they manage financial 
risks very successfully, thereby protecting the sustainability of their banking and other financial businesses during the 1997 Asian financial crisis (IMF Crisis) and the 2008 global financial crisis. For this reason, the Shinhnan Bank case may shows positive relation between $\mathrm{OC} 4$ and $\mathrm{VC} 4$, which is different from the other three cases.

\section{People-orientation and ownership spirit}

One of the important common characteristics of leadership and organizational culture in the four companies in this study is that they are people-oriented. The leaders we interviewed stressed respect of organization members as human beings, including respect for their opinions and ideas. These leaders try to empower and motivate their people by creating non-bureaucratic and open organizational cultures with considerable freedom. They see the need for people in the organization to become more creative and innovative, demonstrating a strong ownership spirit and doing their best to achieve the company's vision and goals.

\section{“Two-tops" leadership structure}

Other important common leadership characteristics of the four companies include their visionary and highly challenge-seeking entrepreneurship and willingness to take risks for sustainable future growth engine and business development. Each of the four leading companies has a specific form of the "two-tops" leadership structure identified in this study. In the four companies, the group chairmen delegate management responsibilities to the professional management CEOs. However, in major decision-making for the long-term vision and strategy and managing of important projects, the group chairmen participate either directly or indirectly. No examples of low challenge-seeking, bureaucratic or highly controlling leadership characteristics of group chairmen were found in any of the cases examined in this study.

\section{Knowledge productivity}

Leaders of all four companies strongly emphasized continuous improvement and innovation of products, services and work processes (KP1), encouraged radical innovation and development of creative new ideas for sustainable development of future growth engines (KP2) and promoted moving into new business areas by 
taking risks. The results of the quantitative analysis indicated that leadership and knowledge productivity in all four companies were strongly related. However, the interviews with the leaders revealed that prioritizing of KP2 and taking risks during implementation differed between companies.

People-oriented and high challenge-seeking leadership and visionary entrepreneurship were significantly and positively correlated to both knowledge productivity and value creation. In the interviews, leaders had clear opinions about how people-oriented values combined with high emphasis on accepting challenges created a culture that is favourable to continuous improvement and radical innovation. Thus, pushing for performance without considering the engagement and creativity of the company's people may not lead to knowledge productivity and value creation.

\section{Differences}

Although the four leading companies examined in this study have important commonalities with regard to knowledge productivity, each of the companies also has its own characteristics. Some examples are described below.

LG Electronics emphasized continuous improvement and innovation of products, services and work processes, which is similar in concept to KP1. The previous CEO of the company implemented a special program called TDR (Tear-down and Redesign), a radical innovation method for promoting future growth, new product development and new business development, which is similar in concept to KP2. However, driving radical innovation for new products and new business development for future growth was not a top priority for the current leader, who focused more on a short-term, profitoriented, cost-reduction program called "il-jal-bub" during the study period. Therefore, the company missed an opportunity to develop competitive new products in response to the introduction of Apple's new iPhone in 2009. This critical timing error had a significant negative impact on sales and performance, and resulted in a negative net profit in 2010 for the first time in the company's history.

To overcome this difficult situation, the LG Group appointed a new CEO whose strong leadership helped the company to develop future growth engines, competing with new products in a short period. This is similar to the KP2 approach. As a result, LG Electronics overcame its difficulties in 2013.

On the other hand, the leader of the Samsung Group strongly demanded continuous improvements and radical changes and innovations of products, services and work processes (KP1) and also strongly promoted new product development for the development of future growth engines (KP2). As a result, Samsung Electronics 
effectively overcame the potential negative impact of the introduction of Apple's new iPhone to the world market, and managed to turn the potential risks into a radical growth opportunity. The market share of Samsung Electronics grew rapidly, and the company became the world leader in the smart phone industry in 2010.

WoongJin Group companies are committed to continuous change and radical innovation of products, services and work processes (KP1), valuing new business development for future growth (KP2) and willingness to take risks. Their assertive leadership and high challenge-seeking accelerated innovation has helped to make the company successful. Recently, the company made significant investments in a new business area: high-technology polysilicon manufacturing in the newly developed solar energy industry.

Shinhan's leader focused strongly on boundary-less information and knowledge sharing within the company through "the Shinhan Way", which is embodied in an open teamwork program across departments, divisions and hierarchical layers. In this program, continuous improvement and innovation of services and work processes were emphasized. Respecting organization members and their knowledge and ideas is the main characteristic of a people-oriented organizational culture. This is how the company created a knowledge-productive organizational culture with "Shinhan People Power".

\section{Value creation}

In this study, the concept of value creation comprises financial data on performance in addition to non-financial data. Financial performance data included sales, net profit and market value of the four companies for the 10 years of the research period. Non-financial factors included corporate reputation, image and CSR, employee satisfaction with work environment, employee satisfaction with financial benefits and sustainable capability.

The financial data on performance of the four companies indicated that high value creation was successfully achieved from 2000 to 2010 in terms of revenue and profit growth, market value increases and overcoming the world financial crisis that started in 2008. During this period, value creation and growth of the four companies were higher than the average of the top 10 Korean companies in their industries except for the special and unexpected case of LG Electronics in 2010. The net profit of LG Electronics in 2010 was negative due to the significant impact of the introduction of the Apple's new iPhone to the world market in the third quarter of 2009. The results of the quantitative analysis of the four companies indicated that 
specific leadership characteristics (people-oriented, visionary and entrepreneurial, high challenge-seeking and risk-taking), organizational culture characteristics (people-oriented, high challenge-seeking and innovative) and knowledge productivity (improvement and innovation of products, services and work processes and sustainable development of future growth engine) all have significant and positive correlations with value creation factors in each of the four companies.

Findings from the qualitative analysis of data from the interviews indicated that the four companies are highly recognized in their respective industries in terms of corporate reputation, image and CSR. Employee satisfaction with the work environment and financial benefits in the four companies were very high. Employees in the four companies have a strong ownership spirit and are proud of their membership in the respective companies.

Results of the quantitative analysis of the four companies indicated that low challenge-seeking and high control leadership styles were significantly and negatively correlated with both knowledge productivity and value creation. In addition, those organizational culture characteristics: low challenge-seeking and status quo and bureaucratic and top-down control were significantly and negatively correlated with both knowledge productivity and value creation. Interview results consistently indicated that those characteristics of leadership and organizational culture were not found in the four companies.

\section{Conclusion and discussion (Chapter 9)}

The last chapter provides preliminary answers to the research questions and outlines leadership guidelines, as developed with 30 business leaders, on the basis of the research findings. Furthermore, a critical reflection on the research approach is provided. In addressing the main research question: How do the characteristics of leadership relate to organizational culture, knowledge productivity and value creation in companies?, we found evidence in the four leading Korean companies for the following conclusions.

\section{Conclusion 1. Leadership and organizational culture}

The results of our study on four leading Korean companies clearly indicate that leadership characteristics and organizational culture are significantly correlated. The commonalities of the leadership characteristics (people-oriented, delegating, and empowering people, visionary and entrepreneurial, high challenge-seeking, and 
risk-taking) among the four companies are conceptually similar to their organizational culture characteristics (people-oriented, high challenge-seeking and innovative). This supports the claim of Schein (2004) that "culture and leadership are two sides of the same coin" (2004, p. 22).

From studying those companies that achieved successful value creation, we learn that their common leadership characteristics allowed the firms to create knowledgeproductive and innovative organizational cultures with similar characteristics. Commonalities of the organizational culture among the four companies are that they are people-oriented, high challenge-seeking and innovative. The two-tops leadership structures are also similar among the four companies, combining strengths of the leadership of the Group Chairman and strengths of the professional managers (CEOs) who lead each company under the Group Chairman's leadership. Most large business groups in Korea have similar two-tops leadership structures.

The four companies each have their own people-oriented organizational cultures, which provide a strong base for their high knowledge productivity and sustained value creation. These findings are similar to those of the research by Taormina (2007) showing that flexible leadership behaviours are positively correlated with and stronger predictors of innovative culture than controlling leadership behaviours. Jung et al. (2008) also claimed that freedom within the organization and a boundary-less open culture are important for fostering creativity and innovation.

Leadership characteristics such as low challenge-seeking and high control, and organizational culture characteristics such as low challenge-seeking and status-quo, bureaucratic and top-down control could not be found in the four companies of this study.

\section{Conclusion 2. Leadership and knowledge productivity}

In today's advanced knowledge economy, one of the most critical roles of leadership is to create a knowledge-productive organizational culture in order to achieve high value creation. The quantitative analysis of the surveys of the four leading Korean companies identified the following common leadership characteristics: people-oriented (LS1), visionary and entrepreneurial (LS2) and high challenge-seeking and risk-taking (LS3). These leadership characteristics correlated significantly and positively with the following knowledge productivity factors: improvement and innovation of products, services and work processes (KP1) and sustainable development of future growth engine (KP2). Leadership characteristics have become more humanitarian and peopleoriented, respecting organization members and their knowledge and ideas. Recent studies by Yang (2007), Von Krogh, Nonaka and Rechsteiner (2012) also found that 
people-oriented leadership roles like innovator, mentor or facilitator were found to be positively related to knowledge sharing in organizations.

\section{Future growth engine}

The power of sustainable growth was evident in the four Korean companies in this study. The idea of a "future growth engine" (“미래성장동력" in Korean) is a common concept in Korea. It means "newly developed business and industry that will ensure the future growth of each of the companies as well as the economy and industries of the country as a whole". For future growth engine development, it is important that leaders should actively seek challenges and take risks, sharing their vision for the company and manifesting a spirit of entrepreneurship. "Future growth engine" is almost the same as the concept of knowledge productivity (KP2) used in this study, which connotes improvement and radical innovation for sustainable development and future growth (Kessels, 1996; Kessels et al., 2011).

From the interviews, the researcher learned that future growth engine business development requires three key elements for success: 1) leaders that place a high priority on challenge-seeking, entrepreneurship and a strong willingness to take risks; 2) high knowledge productivity and strong support from leadership for radical innovation, creative turmoil and reflective skills; and 3) professional management and teamwork skills with a strong ownership spirit.

\section{Conclusion 3: Leadership and value creation}

This research has explored how leadership characteristics and value creation in business organization are related, and described the interactions among organizational culture, knowledge productivity, leadership and value creation.

Data on the financial performance of the four Korean companies revealed that they all achieved exceptionally high value creation and sustainable growth over the 10 years of the study period. The four cases in this research indicate that in such work environments, a knowledge-productive organizational culture can be created.

The leaders of the four companies adopted specific management principles, which include transparency and integrity policies and fulfilment of CSR, which are closely related to corporate reputation, image, and employee satisfaction with the company. Conclusion 4. Organizational culture and knowledge productivity

What type of organizational culture can maximize knowledge productivity? The 
results of the quantitative analysis of the four companies identified the following two commonalities of organizational culture: people-oriented $(\mathrm{OCl})$ and highly challengeseeking and innovative (OC2). These organizational culture characteristics were significantly and positively correlated with the two knowledge productivity concepts: continuous improvement and innovation of products, services and work processes (KP1) and sustainable development of future growth engines (KP2).

Analysis of the data from the interviews revealed that the four companies continuously invested substantial time and effort in human resources and talent development programs. They all cherished the principle of lifelong learning. This learning culture combined with a high challenge-seeking, creative and innovative spirit enabled efficient knowledge sharing and productive knowledge utilization to encourage sustainable future growth.

\section{Conclusion 5. Knowledge productivity and value creation}

As value creation is the main objective and responsibility of leaders of business enterprises and institutions, it is vital to understand not only the process of improving knowledge productivity, but also how to implement and apply knowledge in the day-to-day practices of field business operations. The results of the quantitative analysis of the four companies identified the facts that the knowledge productivity factors (KP1 and KP2) were found to be significantly and positively correlated with the main value creation factors: corporate reputation, image and CSR (VC1), employee satisfaction with work environment (VC2), employee satisfaction with financial benefits (VC3) and sustainability (VC4).

Knowledge productivity requires an effective lifelong learning climate that encourages boundary-less sharing of knowledge, creative thinking and imagination, and an entrepreneurial spirit not only at the top, but at all levels within companies and institutions. During the interviews, respondents from each company often mentioned that their leaders strongly emphasized lifelong learning and talent development programs. The findings from the literature review and empirical research in this study support the proposition that knowledge productivity is the twenty-first century growth engine for value creation. This conclusion indicates the future direction for knowledge-based companies and societies.

Conclusion 5 contains a proposition that in a twenty-first century advanced knowledge economy, knowledge productivity plays a critical role in value creation not only for business corporations, but also for society and national economies, by 
advancing future knowledge development. Findings from this study in Korean companies clearly indicate that knowledge productivity is significantly and positively correlated with value creation and serves as a future growth engine.

\section{Conclusion 6. Favourable leadership styles for sustainable value creation}

Achieving increased value creation and sustainable company growth is the most important responsibility and challenge for business leaders today. In this study, we found that knowledge productivity in terms of gradual improvement and radical innovation of work processes, products and services was strongly related to value creation in successful companies.

The findings in this study indicate that one of the most important leadership characteristics is people orientation. Leaders must respect organization members as human beings, and also respect their opinions and ideas. Leaders can empower and motivate people by leading their organizations in a non-bureaucratic and open way, and allowing significant freedom so that there are no limits on people's imagination and creative thinking. Under such leaders, people become more creative and innovative, exhibit strong psychological ownership (Bae et al. 2010) and do their best to achieve the company's vision and goals. The findings of this study are similar to the results of a previous empirical study by Zhang and Bartol (2010). They found that empowering leadership positively influenced employee creativity by increasing employees' intrinsic motivation (i.e., autonomy and competence). Wang and Cheng (2010) also found that benevolent leadership, which is close to the people-oriented leadership style identified here, had a positive impact on employee creativity.

Important common characteristics of the leaders of the four companies are that they are visionary and entrepreneurial, high challenge-seeking and risk-taking and people-oriented. All these characteristics are important for knowledge-intensive development of future growth businesses and achievement of sustainable capability. The results of this study strongly support the initial conceptual framework of the research, in which the relationships among leadership, organizational culture, knowledge productivity and value creation were revealed. The empirical findings enable the characterization of these relationships to be improved, as shown in the revised conceptual model in Figure 10.1. 


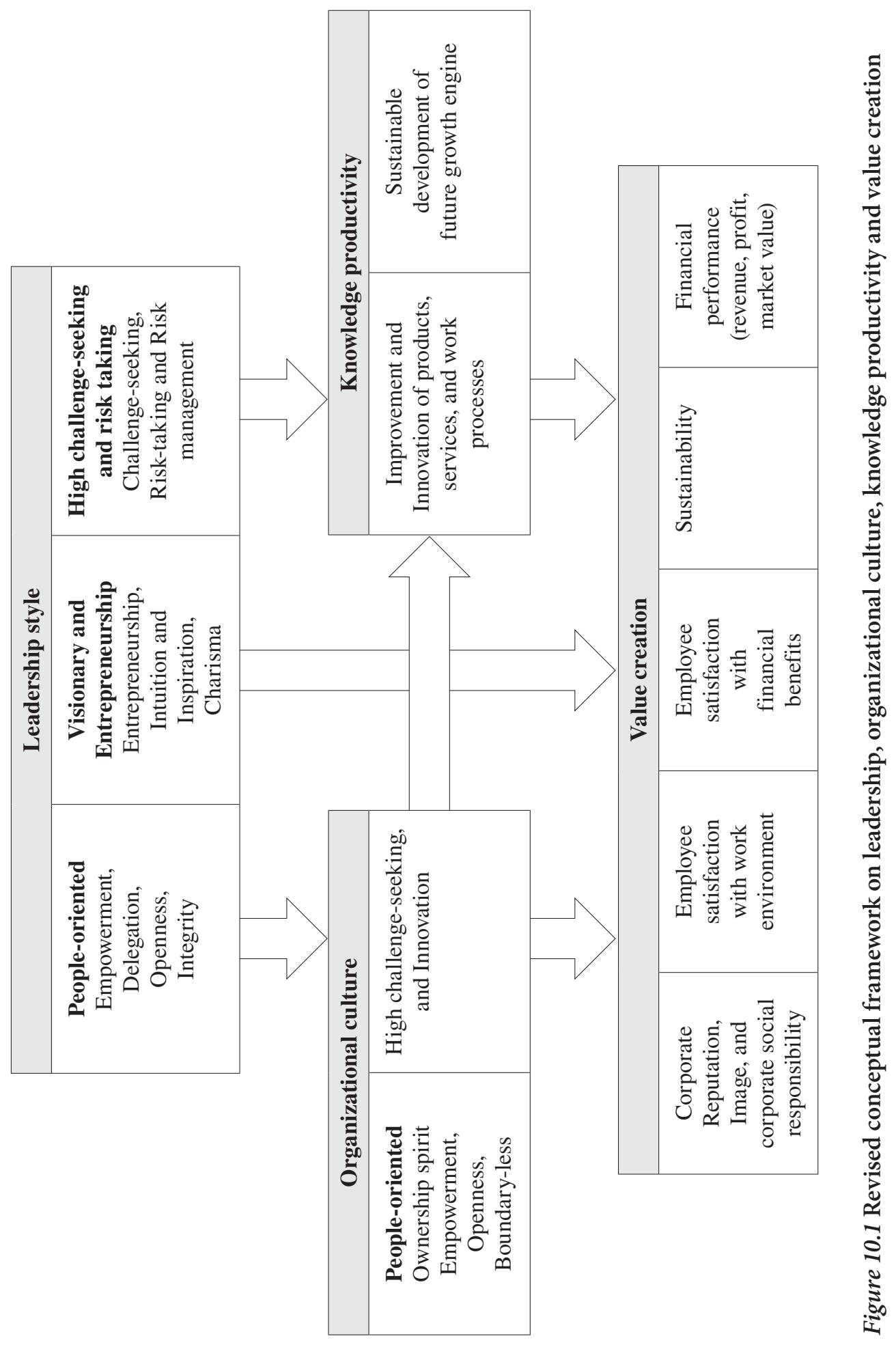


One of the ambitions of this study is to narrow the gap between the academic research on leadership and value creation and the adoption of the findings by business leaders in day-to-day practice. Based on the findings from this study, we developed a set of guidelines for business leaders who wish to build a favourable culture for knowledge productivity and sustainable value creation in their organizations. The preliminary version of these guidelines was reviewed with $\mathbf{3 0}$ business leaders of Korean companies who participated in the study by discussing the main findings and exploring their implications. Their comments and opinions were incorporated in the following guidelines for business leaders. All the participating captains of industry are members of Korean business associations, such as the Korea Management Association, the Federation of Korean Industries and the Korea Employers Federation. The summary of the guidelines reads as follows:

Guideline 1. Prioritize value creation as the top priority of the company, as value creation should be regarded as a "shared vision and dream" for all members of the organization.

Value creation enables employees to have a vision and dream for the future and encourages them to do their best with a strong ownership spirit. Value creation meets stakeholders' expectations and allows the company to contribute to society by meeting its CSR. Most importantly, value creation enables sustainable growth of the company.

Guideline 2. Implement people-oriented leadership practices.

Respect organization members as human beings and fellow workers by acknowledging the value of their knowledge and ideas. Encourage a nonbureaucratic, open organizational culture and active delegation of responsibilities with bottom-up decision-making. Emphasize boundary-less open communication, especially between leaders and subordinates.

Guideline 3. Create a knowledge-productive and innovative organizational culture. Provide sufficient freedom to the organization members to be creative and innovative. This requires a boundary-less sharing of information, knowledge and ideas among organization members as part of the company's wealth creation strategy. Respect for and acceptance of different ideas and opinions of others with 
flexible, open minds for convergent creation and to adapt to today's business environment are prerequisites.

Create a life-long learning culture and invest in the continuous development of human resources and talent. Encourage organization members to take pride and have a spirit of professionalism in their work.

Guideline 4. Prioritize challenging vision and goals that include risk-taking, while seeking new future growth opportunities and adapting effectively to rapid-changing business environments. Invest sufficient time and effort into sharing the company's vision and goals with all organization members.

Organize and operate risk management systems and establish guidelines for successful implementation of highly challenging future growth engine business projects, taking risks while minimizing any possible negative impacts, but meanwhile understand and accept mistakes made by organization members in attempting to meet challenging goals.

Guideline 5. Encourage activities related to CSR.

Encourage active participation in social activities on the part of employees for the good of the community, seeking sustainable growth in cooperation and co-existence with ecological systems, creating social shared value for the nation, global society and mankind. A future-oriented, environmentally friendly technology not only supports sustainable development, it also fuels continuous improvements and radical innovations and improves knowledge productivity.

Guideline 6. Emphasize transparency, integrity and honesty as an inflexible part of policy, thereby creating a safe and trustworthy work environment while maintaining a strong corporate reputation and image. Instead of imposing rules, an atmosphere should be created that allows learning about and discussion of moral and integrityrelated questions and dilemmas.

\section{Critical review of the research findings and methodological issues}

Despite the fruitful cooperation between the researcher and business leaders in this study, the data collection process and analysis have several limitations, as outlined below. The conclusions of this study are mainly based on the correlation analysis of the relationships between characteristics of the main variables. These results do not allow inference of causal relationships, nor were the mediating effects of the main 
variables examined. This is an important limitation of this study in terms of answering the question as to what leadership characteristics lead to value creation. Future research will need to identify the causal relationships among the main variables using a more elaborate research design and methods of analysis.

In this study, four successful and leading Korean companies were deliberately selected as case study models for the empirical research to facilitate understanding of the relationships between the main concepts in highly successful companies. Therefore, the results may not necessarily be generalized to all other Korean and foreign companies. For example, low-performing companies were not included in this research. In future research, comparing high- and low-performing companies may provide a clearer view of the distinctive factors that determine success or failure of a company. Future research should also utilize a broader sample, including companies exhibiting high-, medium- and low-level performance, and also companies from many different regions and countries. This will support the objective of developing more generalized and globalized conclusions. However, the approach taken in this study did allow for an in-depth exploration of various research concepts and an opportunity to learn from senior management practices in the successful enterprises examined here.

\section{Directions for future research}

In the critical review of the methodological issues, some suggestions for more elaborate and rigorous research have already been proposed. This final section on directions for future studies also includes suggestions for advanced cooperation between the academic world and business leaders to reinforce the validity and practicality of research in the domain of leadership and value creation in a knowledge economy.

Previous research has mostly been based on the leadership and organizational culture characteristics prevalent in the period from the 1970s to 2010, mainly in western contexts. Therefore, theories from research performed in earlier decades may not adequately reflect the leadership and organizational culture characteristics of today. This is a topic that is often discussed among business leaders at the conferences and meetings of the Korean Academic Society for Professional Management. They stress the difficulty of relating the results of academic studies to today's business practices. To focus on issues related to today's advanced modern 
leadership and organizational culture, future research projects should also involve business leaders and top managers sharing their experiences and knowledge. This is an important prerequisite to reduce the gap between academic theories and leadership practice in the field further.

Studies on the relationships between leadership, knowledge productivity and value creation are sparse. However, business leaders expect that knowledge productivity will play an increasingly important role in our knowledge society as the twenty-first century growth engine for value creation and sustainable future growth. It is worthwhile to investigate further how learning, knowledge development, incremental improvement, radical innovation and economic value creation interrelate. These aspects are directly related to human resource development, which is central for leadership in these successful companies. Therefore, future research on subjects related to the concept of knowledge productivity should focus not only on practical approaches and applications in industry and field business management settings, but also on linking human resource development and knowledge development.

Corporate social responsibility (CSR) contributes to the value creation of companies mainly by improving corporate reputation and image and increasing satisfaction of employees and customers. This study also stressed the importance of CSR for stimulating innovation. The related concept of creating shared value (CSV) (Porter \& Kramer, 2011) focuses on operating policies and practices that enhance the economic competitiveness of a company while simultaneously advancing the economic and social conditions of the communities in which it operates. For these reasons, future research exploring the relationships among leadership, organizational culture, knowledge productivity and value creation need to consider including the concept of CSV as another main factor within the domain of value creation. 


\section{Samenvatting in het Nederlands}

\section{Leiderschap, organisatiecultuur, kennisproductiviteit en waardencreatie in vier succesvolle Koreaanse ondernemingen}

Naar richtlijnen voor mensgericht leidinggeven

\section{Inleiding}

Deze studie verkent de relaties tussen leiderschapskenmerken, organisatiecultuur, kennisproductiviteit en waardencreatie in vier zeer succesvolle Koreaanse ondernemingen. Het empirische deel van het onderzoek is uitgevoerd bij de bedrijven LG Electronics, Samsung Electronics, Woong-Jin Group en de Shinhan Bank.

Voor kennisintensieve organisaties is het belangrijk om inzicht te verwerven in welke wijze van leiderschap ondersteunend is voor kennisproductiviteit, het realiseren van voortdurende vernieuwing en radicale innovatie ten behoeve van waardencreatie. Het is echter een delicate zaak om deze specifieke kenmerken te onderzoeken binnen succesvolle ondernemingen. Het is voor de eerste keer dat de vier organisaties toegestemd hebben om deel te nemen aan extern onderzoek naar deze factoren.

Op basis van een literatuuronderzoek naar de belangrijkste onderzoeksthema's is een conceptueel raamwerk ontwikkeld dat ten grondslag ligt aan de dataverzameling. Die is uitgevoerd door middel van een survey onder 387 leidinggevenden, en aanvullende interviews met topmanagers uit de vier organisaties. De resultaten wijzen in een richting dat een sterk mensgerichte, uitdagende en ondernemende stijl van leidinggeven met een open communicatie, en een focus op kennisdeling samenhangt met waardencreatie en een duurzame, toekomstgerichte bedrijfsontwikkeling.

In samenwerking met een groep vooraanstaande bestuurders zijn de onderzoeksbevindingen vertaald in een set richtlijnen ten behoeve van leiderschap ten behoeve van waardencreatie. 


\section{Probleemverkenning en onderzoeksvragen}

Waardencreatie wordt alom beschouwd als een van de belangrijkste doelen van leiders van bedrijven en instellingen die een bijdrage beogen te leveren aan de economische ontwikkeling van een regio of land. De doelstelling van deze studie is daarom het verkennen van de relatie tussen leiderschapskenmerken en waardencreatie, en daarin de interactie te beschrijven tussen organisatiecultuur en kennisproductiviteit.

In de recente periode hebben zich in de economische realiteit ingrijpende veranderingen voltrokken, waarbij er een verschuiving heeft plaatsgevonden van het belang van kapitaal, ruwe grondstoffen en fysieke arbeid naar de ontwikkeling en toepassing van kennis als een van de belangrijkste productiefactoren (Bukowitz \& Williams, 2002; Drucker, 1993). Het is daarom noodzakelijk om de leiderschapskenmerken te achterhalen die een kennisproductieve organisatiecultuur bevorderen en zo waarde toevoegen. Deze belangstelling ligt ten grondslag aan de belangrijkste onderzoeksvragen die het vertrekpunt voor deze studie vormen:

1. Hoe hangen de kenmerken van leiderschap, organisatiecultuur, kennisproductiviteit en waardencreatie samen, en met name in zeer succesvolle Koreaanse ondernemingen?

2. Is het mogelijk om op basis van de antwoorden op de eerste vraag een set van richtlijnen voor leiderschap te formuleren die ondersteunend zijn aan de waardencreatie in kennisproductieve organisaties?

\section{Conceptueel raamwerk}

Door middel van waardencreatie kan een onderneming tegemoetkomen aan de verwachtingen van de belanghebbenden, zoals de investeerders die vertrouwen stellen in de leiding van een bedrijf. Waardencreatie stelt ook medewerkers in staat om een perspectief op de toekomst te ontwikkelen waarin zij een sterk gevoel van betrokkenheid en eigenaarschap ervaren(Weiss et al., 1967). Waardencreatie stelt een organisatie in staat om duurzaam te groeien en te voldoen aan de verplichtingen ten aanzien van de samenleving waar zij deel van uitmaakt (Husted \& Allen, 2007).

Waardencreatie is niet alleen een kwestie van opbrengst, winstgroei en marktaandeel; het heeft ook betrekking op de reputatie en de tevredenheid van klanten en 
medewerkers. Dat is de redden waarom waardencreatie gezien moet worden als de belangrijksteverantwoordelijkheid van topmanagers en leidinggevenden (Rho, Lim, \& Hwang, 2004).

In de context van dit onderzoeksproject omvat het begrip waardencreatie: (a) opbrengst en netto winstgroei; (b) toename van de marktwaarde; (c) toename van de tevredenheid van klanten en medewerkers; (d) versterking van de reputatie en het bedrijfsimago; en (e) het vervullen van de sociale verantwoordelijkheid ten aanzien van de samenleving.

Een kennisproductieve organisatie werkt voortdurend aan stapsgewijze verbetering en radicale vernieuwing van producten, diensten en werkwijzen (Kessels, Verdonschot, \& De Jong, 2011). Het produceren van kennis kan men opvatten als een doorgaand leerproces dat geïntegreerd is in de dagelijkse werkomgeving en waaraan alle medewerkers van elk niveau deelnemen (Kessels \& Keursten, 2002). Een dergelijk leerproces richt zich niet alleen op de ontwikkeling van materiedeskundigheid en verbeterde probleemoplossing, maar ook op reflectieve bekwaamheden, open communicatie en samenwerking, en op de motivatie en betrokkenheid van medewerkers. Kennisproductiviteit stelt een organisatie in staat om de bekwaamheden te ontwikkelen om niet alleen innovatief te zijn op dit moment, maar ook in de toekomst (Kessels, 2004; Kim \& Mauborgne, 2005).

Een organisatiecultuur met een open communicatie draagt bij aan het leren dat ten grondslag ligt aan het delen van kennis en ervaring. Een dergelijke cultuur motiveert medewerkers om innovatief en creatief te zijn en gaat gepaard met een sterk gevoel van trots en vervulling, waarin hun beste kwaliteiten naar boven komen en zich een sterk gevoel van eigenaarschap kan ontwikkelingen, wat uiteindelijk bijdraagt aan het realiseren van de visie en de doelen van de organisatie (Alimo-Metcalfe et al., 2008; Harrison \& Pelletier, 1997; Hutchings \& Michailora, 2004; Jung, Wu, \& Chow, 2008; Shin \& Zhou, 2003).

Aan de keuze van de vier Koreaanse bedrijven in dit onderzoeksproject liggen de volgende overwegingen ten grondslag. De vier bedrijven hebben een specifiek leiderschapskenmerk dat ook bekend staat als "Two-tops Leadership", met een sterke medewerkersgerichtheid, zeer uitdagende doelstellingen, risico-nemend ondernemerschap en een organisatiecultuur die aanstuurt op kennisproductiviteit en hoge waardencreatie. Het is het soort leiderschap dat bijgedragen heeft aan de 
succesvolle industrialisatie en economische groei van Korea in de recente geschiedenis. Een andere reden voor de keuze voor deze succesvolle Koreaanse bedrijven is dat onderzoek naar leiderschap, organisatiecultuur en waardencreatie veelal gebaseerd is op westerse modellen. Onderzoek naar deze onderwerpen in Koreaanse ondernemingen is schaars. De vier ondernemingen in deze studie vertonen een substantiële groei in de onderzoeksperiode (2000-2010), diversifieerden hun activiteiten en breidden deze wereldwijd uit. Deze studie beoogt een nieuw licht te laten schijnen op hoe dergelijke, zeer succesvolle Koreaanse bedrijven hun kenmerkende leidershapstijl hebben ontwikkeld en daarbij een organisatiecultuur die tot enorme waardencreatie heeft geleid.

Een belangrijk aspect van de Koreaanse organisatiecultuur is het gevoel van eigenaarschap van de medewerkers, wat in het Koreaans omschreven wordt als “주인의식" (Juin-Eisik) (Jung et al., 2008; Shin \& Zhou, 2003). In de Koreaanse zakenwereld is dit een algemeen gebruikt begrip wat verwijst naar de mentaliteit van medewerkers die van hun bedrijf en hun werk houden en zich geheel inzetten voor de organisatie met een sterk gevoel van loyaliteit. Als leidinggevenden hun medewerkers als waardevolle mensen respecteren en hun meningen en ideeën waarderen, zal dit gevoel van eigenaarschap toenemen (Tosi et al., 2004). Het gevoel van eigenaarschap is niet gerelateerd aan aandeelhouderschap. "Juin-Eisik" is sterk verbonden met het gevoel van verantwoordelijkheid en missie dat medewerkers in staat stelt om van hun werk te houden en er voldoening in te beleven. Deze medewerkers stellen een hoog vertrouwen in hun leidinggevenden.

Effectieve leiders communiceren een uitdagende visie en waarderen ondernemerschap (Shin \& Zhou 2003; Tsui et al. 2006). Zij delen hun visie en waarden met alle leden van de organisatie op een open wijze (Slater, 1998; Slater, 1999). We verwachten dat de rol van leidinggevenden ten aanzien van kennisproductiviteit nauw verbonden is met een attitude van uitdaging en risico nemend ondernemerschap (Nahavandi \& Malekzadeh, 1993). Aangezien kennisproductiviteit in wezen gebaseerd is op leerprocessen, zal de organisatiecultuur hiertoe moeten uitnodigen. Derhalve is de verwachting dat leidinggevenden medewerkersgericht en respectvol zijn, vertrouwen tonen en daarmee bijdragen aan een leercultuur die gunstig is voor kennisproductiviteit, vernieuwing en radicale innovatie (Chadwick, Barnett, \& Dwyer, 2008; Hutchings \& Michailora, 2004; Jung et al., 2008; Oldham \& Cummings, 1986; Shin \& Zhou, 2003; Trice \& Davis, 1993). 
Leidinggevenden kunnen de waardencreatie indirect bevorderen door middel van een sterke organisatiecultuur. De longitudinale studie van Wilderom, Van den Berg en Wiersma (2012) verschaft evidentie voor de relatie tussen organisatiecultuur, bedrijfsresultaten en kenmerken van charismatisch leiderschap. De verwachting is dat in een kenniseconomie leidinggevenden de waardencreatie rechtstreeks kunnen beïnvloeden door bewust hun aandacht te richten op de bevordering van kennisproductiviteit.

\section{Onderzoeksontwerp}

Om antwoord te vinden op de onderzoeksvragen zijn gegevens verzameld over de belangrijkste begrippen uit het conceptuele raamwerk binnen vier zeer succesvolle Koreaanse bedrijven, namelijk LG Electronics, Samsung Electronics, Woong-Jin Group en de Shinhan Bank. Deze bedrijven zijn in de afgelopen 20 jaar in staat geweest om een aanzienlijke waardencreatie te realiseren.

De gegevensverzameling heeft plaatsgevonden door middel van een vragenlijst en een reeks van semigestructureerde interviews met bestuurders, topmanagers en stafmedewerkers. De uitgewerkte interviewverslagen zijn gevalideerd door de gesprekspartners. De gegevens van elke organisatie zijn eerst geanalyseerd in afzonderlijke case studies en naderhand samengebracht in een cross-case analyse. De bevindingen van de cross-case analyse vormden de basis voor het ontwerp van richtlijnen voor leiderschap, met een focus op het bevorderen van kennisproductiviteit om zo de waardencreatie bewust te versterken.

Op basis van een analyse van de financiële gegevens, die verstrekt zijn door het Korean Institute for Industrial Economics \& Trade (KEIT, 2011), van de top 100 Koreaanse bedrijven, hebben we kunnen vaststellen dat in de periode 2000 - 2010 de vier onderzochte kennisintensieve organisaties een waardencreatie hebben gerealiseerd die ver uitgaat boven het gemiddelde van vergelijkbare ondernemingen in hun sector. Het bleek echter moeilijk om toegang te krijgen tot de topleiding van deze bedrijven, omdat het verzamelen van gegevens met betrekking tot gevoelige onderwerpen zoals het leiderschap van de bestuursvoorzitter en de CEO's, kennisproductiveit en waardencreatie niet direct vanzelfsprekend is. Voor elk van deze bedrijven was het de eerste keer dat zij toestemming gaven om dergelijke gevoelige informatie ter beschikking te stellen voor wetenschappelijk onderzoek, uitgevoerd door externe onderzoekers. 


\section{Instrumentontwikkeling}

Voor de dataverzameling is een nieuwe vragenlijst ontwikkeld, gebaseerd op een uitvoerige literatuurstudie, met gebruikmaking van elementen uit bestaande instrumenten. De vragenlijst bevat 106 items: 28 items voor leiderschap (inclusief communicatie, delegeren, integriteit, ondernemerschap, inspiratie, charisma, uitdaging, risico nemen en risico beheersing), 21 items voor organisatiecultuur (inclusief medewerkersgerichtheid, eigenaarschap, empowerment, uitdaging, open communicatie en innovatie), 29 items voor kennisproductiviteit (inclusief leren, stapsgewijze verbetering, radicale innovatie, en duurzame ontwikkeling) en 28 items voor waardencreatie (inclusief reputatie, imago, sociale verantwoordelijkheid CSR, medewerkerstevredenheid, duurzaamheid en financiële prestaties). De items zijn ondergebracht in een vragenlijst met stellingen waarop geantwoord kon worden met behulp van een vijf-puntschaal van (1) helemaal mee oneens, tot (5) helemaal mee eens. Een proefversie van de vragenlijst is uitgezet bij een van de deelnemende organisaties. Op basis van de resultaten zijn enkele items gewijzigd of zelfs verwijderd. De vragenlijst is ontwikkeld in zowel de Engelse als de Koreaanse taal; echter de Koreaanse versie is gebruikt voor de feitelijke dataverzameling in de vier organisaties.

\section{Dataverzameling en response}

In totaal zijn 480 vragenlijsten verspreid onder topmanagers, managers en medewerkers, waarvan er 387 anoniem en volledig ingevuld geretourneerd zijn (Samsung Electronics: 70, LG Electronics: 100, Shinhan Bank: 100, Woong-Jin Group: 117). De respons op de vragenlijst was $84 \%$.

\section{Factor analyse en betrouwbaarheid}

De betrouwbaarheid van de items is onderzocht met behulp van een reeks exploratieve factor analyses. De ladingen van het merendeel van de factoren bleek betrouwbaar en passend. Slechts één item voor kennisproductiviteit moest worden verwijderd vanwege een te lage factorlading.

De resulterende factoren en hun respectievelijke variabelen zijn als volgt:

Leiderschap (28 items) bestaat uit vier variabelen: LS1 (medewerkersgericht: 17 items), LS2 (visie en ondernemerschap: 6 items), LS3 (Uitdaging en risico nemend: 2 
items) en LS4 (risicomijdend en controle: 3 items).

Organisatie cultuur (21 items) bestaat uit vier variabelen: $\mathrm{OC1}$ (medewerkersgericht: 13 items), OC2 (uitdaging en innovatie: 2 items), OC3 (risicomijdend en status quo: 3 items) en OC4 (bureaucratie en top-down: 3 items).

Kennisproductiviteit (28 items) bestaat uit 2 variabelen: KP1 (verbeteringen en innovatie van producten, diensten en werkwijzen: 18 items) en KP2 (duurzaam vermogen tot kennisontwikkeling: 10 items).

Waardencreatie (28 items) bestaat uit vier variabelen: VC1 (reputatie, imago en CSR: 12 items), VC2 (medewerkerstevredenheid met het werkklimaat: 9 items), VC3 (medewerkerstevredenheid met de financiële beloning: 3 items) en VC4 (duurzaamheid: 4 items).

De Cronbach's alpha scores voor alle 14 variabelen variëren van 0.605 tot 0.953 , wat duidt op een acceptabel niveau van betrouwbaarheid.

Met behulp van een confirmatieve factor analyse is de validiteit van de variabelen geverifieerd.

\section{Interviewhandleiding}

In aanvulling op de vragenlijst is een interviewhandleiding samengesteld aan de hand waarvan de vervolggesprekken gevoerd zijn met bestuursvoorzitters, CEO's en stafmedewerkers. Alvorens de interviews uit te voeren zijn vier open gesprekken gevoerd in elk bedrijf om een eerste begrip te krijgen van het leiderschap, de organisatiecultuur, de kennisproductiviteit en de waardencreatie, om zo kernthema's voor de vervolggesprekken beter te kunnen benoemen. De namen van de geïnterviewden en hun inbreng zijn strikt vertrouwelijk behandeld.

\section{Variabelen met betrekking tot waardencreatie}

Voor de dataverzameling met betrekking tot waardencreatie zijn drie methoden gevolgd: een vragenlijst (28 items), jaarverslagen en de financiële gegevens van de vier deelnemende organisaties, en die van de top 100 Koreaanse bedrijven in de periode van 2000 tot en met 2010. De financiële gegevens zijn beschikbaar gesteld door het Korean Institute for Industrial Economics and Trade (KEIT, 2011). Op basis hiervan was het mogelijk om een vergelijking te maken tussen de vier onderzochte bedrijven en de top-10 organisaties in hun eigen sector. 
Om de onderzoeksbevindingen te kunnen delen met leiders van ondernemingen en ook om de kloof te verkleinen tussen wetenschappelijk onderzoek en het dagdagelijkse management, is bewust gezocht naar een manier om topmanagers te betrekken bij de interpretatie van de onderzoeksresultaten. De onderzoeksresultaten zijn met bestuurders en CEO's gedeeld en op basis daarvan zijn in overleg met hen praktische richtlijnen voor leiderschap ontwikkeld. Dertig bestuurders, allen leden van Koreaanse ondernemersverenigingen, hebben deelgenomen aan de discussies over de conceptversie van de richtlijnen. Hun commentaren en suggesties zijn verwerkt in een definitieve versie, die bij het verslag van deze studie zijn opgenomen. De deelname van deze topmanagers aan dit deel van het onderzoek heeft een impuls gegeven aan de actieve betrokkenheid van leidinggevenden bij wetenschappelijk onderzoek naar leiderschap, bedrijfsvoering en waardencreatie in Korea.

\section{Case study verslagen}

Voor elk van de vier deelnemende bedrijven is een apart onderzoeksrapport samengesteld met de resultaten van zowel de kwantitatieve als de kwalitatieve analyses. De onderzoeksverslagen zijn ter validering aan de deelnemers voorgelegd. Op basis van hun reacties heeft de onderzoeker in overleg met de leiding van de organisaties enige veranderingen doorgevoerd en aanvullingen toegevoegd. De vier onderzoeksrapporten hebben als basis gediend voor de cross case analyse.

\section{Kenmerken van de onderzoekspopulatie}

Het merendeel van de respondenten bestaat uit hoog opgeleide en ervaren managers. Zoals in de meeste Koreaanse bedrijven wordt ook in de vier onderzochte bedrijven de topstructuur van het kader nog steeds gedomineerd door mannelijke leidinggevenden.

\section{De relaties tussen de hoofdvariabelen}

Zoals verwacht zijn de relaties tussen de leiderschapskenmerken en de organisatiecultuur zeer hecht. Deelnemers aan de interviews vonden het zelfs lastig om de specifieke leiderschapskenmerken en cultuurkenmerken te scheiden. Hoewel er hier en daar verschillen zijn tussen de leiderschapskenmerken in de vier 
organisaties hebben zij gemeenschappelijk dat ze sterk medewerkersgericht zijn, visionair en ondernemend met een focus hebben op het aangaan van uitdagingen, het nemen van risico's en het nastreven van innovatie. Deze kenmerken van leiderschap en cultuur vertonen een sterke correlatie met kennisproductiviteit en waardencreatie. Kennisproductiviteit en waardencreatie zijn ook sterk met elkaar verbonden. Veel geïnterviewden onderstrepen het belang van voortdurende verbetering en radicale innovatie en zien het bevorderen van een cultuur die aanzet tot het openlijk delen van informatie en kennis als een cruciale missie van leiderschap. Het stimuleren van leren en creatief denken maakt daar deel van uit. Dit belang gaat samen met een sterke medewerkersgerichtheid, waarin respect en waardering een zwaarwegende rol spelen en wat tot uitdrukking komt in een zeer betrokken psychologisch eigenaarschap van de medewerkers.

Er waren enkele verschillen in correlatie met betrekking tot de organisatiecultuur (OC4) en duurzame ontwikkeling (VC4) bij de Shinhan Bank ten opzichte van de andere drie bedrijven, en dan met name de aspecten bureaucratie en top-down cultuur. Een mogelijke verklaring is wellicht te vinden in het feit dat de Koreaanse financiële sector en in het bijzonder de banken, een meer conservatieve en meer risicomijdende cultuur hebben ontwikkeld. Met name de Shinhan Bank is zeer succesvol in het managen van financiële risico's en bevordert daarmee een duurzame ontwikkeling. De Aziatische financiële crisis in 1997 (de IMF Crisis) en de mondiale financiële crisis van 2008, hebben aan die terughoudendheid met betrekking tot risicovol gedrag bijgedragen.

\section{"Two-tops" leiderschap structuur}

Elk van de vier bedrijven heeft een specifieke vorm van "two-tops" leiderschap structuur. De bestuursvoorzitters - veelal grootaandeelhouder - delegeren de managementverantwoor

delijkheden voor een groot deel aan de CEO's van de afzonderlijke bedrijven. De voorzitters participeren echter actief in de besluitvorming rond de lange-termijn strategie en de grote innovatieprojecten. Geen van de voorzitters vertonen kenmerken van bureaucratisch en controlerend leiderschap.

\section{Kennisproductiviteit}

De leiders van de vier bedrijven benadrukken het belang van voortdurende 
verbetering en radicale vernieuwing van producten, diensten en werkwijzen (KP1) en moedigen de ontwikkeling aan van creatieve ideeën om zo een duurzame vernieuwingsstrategie te kunnen ontwikkelen (KP2). Hierbij hoort het betreden van nieuwe werkgebieden en het nemen van risico's. De kwantitatieve analyses laten een sterke relatie zien tussen leiderschap en kennisproductiviteit. Er zijn echter enkele verschillen tussen bedrijven in het bevorderen van KP2 en de risico's die daarmee gepaard gaan. Uit de interviews komt duidelijk naar voren dat het eenzijdig sturen op prestatieverbetering zonder aandacht te geven aan de betrokkenheid en creativiteit van de medewerkers niet zal leiden tot kennisproductiviteit en waardencreatie.

\section{Verschillen}

Ondanks de grote overeenkomsten tussen de vier bedrijven met betrekking tot het streven naar kennisproductiviteit, zijn er ook enkele verschillen.

LG Electronics benadrukt voortdurende verbetering en innovatie (KP1). Een vroegere CEO ontwikkelde daarvoor zelfs een special programma met de titel TDR (Tear-down and Redesign - Breek af en Herontwerp), wat gezien werd als een radicale methode om toekomstige groei, productontwikkeling en business development te bevorderen (KP2). Voor de opvolger was TDR echter geen prioriteit en richtte zich meer op de korte termijn winstgevendheid met een nadruk op kostenreductie. Deze strategiewijziging wordt als achtergrond gezien voor de reden waarom het bedrijf de kansen liet lopen om nieuwe producten te ontwikkelen in antwoord op de introductie van Apple's iPhone in 2009. Deze inschattingsfout had een sterk negatieve invloed op de omzet, bedrijfsresultaten en netto winst in 2010, iets wat voor het eerst gebeurde in de bestaansgeschiedenis van het bedrijf. Om de moeilijke situatie te boven te komen, benoemde de LG Group een nieuwe CEO die juist weer de aandacht legde bij de ontwikkeling van toekomstige groeimogelijkheden, waardoor het bedrijf de problemen in 2013 weer te boven kon komen.

In diezelfde periode benadrukte de voorzitter van Samsung Group zeer sterk de noodzaak van voortdurende verbetering en radicale innovatie (KP1) en richtte ook de aandacht op duurzame toekomstige groeimogelijkheden (KP2). Als gevolg daarvan slaagde Samsung Electronics er in om de negatieve invloed en potentiële risico's van de komst van de Apple iPhone om te buigen. Het marktaandeel van Samsung Electronics groeide snel en het bedrijf werd in 2010 zelfs wereldleider in de smartphone industrie. 
Ook de bedrijven binnen de WoongJin Group richten zich op voortdurende verbeteringen en radicale vernieuwing (KP1) en investeren in kennisontwikkeling en business development voor toekomstige groei (KP2), waarbij ze aanzienlijke risico's nemen. Recent heeft het bedrijf nieuwe werkgebieden betreden zoals de hightech polysilicon fabricage in de zonne-energie sector.

De leider van Shinhan Bank legt een sterke nadruk op het grenzeloos en ongehinderd delen van informatie, kennis en expertise binnen de onderneming op een wijze die het bedrijf de "the Shinhan Way" noemt. Deze werkwijze is diep geworteld in vormen van open teamwork over afdelingen, divisies en hiërarchische lagen heen. In deze aanpak gaan voortdurende verbetering en innovatie samen met een diep respect voor medewerkers en hun ideeën en bijdragen. Deze benadering ligt ten grondslag van wat in Korea algemeen bekend staat als de kennisproductieve organisatiecultuur met "Shinhan People Power".

\section{Waardencreatie}

In deze studie omvat het concept waardencreatie zowel financiële en niet-financiële indicatoren. Financiële prestaties worden uitgedrukt in termen van omzet, netto winst en marktaandeel gedurende de 10 jaar die het onderzoek bestrijkt. Nietfinanciële factoren betreffen de percepties van reputatie en imago, CSR, medewerkerstevredenheid met de werkomgeving en met de financiële beloning, en duurzame ontwikkeling.

De financiële gegevens van de vier ondernemingen laten een hoge waardencreatie zien tussen 2000 en 2010, met een duidelijk herstel na de financiële crisis in 2008. Deze vier bedrijven presteren elk hoger dan het gemiddelde van de top 10 Koreaanse bedrijven in hun sector in dezelfde periode. Een uitzondering hierop vormde LG Electronics in 2010.

De resultaten van de kwantitatieve analyses laten zien dat met name de leiderschapskenmerken (medewerkersgerichtheid, visionair en ondernemend, uitdaging en risiconemen), de vergelijkbare cultuurkenmerken en de beide factoren van kennisproductiviteit, alle significant positieve correlaties hebben met de vier factoren van waardencreatie in de onderzochte bedrijven.

De bevindingen op basis van de kwalitatieve analyses van de interviews wijzen op een erkenning van het belang van reputatie, imago en sociale verantwoordelijkheid 
(CSR). De medewerkerstevredenheid is zeer hoog in de bedrijven. Medewerkers voelen een sterk psychologisch eigenaarschap en zijn er trots op bij het bedrijf te werken.

De resultaten van de kwantitatieve analyses laten een negatieve correlatie zien tussen enerzijds risicomijding en sterk controlerend leiderschap en anderzijds kennisproductiviteit en waardencreatie. In de interviews werd consistent gewezen op het ontbreken van die risicomijdende en controlerende kenmerken van leiderschap en cultuur binnen de vier onderzochte bedrijven.

\section{Conclusie en discussie}

Het onderzoeksverslag eindigt met een voorlopige beantwoording van de onderzoeksvragen en een ontwerp van richtlijnen voor bestuurders die de leiding voeren over kennisintensieve ondernemingen. Tenslotte volgt er een kritische reflectie op de gevolgde onderzoeksbenadering.

De hoofdvraag luidde: Hoe verhouden de kenmerken van leiderschap zich tot organisatiecultuur, kennisproductiviteit en waardencreatie in bedrijven? $\mathrm{Op}$ basis van het onderzoek bij vier zeer succesvolle Koreaanse organisaties is er aanleiding voor de volgende conclusies.

\section{Conclusie 1. Leiderschap en organisatiecultuur}

De resultaten van het onderzoek laten een sterke samenhang zien tussen leiderschapskenmerken en organisatiecultuur. De vier onderzochte bedrijven laten overeenkomsten zien in een sterke gerichtheid op medewerkers, het delegeren van bevoegdheden, visionair ondernemerschap, uitdaging, risico-nemen en innovatie. Dit geldt zowel voor het leiderschap als voor de organisatiecultuur. Deze bevinding ondersteunt de bewering van Schein dat cultuur en leiderschap twee kanten zijn van dezelfde medaille (Schein, 2004, p. 22). De typische "two-tops"-structuur combineert de visionaire kracht van de groepsvoorzitter met de bekwaamheden van de professionele CEO's van de afzonderlijke bedrijven. De sterke medewerkersgerichtheid, de kennisproductiviteit die zich uit in een stroom van voortdurende verbeteringen en radicale vernieuwingen, en de resulterende waardencreatie zijn nauw aan elkaar verbonden. In de vier onderzochte bedrijven waren geen voorbeelden te vinden van leiderschap en organisatiecultuur die wijzen op een gebrek aan uitdaging, het in stand houden van de status-quo en bureaucratie en het uitoefenen van top-down 
beheersing.

\section{Conclusie 2. Leiderschap en kennisproductiviteit}

De kwantitatieve analyses laten een significant positieve correlatie zien tussen de leiderschapskenmerken en kennisproductiviteit. Ook de interviews benadrukken het belang van een medewerkersgerichte houding met aandacht en respect voor ieders kennis en ideeën. Recente studies van Yang (2007) en van Von Krogh, Nonaka en Rechsteiner (2012) wijzen ook op een positieve relatie tussen een sterk mensgericht leiderschap - wat tot uitdrukking komt in rollen als facilitator en mentor - en het delen van kennis.

In de vier organisaties is veel aandacht voor duurzame groei-ontwikkeling. Het begrip "future growth engine" (“미래성장동력" in het Koreaans) wordt veel gebruikt in Korea. Het staat voor "nieuw ontwikkelde activiteiten die de toekomstige groei en ontwikkeling van een afzonderlijk bedrijf, de economie en een gehele natie kan bevorderen". Leiders zien het als een belangrijke taak om zorg te dragen voor het bevorderen van een duurzame groei-ontwikkeling. Dit begrip vertoont grote overeenkomst met het concept kennisproductiviteit (KP2) in deze studie dat verwijst naar het vermogen om aan duurzame kennisgroei in de toekomst te kunnen werken. De leidinggevenden in dit onderzoek geven hoge prioriteit aan het op een ondernemende wijze werken aan uitdagende projecten en zij zijn bereid om daarin ook risico's te nemen. Zij zetten actief in op radicale innovatie, wakkeren creatieve onrust aan en bevorderen tegelijkertijd de ontwikkeling van reflectieve bekwaamheden die het leren van en over deze vernieuwingsactiviteiten mogelijk maken. De beoogde kennisproductiviteit vindt bij voorkeur plaats in teamwerk, waarbij medewerkers een sterk gevoel van psychologisch eigenaarschap kunnen ontwikkelen.

\section{Conclusie 3. Leiderschap en waardencreatie}

De analyses van de financiële prestaties van de vier bedrijven laten een bijzonder hoge waardencreatie zien over de periode van tien jaar die het onderzoek bestrijkt. De leidinggevenden beschouwen managementprincipes als transparantie, integriteit en het vervullen van een maatschappelijke verantwoordelijkheid als belangrijke uitgangspunten. Dit komt ook tot uitdrukking in een sterke reputatie en medewerkerstevredenheid.

\section{Conclusie 4. Organisatiecultuur en kennisproductiviteit}

De kwantitatieve analyses laten zien dat er tussen een medewerkersgerichte (OC1), uitdagende en innovatieve (OC2) organisatiecultuur en kennisproductiviteit (KP1 
en KP2) een nauwe samenhang bestaat.

Uit de interviews bleek dat de vier bedrijven over een lange periode consequent en substantieel investeren in opleidingen en talentontwikkelingsprogramma's. Een leven lang leren staat hoog in het vaandel. Deze sterk ontwikkelde leercultuur gaat samen met een zeer uitdagende, creatieve en innovatieve mentaliteit. Deze combinatie maakt kennisdeling mogelijk en een productief gebruik van kennis in de ontwikkeling van toekomstige en duurzame groeimogelijkheden.

\section{Conclusie 5. Kennisproductiviteit en waardencreatie}

Als waardencreatie beschouwd wordt als de belangrijkste doelstelling en verantwoordelijkheid van leiders in bedrijven en organisaties dan is het van belang om te begrijpen hoe in kennisintensieve werkverbanden kennisproductiviteit tot stand komt en hoe die in de dagelijkse werkpraktijk tot uitdrukking komt.

De resultaten van de kwantitatieve analyses laten een positieve samenhang zien tussen kennisproductiviteit en waardencreatie. Aansluitend bij conclusie 4 speelt ook hier de sterke leercultuur een belangrijke rol, die een leven lang leren, het delen van expertise en het op een creatieve en uitdagende manier bevorderen van kennisontwikkeling, ondersteunt. De eerdere literatuurstudie en de empirische resultaten in dit onderzoek ondersteunen de gedachte dat kennisproductiviteit een belangrijke duurzame groeifactor is in de 21ste eeuw. Kennisintensieve bedrijven en samenlevingen zullen zich hierop consequent moeten inrichten.

\section{Conclusie 6. Leiderschapsstijlen die gunstig zijn voor waardencreatie}

Het onderzoek naar de vier zeer succesvolle Koreaanse ondernemingen levert aanwijzingen dat kennisproductiviteit en waardencreatie nauw met elkaar verbonden zijn. Een van de belangrijkste leiderschapskenmerken is de sterke mensgerichtheid. Leidinggevenden respecteren hun medewerkers en waarderen hun meningen en ideeën. Zij leiden hun organisaties op een niet-bureaucratische en open manier, die een aanzienlijke vrijheid verschaft, waarin creativiteit, verbeelding en innovatieve denk- en werkprocessen veel ruimte krijgen. In een dergelijke omgeving ontwikkelen medewerkers een sterk gevoel van psychologisch eigenaarschap (Bae et al. 2010) en zullen zich volledig inzetten om de visie en de doelen van de organisatie mee te helpen realiseren.

De bevindingen van deze studie komen overeen met de resultaten van het onderzoek van Zhang en Bartol (2010). Zij vonden dat leiderschap dat zorgt voor empowerment van medewerkers een positieve invloed heeft op de creativiteit van mensen door het bevorderen van de intrinsieke motivatie (met name het gevoel van 
autonomie en bekwaamheid). Ook Wang en Cheng (2010) vonden dat een mensgericht en welwillend leiderschap een positieve invloed had op de creativiteit van medewerkers. De leiderschapskenmerken in deze studie vertonen grote overeenkomsten met het begrip transformationeel leiderschap (Bass \& Avolio, 1993).

Belangrijke gemeenschappelijke leiderschapskenmerken in deze studie zijn het visionaire ondernemerschap, de uitdagende en risiconemende stijl, en de sterke mensgerichtheid.

De resultaten van deze studie ondersteunen de verwachte samenhang tussen bepaalde leiderschapskenmerken, cultuurkenmerken, kennisproductiviteit en waardencreatie zoals die bij aanvang zijn geformuleerd. De bevindingen maken het mogelijk om die leiderschaps- en cultuurkenmerken nader te specificeren en in verband te brengen met de aspecten van kennisproductiviteit zoals het werken aan stapsgewijze verbetering en radicale vernieuwing, en het bewust ontwikkelen van een leercultuur die duurzame innovatie en groei in de toekomst mogelijk maakt.

\section{Richtlijnen voor leiderschap}

Een van de ambities van deze studie is een bijdrage te leveren aan het overbruggen van de kloof tussen wetenschappelijk onderzoek naar leiderschap en de toepassing van de resultaten door topmanagers in de dagdagelijkse praktijk. Daarom is op basis van de bevindingen van deze studie, samen met bestuurders, een set met richtlijnen voor leiderschap ontwikkeld. Deze richtlijnen beogen een gunstige organisatiecultuur te bevorderen voor kennisproductiviteit en duurzame waardencreatie.

Daartoe zijn de resultaten van dit onderzoek en een eerste versie van de richtlijnen voorgelegd aan een dertigtal bestuursvoorzitters en CEO's van Koreaanse ondernemingen, allen lid van de Korea Management Association, de Federation of Korean Industries en de Korea Employers Federation. Hun kritische commentaren en aanvullingen zijn opgenomen in een set van uiteindelijk zes richtlijnen waarvan hier een korte samenvatting volgt.

Richtlijn 1. Leg prioriteit bij de waardencreatie van de onderneming en wel zo dat alle leden van de organisatie deze kunnen beschouwen als een "gedeelde visie en droom". 
Waardencreatie stelt medewerkers in staat om een eigen beeld en droom van de toekomst te vormen en moedigt hen aan om zich hiervoor in te spannen met een sterk gevoel van eigenaarschap. Waardencreatie vervult de verwachtingen van de stakeholders en stelt de onderneming in staat om bij te dragen aan de samenleving waar ze deel van uit maakt, en zij kan daardoor haar maatschappelijke verantwoordelijkheid dragen. Waardencreatie maakt een duurzame groei van de onderneming mogelijk.

Richtlijn 2. Maak werk van mensgerichte leiderschapspraktijken.

Respecteer werknemers als waardevolle mensen en benader ze als mede-werkers door erkenning en waardering te tonen voor hun kennis en ideeën. Bevorder een niet-bureaucratische en open organisatiecultuur, delegeer bewust verantwoordelijkheden en bevorder een proces van bottom-up besluitvorming. Benadruk een onbegrensde, open communicatie tussen leidinggevenden en medewerkers.

Richtlijn 3. Creëer een kennisproductieve en innovatieve bedrijfscultuur.

Voorzie in voldoende vrijheid voor medewerkers om creatief en innovatief te zijn. Dit veronderstelt een onbelemmerd delen van informatie, expertise en ideeën, wat onderdeel uitmaakt van een bedrijfsstrategie die gericht is op het creëren van voorspoed. Respecteer en aanvaard afwijkende ideeën en opvattingen van anderen, aangezien ze behulpzaam kunnen zijn bij het zich beter aanpassen aan een voortdurend veranderende bedrijfsomgeving. Bevorder een cultuur van een leven lang leren en investeer in opleidingen en talentontwikkeling. Moedig medewerkers aan om een hoog niveau van professionaliteit na te streven en daar trots op te zijn.

Richtlijn 4. Geef prioriteit aan uitdagende visie en doelen en deel die met alle medewerkers. Sta hen toe om risico's te nemen bij het zoeken naar nieuwe en toekomstige groeimogelijkheden. Wees alert op een snelle aanpassing aan veranderende bedrijfsomgevingen.

Organiseer systemen voor risicomanagement die ruimte bieden voor uitdagende en toekomstgerichte groeiprojecten, terwijl ze de mogelijke negatieve gevolgen vroegtijdig onderkennen. Heb begrip voor en accepteer fouten van medewerkers, zeker wanneer zij zich inzetten voor het realiseren van uitdagende doelstellingen.

Richtlijn 5. Moedig activiteiten aan die gericht zijn op het vervullen van de maatschappelijke verantwoordelijkheid (CSR) 
Moedig deelname aan sociale activiteiten aan die gericht zijn op de gemeenschap waar de onderneming deel van uit maakt. Streef naar een duurzame groei met zorg voor de ecologische systemen, waarbij de belangen van de gemeenschap, de natie en de mensheid niet geschaad worden. Een toekomstgerichte, milieuvriendelijke technologie draagt niet alleen bij aan een duurzame ontwikkeling, zij zet ook aan tot stapsgewijze verbeteringen en radicale innovaties en zo tot kennisproductiviteit.

Richtlijn 6. Benadruk het belang van transparantie, integriteit en eerlijkheid als een onwrikbaar onderdeel van het beleid. Het zorgdragen voor een veilige en betrouwbare werkomgeving ondersteunt een sterke reputatie en gunstig bedrijfsimago. Hecht meer belang aan een atmosfeer waarin leidinggevenden en medewerkers over morele en integriteit gerelateerde zaken kunnen discussiëren en daarvan leren, in plaats van het voorschrijven en opleggen van regels.

\section{Kritische terugblik op de onderzoeksaanpak en toekomstplannen.}

De dataverzameling en -analyse vertonen een aantal belangrijke beperkingen. De conclusies zijn voornamelijk gebaseerd op correlaties tussen de kenmerken van de verschillende variabelen. De onderzoeksresultaten staan geen causale relaties toe en ook de mediërende effecten van een aantal variabelen zijn niet onderzocht. Dit is een beperking bij het beantwoorden van de vraag welke leiderschapskenmerken de waardencreatie bevorderen. Hiervoor is een uitgebreider en complexer onderzoeksdesign noodzakelijk.

Voor deze studie zijn met opzet vier succesvolle Koreaanse bedrijven geselecteerd. Deze aanpak maakte het weliswaar mogelijk om een goed inzicht te krijgen in de specifieke kenmerken van deze leidende organisaties, een generalisatie naar het bedrijfsleven in het algemeen is hierdoor niet mogelijk. In toekomstig onderzoek zou een variëteit van hoog- en laag-presterende bedrijven onderdeel van de populatie moeten uitmaken, om zo een scherper beeld te kunnen vormen over slaag- en faalfactoren. Hetzelfde is van toepassing op een uitbreiding van regio's en landen.

Veel onderzoek naar leiderschap en organisatiecultuur is vooral in westerse contexten uitgevoerd. Dit is een thema wat deelnemers aan conferenties en vergaderingen van de Korean Academic Society for Professional Management regelmatig bespreken. Zij benadrukken de noodzakelijkheid maar ook de moeilijkheid om de resultaten van wetenschappelijk onderzoek toe te passen in de 
eigen werkpraktijk. Daarom is het wenselijk om bestuurders en topmanagers actief bij onderzoek te betrekken en hun ervaringen en kennis daarbij in te zetten en te delen. Het onderhavige project heeft die samenwerking bewust nagestreefd, wat heeft geleid tot een grote betrokkenheid van de professionele gemeenschap topmanagers in Korea en hun belangstelling voor de onderzoeksresultaten.

Hoewel onderzoek naar de relatie tussen leiderschap en kennisproductiviteit schaars is, wordt het belang ervan algemeen gedeeld. Daarom is het de moeite waard om de relatie tussen leren, kennisontwikkeling, stapsgewijze verbetering, radicale innovatie en economische waardencreatie verder te onderzoeken. Deze zaken hangen nauw samen met human resource ontwikkeling (HRD), wat veel aandacht krijgt van leidinggevenden in succesvolle bedrijven. Toekomstig onderzoek zou de relatie tussen HRD, kennisproductiviteit en bedrijfssucces verder moeten verkennen.

Tijdens het onderzoek bleek dat aspecten als maatschappelijk verantwoord ondernemen, innovatie, medewerkerstevredenheid, reputatie en waardencreatie nauw samenhangen. Een volgende stap in toekomstig onderzoek zou het begrip gedeelde waardencreatie (creating shared value, CSV) moeten betrekken, een concept waarmee Porter en Kramer (2011) de aandacht vestigen op leiderschapspraktijken die zowel de economische voorspoed van een bedrijf nastreven als de belangen behartigen van de sociale gemeenschap waarvan de organisatie deel uitmaakt. Het begrip gedeelde waardencreatie (CSV) kan een belangrijke uitbreiding van de klassieke bedrijfsresultaten zijn en daarmee onderwerp van leiderschap. 


\section{References}

Alavi, M., Kayworth, T. R., \& Leidner, D. E. (2006). An empirical examination of the influence of organizational culture on knowledge management practices. Journal of Management Information Systems, 22(3), 191-224.

Alawi, A., Marzooqi, A., \& Mohammed, Y. (2007). Organizational culture and knowledge sharing: critical success factors. Journal of Knowledge Management, 11(2), 22-42.

Alimo-Metcalfe, B., Alban-Metcalfe, J., Bradley, M., Mariathasan, J., \& Samele, C. (2008). The impact of engaging leadership on performance, attitudes to work and wellbeing at work. Journal of Health Organization and Management, 22(6), 586-598.

Anantatmula, V. S. (2007). Linking KM effectiveness attributes to organizational performance. Information and Knowledge Management, 37(2), 133-149.

Asoh, D., Belardo, S., \& Neilson, R. (2002). Knowledge management: Issues, challenges, and opportunities for the government in the New Economy, proceedings of the 35th Hawaii International Conference on Systems Sciences, HICSS35, IEEE Computer Society, Los Alamitos, CA.

Avey, J. B., Wernsing, T. S., \& Palanski, M. E. (2012). Exploring the process of ethical leadership: the mediating role of employee voice and psychological ownership, Journal of Business Ethics, 107, 21-34.

Avolio, B. J., Sivasubramaniam, N., Murry, W. D., Jung, D., \& Garger, J. W. (2003). Chapter 7: Assessing shared leadership. In Pearce, C. L., \& Conger, J. A. (Eds.), Shared leadership, 143-172, Thousand Oaks, CA: Sage.

Bae, S. H., Kim, Y. J., \& Kim, M. S. (2010). The mediating effect of psychological ownership and the moderating effect of negative affectivity in the relationship between organization justice and organizational outcome variables, Korean Journal of Human Resource Management, 17(4): 97-125.

Bae, Y. H. Choi, J. S., Lee, W. S., Hwang, S. W., Lee, J. R., Ha, T. J., Chang, B. Y., Koh, B. I. Kim, B. Y., \& Chung, H. S. (2010). Selecting future growth engine industries and prioritizing technological innovation strategies, Science and Technology Policy Institution, Korea.

Bae, J. H., Kim, B. D., \& Kim, J. H. (2008). The effect of corporate social investment on the market value of a Korean firm: An event-study methodology. Korean Journal of Management, 16(2), 159-192.

Balmer, J. M. T., \& Greyser, S. A. (2006). Corporate marketing: integrating corporate identity, corporate branding, corporate communications, corporate image and corporate reputation. European Journal of Marketing, 40(7), 730-741. 
Barnett, R. C., \& Brennan, R. T. (1997). Change in job conditions, change in psychological distress, and gender: A longitudinal study of dual-earner couples, Journal of Organizational Behavior, 18: 253-274.

Barney, J. B. (1986). Strategic factor markets: Expectations, luck and business strategy. Management Science, 42, 1231-1241.

Bass, B. M. (1985). Leadership and performance beyond expectations. New York: Free Press.

Bass, B. M. (1990). From transactional to transformational leadership: Learning to share the vision. Organizational Dynamics, 18(3), 19-31.

Bass, B. M., \& Avolio, B. J. (1993). Transformational leadership and organizational culture. Public Administration Quarterly, 17(1), 112-121.

Becker, G. S. (1964). Human capital: A theoretical and empirical analysis, with special reference to education. Chicago, University of Chicago press.

Beckman, T. J. (1999). The current state of knowledge management, in Liebowitz, J. (Eds.), Knowledge Management Handbook, CRC Press, Boca Raton, FL.

Berson, Y., \& Linton, J. (2005). An examination of the relationships between leadership style, and employee satisfaction in $\mathrm{R} \& \mathrm{D}$ versus administrative environments. $R \& D$ Management, 35, 51-60.

Berson, Y., Oreg, S., \& Dvir, T. (2008). CEO values, organizational culture and firm outcomes. Journal of Organizational Behavior, 29, 615-633.

Brockman, B. K., \& Morgan, R. M. (2003). The role of existing knowledge in new product innovativeness and performance. Decision Sciences, 34, 385-419.

Brown, L., Gallagher, S. M., \& Brown, C. (2008). How CEOs can promote a strong market culture. Strategy \& Leadership, 36(5), 28-33.

Bryman, A. (1992). Charisma and leadership in organizations. London: Sage.

Bukowitz, W. R., \& Williams, R. L. (2000). The knowledge management fieldbook, Upper Saddle River, N.J.: Financial Times, Prentice Hall.

Burgelman, R. A. (1983). Corporate entrepreneurship and strategic management: Insight from a process study. Management Science, 29(12), 1349-1364.

Burns, J. M. (1978). Leadership. New York: Harper \& Row.

Cameron, K. S., \& Freeman, S. J. (1991). Cultural congruence, strength, and type: Relationships to effectiveness. In R. W. Woodman \& W. A. Pasmore (Eds.), Research in organizational change and development, 5: 23-28. Greenwich, CT: JAI Press.

Carmeli, A., Schaubroeck, J., \& Tishler, A. (2011). How CEO empowering leadership shapes top management team processes: Implications for firm performance. The Leadership Quarterly, 22, 399-411. 
Carroll, A. B. (1979). A three-dimensional conceptual model of corporate social performance. Academy of Management Review, 4, 497-505.

Castaneda, M., \& Nahavandi, A. (1991). Link of manager behavior to supervisor performance rating and subordinate satisfaction. Group \& Organization Management, 16, 357-366.

Castells, M. (1998). End of millennium: The information age, Oxford, Blackwell.

Chadwick, K., Barnett, T., \& Dwyer, S. (2008). An empirical analysis of the entrepreneurial orientation scale. Journal of Applied Management and Entrepreneurship, 13(4), 64-86.

Chah, D. O. (2005). A study of recent research on CEO leadership. The Korean Journal of Human Resource Management, 29(4), 205-258.

Chang, S. C., \& Lee, M. S. (2007). A study on relationship among leadership, organizational culture, the operation of learning organization and employees' job satisfaction, Learning Organization, 14(2), 155-185.

Chang, S. I. (2012). Study on human resource management in Korea's chaebol enterprise: a case study of Samsung Electronics. International Journal of Human Resource Management, 23(7), 1436-1461.

Cho, H. Y., Kim, K. J., \& Park, K. Y. (2011). An exploratory analysis of antecedents and consequences of psychological ownership, Korean Journal of Hospitality Administration, 20(4), 75-97.

Curtin, L. L. (1995). The "gold collar" leader...?. Nursing Management, 26(10), 7-8.

Davenport, T. H., De Long, D. W., \& Beers, M. C. (1998). Successful knowledge management projects. Sloan Management Review, 39, 43-57.

Davis, J. L., Bell, R. G., Payne, G. T., \& Kreiser, P. M. (2010). Entrepreneurial orientation and firm performance: The moderating role of managerial power. American Journal of Business, 25(2), 41-54.

Davis, S. (1984). Managing corporate culture. Cambridge, MA: Ballinger.

De Jong, T. (2010). Linking social capital to knowledge productivity: An explorative study on the relationship between social capital and learning in knowledge productive networks, Phd thesis, Enschede NL: University of Twente.

Deal, T. E., \& Kennedy, A. A. (1982). Corporate Cultures, Reading, MA: AddisonWesley.

Debowski, S. (2006). Knowledge management, Milton, QLD: John Wiley \& Sons.

Delong, D. W., \& Fahey, L. (2000). Diagnosing cultural barriers to knowledge management. The Academy of Management Executive, 14(4), 113-127. 
Denison, D. (2000). Organizational culture: Can it be a key lever for driving organizational change? in S. Cartwright and C. Cooper. (Eds.) The Handbook of Organizational Culture. London: John Wiley \& Sons.

Denison, D., \& Mishra, A. (1995). Toward a theory of organizational cultures and effectiveness. Organization Science, 6, 204-223.

DeTienne, K. B., Dyer, G., Hoopes, C., \& Harris, S. (2004). Toward a model of effective knowledge management and directions for future research: culture, leadership, and CKOs. Journal of Leadership \& Organizational Studies, 10(4), 26-43.

Drucker, P. F. (1969). The shame of marketing. Marketing/Communications, 297 (August), 60-64.

Drucker, P. F. (1993). Post-capitalist society, Oxford: Butterworth-Heinemann.

Drucker, P. F. (1999). Knowledge-worker productivity: The biggest challenge. California Management Review, 41, 79-94.

Du, S., Bhattacharya, C. B., \& Sen, S. (2010). Maximizing business returns to corporate social responsibility (CSR): The role of CSR communication. International Journal of Management Reviews, 12(1), 8-19.

Dvir, T., Eden, D., Avolio, B. J., \& Shamir, B. (2002). Impact of transformational leadership on follower development and performance: a field experiment. Academy of Management Journal, 45(4), 735-744.

Ergeneli, A., Gohar, R., \& Temirbekova, Z. (2007). Transformational leadership: Its relationship to culture value dimensions. International Journal of Intercultural Relations, 31(6), 703-724.

Fiedler, F. E. (1967). A theory of leadership effectiveness. New York: McGraw-Hill.

Fiol, C. M., Harris, D., \& House, R. J. (1999). Charismatic leadership: Strategies for effecting social change. Leadership Quarterly, 10(3), 449-481.

Frederick, W. C. (1986). Toward CSR3; Why ethical analysis is indispensible and unavoidable in corporate affairs. California Management Review, 28, 126-141.

García-Morales, V. J., Jiménez-Barrionuevo, M. M., \& Gutiérrez-Gutiérrez, L. (2012). Transformational leadership influence on organizational performance through organizational learning and innovation. Journal of Business Research, 65, 1040-1050.

Garvey, B., \& Williamson, B. (2002). Beyond knowledge management; dialogue, creativity and the corporate curriculum. Harlow: Prentice Hall.

Gloet, M. (2006). Knowledge management and the link to HRM. Management Research News, 29(7), 402-413. 
Gold, A. H., Malhotra, A., \& Segars, A. H. (2001). Knowledge management: An organizational capabilities perspective. Journal of Management Information systems, 18(1), 185-214.

Greengard, S. (1998). Storing, shaping and sharing collective wisdom. Workforce, 77(10), 82-88.

Groves, K. S., \& LaRocca, M. A. (2011). An empirical study of leader ethical values, transformational and transactional leadership, and follower attitudes toward corporate social responsibility. Journal of Business Ethics, 103, 511-528.

Gumusluoglu, L., \& Ilsev., A. (2009). Transformational leadership, creativity, and organizational innovation. Journal of Business Research, 62, 461-473.

Hambrick, D. C., \& Mason, P. A. (1984). Upper echelons: The organization as a reflection of its top managers. Academy of Management Review, 9(2), 193-206.

Harrison, R., \& Kessels, J. (2004). Human resource development in a knowledge economy, Basingstoke, UK: Palgrave MacMillan.

Harrison, E. F., \& Pelletier, M. A. (1997). Managerial attitudes towards strategic decisions: Maximizing versus satisficing outcomes. Management Decision, 35(5), 358-364.

Hart, S. L., \& Quinn, R.E. (1991). Roles executives play: CEOs, behavioral complexity and firm performance. Human Relations, 46(5), 543-574.

HayGroup. (2012). Lighting the path to success: Find out what separates the FORTUNE World's Most Admired Companies from the rest. HayGroup Report, 1-20.

Hersey, P., \& Blanchard, K. H. (1982). Management of organization behavior: Utilizing human resources. 4th ed. Englewood Cliffs, N. J.: Prentice Hall, Inc.

Hooker, C., \& Csikszentmihalyi, M. (2003). Flow, creativity, and shared leadership. In Pearce, C. L., \& Conger, J. A. (Eds.), Shared Leadership, 217-234, Thousand Oaks, CA: Sage.

House, R. J., \& Aditya, R. M. (1997). The social scientific study of leadership: Quo vadis?. Journal of Management, 23, 409-473.

Huang, Y-C., \& Jim Wu, Y-C. (2010). Intellectual capital and knowledge productivity: The Taiwan biotech industry, Management Decision, 48(4), 580598.

Husted, B. W., \& Allen, D. B. (2007). Strategic corporate social responsibility and value creating among large firms. Long Range Planning, 40(6), 594-610.

Hutchings, K., \& Michailora, S. (2004). Facilitating knowledge sharing in Russian and Chinese subsidiaries: The role of personal networks and group membership. Journal of Knowledge Management, 8(2), 84-94. 
Ireland, R. D., \& Hitt, M. A. (1999). Achieving and maintaining strategic competitiveness in the 21st century: The role of strategic leadership. The Academy of Management Executive, 13, 43-57.

Jin, C. H., \& Yeo, H. C. (2011). Satisfaction, corporate credibility, CEO reputation and leadership effects on public relationships. Journal of Targeting, Measurement \& Analysis for Marketing, 19(2), 127-140.

Jung, D., Wu, A., \& Chow, C. W. (2008). Towards understanding the direct and indirect effects of CEO's transformational leadership on firm innovation. The Leadership Quarterly, 19(5), 582-594.

Kang, S. J., Kessels, J., Lee, E. S., \& Cho, Y. S. (2014a). Measuring the CEO leadership styles and the organizational culture. Journal of CEO and Management Studies, 17(1), 77-102.

Kang, S. J., Kessels, J., Lee, E. S., \& Cho, Y. S. (2014b). Measurement of knowledge productivity and value creation. Journal of CEO and Management Studies, 17(3), 23-44.

Khan, J. (1999). The world's most admired companies. Fortune, October (11), 1-7.

Kanter, R. M. (1989). When giants learn to dance, New York: Simon \& Schuster.

Kao, P. H., \& Kao, H. (2007). Taiwanese executive's leadership styles and their preferred decision-making models used in Mainland China. Journal of American Academy of Business, 10(2), 71-79.

Kessels, J., \& Keursten, P. (2002). Creating a knowledge productive work environment. LLinE, Lifelong Learning in Europe. 7(2), 104-112.

Kessels, J. (1996). The corporate curriculum, Inaugural lecture, Leiden University, Netherlands.

Kessels, J. (2004). The knowledge revolution and the knowledge economy: The challenge for HRD, In: Woodall, J., Lee, M., \& Stewart, J. (eds.) (2004). New Frontiers in HRD. London: Routledge. pp. 165-179.

Kessels, J. W. M. (2001). Learning in organizations: A corporate curriculum for the knowledge economy. Futures, 33, 479-506.

Kessels, J., Verdonschot, S., \& De Jong, T. (2011). Characteristics of learning environments which support knowledge productivity and which facilitate innovation, In: IPOB (ed.) The future of knowledge intensive service work. Theory and practice of managing human and organizational source, pp. 221232. Marburg: Metropolis-Verlag 
Keursten, P., Verdonschot, S., Kessels, J., \& Kwakman, K. (2006). Relating learning, knowledge creation and innovation: Case studies into knowledge productivity, International Journal of Learning and Intellectual Capital, 3(4), 405-420.

Kilroy, D. B. (1999). Creating the future: How creativity and innovation drive shareholder wealth, Management Decision, 37(4), 363-371.

Kim, S. J., \& Chung, W. C. (2007). Reform of the educational system for creative human resources as future growth engine, Korean Economic Journal, 46(4), 187-214.

Kim, W. C., \& Mauborgne, R. (2005). Blue ocean strategy: From theory to practice, California Management Review, 47(3), 105-121.

Kim, Y. K. (2011). Performing USR (Union Social Responsibility) to raise the employee's job satisfaction and organizational commitment, Seoul School of Integrated Science \& Techologies, 1-114.

Kim, Y. K., Bae, S. H., \& Kwon, S. W. (2013). Union Social Responsibility: Turning a great idea into action in a labor society, Nanam Publication, 1-189.

Kim, Y. S., \& Cho, K. J. (2013). The effects of perceived psychological contract on job satisfaction and supervisor loyalty, Korean Journal of Tourism and Leisure, 25(6), 279-293.

Kludge, J., Stein, W., \& Licht, T. (2001). Knowledge unplugged, New York, NY.: Palgrave.

Korte, W.B., \& Wynne, R. (1996). Telework: Penetration, Potential and Practice in Europe, Amsterdam: IOS Press.

Koski, J. T. (2001). Reflections on information glut and other issues in knowledge productivity. Futures, 33(6), 483-495.

Kotter, J. P., \& Heskett, J. L. (1992). Corporate culture and performance, New York, NY: Macmillan.

Krames, J. A. (2005). Jack Welch and the 4e's of leadership: How to put GE's leadership formula to work in your organization, New York: McGraw-Hill.

Kwak, J. W., \& Kim, B. J. (2012). Commitment and organizational citizenship behavior: The moderating role of leader-member exchange and perceived organizational support, International Business Review, 16(4), 149-177.

Kwon, S. J., \& Choi, A. K. (2014). The effect of supervisor's communication styles on secretary's rapport, trust, and loyalty to supervisor, Korean Journal of Business Education, 28(2), 1-24.

Kwon, Y. H., \& Kim, J. Y. (2010). The effect of the reporting about CEO and employee's corporate social responsibility on corporate image and evaluation. Korean Business Review, 3(2), 43-59. 
Lam, J. (2002). Defining the effects of transformational leadership on organizational learning: A cross-cultural comparison. School Leadership \& Management, 3(4), 439-452.

Lance, C. E., \& Vandenberg, R. J. (2002). Confirmatory factor analysis. In: F. Drasgow \& N. Schmitt (Eds.), Measuring and analyzing behavior in organizations. San Francisco, CA: Jossey-Bass, 221-254.

Lee, H., \& Choi, B. (2003). Knowledge management enablers, processes, and organizational performance: An integrative view and empirical examination. Journal of Management Information Systems, 20(1), 179-228.

Lee, S. C. (1999). Methodology for building knowledge management. Academic Symposium on Knowledge Management, 239-260.

Lincoln, J. R., Gerlach, M. L., \& Ahmadjian, C. (1996). Keiretsu networks and corporate performance in Japan. American Sociological Review, 61(1), 67-88.

Makri, M., \& Scandura. T. A. (2010). Exploring the effects of creative CEO leadership on innovation in high-technology firm. The Leadership Quarterly, 21(1), 7588.

Marques, D. P., \& Simon, F. J. G. (2006). The effect of knowledge management practices on firm performance. Journal of Knowledge Management, 10(3), 143156.

McGuire, J. (1963). Business and Society. New York: McGraw-Hill.

McMurray, A. R., \& Bentley, E. L. (1987). Situational leadership: Conscious criteria applied in educational leaders' decisions, presentation paper at the annual meeting of the American Educational Research Association.

Menon, A., \& Varadarajan, P. R. (1992). A model of marketing knowledge use within firms. Journal of Marketing, 56, 53-77.

Mischel, W. (1973). Toward a cognitive social reconceptualization of personality. Psychological Review, 80, 253-283.

Nahavandi, A., \& Malekzadeh, A. R. (1993). Leader style in strategy and organizational performance: An integrative framework. Journal of Management Studies, 30(3), 405-425.

Nahavandi, A., \& Malekzadeh, A. R. (1998). Leadership and cultural transnational strategic alliances. In: M. C. Gertsen, A-M. Søderberg \& J. E. Torp (Eds), Cultural Dimensions of International Mergers and Acquisitions. Berlin: Walter de Gruyter.

Naisbitt, J. (1982). Megatrends: Ten new directions transforming our lives, New York: Warner Books. 
Nguyen, H. N., \& Mohamed, S. (2011). Leadership behaviors, organizational culture and knowledge management practices: An empirical investigation. Journal of Management Development, 30(2), 206-221.

Nonaka, I. (1991). The knowledge-creating company, Harvard Business Review, November- December, 96-104.

Nonaka, I., \& Takeuchi, H. (1995). The knowledge-creating company, Oxford University Press: New York.

Nonaka, I., Toyama, R., \& Konno, N. (2000). SECI, Ba and leadership: A unified model of dynamic knowledge creation. Long Range Planning, 33(1), 5-34.

Northouse, P. G. (2010). Leadership theory and practice, 5th edn. Sage, Los Angeles, CA.

O' Reilly, C. A. (1989). Corporations, culture, and commitment: Motivation and social control in organizations. California Management Review, 31(4), 9-25.

O' Reilly, C. A., Chatman, J., \& Caldwell, D. F. (1991). People and organizational culture: A profile comparison approach to assessing person-organization fit. Academy of Management Journal, 34(3), 487-516.

Oldham, G. R., \& Cummings, A. (1986). Employee creativity: Personal and contextual factors at work. The Academy of Management Journal, 39(3), 607634.

Park, J. K. (2009). The major economic policy of historical administrations in Korea. Policy Research, Korea Economic Research Institution, 6, 1-502.

Pavitt, C. (1999). Theorizing about the group communication-leadership relationship: Input- process-output and functional models. In L. R. Frey, D. S. Gouran, \& M. S. Poole (Eds.), The handbook of group communication theory and research, 313334, Thousand Oaks, CA: Sage.

Peterson, S. J., Walumbwa, F. O., Byron, K., \& Myrowitz, J. (2009). CEO positive psychological traits, transformational leadership, and firm performance in high- technology start-up and established firms, Journal of Management, 35(2), 348-368.

Pettigrew, A. M. (1979). On studying organizational cultures. Administrative Science Quarterly, 24(4), 570-581.

Piccolo, R. F., Bono, J. E., Heinitz, K., Rowold, J. Duehr, E., \& Judge. T. A. (2012). The relative impact of complementary leader behaviors: Which matter most? The Leadership Quarterly, 23, 567-581.

Pierce, J. L., O'Driscoll, M. P., \& Coghlan, A. M. (2004). Work environment structure and psychological ownership: the mediating effects of control, The Journal of Social Psychology, 144(5), 507-534. 
Pieterse, A. N., Van Knippenberg, D., Schippers, M., \& Stam. D. (2010). Transformational and transactional leadership and innovative behavior: The moderating role of psychological empowerment. Journal of Organizational Behavior, 31, 609-623.

Podsakoff, P. M., Mackenzie, S. B., \& Bommer. W. (1996). Transformational leader behaviors and substitutes for leadership as determinants of employee satisfaction, commitment, trust, and organizational citizenship behaviors. Journal of Management, 22(2), 259-298.

Podsakoff, P. M., Mackenzie, S. B., Moorman, R. H., \& Fetter, R. (1990). Transformational leader behaviors and their effects on followers trust in leader, satisfaction, and organizational citizenship behaviors. The Leadership Quarterly, 1, 107-142.

Politis, J. D. (2002). Transformational and transactional leadership enabling (disabling) knowledge acquisition of self-managed teams: the consequences for performance. Leadership \& Organization Development Journal, 23(4), 186197.

Porter, M. E., \& Kramer, M. R. (2011). The big idea: Creating shared value. Harvard Business Review, January-February, 1-17.

Pride, W. M., \& Ferrell, O. C. (2006). Marketing: concepts and strategies, Houghton Mifflin, Boston, MA.

Quinn, R. E., \& McGrath, M. R. (1985). The transformation of organizational culture: a competing values perspective. In P. J. Frost, L. F. Moore, M. R. Louis, C. C. Lundberg, \& J. Martin (Eds.), Organizational culture (pp. 315-344). Beverly Hills, CA: Sage.

Rho, B. H., Lim, C. U., \& Hwang, K. J. (2004). A field research on Korean firm's reputation. Korean Management Review, 15(1), 29-44.

Roberts, P. W., \& Dowling, G. R. (2002). Corporate reputation and sustained superior financial performance. Strategic Management Journal, 23, 1077-1093.

Robinson, H. S., Anumba, C. J., Carrillo, P. M., \& Al-Ghassani, A. M. (2006). STEPS: A knowledge management maturity roadmap for corporate sustainability. Business Process Management Journal, 12(6), 793-808.

Roh, K. H., \& Yoo, T. Y. (2013). The effect of perceived corporate philanthropy on organizational citizenship behavior: Mediating effect of organizational commitment and moderating effect of service values. Korean Journal of Industrial and Organizational Psychology, 26(2), 195-218. 
Sarros, J. C., Cooper, B. K., \& Santora, J. C. (2008). Building climate for innovation through transformational leadership and organizational culture. Journal of Leadership \& Organizational Studies, 15(2), 145-158.

Schein, E. H. (1985). Organizational culture and leadership. San Francisco: JosseyBass.

Schein, E. H. (1992). Organizational culture and leadership (2nd edn.). San Francisco: Jossey-Bass.

Schein, E. H. (2004). Organizational culture and leadership (3rd edn.). San Francisco: Jossey-Bass.

Schriesheim, C. A., Castro, S. L., Zhou, X., DeChurch, L. A. (2006). An investigation of path-goal and transformational leadership theory predictors at the individual level of analysis. The Leadership Quarterly, 17: 21-38.

Schumpeter, J. A., (1987). Capitalism, socialism and democracy, London: Unwin.

Shin, S. J., \& J. Zhou, (2003). Transformational leadership, conservation, and creativity: Evidence from Korea. The Academy of Management Journal, 46(6), 703-714.

Shin, Y. K. (1996). Trait and leadership styles of CEOs in Korean companies. Korean Journal of Management, 14(2), 203-233.

Shipman, A. S., Byrne, C. L., \& Mumford, M. D. (2010). Leader vision formation and fore casting: the effects of forecasting extent, resources, and timeframe, The Leadership Quarterly, 21, 439-456.

Singh, S. K. (2008). Role of leadership in knowledge management: A study. Journal of Knowledge Management, 12(4), 3-15.

Slater, R. (1999). The GE way fieldbook 'Jack Welch's battle plan for corporate revolution.' McGraw-Hill.

Slater, S. F., \& Narver, J. C. (1995). Market orientation and the learning organization, Journal of Marketing, 59, 63-74.

Song, J. H., Kolb, J. A., Lee, U. H., \& Kim, H. K, (2012). Role of transformational leadership in effective organizational knowledge creation practices: mediating effect of employee's work engagement. Human Resource Development Quarterly, 23(1), 66-101.

Spears, L. C. (2002). Tracing the past, present, and future of servant-leadership. Focus on leadership. Servant-leadership for the 21st century (eds.) Spears, L. C. Lawrence, M. York: John Wiley \& Sons, Inc., 1-16.

Stam, C. D. (2007). Knowledge productivity. Designing and testing a method to diagnose knowledge productivity and plan for enhancement, Ph.D. thesis, Enschede: University of Twente. 
Takeuchi, H. (2001). Towards a universal management concept of knowledge, in Nonaka, I. and Teece, D.J. (Eds), Managing Industrial Knowledge - Creation, Transfer and Utilization, Sage, London, 315-335.

Taormina, R. J. (2007). Interrelating leadership behaviors, organizational socialization, and organizational culture. Leadership \& Organization Development Journal, 29(1), 85-102.

Teece, D. J. (2003). Explicating dynamic capabilities: asset selection, coordination, and entrepreneurship in strategic management theory, U. C. Berkeley.

Tichy, N. M., \& Sherman. S. (1993). Control your destiny or someone else will. New York: Doubleday.

Tosi, H. L., \& Greckhamer, T. (2004). Culture and CEO compensation. Organization Science, 15(6), 657-670.

Tosi, H. L., Misangyi, V. F., Fanelli, A., Waldman, D. A., \& Yammarino, F. J. (2004). CEO charisma, compensation, and firm performance. The Leadership Quarterly, 15, 405-420.

Trice, A., \& Davis, R. (1993). Heuristics for reconciling independent knowledge bases. Information Systems Research, 4(2), 262-288.

Trice, H. M., \& Beyer, J. M. (1993). The cultures of work organizations, Englewood Cliffs, NJ: Prentice Hall.

Tseng, S. M. (2010). The correlation between organizational culture and knowledge conversion on corporate performance. Journal of Knowledge Management, 14(2), 269-284.

Tsui, A. S., Zhang, Z. X., Wang, H., Xin, K. R., \& Wu, J. B. (2006). Unpacking the relationship between CEO leadership behavior and organizational culture. The Leadership Quarterly, 17, 113-137.

Van Lakerveld, J. (2005). Het corporate curriculum: Onderzoek naar werkleeromstandigheden in instellingen voor zorg en welzijn [The corporate curriculum; Research on learning conditions in health care institutions] Phd thesis, Universiteit Twente.

Von Krogh, G. (1998). Care in knowledge creation. California Management Review, 40(3), 133-154.

Von Krogh, G., Nonaka, I., \& Rechsteiner, L. (2012). Leadership in organizational knowledge creation: A review and framework, Journal of Management Studies, 49(1), 240-277. 
Vroom, V. H., \& Jago, A. G. (1988). The new leadership: Managing participation in organizations, Englewood Cliffs, N.J.: Prentice Hall, Inc.

Waldman, D. A., Ramirez, G. G., House, R. J., \& Puranam, P. (2001). Does leadership matter? CEO leadership attributes and profitability under conditions of perceived environmental uncertainty, Academy of Management Journal, 44(1), 134-143.

Waldman, D. A., Siegel, D. S., \& Javidan, M. (2006). Components of CEO transformational leadership and corporate social responsibility. Journal of Management Studies, 43(8), 1703-1725.

Waldman, D. A., Sully de Luque, M., Washburn, N., \& House, R. J. et al. (2006). Cultural and leadership predictors of corporate social responsibility values of top management: A global study of 15countries. Journal of International Business Studies, 37, 821-837.

Wang, A.-C., \& Cheng, B.-S. (2010). When does benevolent leadership lead to creativity? The moderating role of creative role identity and job autonomy. Journal of Organizational Behavior, 31, 106-121.

Wang, H., Tsui, A. S., \& Xin, K. R. (2011). CEO leadership behaviors, organizational performance, and employees' attitudes. The Leadership Quarterly, 22, 92-105.

Weiss, D. J., Dawis, R. V., England, G.W., \& Lofquist, L. H. (1967). Manual for the Minnesota Satisfaction Questionnaire, Minnesota Studies in Vocational Rehabilitation, 22.

Wilderom, C. P. M., Van Den Berg, P. T., \& Wiersma, U. J. (2012). A longitudinal study of the effects of charismatic leadership and organizational culture on objective and perceived corporate performance. The Leadership Quarterly, 23, 835-848.

Woo, S. J., \& Park, S. C. (2001). Effects of core factors of knowledge management on business performance. Journal of Business Research, 16(2), 49-71.

Woodman, R. W., Sawyer, J. W., \& Griffin, R. W. (1993). Toward a theory of organizational creativity. Academy of Management Review, 18(2), 293-321.

Yang, J.-T. (2007). Knowledge sharing: Investigating appropriate leadership roles and collaborative culture. Tourism Management, 28, 530-543.

Yusof, N. I., Masrek, M. N., Noordin S. A., \& Johare, R. (2012). Job design and knowledge productivity: A conceptual framework. presented at the $19^{\text {th }}$ Conference of the International Business Information Management Association (IBIMA) in Barcelona. 
Zhang, X., \& Bartol, K. M. (2010). Linking empowering leadership and employee creativity: The influence of psychological empowerment, intrinsic motivation, and creative process engagement. Academy of Management Journal, 53(1), 107-128.

Zheng, W. Yang, B., \& McLean, G. N. (2010). Linking organizational culture, structure, strategy, and organizational effectiveness: Mediating role of knowledge management. Journal of Business Research, 63, 763-771.

Zhu, W., Chew, I. K. H., \& Spangler, W. D. (2005). CEO transformational leadership and organizational outcomes: The mediating role of human-capitalenhancing human resource management. The Leadership Quarterly, 16, 3952 . 


\section{Appendices}

\section{Survey Questionnaire}

The purpose of this research is to investigate the relationship among CEO leadership style, organizational culture, knowledge productivity, and value creation. The survey is anonymous and all answers will be used strictly for the academic research only. The results of this survey analysis will be used for writing an academic paper which is expected to be reported in academic and professional journals.

Your responses will provide insights into the CEO leadership styles, organizational culture, knowledge productivity, and value creation of your company, and relations among the four main factors in your company. We are only interested in your personal opinion on each questions, so please do not consult with others for answering this survey questionnaire.

Please respond to all of the questions, and do not leave any items blank.

Completion of the entire survey may take about 15-20 minutes. We appreciate your participation in this study.

If you have any questions concerning the survey, please feel free to contact us.

May, 2010

Researcher: Kang, Suk Jean, University of Twente, The Netherlands Research advisor: Prof. Joseph Kessels, University of Twente, The Netherlands

Please answer the following questions about yourself 
1. How old are you? ( ) years

2. Are you: (1)Male (2)Female

3. Your education level achieved (graduated from):

(1)High school (2) 2 year college (3)University(4year) (4)Received Master's degree

(5) Received Ph.D./Doctoral degree

4. What is your current position?

(1)Employee (2)Assistant manager (3)Manager (4) General manager (5)Executive

5. How long have you been employed by the current company? ( )years

\section{Leadership Survey}

- The following statements describe your CEO leadership style. Please circle on one number in each line across.

\begin{tabular}{|c|c|c|c|c|c|c|}
\hline No. & Question & & & & & $\begin{array}{l}\text { ngly } \\
\text { eee }\end{array}$ \\
\hline 1 & $\begin{array}{l}\text { Our CEO delegates authority and responsibilities to } \\
\text { operating executives and managers. }\end{array}$ & 1 & 2 & 3 & 4 & 5 \\
\hline 2 & $\begin{array}{l}\text { Our CEO encourages open communication without } \\
\text { boundaries. }\end{array}$ & 1 & 2 & 3 & 4 & 5 \\
\hline 3 & $\begin{array}{l}\text { Our CEO invests enough time and effort for empowering } \\
\text { employees and organization. }\end{array}$ & 1 & 2 & 3 & 4 & 5 \\
\hline 4 & $\begin{array}{l}\text { Our CEO listens and respects employees' ideas and } \\
\text { opinions. }\end{array}$ & 1 & 2 & 3 & 4 & 5 \\
\hline 5 & $\begin{array}{l}\text { Our CEO has intuition and inspiration from significant } \\
\text { business operation experiences. }\end{array}$ & 1 & 2 & 3 & 4 & 5 \\
\hline 6 & $\begin{array}{l}\text { Our CEO sometimes directly involves and contributes to } \\
\text { new knowledge/idea development. }\end{array}$ & 1 & 2 & 3 & 4 & 5 \\
\hline 7 & $\begin{array}{l}\text { Our CEO is willing to take risks if necessary for implement } \\
\text { new ideas and projects to achieve high level goals and } \\
\text { objectives. }\end{array}$ & 1 & 2 & 3 & 4 & 5 \\
\hline 8 & Our CEO sometimes shows charismatic leadership. & 1 & 2 & 3 & 4 & 5 \\
\hline 9 & We respect and trust our CEO. & 1 & 2 & 3 & 4 & 5 \\
\hline 10 & $\begin{array}{l}\text { Our CEO tries to motivates employees to do their best with } \\
\text { psychological ownership. }\end{array}$ & 1 & 2 & 3 & 4 & 5 \\
\hline
\end{tabular}




\begin{tabular}{|c|c|c|c|c|c|c|}
\hline 11 & Our CEO always shares the vision and goals with employees. & 1 & 2 & 3 & 4 & 5 \\
\hline 12 & $\begin{array}{l}\text { Our CEO is doing his/her best to build a creative and } \\
\text { innovative open organization. }\end{array}$ & 1 & 2 & 3 & 4 & 5 \\
\hline 13 & $\begin{array}{l}\text { Our CEO often makes top down decisions without being } \\
\text { influenced by subordinates opinions. }\end{array}$ & 1 & 2 & 3 & 4 & 5 \\
\hline 14 & $\begin{array}{l}\text { Our CEO can well predict potential risks in the business } \\
\text { environmental change we face. }\end{array}$ & 1 & 2 & 3 & 4 & 5 \\
\hline 15 & $\begin{array}{l}\text { Our CEO has an ability to develop and implement counter } \\
\text { measurement strategies to overcome risks. }\end{array}$ & 1 & 2 & 3 & 4 & 5 \\
\hline 16 & $\begin{array}{l}\text { Our CEO invests sufficient time for communication with } \\
\text { management and employees. }\end{array}$ & 1 & 2 & 3 & 4 & 5 \\
\hline 17 & $\begin{array}{l}\text { Our CEO always maintains integrity and transparent } \\
\text { management. }\end{array}$ & 1 & 2 & 3 & 4 & 5 \\
\hline 18 & Our CEO is open to accept change and innovation. & 1 & 2 & 3 & 4 & 5 \\
\hline 19 & $\begin{array}{l}\text { Our CEO seeks challenges and takes risks to enter into } \\
\text { unexperienced new business. }\end{array}$ & 1 & 2 & 3 & 4 & 5 \\
\hline 20 & $\begin{array}{l}\text { Our CEO prefers to maintain decentralized organization } \\
\text { with delegation of major activities. }\end{array}$ & 1 & 2 & 3 & 4 & 5 \\
\hline 21 & $\begin{array}{l}\text { Our CEO controls on most of the important decisions and } \\
\text { wants to be involved in major activities. }\end{array}$ & 1 & 2 & 3 & 4 & 5 \\
\hline 22 & $\begin{array}{l}\text { Our CEO tolerates and accepts dissent and diversity of } \\
\text { employees' decision-making and behaviors. }\end{array}$ & 1 & 2 & 3 & 4 & 5 \\
\hline 23 & $\begin{array}{l}\text { Our CEO seeks strategies that deviated very little from } \\
\text { existing ones, and I attempt to maintain the status quo. }\end{array}$ & 1 & 2 & 3 & 4 & 5 \\
\hline 24 & $\begin{array}{l}\text { Our CEO prefers to maintain control and centralized } \\
\text { organization. }\end{array}$ & 1 & 2 & 3 & 4 & 5 \\
\hline 25 & $\begin{array}{l}\text { Our CEO considers entrepreneurship very important for } \\
\text { managing the company and people. }\end{array}$ & 1 & 2 & 3 & 4 & 5 \\
\hline 26 & $\begin{array}{l}\text { Our CEO prefers to take a future oriented approach for our } \\
\text { company. }\end{array}$ & 1 & 2 & 3 & 4 & 5 \\
\hline 27 & $\begin{array}{l}\text { Our CEO encourages employees' development of creative } \\
\text { ideas. }\end{array}$ & 1 & 2 & 3 & 4 & 5 \\
\hline 28 & $\begin{array}{l}\text { Our CEO considers human resources development most } \\
\text { important and invests significant time for this. }\end{array}$ & 1 & 2 & 3 & 4 & 5 \\
\hline
\end{tabular}




\section{Organizational Culture Survey}

- The following statements describe the organizational culture you belong to. Please circle on one number in each line across.

\begin{tabular}{|c|c|c|c|c|c|c|}
\hline \multirow{2}{*}{$\begin{array}{l}\text { No. } \\
1\end{array}$} & \multirow{2}{*}{$\begin{array}{l}\text { Question } \\
\begin{array}{l}\text { Our company has non-bureaucratic and boundary-less } \\
\text { open culture with freedom. }\end{array}\end{array}$} & \multicolumn{3}{|c|}{$\begin{array}{l}\text { Strongly } \\
\text { disagree }\end{array}$} & \multicolumn{2}{|c|}{$\begin{array}{c}\text { Strongly } \\
\text { agree }\end{array}$} \\
\hline & & 1 & 2 & 3 & 4 & 5 \\
\hline 2 & $\begin{array}{l}\text { Our company organization is decentralized with delegated } \\
\text { authority and responsibilities to each operating business } \\
\text { unit. }\end{array}$ & 1 & 2 & 3 & 4 & 5 \\
\hline 3 & $\begin{array}{l}\text { In our company, we have boundary-less open and free } \\
\text { communications across layers. }\end{array}$ & 1 & 2 & 3 & 4 & 5 \\
\hline 4 & $\begin{array}{l}\text { In our company, management and employees are effectively } \\
\text { sharing information, knowledge, and best practices. }\end{array}$ & 1 & 2 & 3 & 4 & 5 \\
\hline 5 & $\begin{array}{l}\text { In our company, management and employees always share } \\
\text { the vision, goals, and strategies. }\end{array}$ & 1 & 2 & 3 & 4 & 5 \\
\hline 6 & $\begin{array}{l}\text { In our company, people are doing their best with } \\
\text { psychological ownership. }\end{array}$ & 1 & 2 & 3 & 4 & 5 \\
\hline 7 & $\begin{array}{l}\text { In our company, management support employees to archive } \\
\text { their objectives and goals. }\end{array}$ & 1 & 2 & 3 & 4 & 5 \\
\hline 8 & In our company, employees' opinions are respected. & 1 & 2 & 3 & 4 & 5 \\
\hline 9 & $\begin{array}{l}\text { In our company, employees are motivated to participate in } \\
\text { decision making. }\end{array}$ & 1 & 2 & 3 & 4 & 5 \\
\hline 10 & $\begin{array}{l}\text { Our company has open culture where people have freedom } \\
\text { to be creative and innovative. }\end{array}$ & 1 & 2 & 3 & 4 & 5 \\
\hline 11 & $\begin{array}{l}\text { In our company, employees are being respected as human } \\
\text { being. }\end{array}$ & 1 & 2 & 3 & 4 & 5 \\
\hline 12 & $\begin{array}{l}\text { In our company, employees are actively involved in learning } \\
\text { new knowledge, information and idea from inside and } \\
\text { outside. }\end{array}$ & 1 & 2 & 3 & 4 & 5 \\
\hline 13 & $\begin{array}{l}\text { In our company, people are taking proactive actions to } \\
\text { implement new idea and action plans. }\end{array}$ & 1 & 2 & 3 & 4 & 5 \\
\hline 14 & $\begin{array}{l}\text { In our company, most of the important decisions are being } \\
\text { made by top-down. }\end{array}$ & 1 & 2 & 3 & 4 & 5 \\
\hline 15 & Our company emphasizes to follow procedures and rules. & 1 & 2 & 3 & 4 & 5 \\
\hline 16 & Our company maintains a stagnant culture. & 1 & 2 & 3 & 4 & 5 \\
\hline 17 & Our company emphasizes order of ranks and positions. & 1 & 2 & 3 & 4 & 5 \\
\hline 18 & $\begin{array}{l}\text { Our company is taking proactive actions to implement new } \\
\text { ideas and action plans. }\end{array}$ & 1 & 2 & 3 & 4 & 5 \\
\hline 19 & Our company is trying to maintain status quo. & 1 & 2 & 3 & 4 & 5 \\
\hline 20 & $\begin{array}{l}\text { Our company prefers to maintain stability not to take risks } \\
\text { and challenges. }\end{array}$ & 1 & 2 & 3 & 4 & 5 \\
\hline
\end{tabular}




\begin{tabular}{|l|l|l|l|l|}
\hline 1 & 2 & 3 & 4 & 5 \\
\hline
\end{tabular}

\section{Knowledge Productivity Survey}

\section{- The following statements describe the knowledge productivity in your organization. Please circle on one number in each line across.}

\begin{tabular}{|c|c|c|c|c|c|c|}
\hline No. & Question & & & & & \\
\hline 1 & $\begin{array}{l}\text { In our company, all the subject matter expertise we need } \\
\text { now and in the near future is available in our organization. }\end{array}$ & 1 & 2 & 3 & 4 & 5 \\
\hline 2 & $\begin{array}{l}\text { We know what problems we are good at solving and those } \\
\text { we are not. }\end{array}$ & 1 & 2 & 3 & 4 & 5 \\
\hline 3 & $\begin{array}{l}\text { We try hard to increase our level of expertise and broaden } \\
\text { the area of knowledge. }\end{array}$ & 1 & 2 & 3 & 4 & 5 \\
\hline 4 & $\begin{array}{l}\text { Our open communication contributes to exchange } \\
\text { experience, learning and knowledge development. }\end{array}$ & 1 & 2 & 3 & 4 & 5 \\
\hline 5 & $\begin{array}{l}\text { In our company, people know what works are meaningful } \\
\text { for them and how to create such works. }\end{array}$ & 1 & 2 & 3 & 4 & 5 \\
\hline 6 & $\begin{array}{l}\text { We take sufficient time to think how to apply to our actual } \\
\text { work what we have learned from the past. }\end{array}$ & 1 & 2 & 3 & 4 & 5 \\
\hline 7 & $\begin{array}{l}\text { Our company management and employees have ability to } \\
\text { create opportunity from turmoil. }\end{array}$ & 1 & 2 & 3 & 4 & 5 \\
\hline 8 & $\begin{array}{l}\text { We try to develop the knowledge and expertise our firm } \\
\text { needs. }\end{array}$ & 1 & 2 & 3 & 4 & 5 \\
\hline 9 & $\begin{array}{l}\text { Our company tries to stimulate people to experiment with } \\
\text { new approaches to solve defined problems. }\end{array}$ & 1 & 2 & 3 & 4 & 5 \\
\hline 10 & $\begin{array}{l}\text { We know the intelligence level of our company in the } \\
\text { industry. }\end{array}$ & 1 & 2 & 3 & 4 & 5 \\
\hline 11 & $\begin{array}{l}\text { We are well aware of the preferred ways to develop and } \\
\text { share knowledge. }\end{array}$ & 1 & 2 & 3 & 4 & 5 \\
\hline 12 & $\begin{array}{l}\text { We analyze the reasons why we make progress or lag behind } \\
\text { in the various fields of expertise. }\end{array}$ & 1 & 2 & 3 & 4 & 5 \\
\hline 13 & $\begin{array}{l}\text { We apply to our actual work what we have learned from the } \\
\text { past. }\end{array}$ & 1 & 2 & 3 & 4 & 5 \\
\hline 14 & $\begin{array}{l}\text { Our company focuses on finding new ways to deal with } \\
\text { critical issues we are facing. }\end{array}$ & 1 & 2 & 3 & 4 & 5 \\
\hline 15 & Our new knowledge and ideas lead to business growth. & 1 & 2 & 3 & 4 & 5 \\
\hline 16 & $\begin{array}{l}\text { Our company is an organization that highlights intelligence, } \\
\text { information and ideas. }\end{array}$ & 1 & 2 & 3 & 4 & 5 \\
\hline 17 & $\begin{array}{l}\text { The market value of our company increases by our creative } \\
\text { knowledge and ideas. }\end{array}$ & 1 & 2 & 3 & 4 & 5 \\
\hline
\end{tabular}




\begin{tabular}{|c|l|c|c|c|c|c|}
\hline 18 & $\begin{array}{l}\text { The creative ideas of employees are respected and } \\
\text { implemented. }\end{array}$ & 1 & 2 & 4 & 5 \\
\hline 19 & $\begin{array}{l}\text { In our company creativity and new ideas are formed by } \\
\text { employees working together. }\end{array}$ & 1 & 2 & 3 & 4 & 5 \\
\hline 20 & $\begin{array}{l}\text { Our company considers developing and learning new } \\
\text { knowledge as the most important priority. }\end{array}$ & 1 & 2 & 3 & 4 & 5 \\
\hline 21 & $\begin{array}{l}\text { In our company, we share knowledge and best practices } \\
\text { effectively without boundaries. }\end{array}$ & 1 & 2 & 3 & 4 & 5 \\
\hline 22 & $\begin{array}{l}\text { We always try to think creatively for developing new } \\
\text { knowledge and improving knowledge productivity. }\end{array}$ & 1 & 2 & 3 & 4 & 5 \\
\hline 23 & $\begin{array}{l}\text { In our company, we always try to create idea to develop new } \\
\text { products and services. }\end{array}$ & 1 & 2 & 3 & 4 & 5 \\
\hline 24 & $\begin{array}{l}\text { In our company, we are encouraged innovative thinking in } \\
\text { order to improve operating systems and productivity. }\end{array}$ & 1 & 2 & 3 & 4 & 5 \\
\hline 25 & $\begin{array}{l}\text { Our company respects creative ideas of management and } \\
\text { employees which come from their expertise and intuition. }\end{array}$ & 1 & 2 & 3 & 4 & 5 \\
\hline 26 & $\begin{array}{l}\text { Our company continuously innovates our businesses with } \\
\text { creative new ideas to change to Blue ocean businesses. }\end{array}$ & 1 & 2 & 3 & 4 & 5 \\
\hline 27 & $\begin{array}{l}\text { Our company is very open to learn and accept best practices } \\
\text { and new knowledge from inside and outside. }\end{array}$ & 1 & 2 & 3 & 4 & 5 \\
\hline 28 & $\begin{array}{l}\text { Our company operates each business unit utilizing } \\
\text { knowledge productively to achieve goals. }\end{array}$ & 1 & 2 & 3 & 4 & 5 \\
\hline 29 & $\begin{array}{l}\text { Our company emphasizes developing new ideas to improve } \\
\text { operation processes continuously. }\end{array}$ & 1 & 2 & 3 & 4 & 5 \\
\hline
\end{tabular}

\section{Value Creation Survey}

- The following statements describe the value creation of your organization. Please circle on one number in each line across.

\begin{tabular}{|c|l|c|c|c|c|c|}
\hline No. & \multicolumn{1}{|c|}{ Question } & \multicolumn{1}{c}{$\begin{array}{c}\text { Strongly } \\
\text { disagree }\end{array}$} & \multicolumn{3}{c|}{$\begin{array}{c}\text { Strongly } \\
\text { agree }\end{array}$} \\
\hline 1 & $\begin{array}{l}\text { Top management team of our firm is esteemed for its } \\
\text { outstanding management capability. }\end{array}$ & 1 & 2 & 3 & 4 & 5 \\
\hline 2 & $\begin{array}{l}\text { Our company is known for its efforts for transparent } \\
\text { management. }\end{array}$ & 1 & 2 & 3 & 4 & 5 \\
\hline 3 & Our company is respected for its high profit and stability. & 1 & 2 & 3 & 4 & 5 \\
\hline 4 & $\begin{array}{l}\text { Our company gives back to the society from what we earned } \\
\text { and has a high social responsibility. }\end{array}$ & 1 & 2 & 3 & 4 & 5 \\
\hline 5 & $\begin{array}{l}\text { Our company is doing business in a fair and honest way } \\
\text { with competitors and suppliers. }\end{array}$ & 1 & 2 & 3 & 4 & 5 \\
\hline
\end{tabular}




\begin{tabular}{|c|c|c|c|c|c|c|}
\hline 6 & $\begin{array}{l}\text { Our company is reputed for its advanced technology } \\
\text { compared to our competitors. }\end{array}$ & 1 & 2 & 3 & 4 & 5 \\
\hline 7 & $\begin{array}{l}\text { Our company is reknowned for its high quality products } \\
\text { and services. }\end{array}$ & 1 & 2 & 3 & 4 & 5 \\
\hline 8 & $\begin{array}{l}\text { The employees are satisfied with the way our company treats } \\
\text { us. }\end{array}$ & 1 & 2 & 3 & 4 & 5 \\
\hline 9 & Our company is known for its focuses on radical innovation. & 1 & 2 & 3 & 4 & 5 \\
\hline 10 & $\begin{array}{l}\text { We are customer-oriented and always try to do our best to } \\
\text { fulfill customer needs. }\end{array}$ & 1 & 2 & 3 & 4 & 5 \\
\hline 11 & $\begin{array}{l}\text { Our company takes high responsibility for environment } \\
\text { protection. }\end{array}$ & 1 & 2 & 3 & 4 & 5 \\
\hline 12 & Our company is managing globally oriented businesses. & 1 & 2 & 3 & 4 & 5 \\
\hline 13 & $\begin{array}{l}\text { Our company is appreciated for its active role for corporate } \\
\text { social responsibility. }\end{array}$ & 1 & 2 & 3 & 4 & 5 \\
\hline 14 & $\begin{array}{l}\text { Our company promotes sustainable management and social } \\
\text { values. }\end{array}$ & 1 & 2 & 3 & 4 & 5 \\
\hline 15 & Our company is fairly well managed by top management. & 1 & 2 & 3 & 4 & 5 \\
\hline 16 & Our company is known as a profit-oriented firm. & 1 & 2 & 3 & 4 & 5 \\
\hline 17 & $\begin{array}{l}\text { Our company is strongly involved in the community activity } \\
\text { and has high social responsibility. }\end{array}$ & 1 & 2 & 3 & 4 & 5 \\
\hline 18 & $\begin{array}{l}\text { Our company focuses on customer needs and customer } \\
\text { satisfaction. }\end{array}$ & 1 & 2 & 3 & 4 & 5 \\
\hline 19 & $\begin{array}{l}\text { Our company is a good place to work for and I am satisfied } \\
\text { with my job. }\end{array}$ & 1 & 2 & 3 & 4 & 5 \\
\hline 20 & I can grow when I work hard in my company. & 1 & 2 & 3 & 4 & 5 \\
\hline 21 & Our company payment level is similar to competitor's. & 1 & 2 & 3 & 4 & 5 \\
\hline 22 & $\begin{array}{l}\text { Promotion and evaluation are fairly executed in our } \\
\text { company. }\end{array}$ & 1 & 2 & 3 & 4 & 5 \\
\hline 23 & Our company offers considerable benefits and bonuses. & 1 & 2 & 3 & 4 & 5 \\
\hline 24 & I can bring out my best abilities for my work. & 1 & 2 & 3 & 4 & 5 \\
\hline 25 & My job is challengeable and creative. & 1 & 2 & 3 & 4 & 5 \\
\hline 26 & I respect and trust my boss. & 1 & 2 & 3 & 4 & 5 \\
\hline 27 & $\begin{array}{l}\text { In our work environment, I feel free to make my } \\
\text { recommendation for company. }\end{array}$ & 1 & 2 & 3 & 4 & 5 \\
\hline 28 & I know what my company and superiors expect from me. & 1 & 2 & 3 & 4 & 5 \\
\hline
\end{tabular}




\section{Interview Guidelines}

1. How old are you? ( ) years

2. Are you: (1)Male (2)Female

3. Your education level achieved (graduated from):

(1)High school (2) 2 year college (3) University (4year)

(2) Received Master's degree (5) Received Ph.D./Doctoral degree

4. What is your current position?

(1)Employee (2)Assistant manager (3)Manager (4)General manager (5)Executive

5. How long have you been employed by the current company? ( )years

1) Interview questions on leadership style

\begin{tabular}{|l|l|}
\hline Question to CEO & 1. How would you describe your own leadership style? \\
\hline $\begin{array}{l}\text { Question to } \\
\text { employees }\end{array}$ & $\begin{array}{l}\text { 2. What do you think of the leadership style of chairman and CEO of your } \\
\text { company? }\end{array}$ \\
\hline $\begin{array}{l}\text { Follow-up } \\
\text { question subjects Delegation of responsibilities } \\
\text { b) Non-bureaucratic and open communication } \\
\text { c) Empowerment of people and organization } \\
\text { d) Risk taking to enter into new businesses } \\
\text { e) Listening and respecting employeesí opinions and ideas } \\
\text { f) Leading change and innovation }\end{array}$ \\
\hline
\end{tabular}

2) Interview questions on organizational culture style

\begin{tabular}{|c|c|}
\hline Questions to all & $\begin{array}{l}\text { 1. How would you describe the culture of your company? } \\
\text { 2. What are its strong points and weak points? }\end{array}$ \\
\hline $\begin{array}{l}\text { Follow-up } \\
\text { question subjects }\end{array}$ & $\begin{array}{l}\text { a) Non-bureaucratic open culture with the freedom for people to be creative } \\
\text { and innovative } \\
\text { b) Boundary-less open communication } \\
\text { c) Sharing vision and values within the organization } \\
\text { d) People bring out their best for the company with a strong psychological } \\
\text { ownership } \\
\text { e) Employees can actively and freely recommend new and creative ideas } \\
\text { f) Aggressively seeking change and innovation }\end{array}$ \\
\hline
\end{tabular}




\section{3) Interview questions on knowledge productivity}

\begin{tabular}{|c|l|}
\hline Questions to all & $\begin{array}{l}\text { 1. How does your company deal with knowledge development? How does } \\
\text { knowledge relate to the productivity of your company? } \\
\text { 2. Do you think the level of knowledge development and successful } \\
\text { implementation is high in your company? }\end{array}$ \\
\hline \multirow{5}{*}{$\begin{array}{l}\text { Follow-up Development of creative knowledge, and improvement of knowledge } \\
\text { productivity } \\
\text { b) Continuous improvement and radical innovation of products, services and } \\
\text { question subjects processes }\end{array}$} & $\begin{array}{l}\text { c) Future growth engine business development and sustainable capability } \\
\text { d) Respecting employeesí creative new ideas and opinions } \\
\text { e) Securing and developing professional talents and knowledge of the company } \\
\text { which needs now and in the future } \\
\text { f) Effectively sharing of knowledge and ideas in the company }\end{array}$ \\
\hline
\end{tabular}

\section{4) Interview questions on value creation}

\begin{tabular}{|c|c|}
\hline Questions to all & $\begin{array}{l}\text { 1. Does your company create value successfully? } \\
\text { 2. How does your company achieve its goals for value creation? }\end{array}$ \\
\hline $\begin{array}{l}\text { Follow-up } \\
\text { question subjects }\end{array}$ & $\begin{array}{l}\text { a) Vision and future strategy of company management } \\
\text { b) Sustainable growth capability and development of future growth engines } \\
\text { business. } \\
\text { c) Development and possession of advanced and competitive technology } \\
\text { d) Employee satisfaction with the work environment and financial rewards. } \\
\text { e) Company reputation and image } \\
\text { g) How does the company meet its corporate social responsibilities }\end{array}$ \\
\hline
\end{tabular}

5) Interview questions on relations between leadership, organizational culture, knowledge productivity and value creation

\begin{tabular}{|c|c|}
\hline Questions to all & $\begin{array}{l}\text { 1. How do you think the leadership style of the Chairman and CEO of your } \\
\text { company impacts on your company's culture? } \\
\text { 2. How does your company organizational culture positively impact on the } \\
\text { creative knowledge development and knowledge productivity of your } \\
\text { company? } \\
\text { 3. Do you think that in your company culture people have the freedom to be } \\
\text { creative and innovative? } \\
\text { 4. Does the knowledge productivity of your company impact positively and } \\
\text { significantly impact on value creation in your company? What is your } \\
\text { opinion about the relation and impact of knowledge productivity on the } \\
\text { value creation in your company? } \\
\text { 5. How does the leadership style and characteristics of your company's } \\
\text { management impact and contribute to knowledge productivity and value } \\
\text { creation in your company? }\end{array}$ \\
\hline
\end{tabular}





\section{Curriculum Vitae}

Suk-Jean Kang (b. 1939) is chairman of the Academic Society of Korea Professional Management and the CEO Consulting Group. He obtained a bachelor's degree in Economics (1964). While working for GE, he completed a Master's program at Yonsei University, Seoul (1978). His master's thesis was "A study of inducement of technology for the development of Korean industry". He also completed the International Senior Managers Program (ISMP) of Harvard Business School (1987), and the Global Leaders Program (GLP) of Seoul National University (1999).

He worked for GE as chairman of GE-Korea for 21 years from 1980 to 2001. During this period, he was awarded the Grand Prize for Management and the Grand Prize for Global Management for the successful establishment and management of GE businesses in Korea, increasing total revenue from \$2.0 million to $\$ 4.0$ billion, an approximately 200 -fold increase. As the result, GE-Korea was recognized as having the most successful model of global business management in Korea and within GE.

While managing GE busineses in Korea, he gave lectures as part of the MBA program of the Graduate School of Business of Seoul National University and the Graduate School of International Studies of Ehwa Womans University as an invited professor. The courses he lectured were "strategic management" and "global business management".

He also served as chairman of the Korea CEO Forum, the Government Restructuring and Evaluation Committee of Korea, and the Korea Government Innovation Committee, as advisor of the Korea Fair Trade Committee, director of the board of LG Electronics, vice chairman of the Korea Management Association, senior advisor of the Korea Employers Federation, and committee member of the World Knowledge Forum.

When the author retired from GE in 2001, he organized the CEO Consulting Group to share his long time extensive management experiences and advanced management knowledge in order to support Korean business leaders in their efforts for building innovative and knowledge-intensive organizational cultures to achieve high value creation. He spearheaded consulting projects with leading Korean companies such as, Samsung, LG, Shinhan Bank, WoongJin Group, Doosan Group, and Nong-Shim Group. 


\section{Relevant publications}

Journal articles

Kang, S. J., Kessels, J., Lee, E. S., \& Cho, Y. S. (2014a). Measuring CEO leadership styles and organizational culture. Journal of CEO and Management Studies, 17(1), 77-102.

Kang, S. J., Kessels, J., Lee, E. S., \& Cho, Y. S. (2014b). Measurement of knowledge productivity and value creation. Journal of CEO and Management Studies, 17(3), 23-44.

Kang, S. J., Kessels, J., Lee, E. S., \& Cho, Y. S. (2014c). Leadership characteristics in leading Korean firms and their implications for HRD. The 13th International Conference of the Academy of Human Resource Development

Lee, E. S., Kang, S. J., \& Shin, C. H. (2010). CEOs' Transformational leadership and creativity: organizational culture as the moderating role. Korea Corporation Management Review, 17(4): 95-110

Kang, S.J., Shin, C. H., Lee, E. S., Kim, J. S., \& Park, H. M. (2008). A theoretical study to measure Korean CEO's leadership, organizational culture, and knowledge productivity.Business Management Research, 1(2): 47-76

\section{Translated books into Korean and published}

Slater, R. (1993). The New GE: How Jack Welch Revived an American Institution. Homewood, Illinois: Richard D. Irwin, Inc. Kang, S. J. (1995), Translated into Korean (GE신화의 비밀, 잭 웰치는 GE를어떻게 변화시켰는가); Seoul: 21 Century Books Publishing.

Slater, R. (2000). The GE Way Fieldbook: Jack Welch's Battle Plan for Corporate Revolution. New York: McGraw-Hill. Kang, S. J., \& Lee, T. B. (2000), Translation into the Korean (잭 웰치와 GE방식필드북); Seoul: Mulpurae Publishing.

Slater, R. (1999). Jack Welch and the GE Way: Management Insights and Leadership Secrets of the Legendary CEO. New York: McGraw-Hill Companies, Inc. Kang, S. J., \& Lee, T. B. (2000), Translated into Korean (잭 웰치와 GE방식); Seoul: Mulpurae Publishing. 
Tichy, N.M., \& Sherman, S. (1993). Control Your Destiny or Someone Else Will. New York: Doubleday. Kang, S. J., \& Kim, D. K. (1994), Translated into Korean (당신의 운명을 지배하라); Seoul: 21 Century Books Publishing.

Lowe, J.C. (2001). Welch An American Icon. New York: John Wiley \& Sons, Inc. Kang, S. J. (2001),Translated into Korean (위대한 영웅 잭 웰치); Seoul: Mulpurae Publishing.

Ashkenas, R., Burke, D., Ulrich, D., \& Kerr, S. (2002). The GE Work-Out. New York: McGraw-Hill. Kang, S. J., \& Lee, T. B. (2002), Translated into Korean (GE 워크아웃); Seoul: Mulpurae Publishing. 
